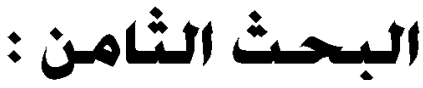

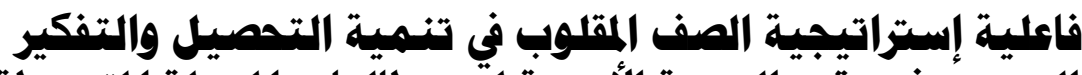

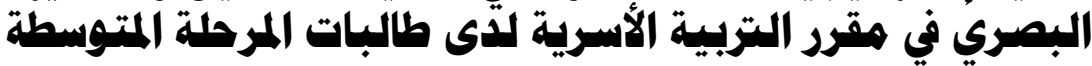

\section{: إلفإ}

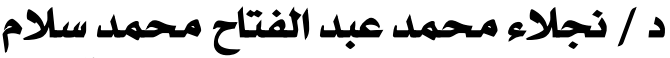

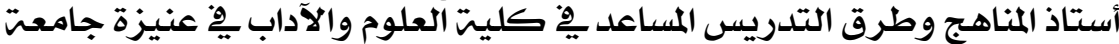

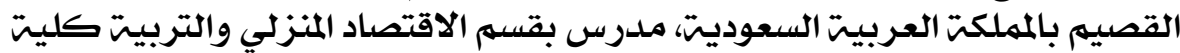

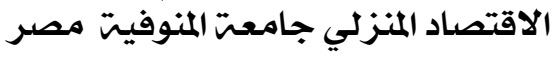





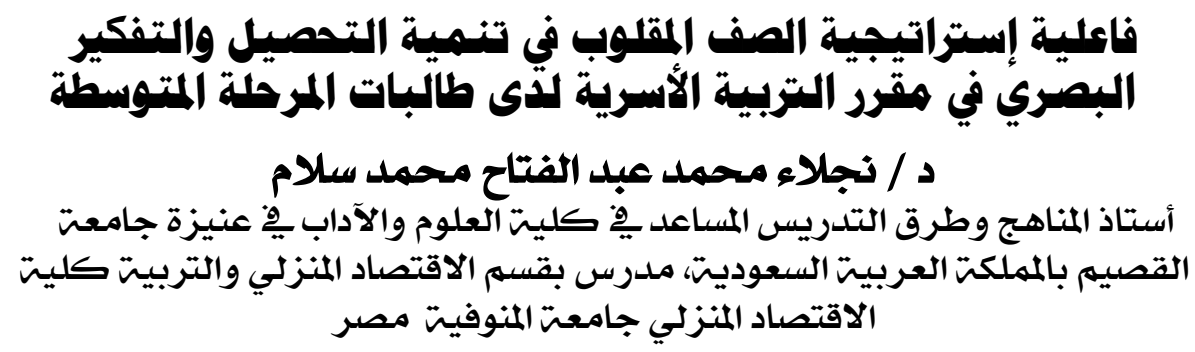

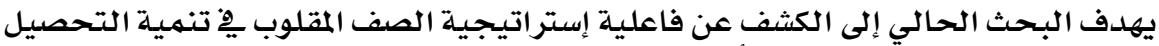

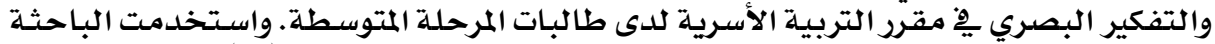

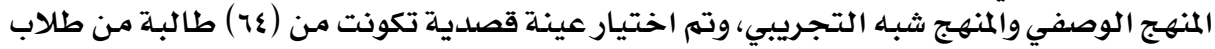

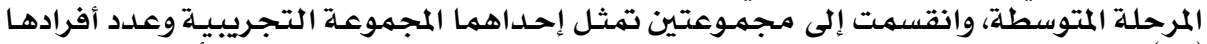

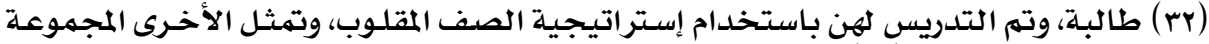

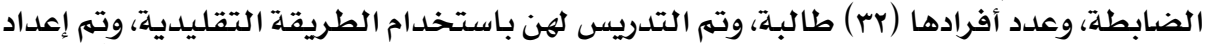

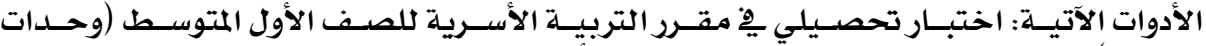

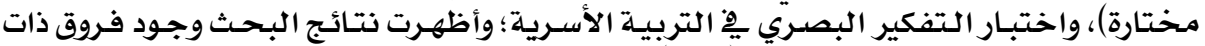

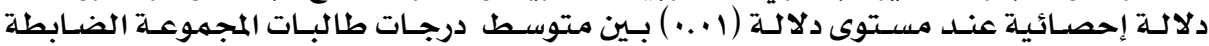

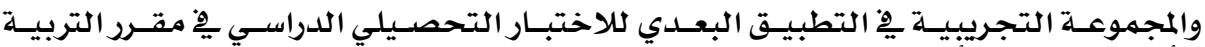

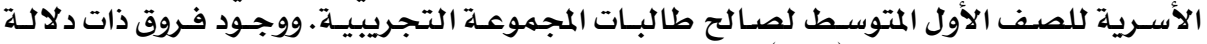

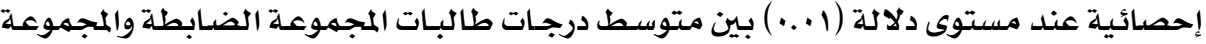

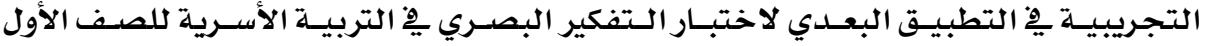

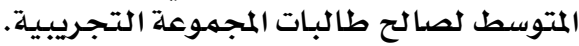

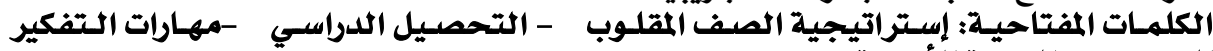
البصري - التربية الأسريرية.

Effectiveness of the Strategy of Flipped Classroom in the Development of Achievement and Visual Thinking Skills in the Curriculum of Family Education in Medium School Students.

\section{Dr. Naglaa Mohamed Abdelfattah Mohamed Sallam}

\section{Abstract:}

The current research is concerned with examining the effectiveness of teaching using the flipped classroom strategy in the development of achievement and visual thinking skills in the family education syllabus in a sample of medium school students in the city of Unaizah, in comparison with the results of the experimental and control groups in the achievement test and the test of visual thinking skills in the pre and post applications. The researcher used the descriptive approach in determining the skills of visual thinking and the quasi-experimental method to discover the effectiveness of teaching using the flipped classroom strategy in the development of achievement and visual thinking skills in the family education course. The 


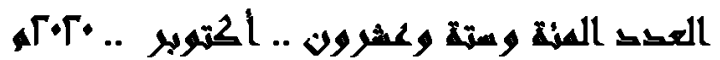

sample consisted of (64) students divided into two experimental groups, One of them represents the experimental group and its members are (32) students, they were taught using the flipped classroom strategy, and the other represents the control group and its members number (32) students, they were taught using the traditional method. The following tools were prepared: Achievement test in the family education course for the first medium grade (selected units) and a test of visual thinking skills in family education. The results of the research showed that there were statistically significant differences at the level of significance (0.01) between the mean scores of the control group and the experimental group in the post application of the academic achievement test in the family education course for the first medium grade in favor of the experimental group students. And there were statistically significant differences at a significance level (0.01) between the mean scores of the control group and the experimental group in the post application of the test of visual thinking skills in family education for the first medium grade in favor of the experimental group students.

Keywords: the strategy of flipped classroom - Academic Achievement Visual Thinking Skills - Family Education

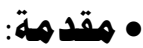

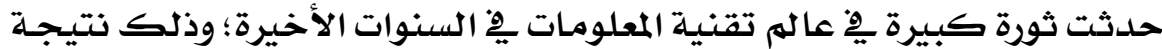

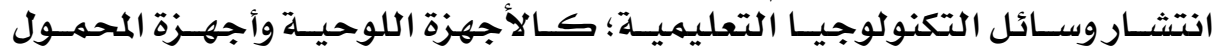

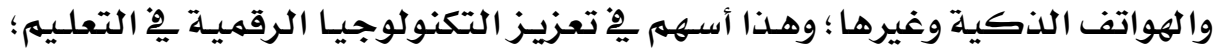

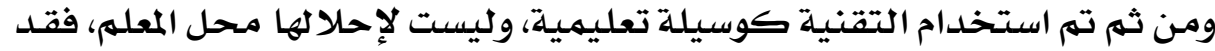

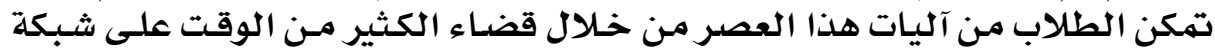

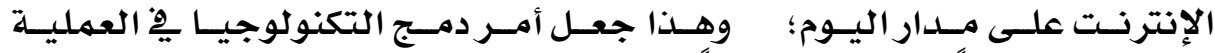

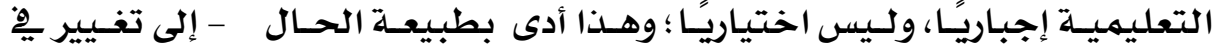

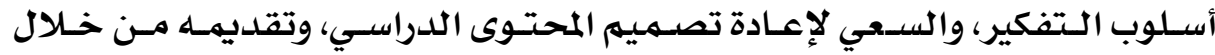

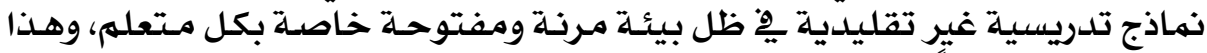

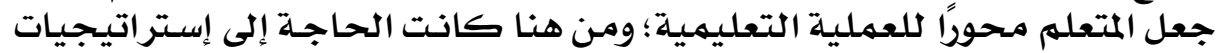

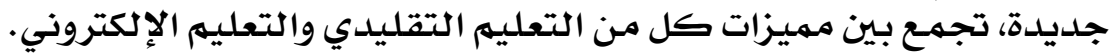

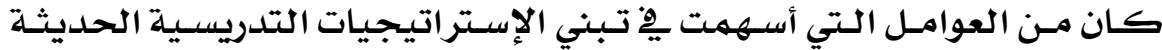

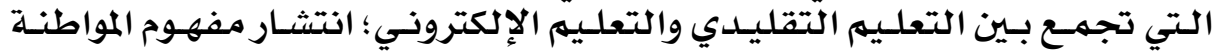

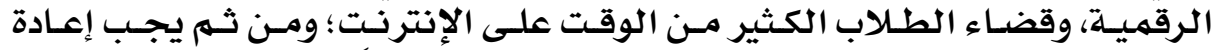

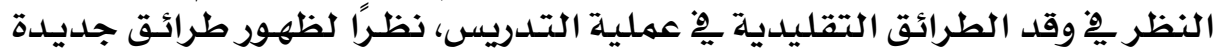

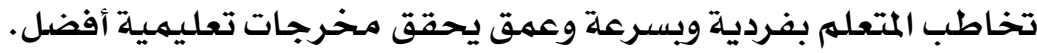

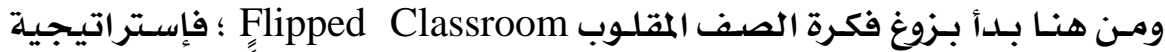

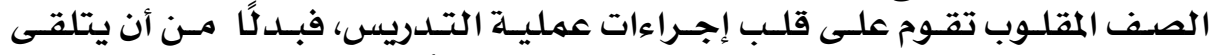

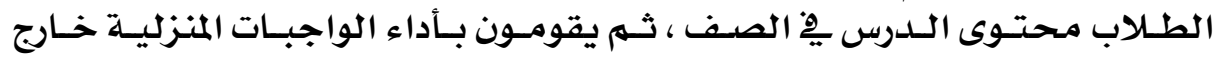

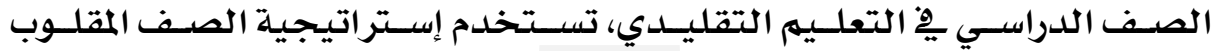




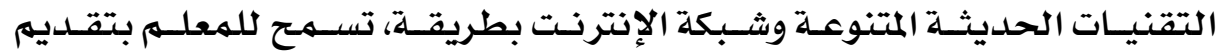

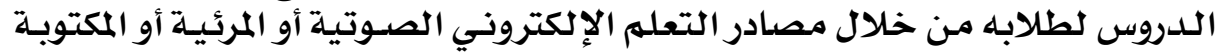

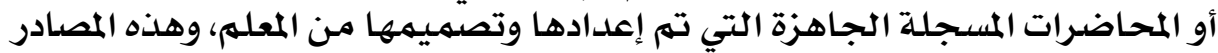

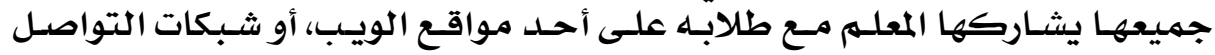

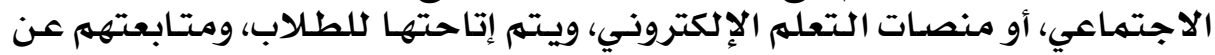

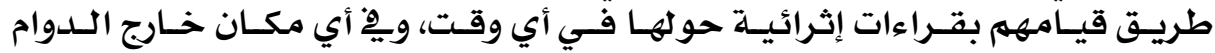

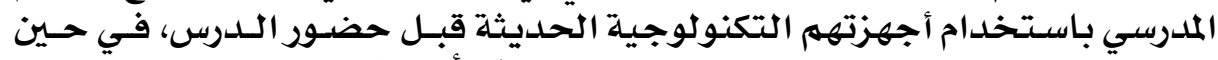

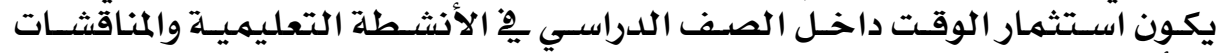

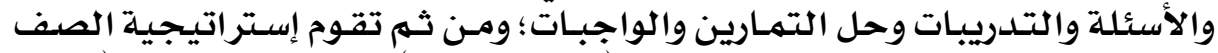

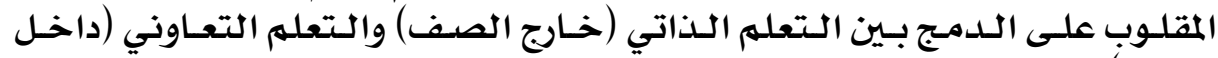

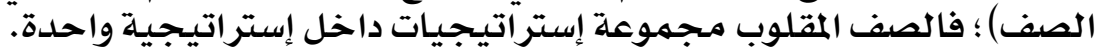

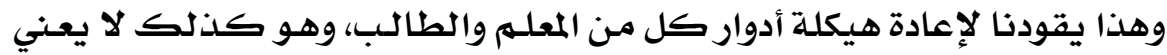

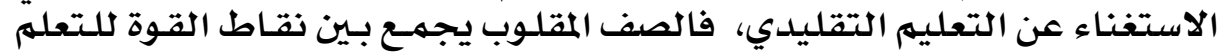

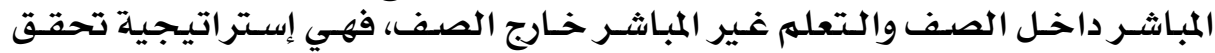

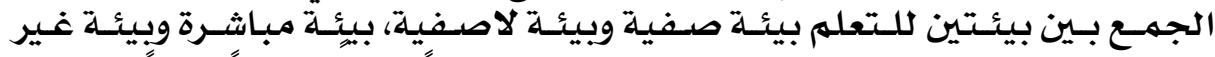

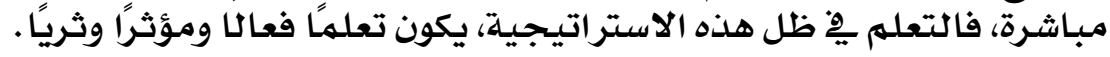

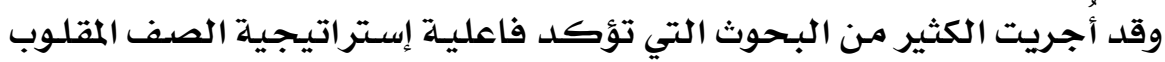

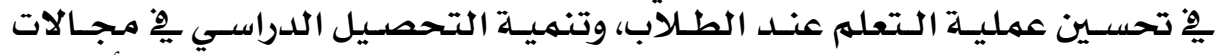

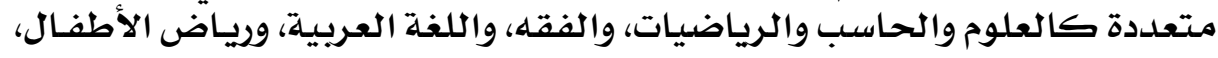

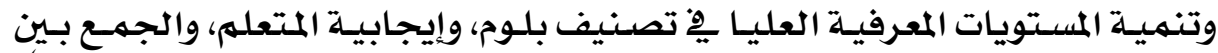

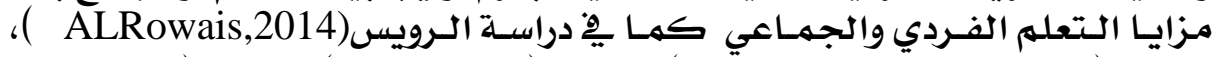

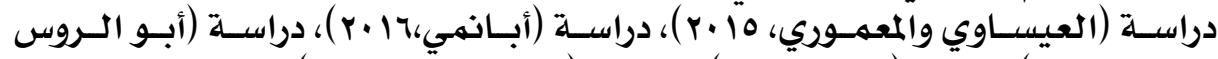

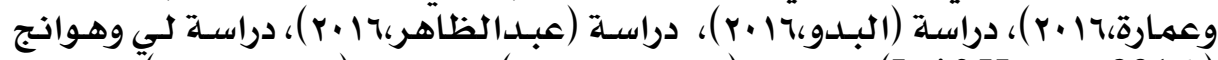

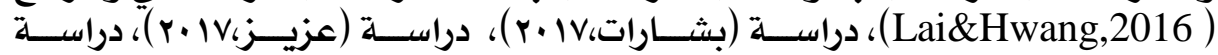

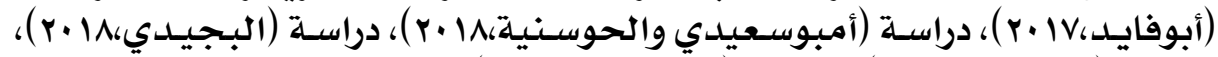

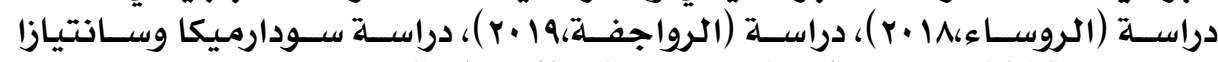

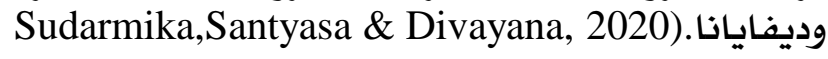

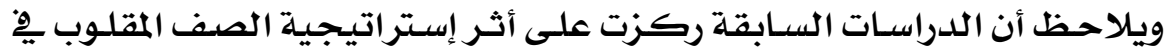

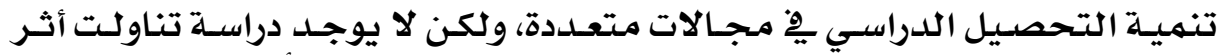

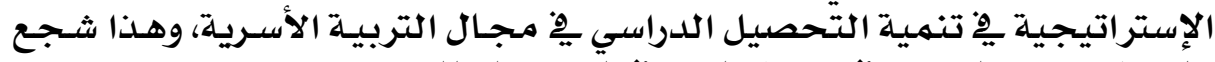

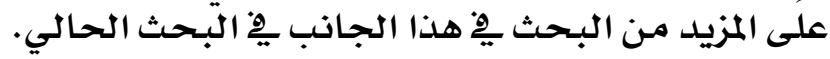

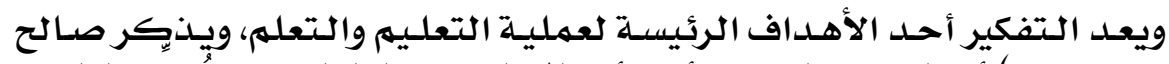

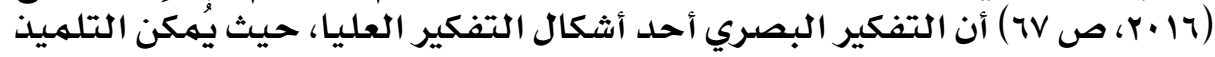

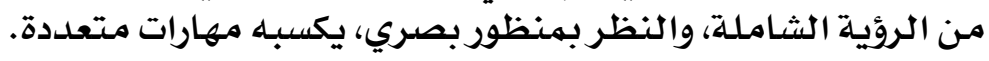


وتتضهن إستراتيـية الصف المقلوب المحتوى الإلكتروني، وتعد أكثر المعلومـات

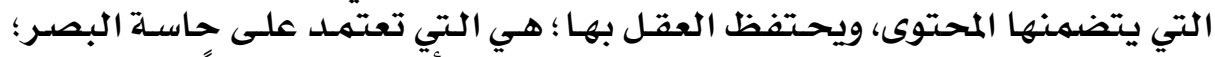

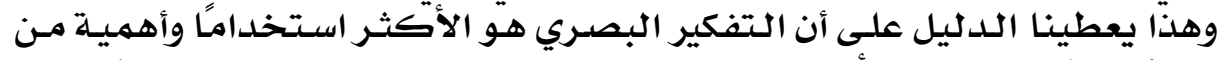

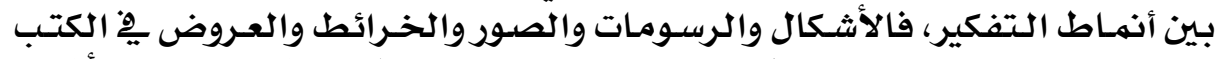

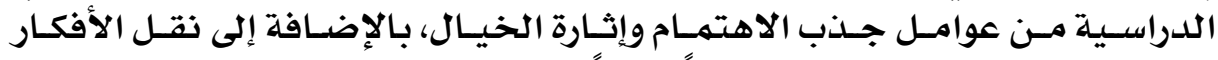

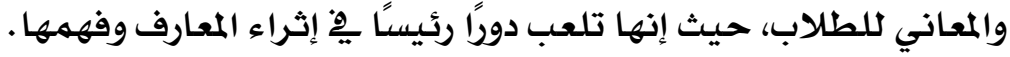

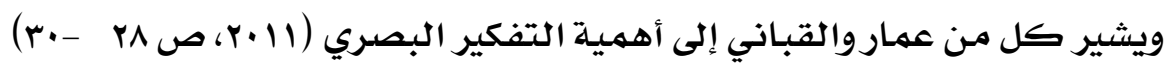

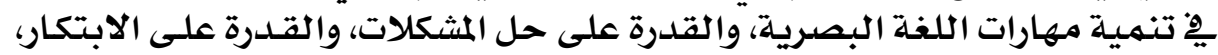

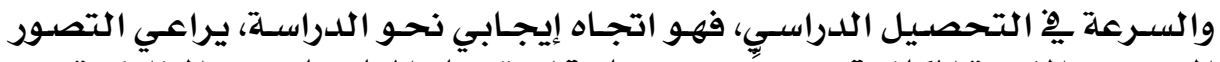

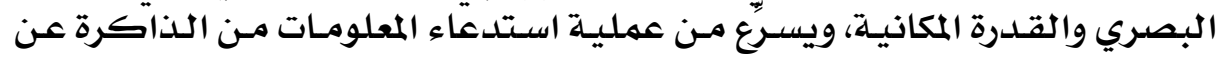

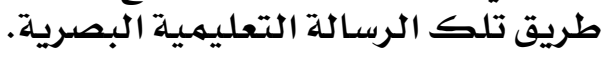

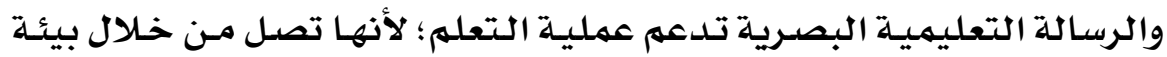

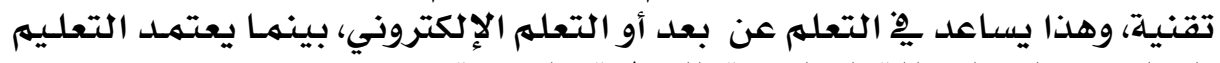

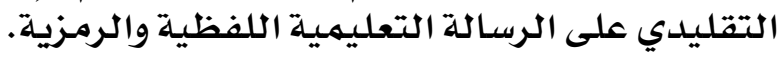

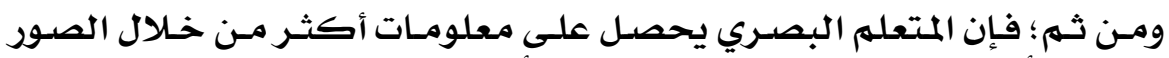

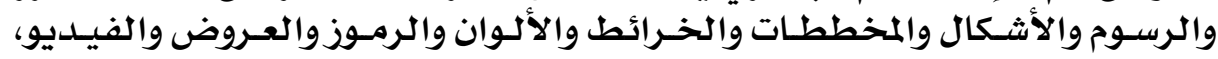

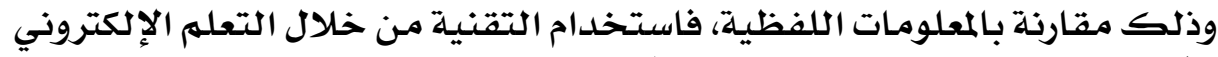

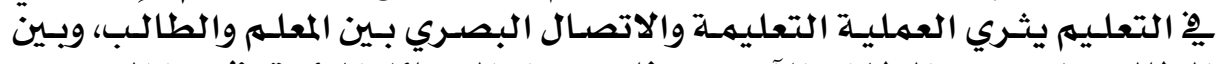

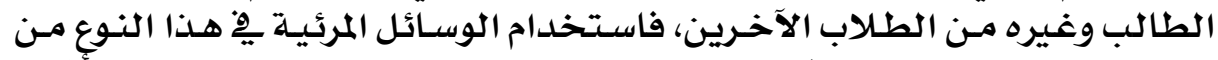

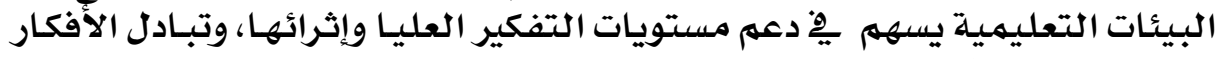

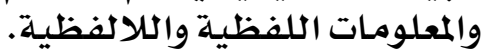

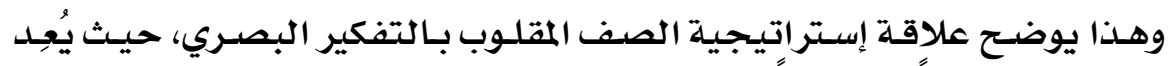

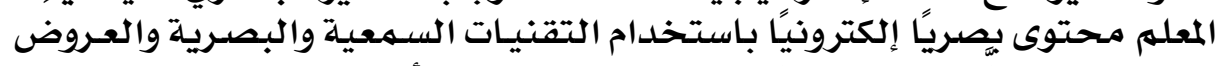

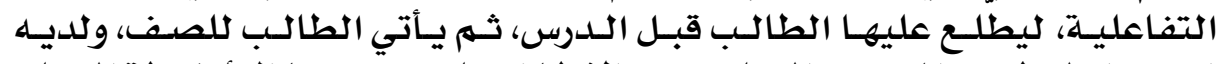

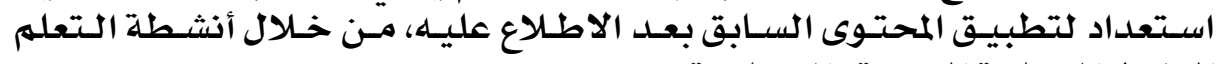

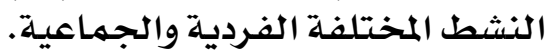

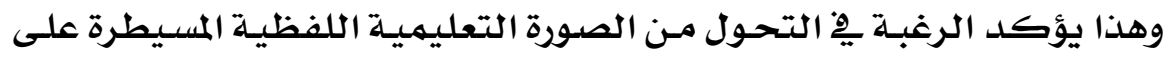

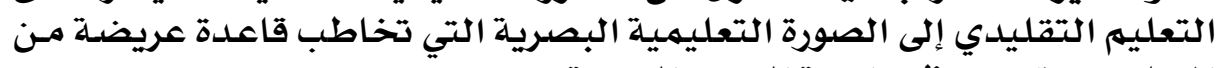

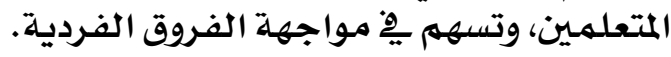

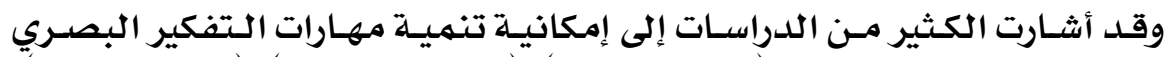

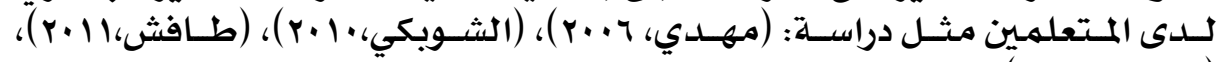

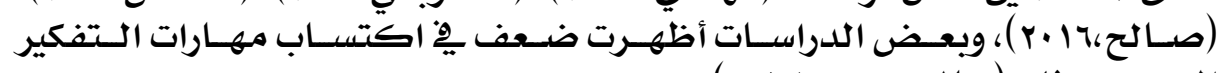

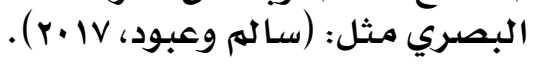




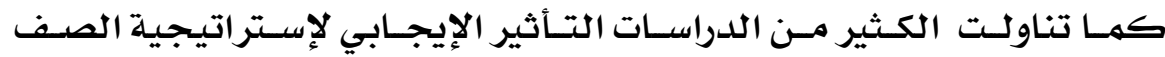

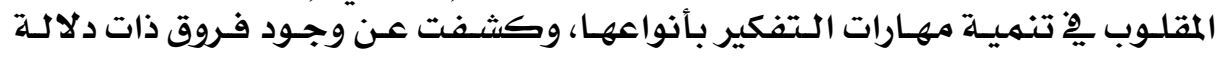

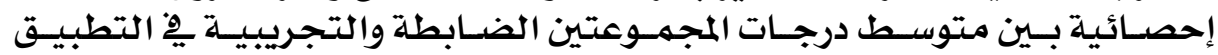

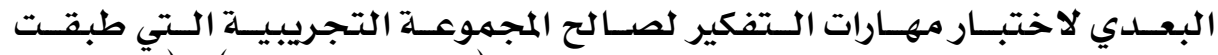

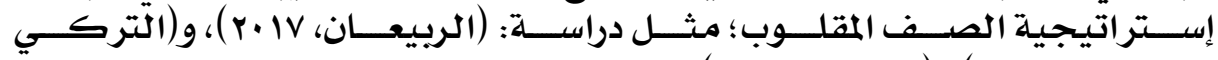

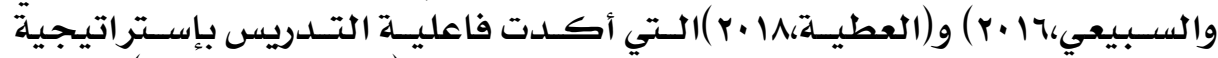

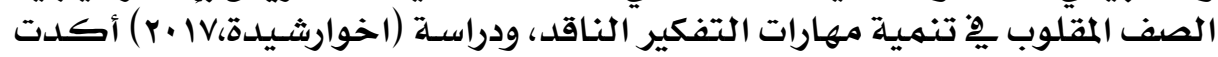

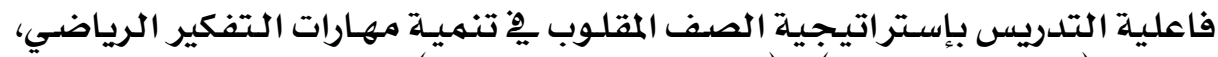

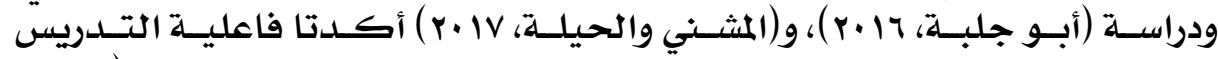

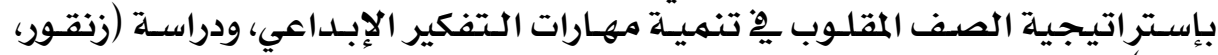

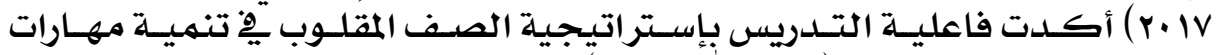

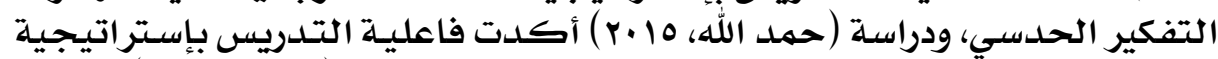

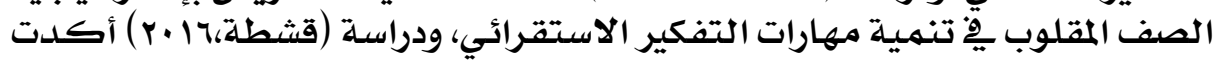
فاعلية التدريس بإستراتيـيـة الصف المقلوب في فتهمية مهارات التفكير التتأملي.

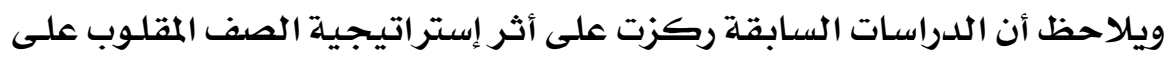

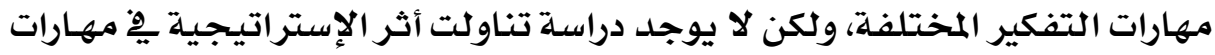

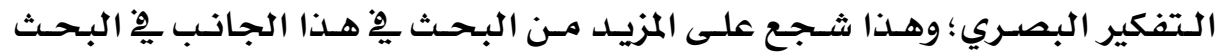
الحاثي.

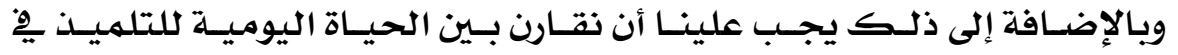

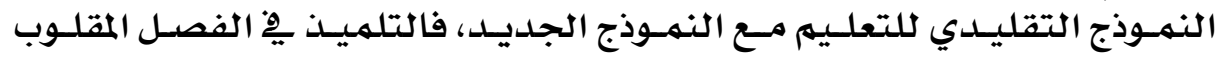

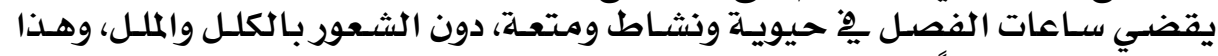

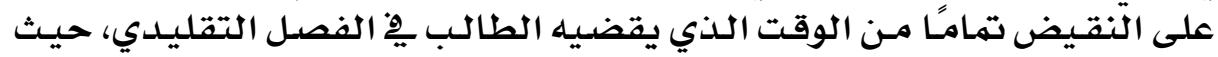

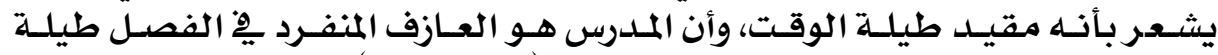

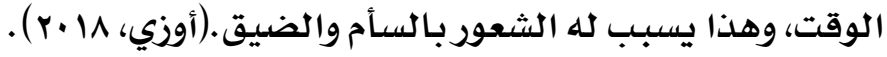

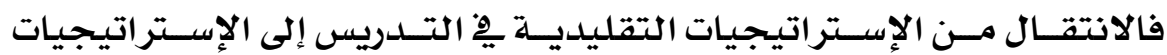

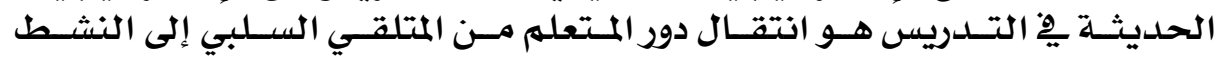

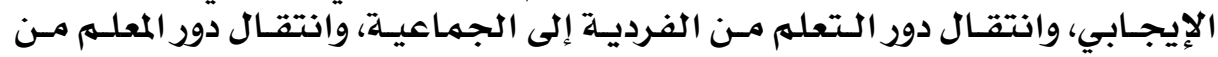

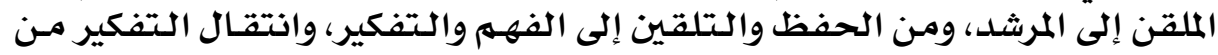

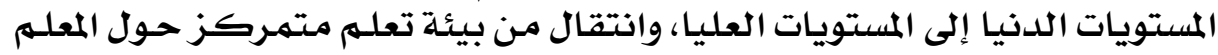

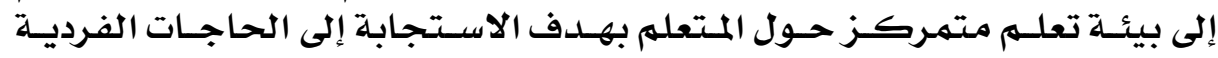
للمتعلم.

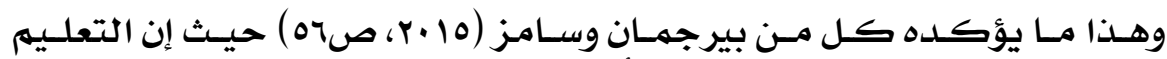

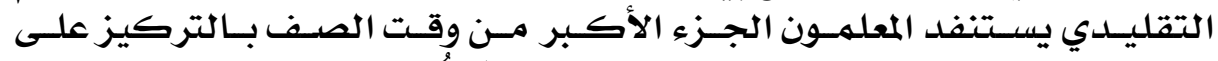

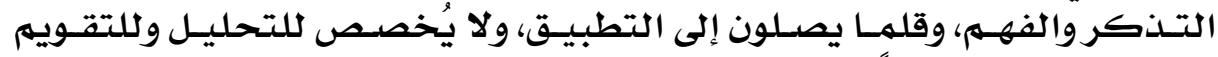

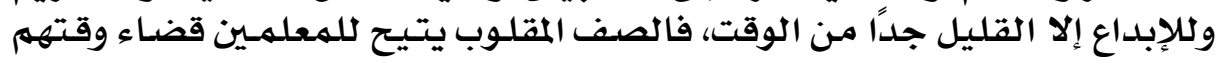




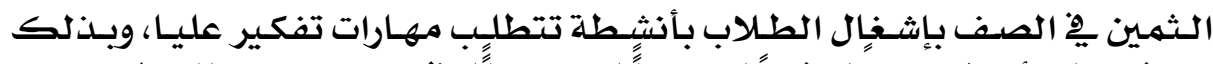

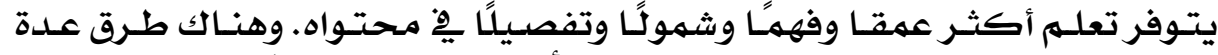

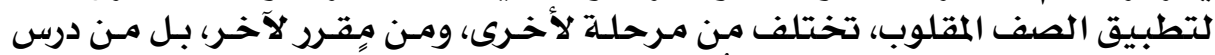

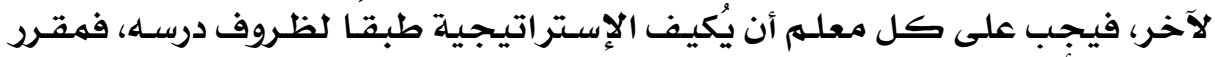

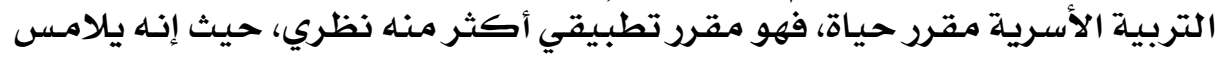

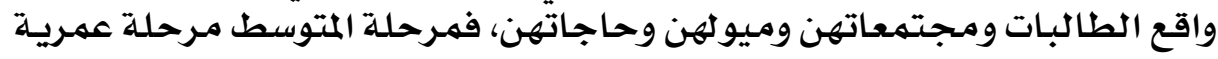

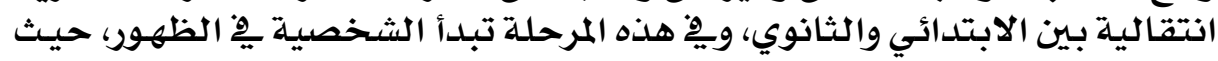

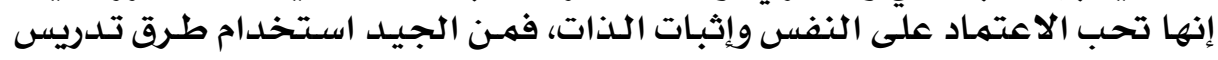

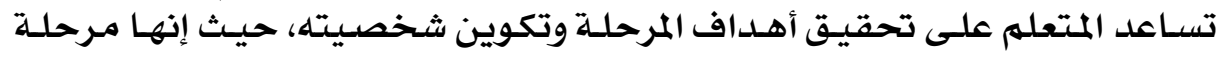

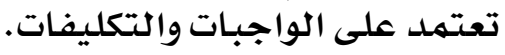

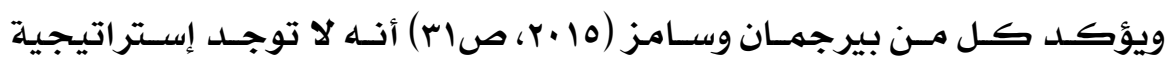

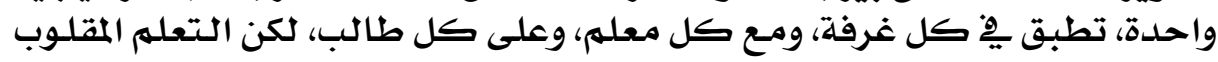

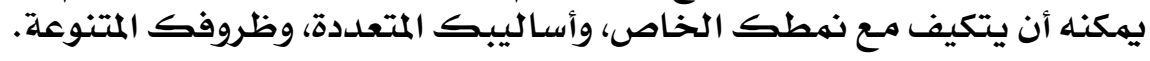

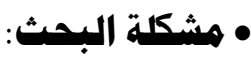

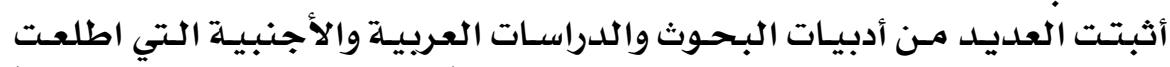

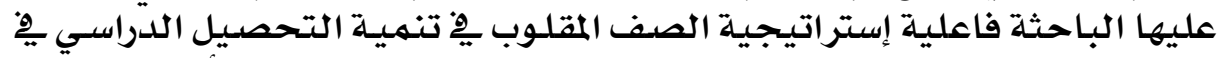

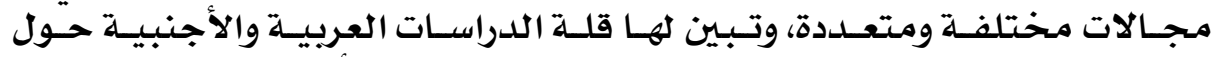

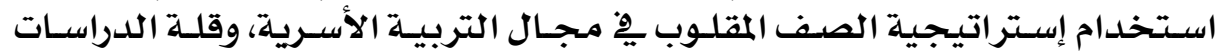

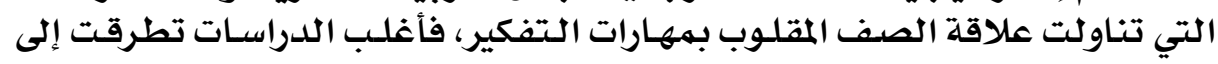

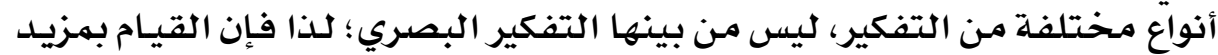

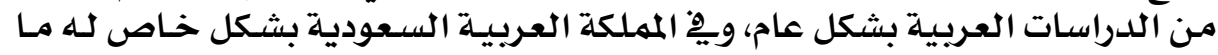

يبرره.

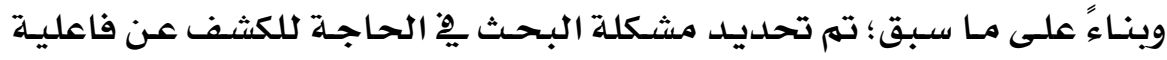

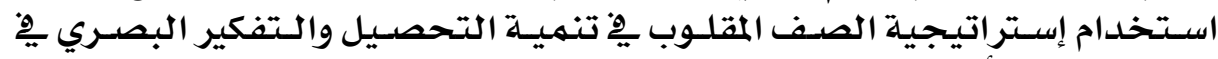
مقرر التربية الأسريـة لدى طالبيات المرحلة المبلة المتوسطة.

وستقوم البـاحثة من خلال صفحات البحث بالإجابة عن السؤال الرئيس الآتي:

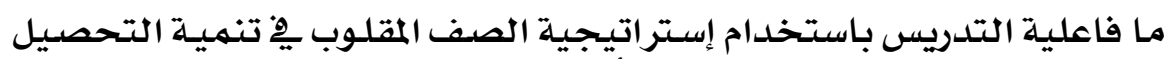

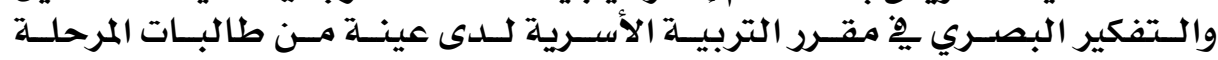
المتوسطة؟

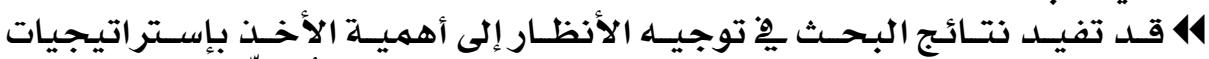

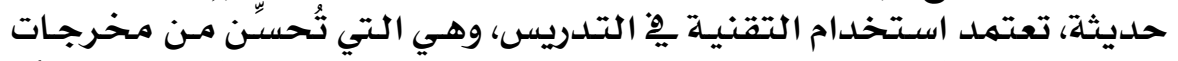

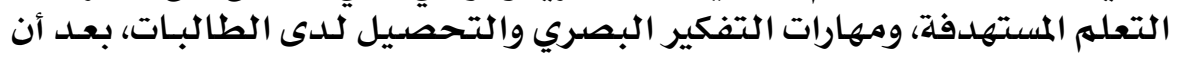
يثبت نجاحها يِ العملية التمدية التدريسية. 


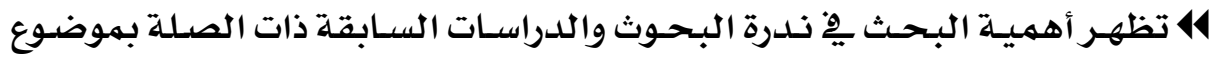

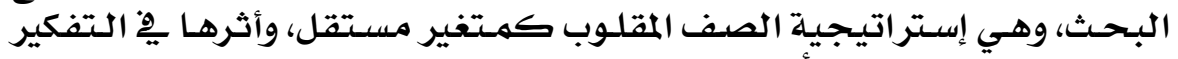
البصري لمجآل التربية الأسرية البحتية.

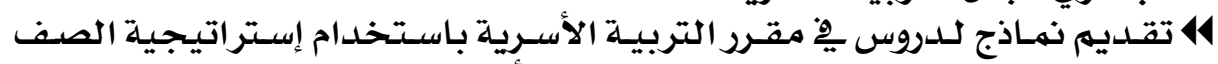

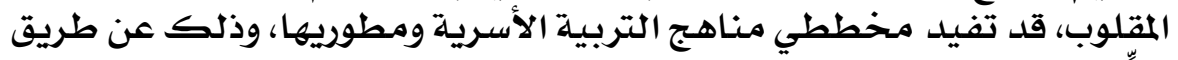

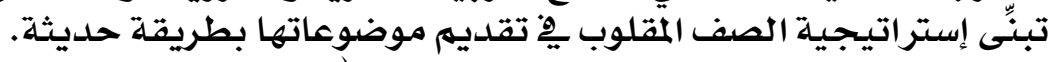

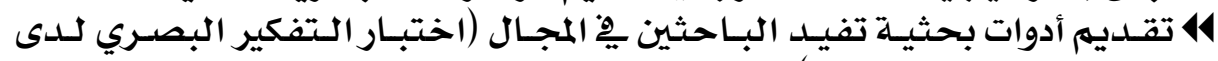

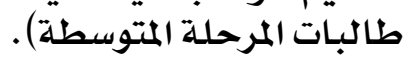

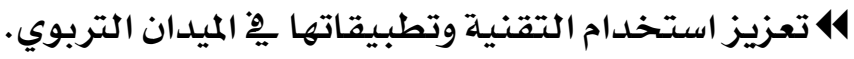

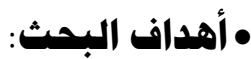

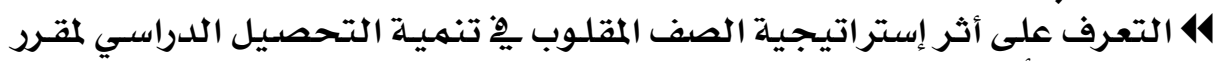

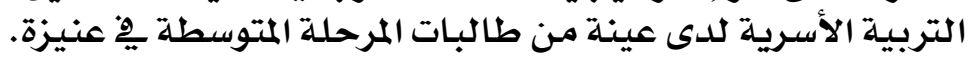

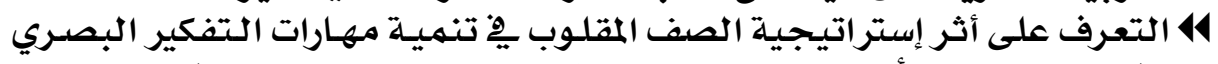

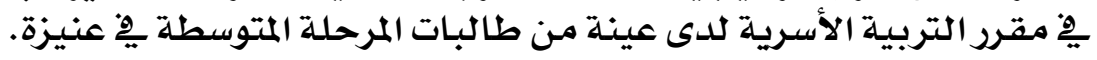

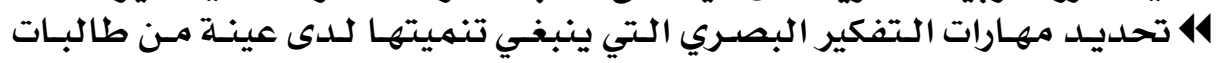
المرحلة المتوسطة مهارات

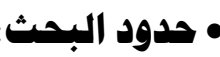

4 حدود موضوعية: اقتصار البحث على وحدات مختـارة من مقرر التربية الأسـرية

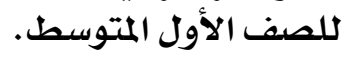

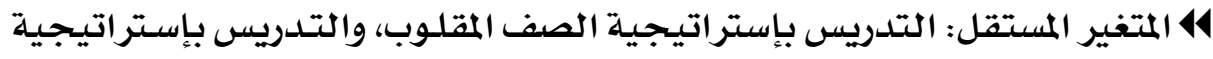

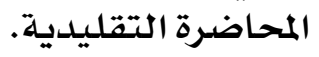

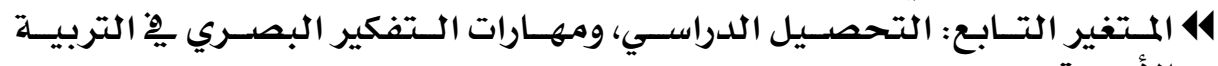
الأسـريـة. 14 حدود مكانية: مـدارس التحفيظ للمرحلـة المتوسطة - مدينـة عنيزة بهنطقة

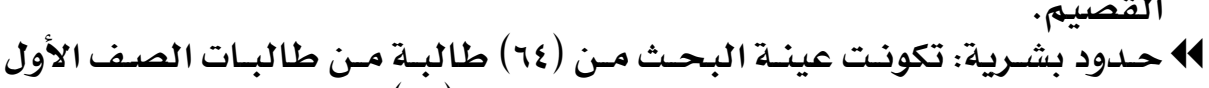

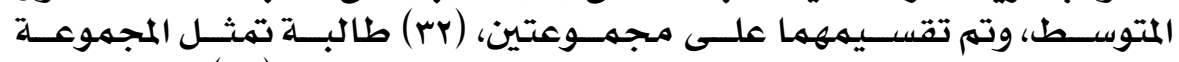

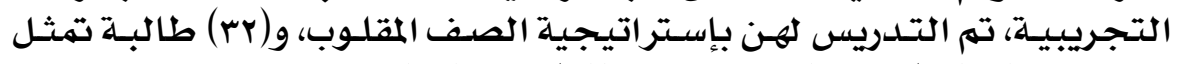

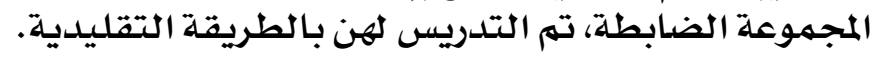

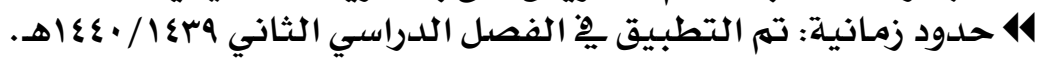

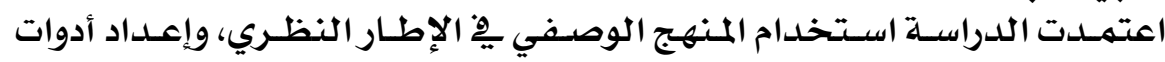

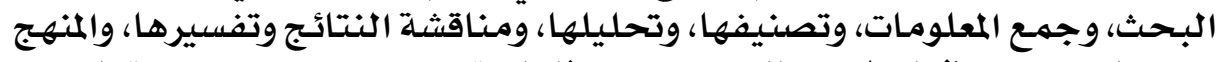

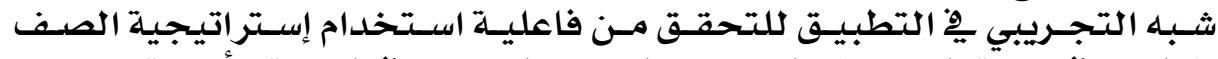

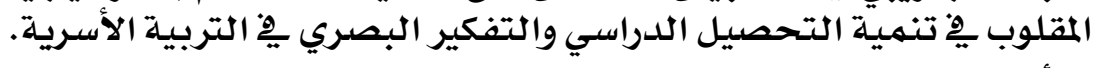

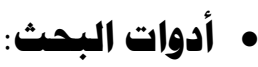

\section{$Y \odot V$}




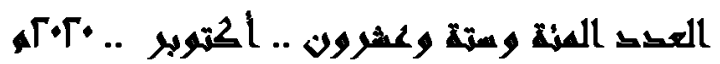

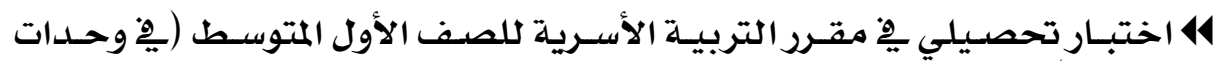

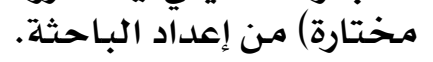

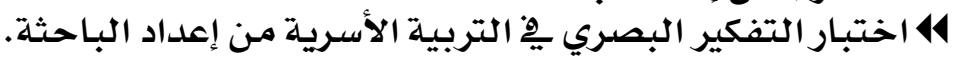
414 محاضرات فيديو تفاعلية، وعروض تقدية التريمية للدروس.

يسعى البحث الحالي للتحقق من صحتة الفروض الآتية:

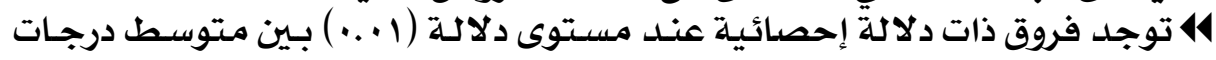

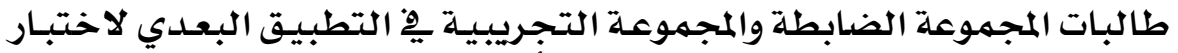

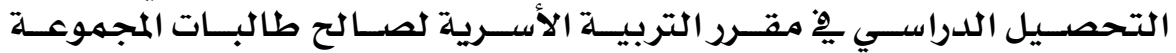

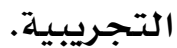

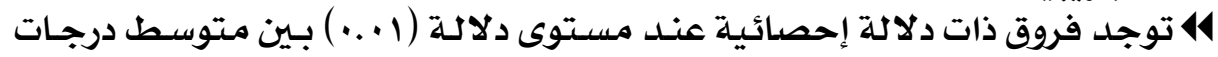

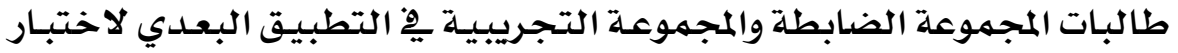
التفكير البصري لصالح طالبات المجموعة التجالجريبية.

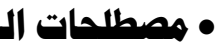

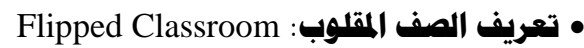

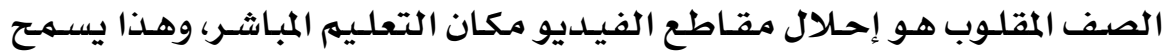

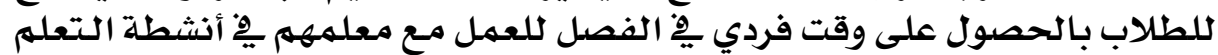

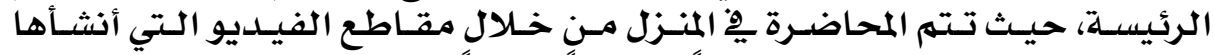

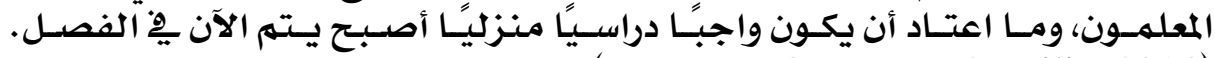
(Bergman, Overmyer \& Wilie, 2014)

• متعريف الصف المقلوب إجرائيًا:

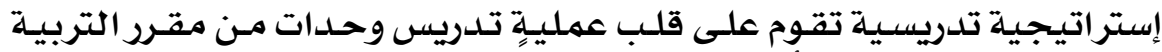

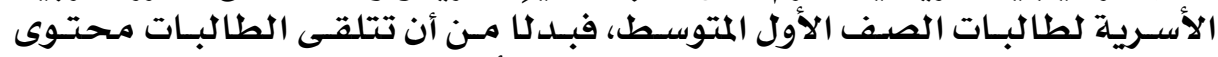

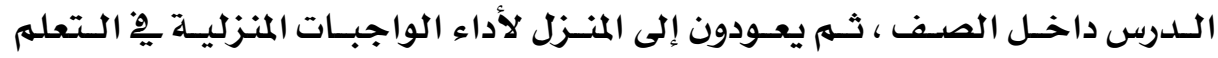

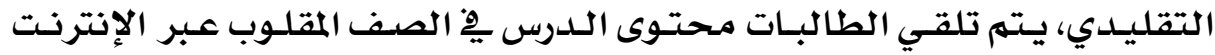

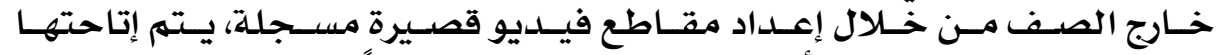

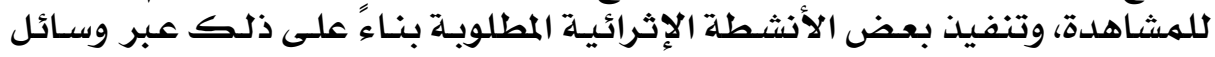

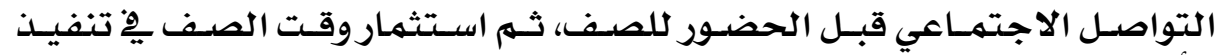

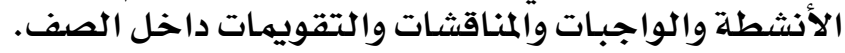

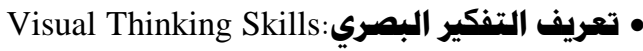

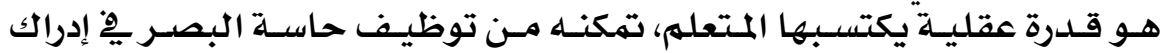

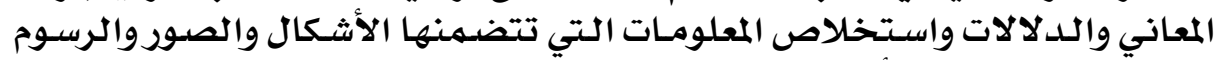

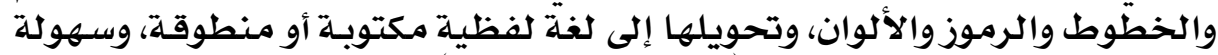

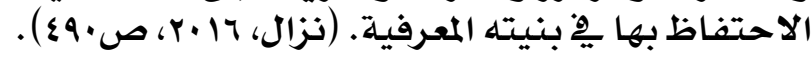

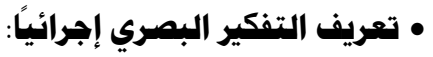




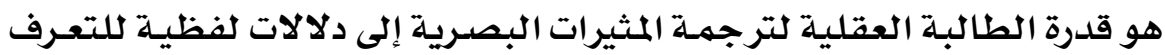

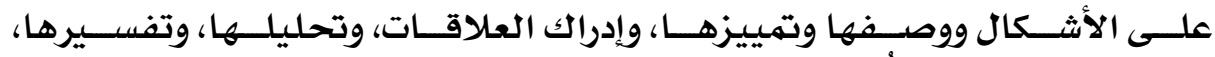

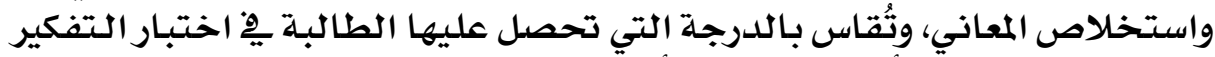

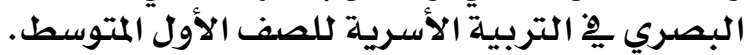

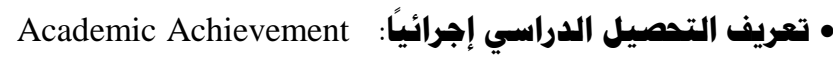

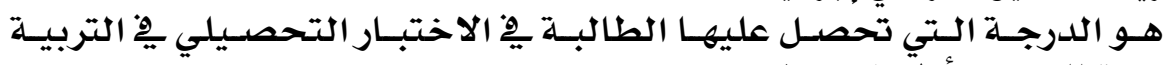

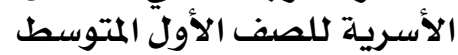

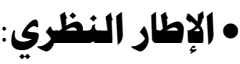

• تعريف إستراتيجية الصف المقلوب:

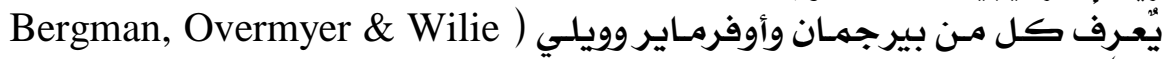

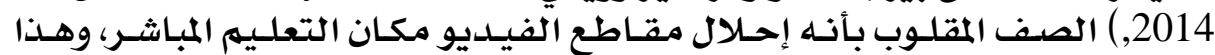

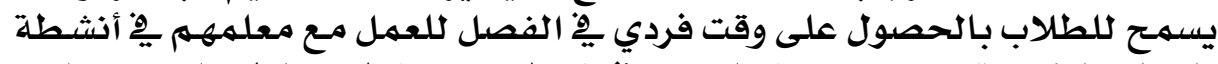

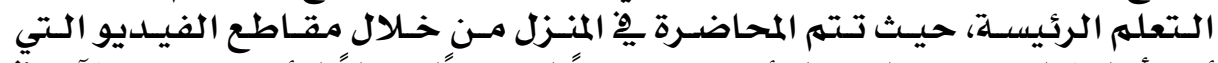

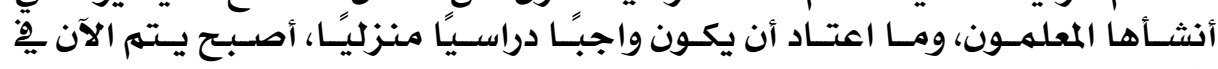
الفصل.

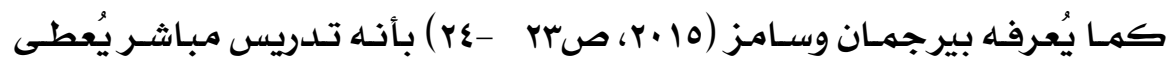

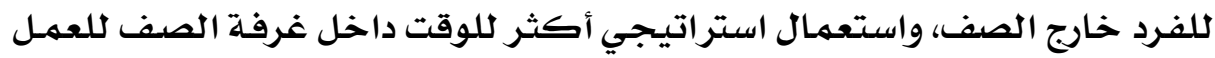

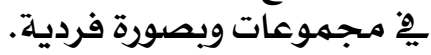

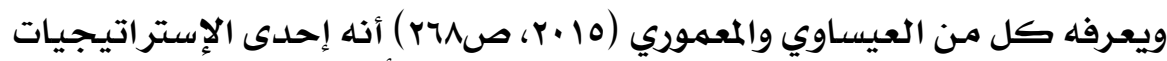

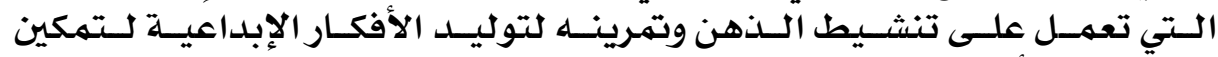

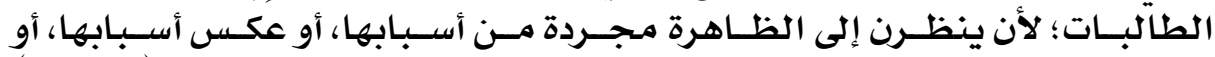

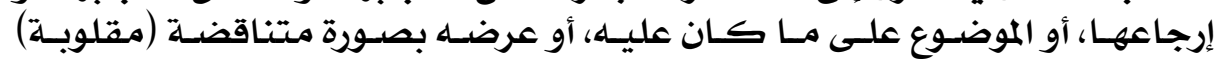

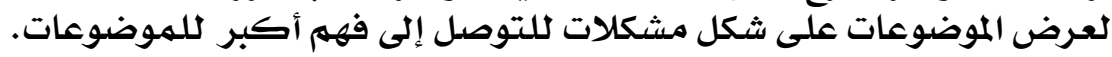

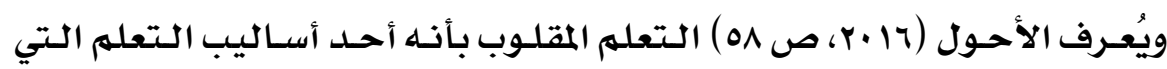

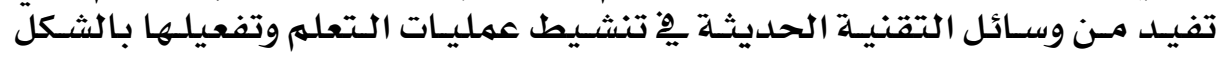

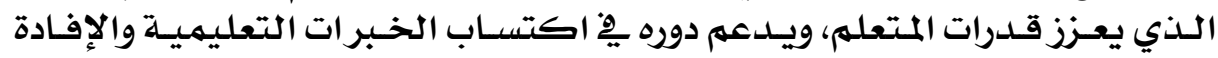

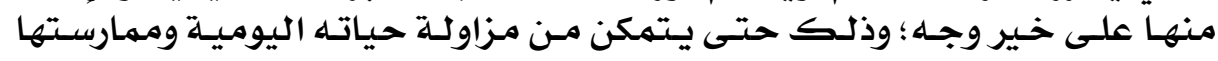
بشكل أفضل.

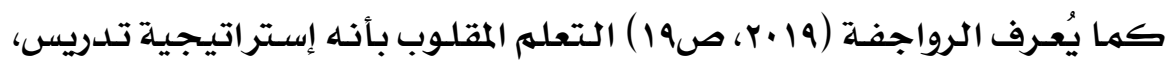

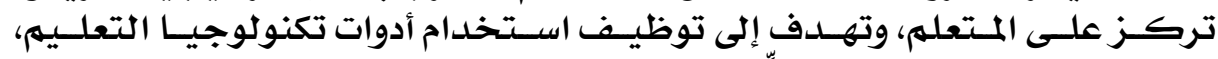

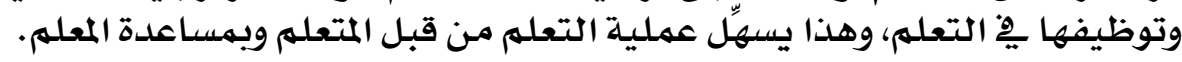

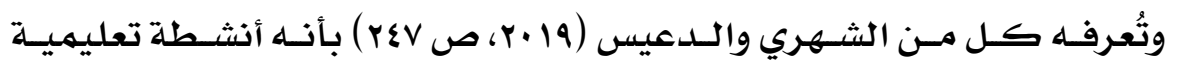

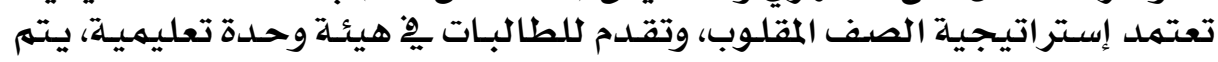




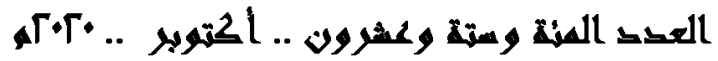

تطويرها باستخدام بعض البر امجج المختلفة؛ مثل برنامج Easy class وإنشاء قناة تعليمية.

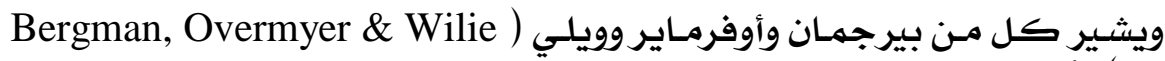
2014, بأن الصف المقلوب لا يعني: 44 أنه مرادف لمقاطع الفيديو عبر الإنترنت.

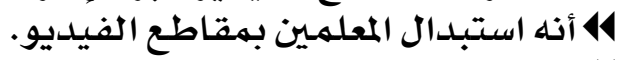
414 أنه مقرر إلكتروني. 414 أن الطابلاب يعملون بدون البرن أساس. 14 قضاء الطلاب الوقت بأكمله ألوان أمام شاشة الكمبيوتر. 14 أن الطلاب يعملون يفّ عزلة.

ويضيف كل من بيرجمان وأوفرماير وويلي ( Bergman, Overmyer \& Wilie 2014, أن الصف المقلوب يتضمن:

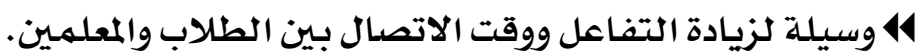
414 بيئة يتحمل فيادة التفا الطلاب مسؤولية تعلمهـه.

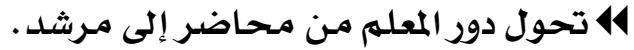
44 المزج بين التعلهم المباشر والتعلم المعلم البنائي. 14 أنه لا مجال للغياب فيه. 14 414

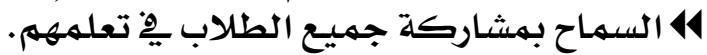
414 إتاحة الفرصة لجميع الطلاب للحصول على تعليم خاص بهمه.

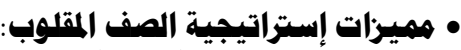
ويذكر زوحي (ع ابr) من إيجابيات الفصل المقلوب الآتي:

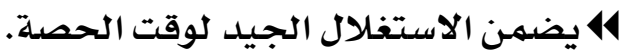

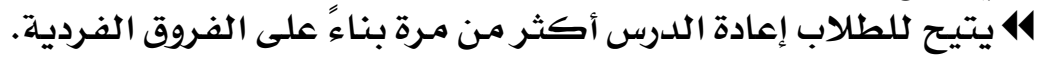

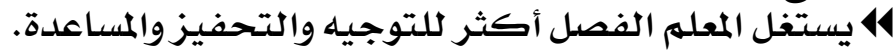
14 يبني علاقات أقوى بين الطالب الفحل والمعلهم.

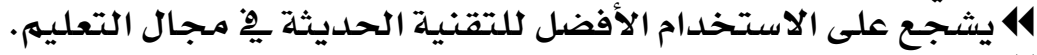

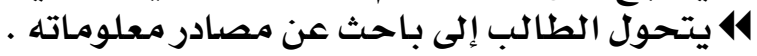

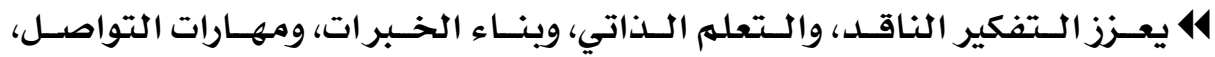
والتعاون بين الطلاب.

وتلخص الباحثة بعض مميزات التدريس بإستراتيجية الصف المقلوب بِّ الآتي: 414 استخدام التعلم الإلكتروني يِّ عملية التعلهم. 14 تطوير البيئة التعليمية التي تعتمدي على التملى التكنولوجيا. 414 إثراء المعلومات وتعميقها. 


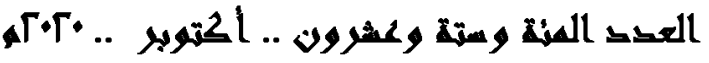

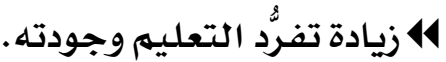

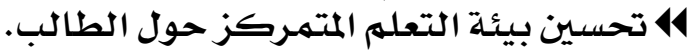

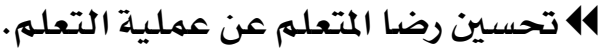

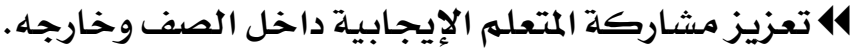

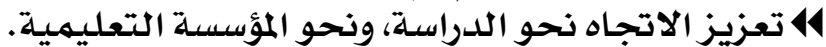

التحقيق الأهداف المعرفية والمهارية والوجداندانية المونية.

4 4 تنهية المستويات المعرفية المعرفية العليا.

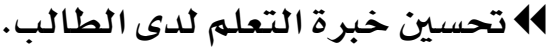

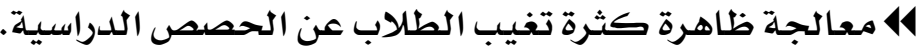

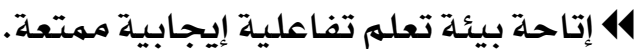

14 تشجيع التعلم المستمر (خارج حدود الزمانية والمكان)، والتعلم المستدام، والتعلم

مدلدى الحياة.

44 التعلم هِّ ظل أمن نفسي، يبتعد عن القلق والتوتر.

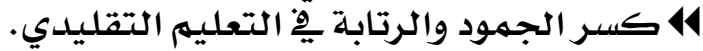

414

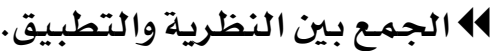

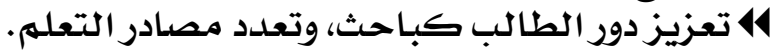

414 تعدد طرق التقويم وشمو لها.

14 الزيادة الدافعية للتعلم. 14

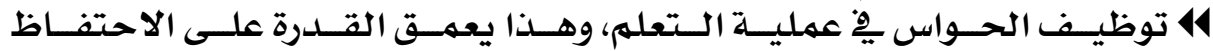

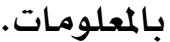

4 يعزز التفكير الابتكاري، والتفكير الناقد، والتفكير التأملي.

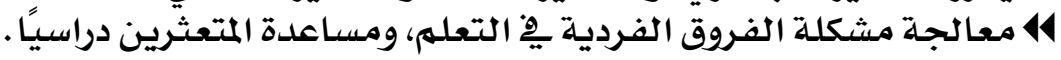
414 القضاء على مشكلاد ملفكات الإدارة الصفية.

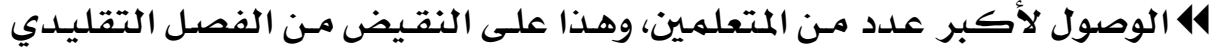

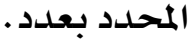

ويشـير كـل مـن (Kim,Kim,Khera,Getman,2014,p.46) إلى أن الاسـتخدام المنهجي للتكنولوجيا التفاعلية؛ هو سمة أساسية من سمات الصف المقلوب.

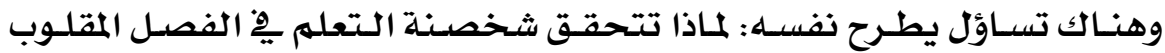

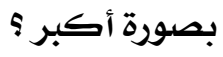

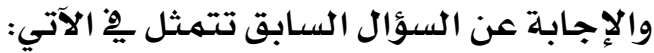

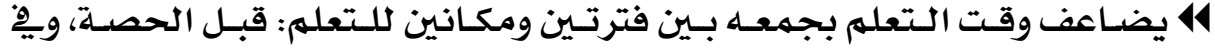
أثنائها.

414 يجمع بين شكلين من التعليم المزيج، المتزامن وغير المتزامن.

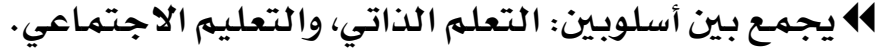
414 يعمق مفهوم التعلم ذي المعنى والتعله البنائي. 


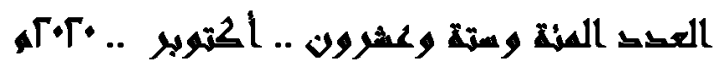

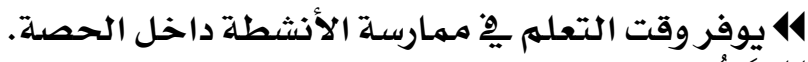

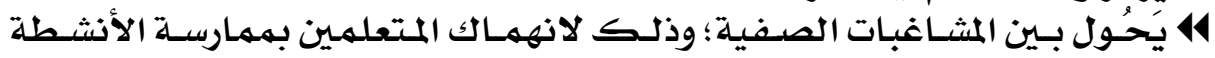
التطبيقية.

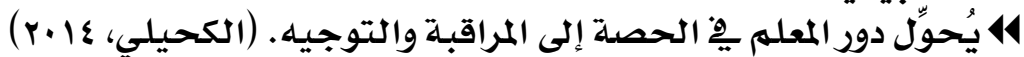

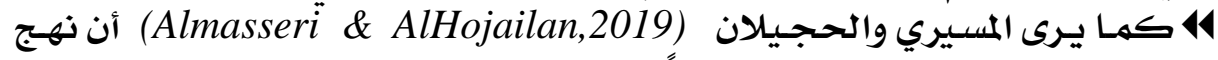

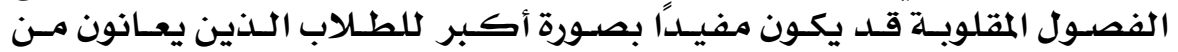

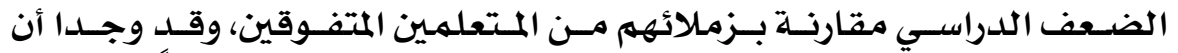

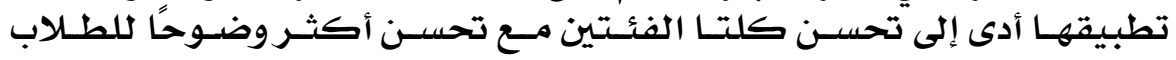

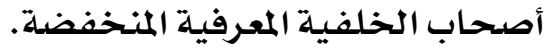

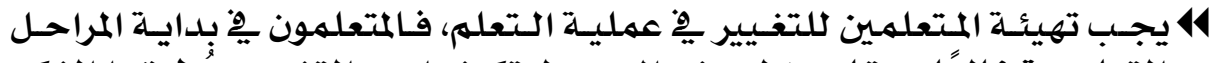

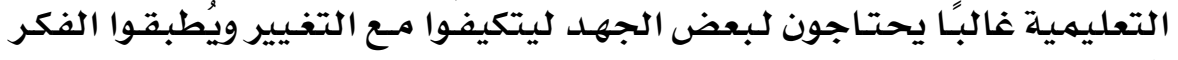
الجديلد.

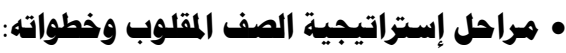
ويمكن تلخيص مـراحل تنفيذ الإستراتيجية بوانية بما أطلقت عليه الكحيلسي التاءات الستة: الحسديلـ : الموضوع أو الدرس الذي ينوي قلب الفصل فيه بشـرط أن يكون صـالحًا

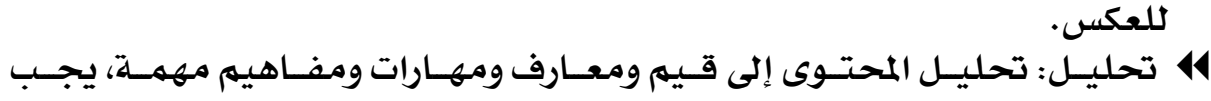
معرفتها. 41 تصميه: تصميهم الفيديو التعليمي أو التفاعلي يتضمن المادة العلميـة بالصوت والصورة . توجيه تصدي

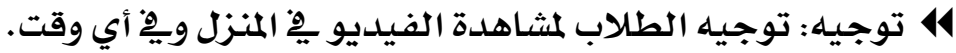

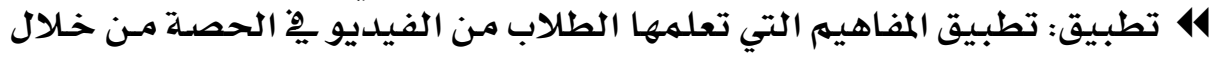

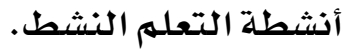

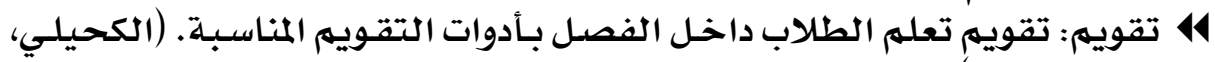
(17. 17 . 10

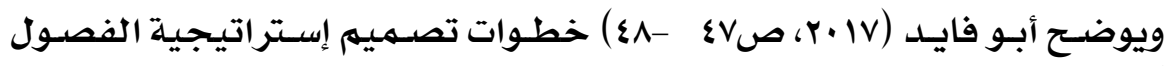
المقلوبـة وهي: أبوفي 1ا خطط: أعـرف اللدروس المراد قلبها، والأهـداف التعليميـة المراد تحقيقها، وضـع خطة للعهل.

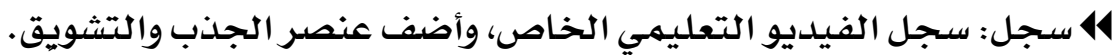

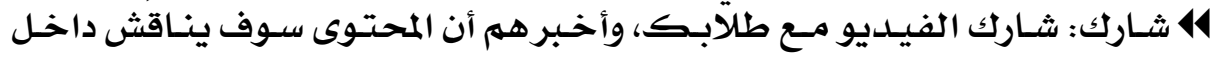
الفصل 14 ناقش: تعمق أكثر نحو الموضوع من خلال مناقشة طلابك.

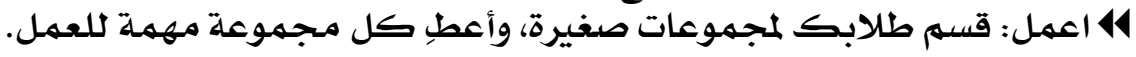




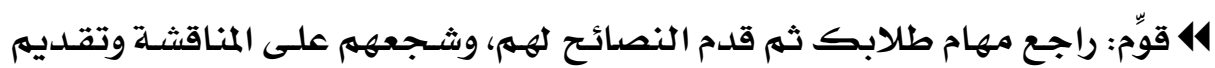
الآراء.

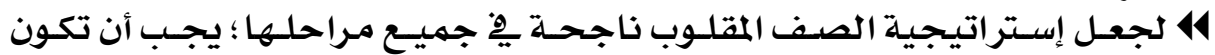

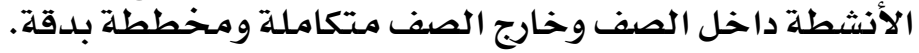

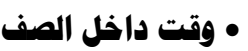

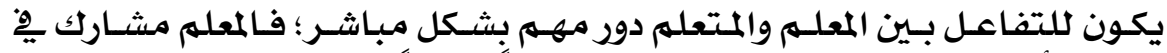

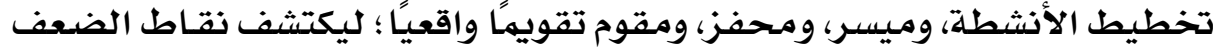

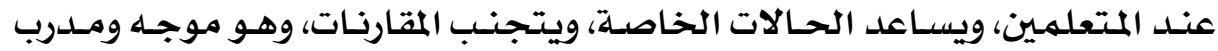

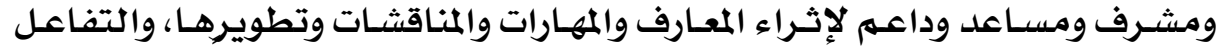

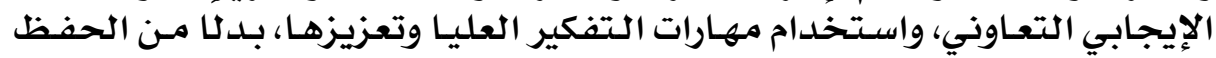

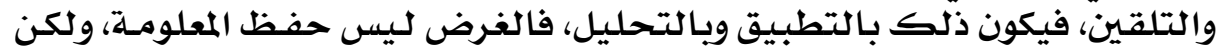

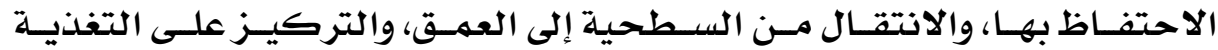

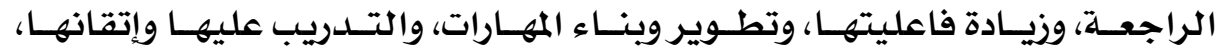

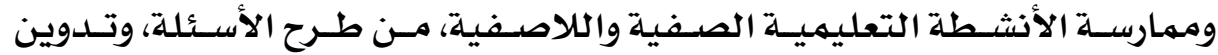

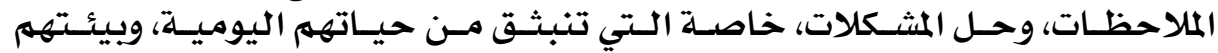

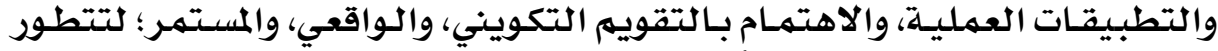

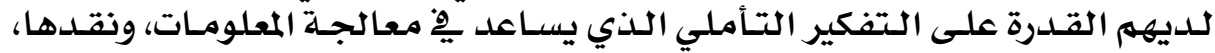
وتحليلها. له.بها.

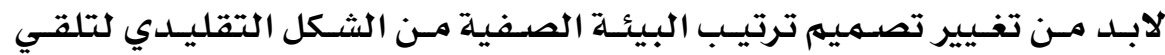

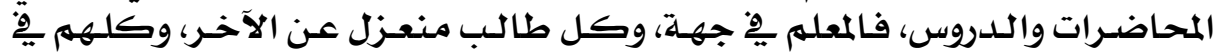

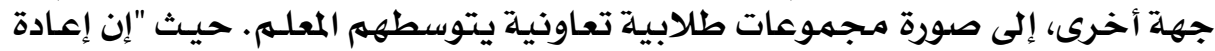

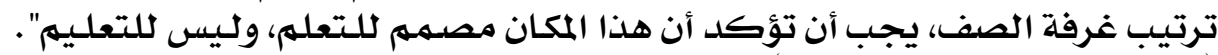

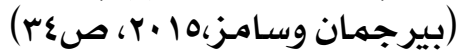

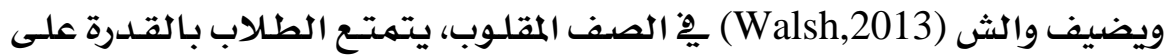

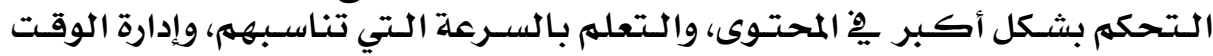

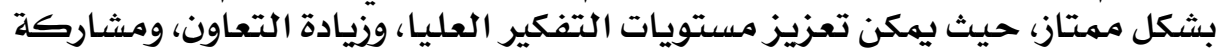

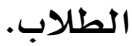

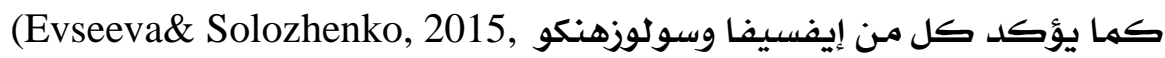

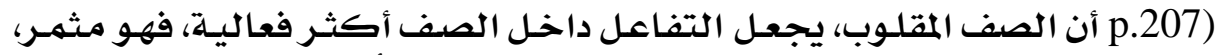

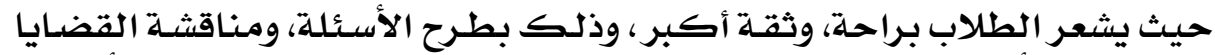

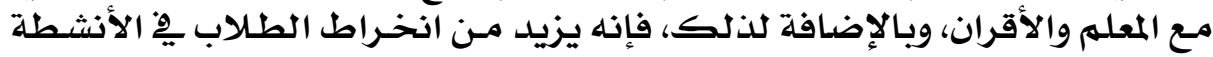

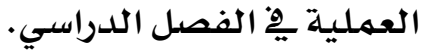

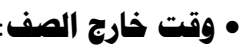

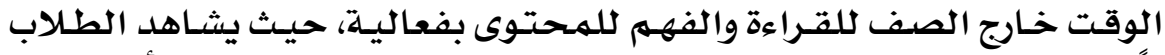

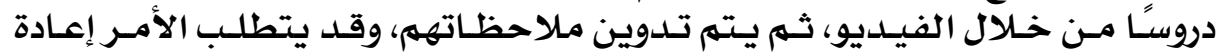




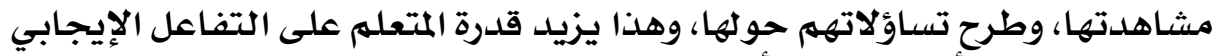

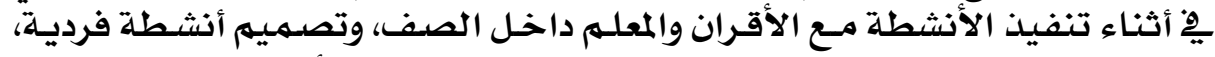

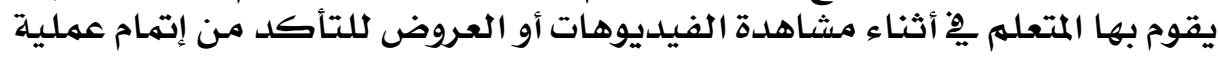

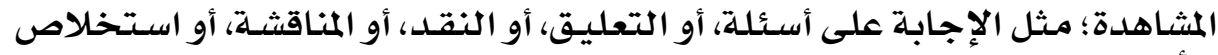

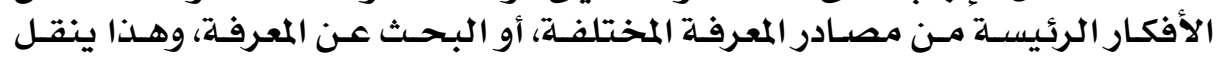

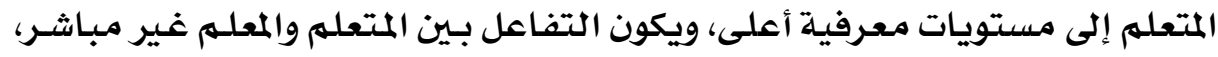

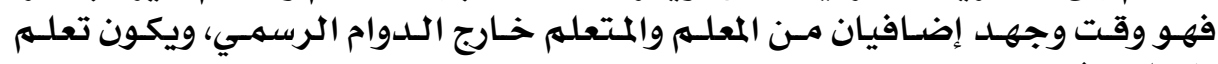

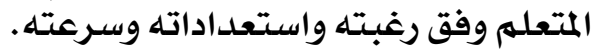

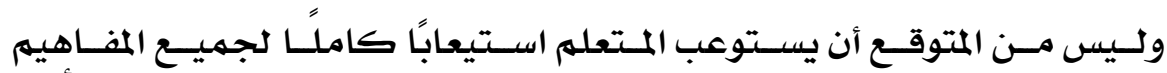

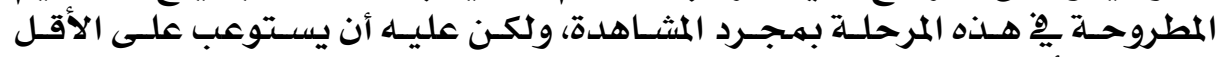

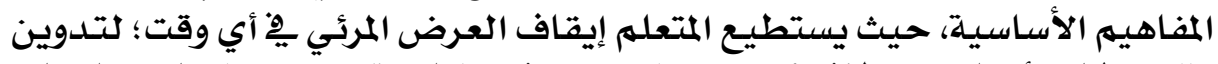

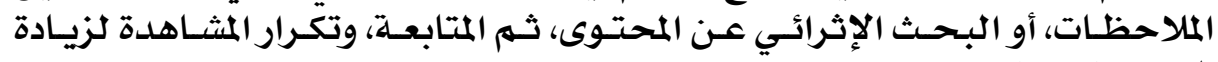
الاستيعاب والفهم. ألماته

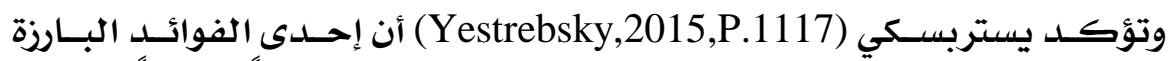

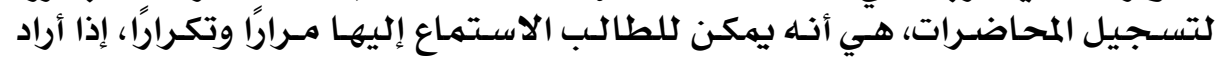

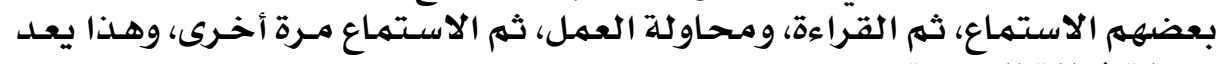
وسيلة فعالة للدراسـة.

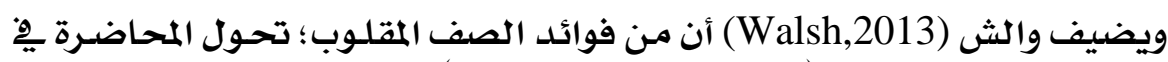

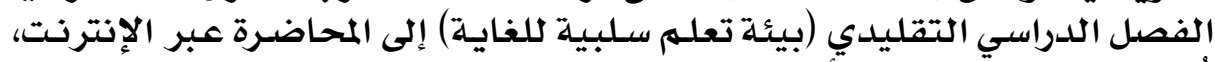

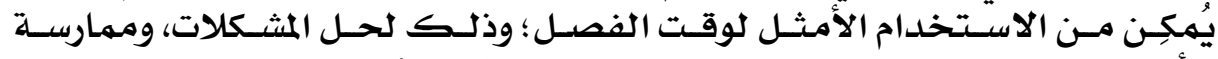

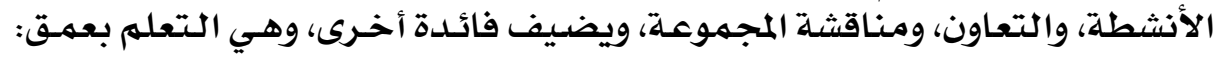

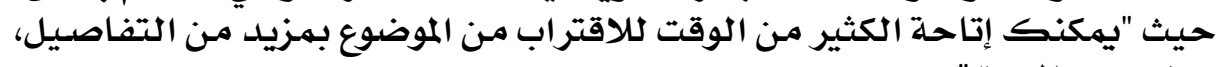

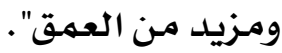

ويشير سامزوآخرون (Sams,A. et al., 2014) إلى معـايير تصسميهم إسـتراتيجية

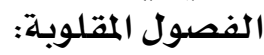

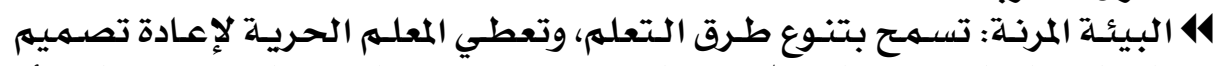

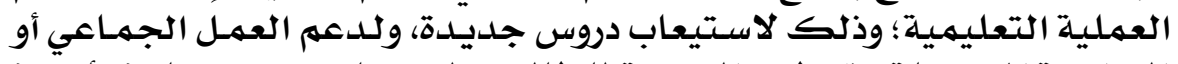

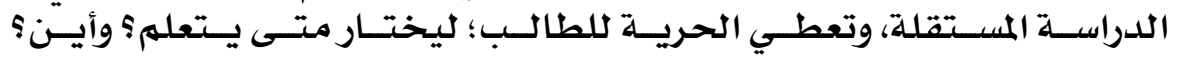

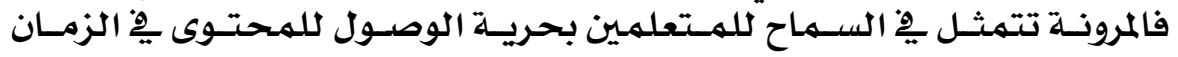

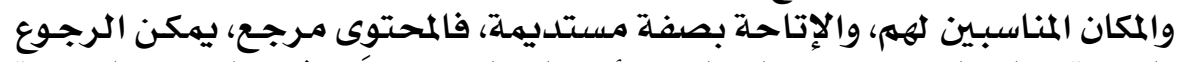

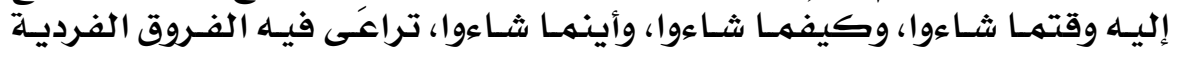

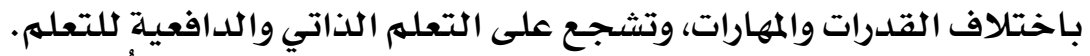

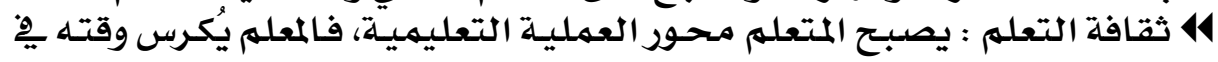

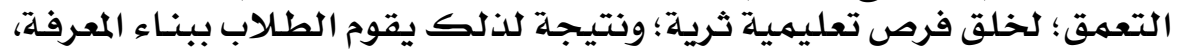




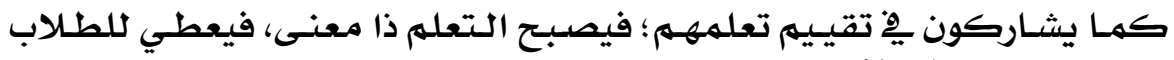

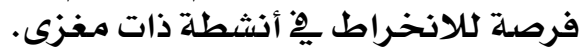

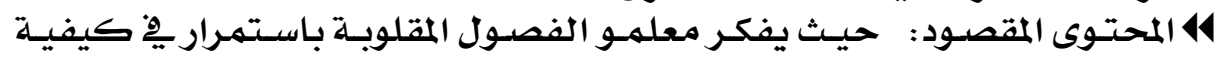

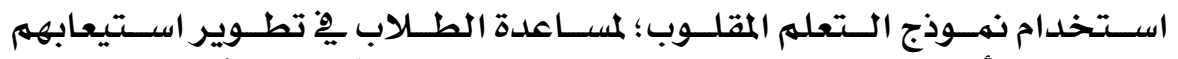

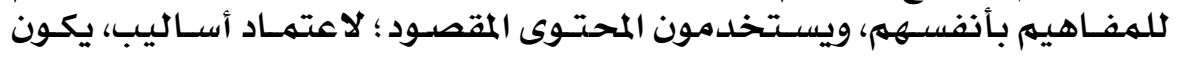

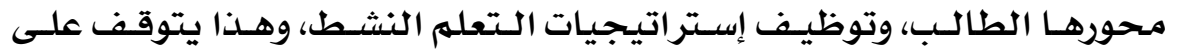

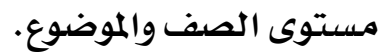

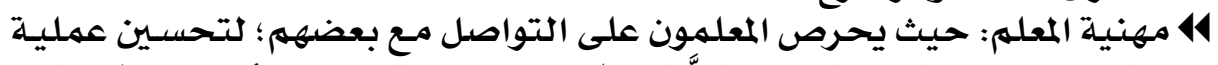

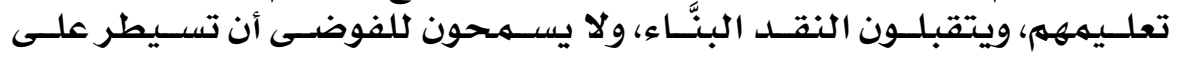

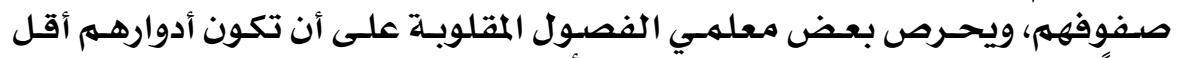

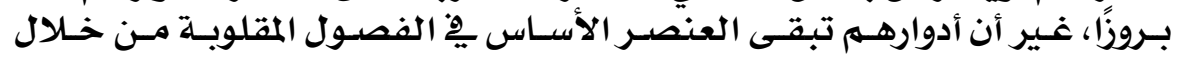

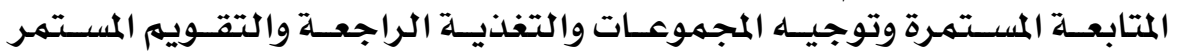

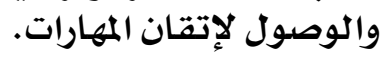

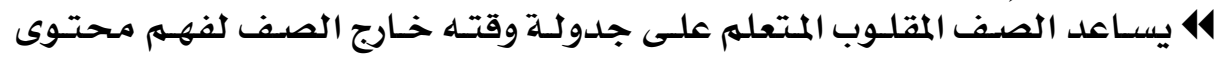

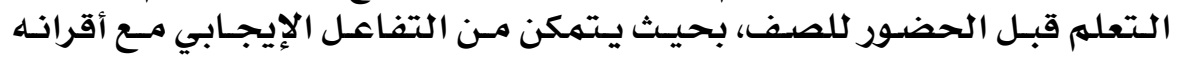

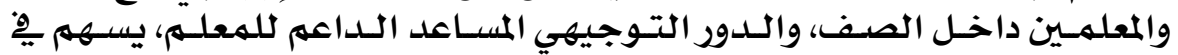

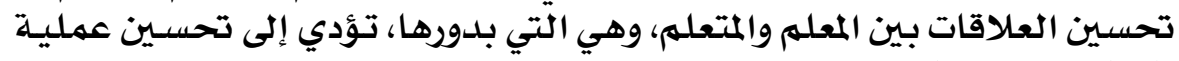

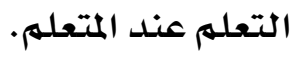

ويشير كل مـن أوفلارتي وفيليبس (O'Flaherty\& Phillips,2015,pp.94-95)

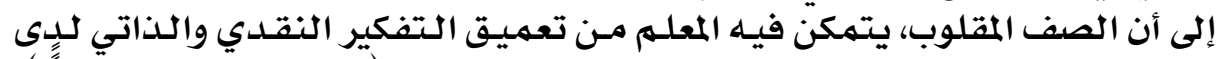

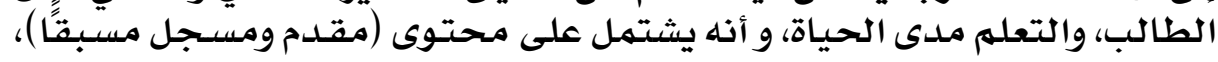

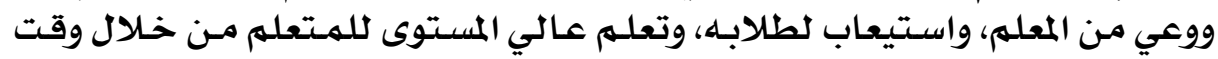

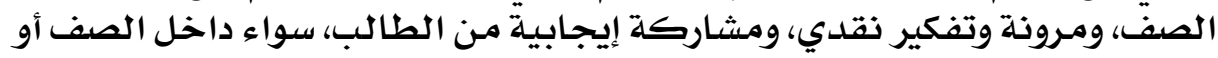
خارجه.

\section{• التمديات التي تواجه تطبيق إستزاتيجية الصف الاملوب:} يشير كل مـن إيفسيفيا وسـولوزهنكو-207.

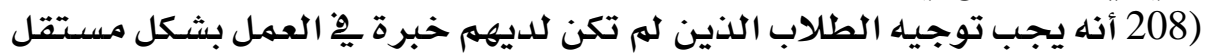

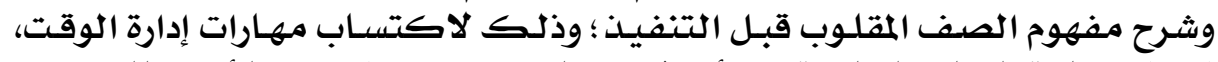

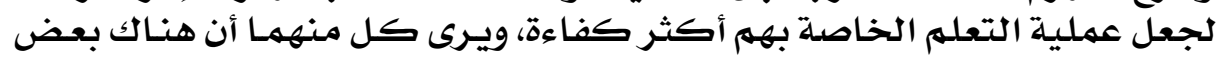

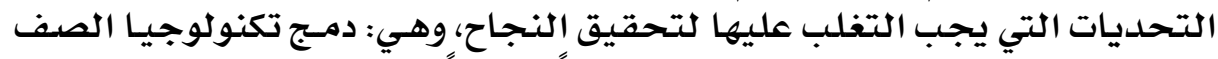

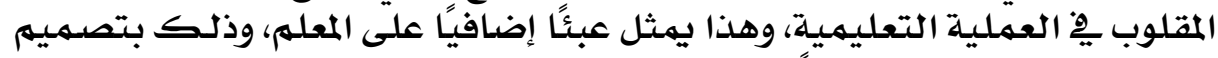

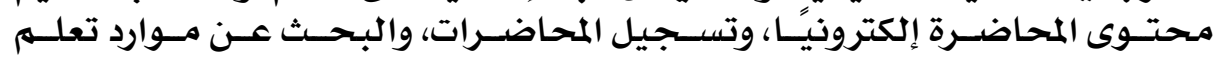

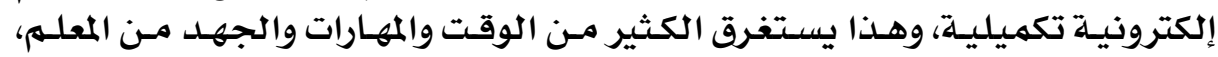

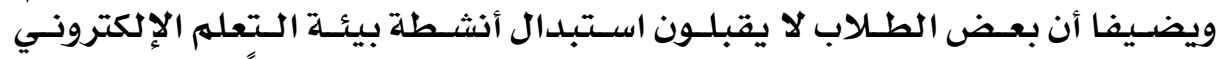

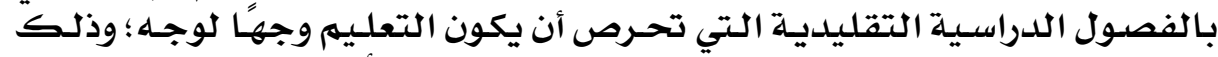

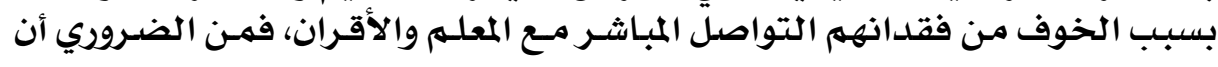


يكون هناك وسائل اتصال إضافيـة، يوفرها عبر الإنترنت مثل الدردشـات والمنتـديات والفيديو كونفرانس، وغير اتهبر إضافيا.

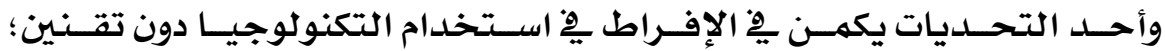

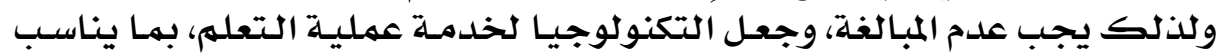

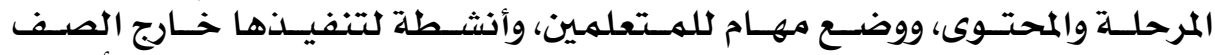

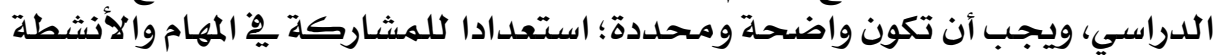

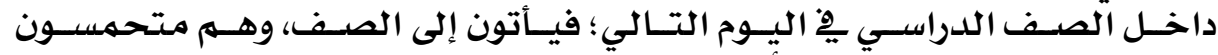

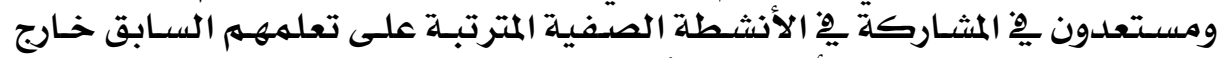

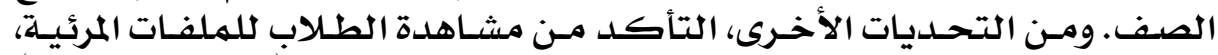

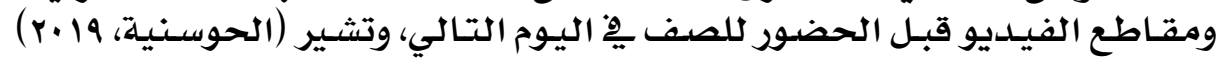

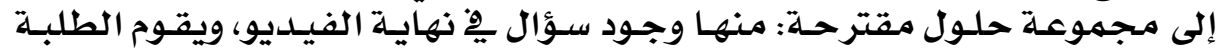

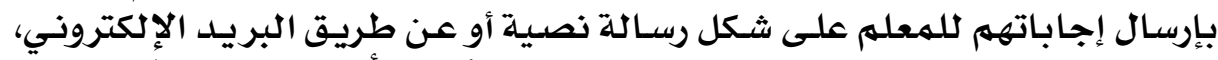

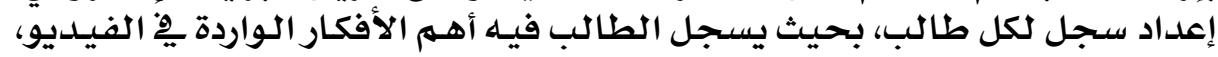

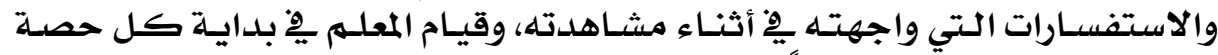

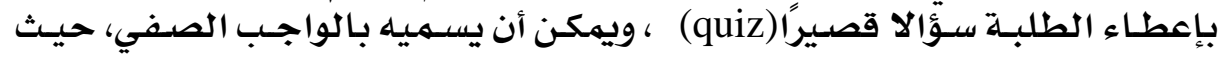

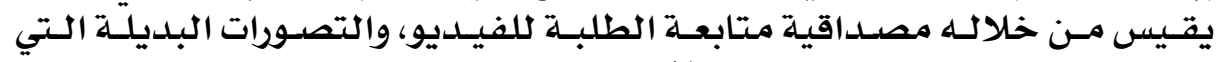

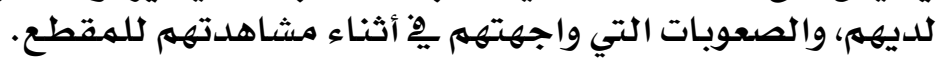

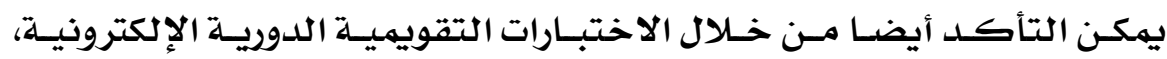

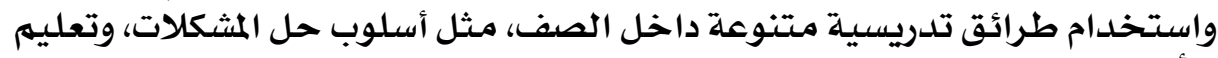

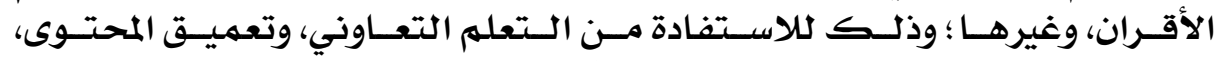

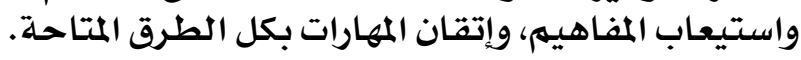

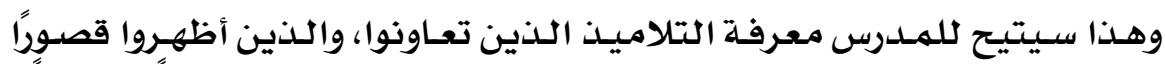

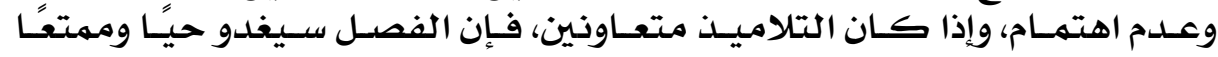

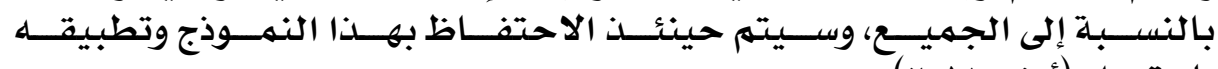

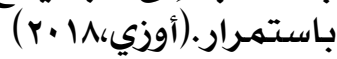

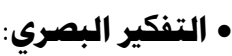

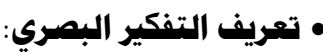

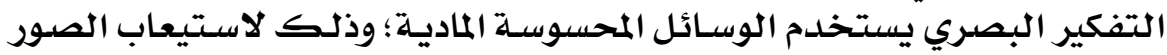

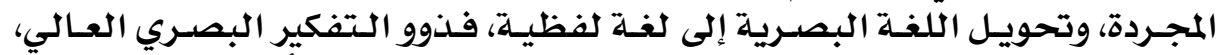

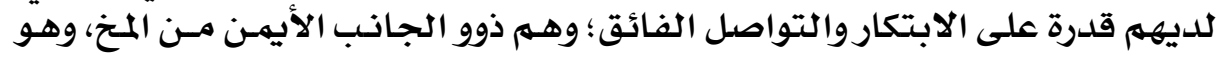

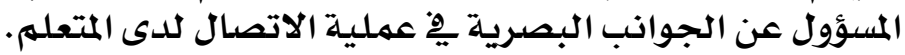

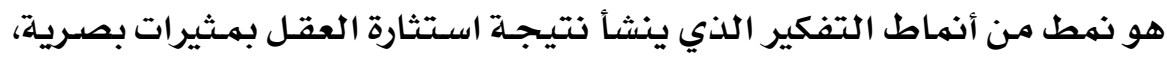

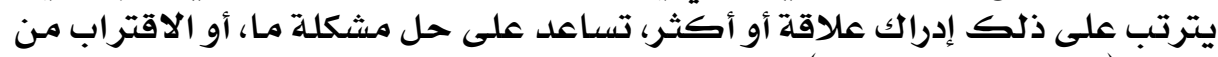

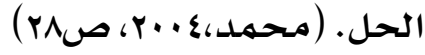




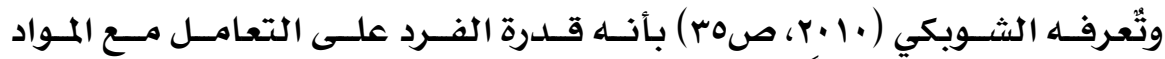

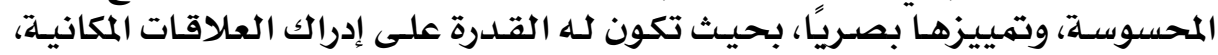

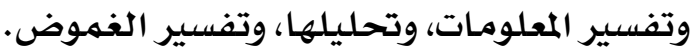

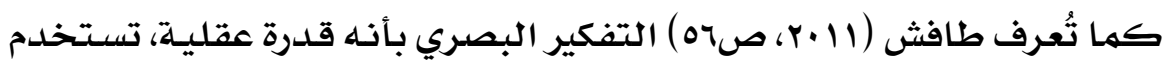

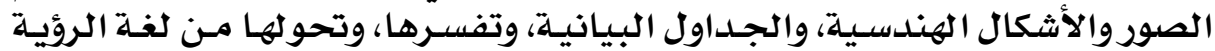

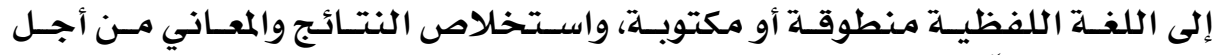

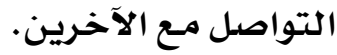

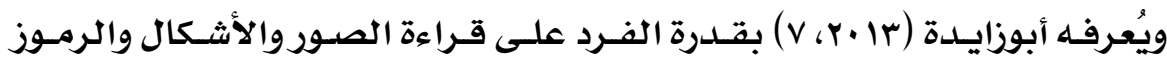

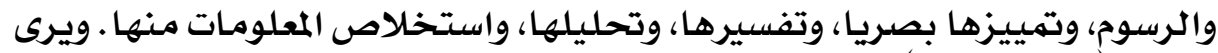

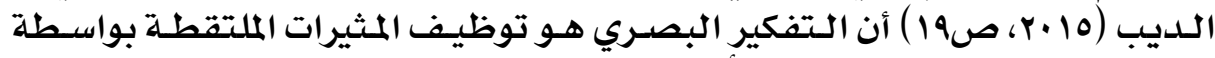

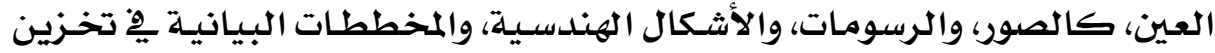

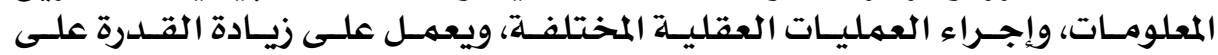

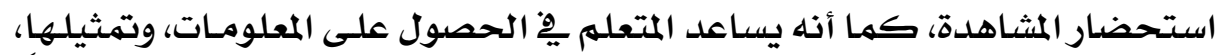

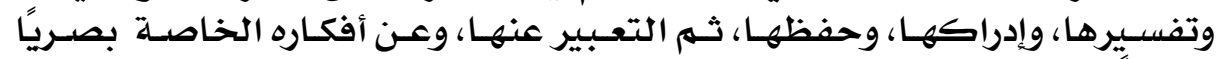

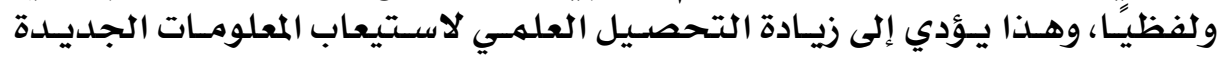
بسرعة وإتقان. ولفئان.

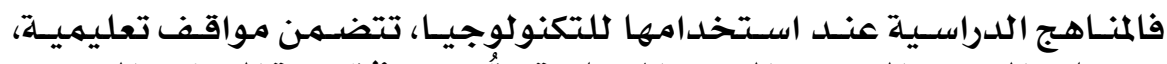

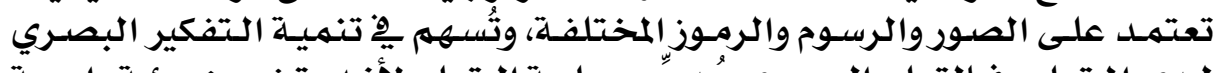

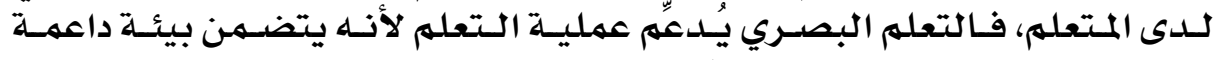

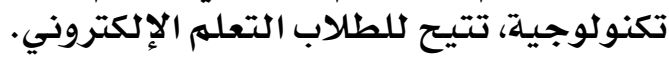

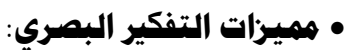

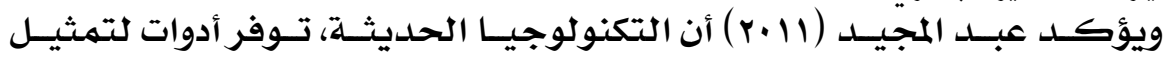

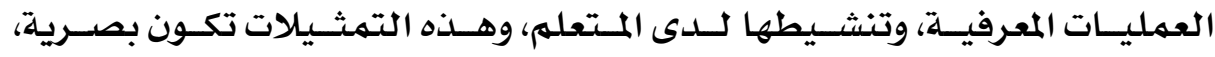

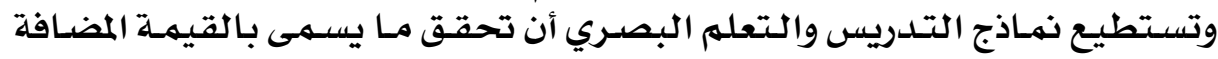

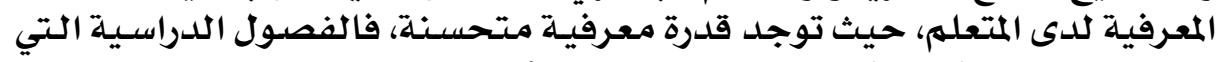

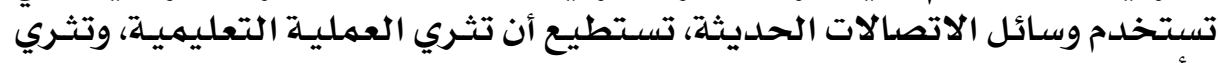

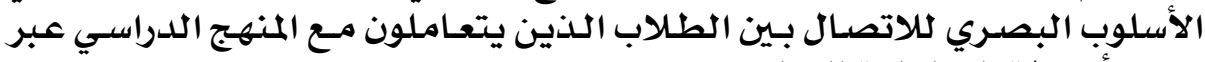

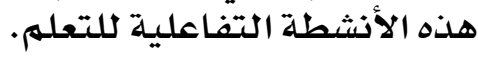

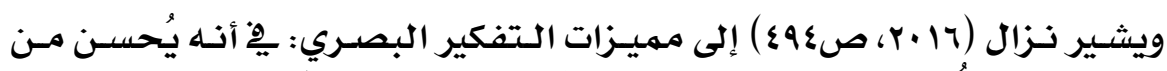

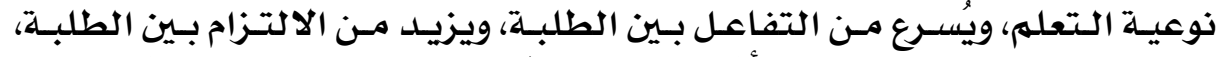

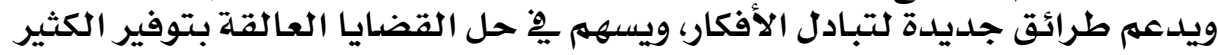

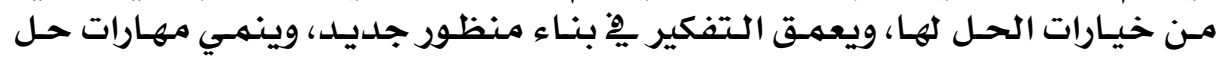
المثكلات لدى الطلاب.

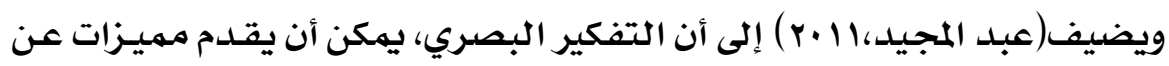
التفكير اللفظي مثل: 


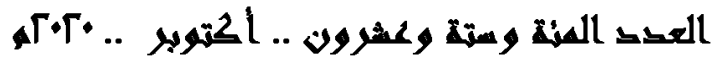

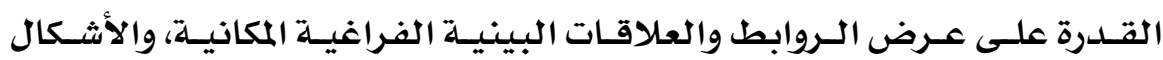

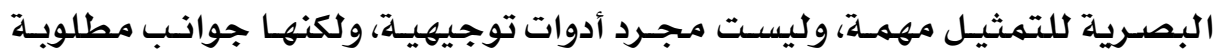

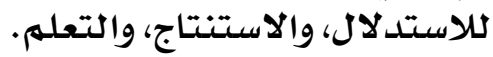

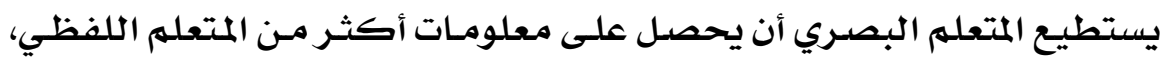

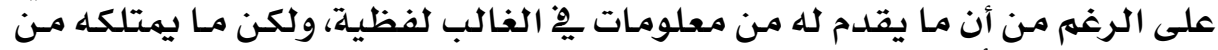

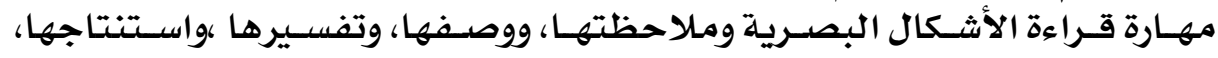

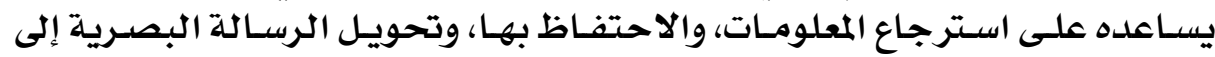

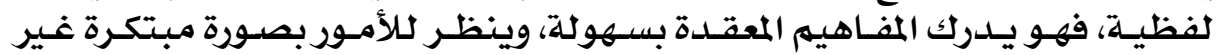

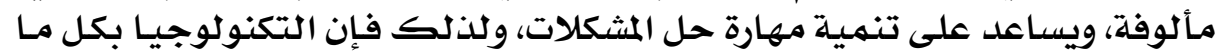

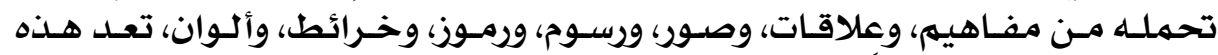

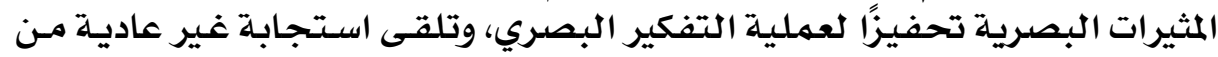

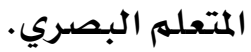

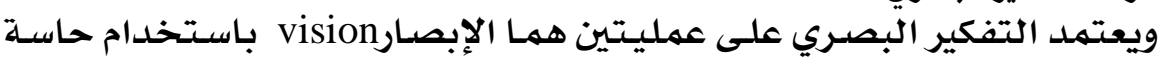

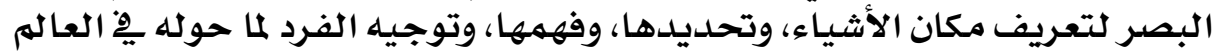

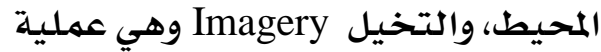

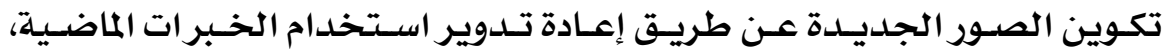

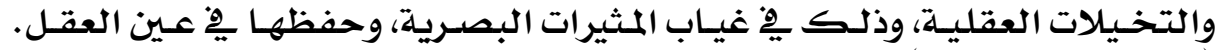

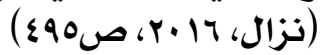

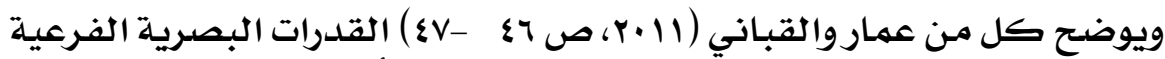

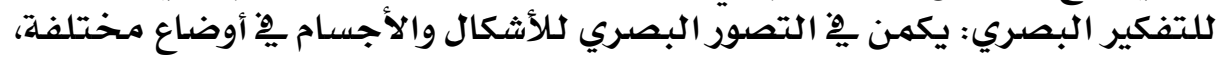

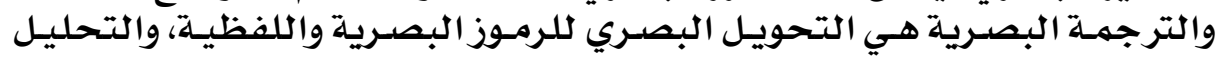

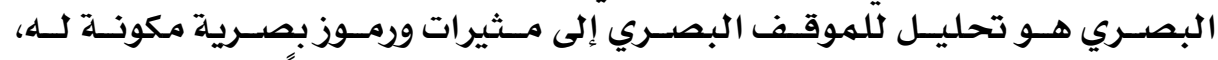

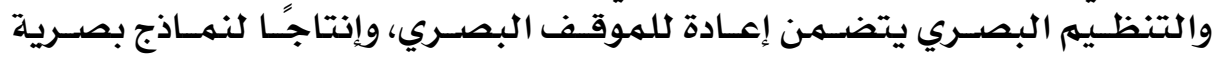
ومواقف يِّ ضوء معطيات بصرية البهية مسبقة.

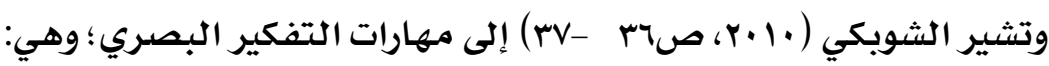

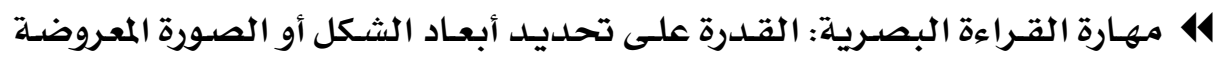
وطبيعتهما.

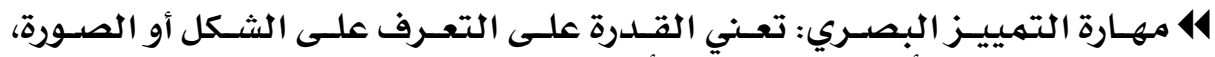

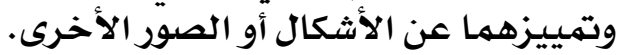

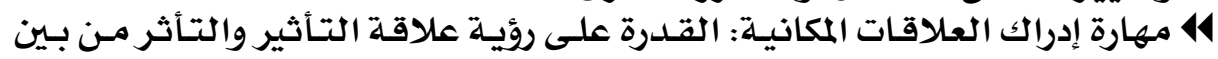

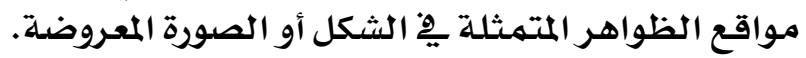

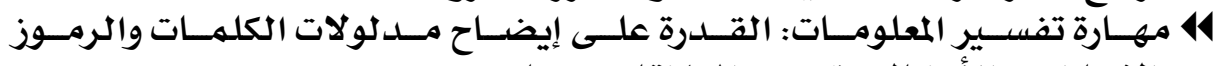
والإشارات، والأشكال، وتقريب المعلومات العلاقات بينها. 


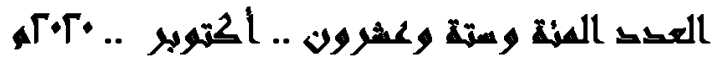

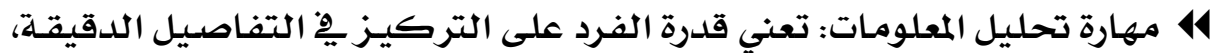

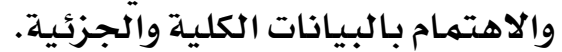

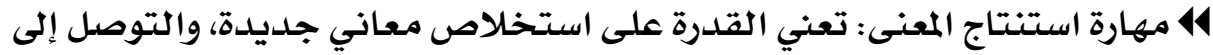

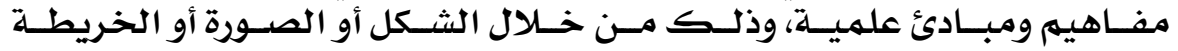

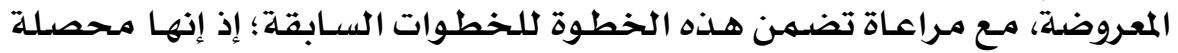
للخطوات الخمسة معسة السـابقة.

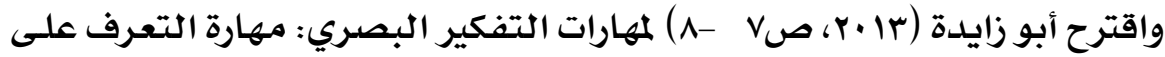

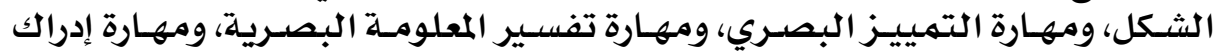

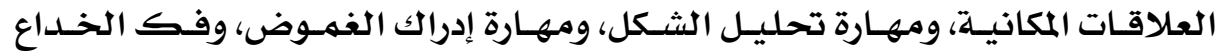

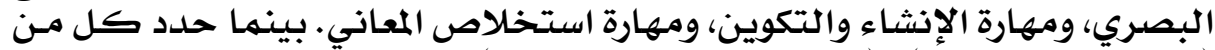

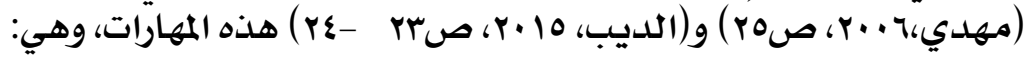

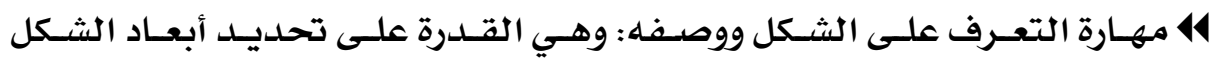
المعروض وطبيعته.

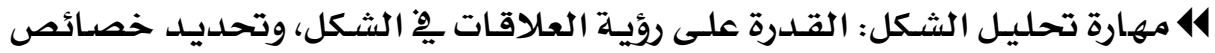
تلك العلاقات وتصنيفها.

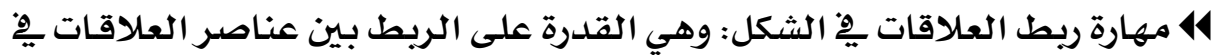

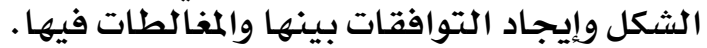

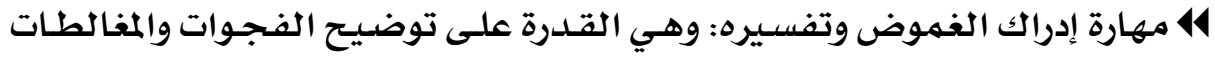

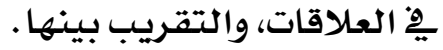

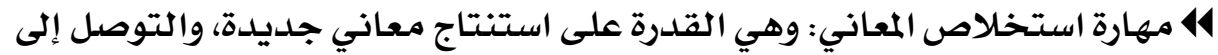

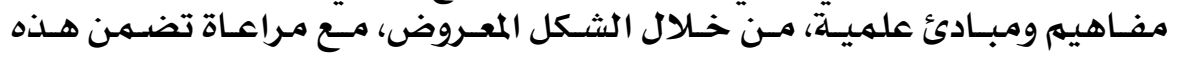

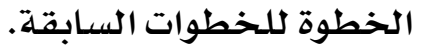

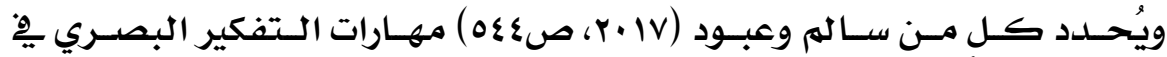

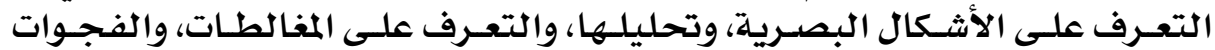

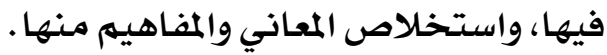

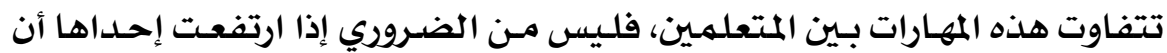

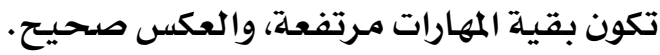

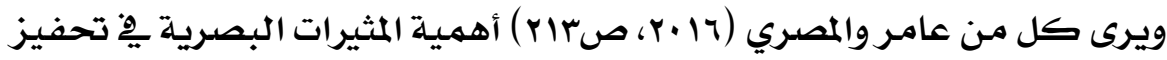

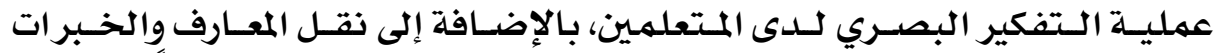

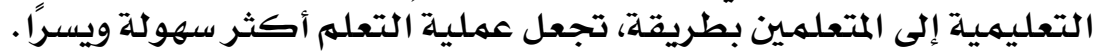

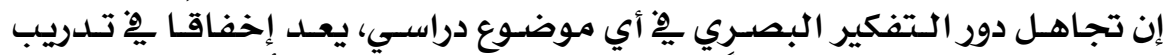

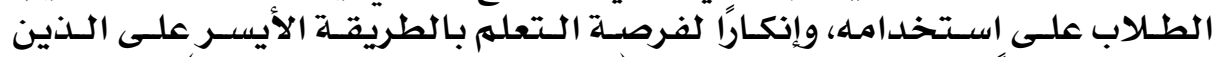

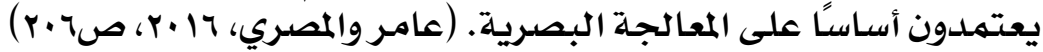
وقد ركز البحث الحالي على المهارات الآتية: 


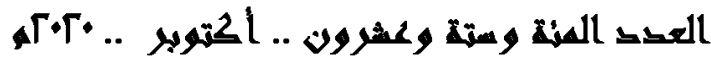

44 التعرف: أي التعرف على الشكل ومحترواه ووصفهـ

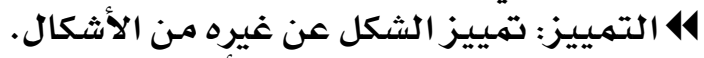

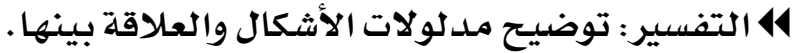

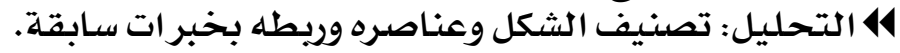

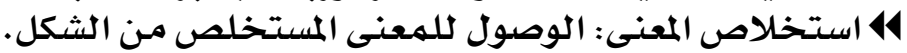
• مالدراسات السابقة:

• أولاً: دراسات تناولت علاقة الصف المقلوب والتصصيل الدراسي:

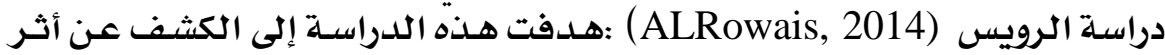

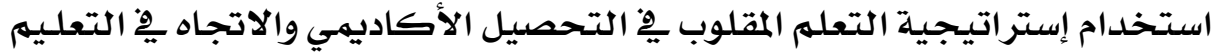

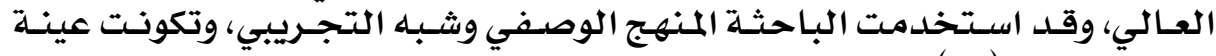

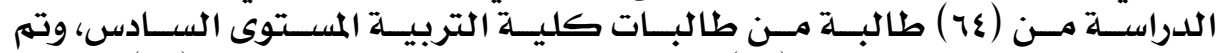

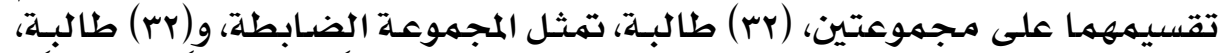

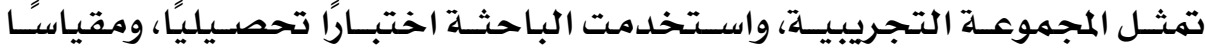

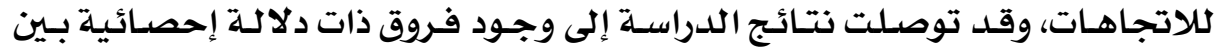

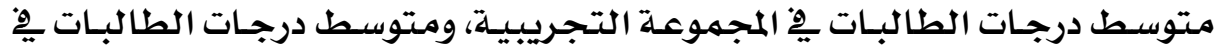

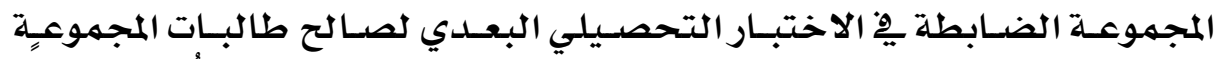

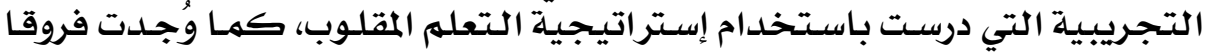

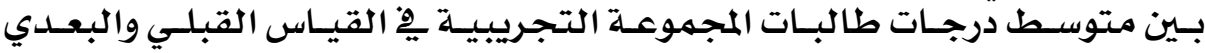

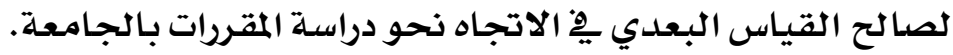

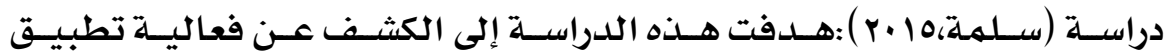

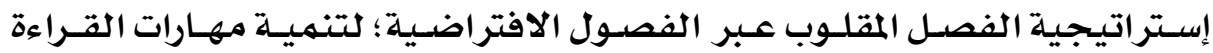

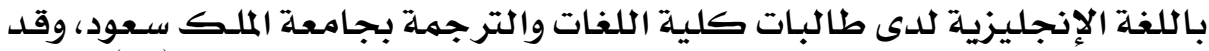

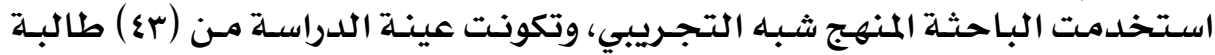

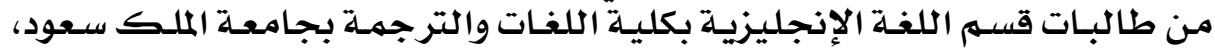

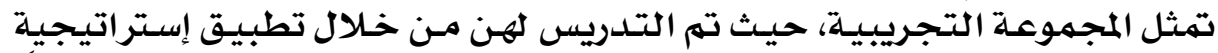

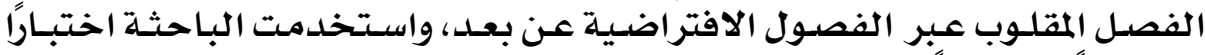

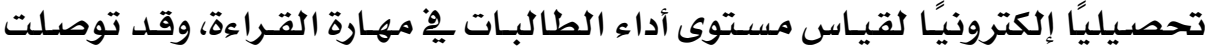

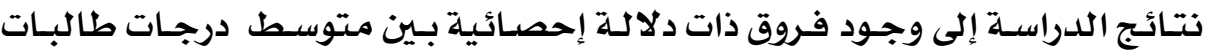

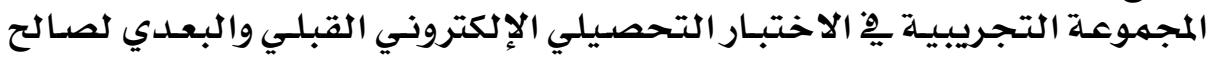
القياس البعدي.

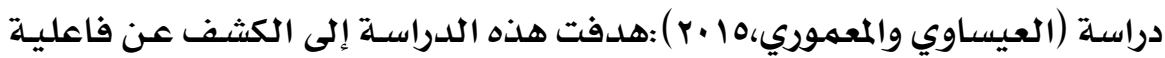

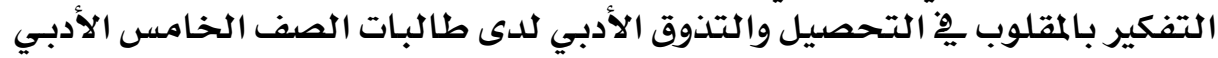

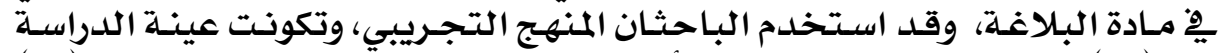

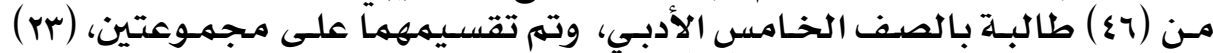

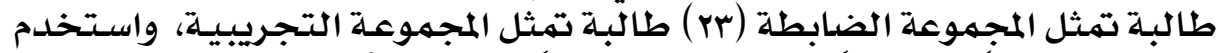

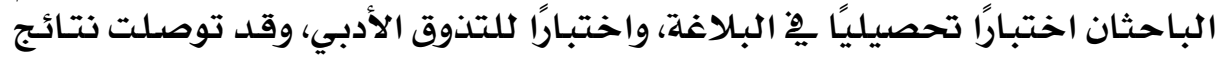

\section{YV.}




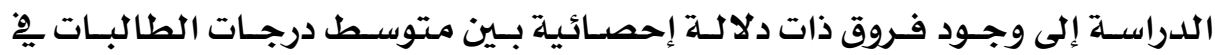

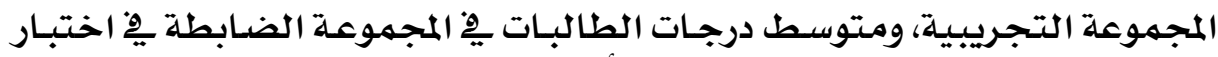

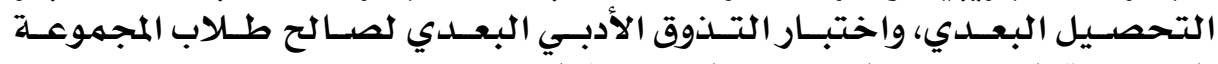

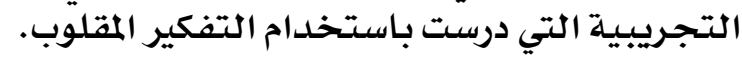

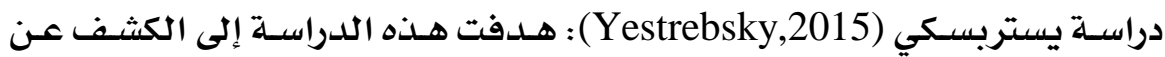

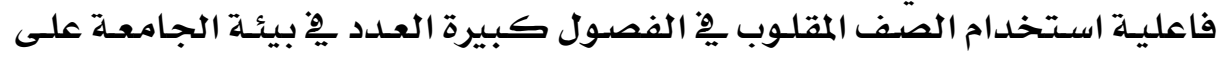

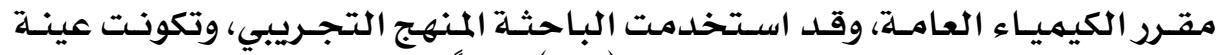

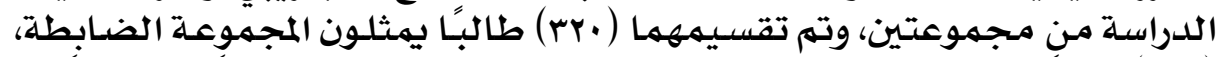

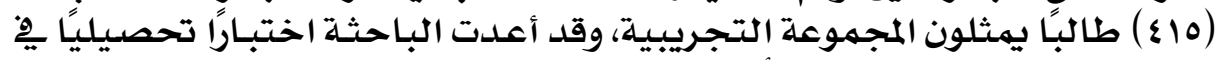

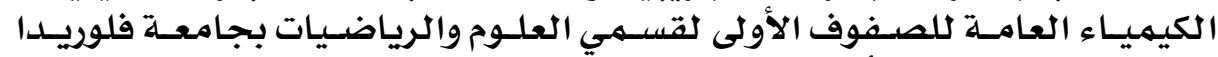

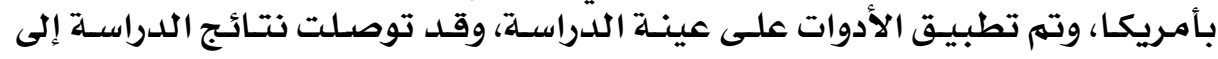

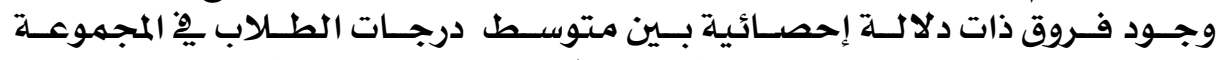

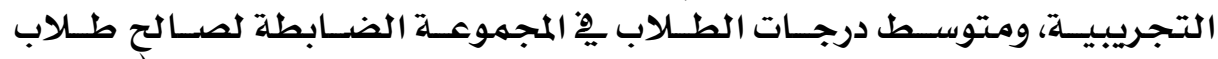

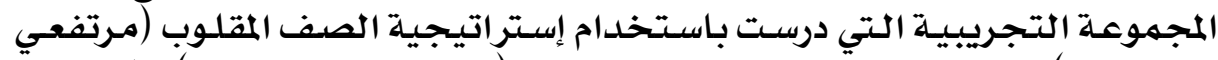

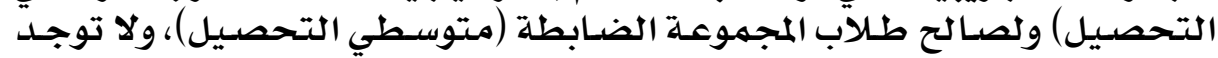

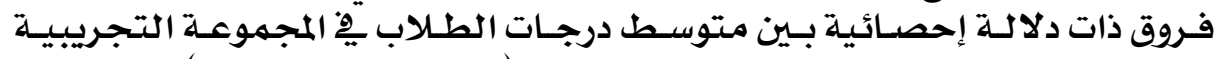

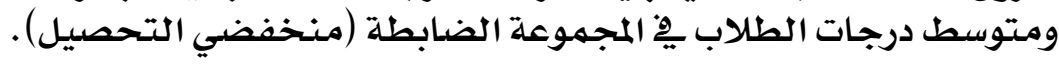

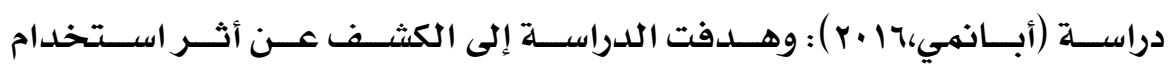

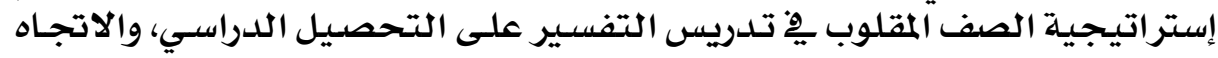

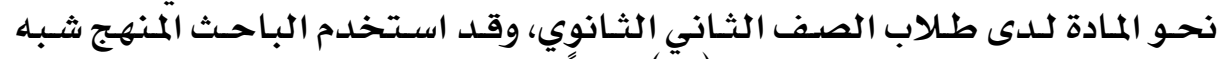

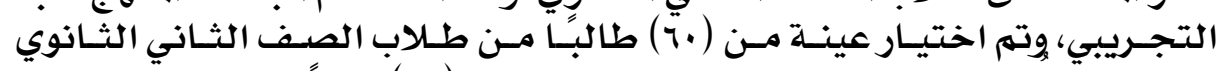

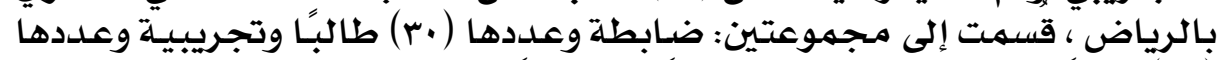

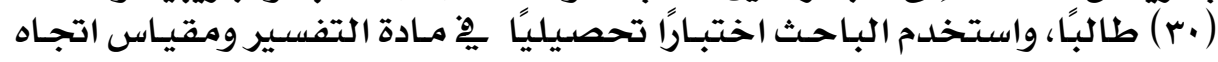

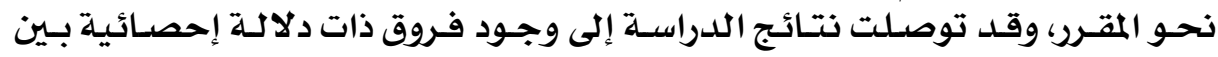

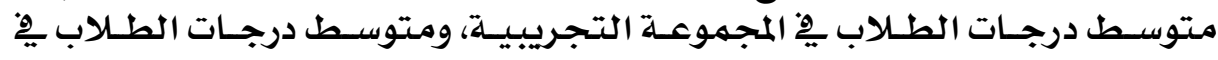

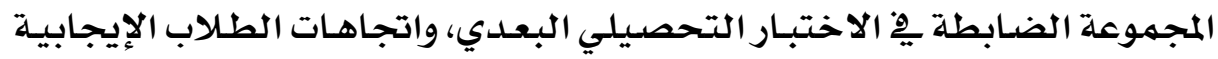

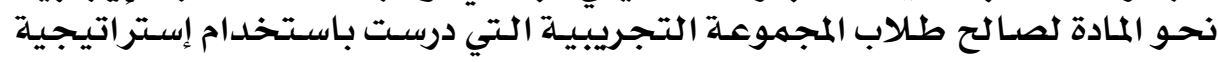
الصف المقلوب.

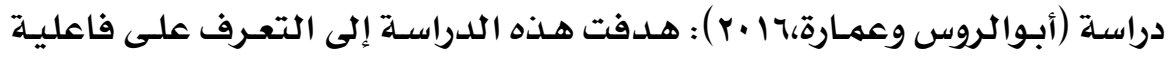

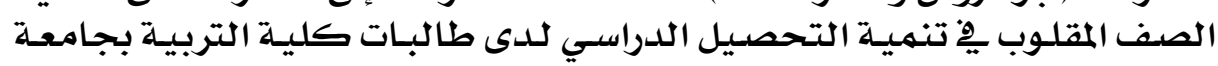

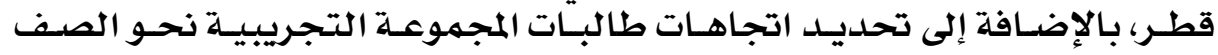

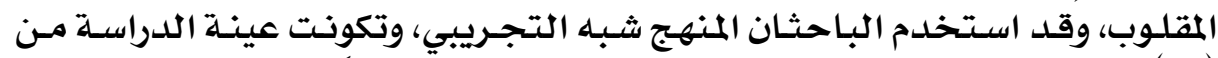

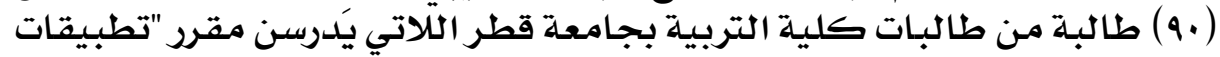

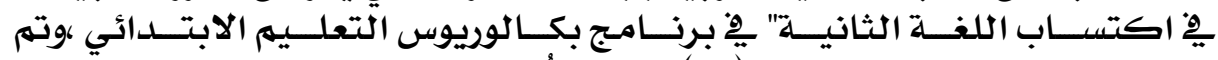

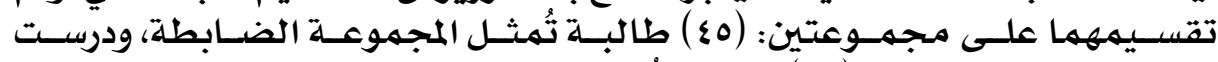

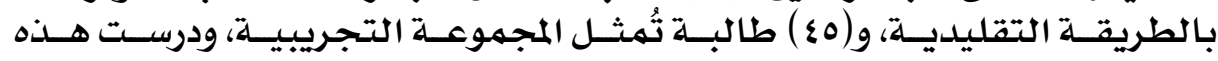




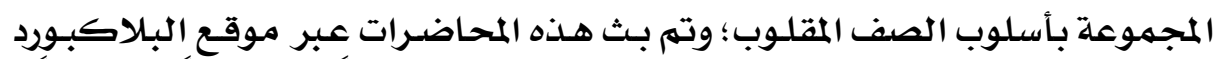

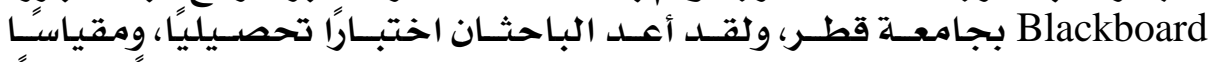

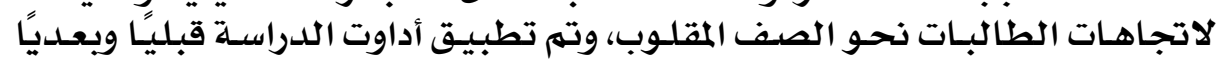

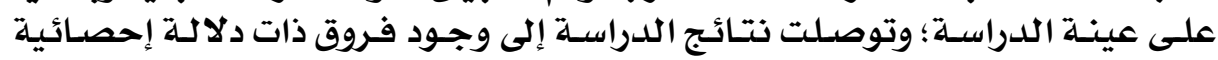

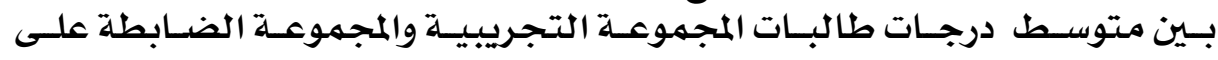

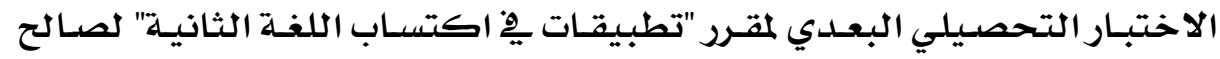

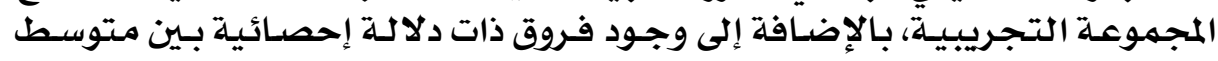

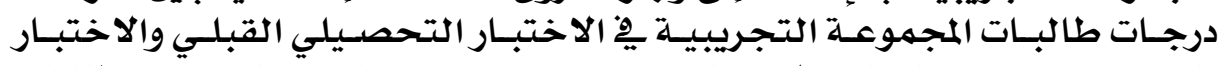

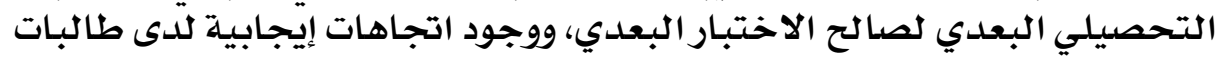

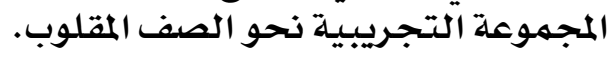

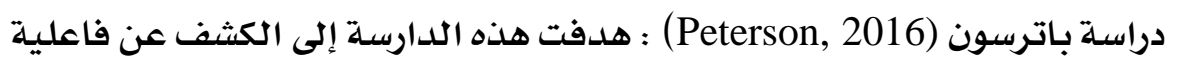

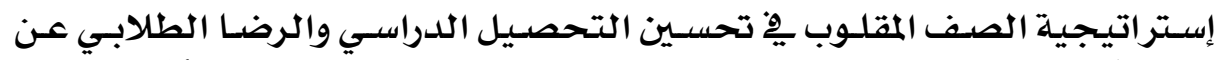

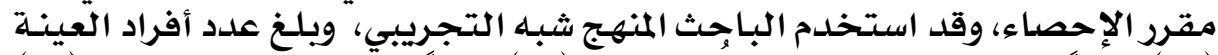

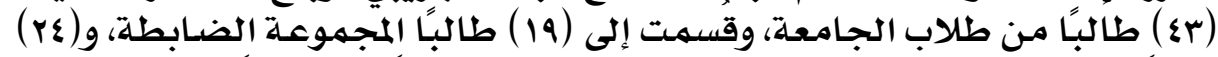

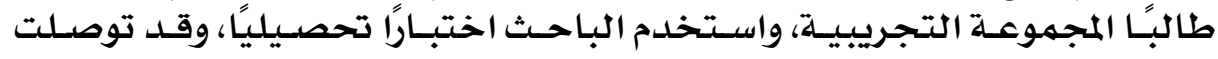

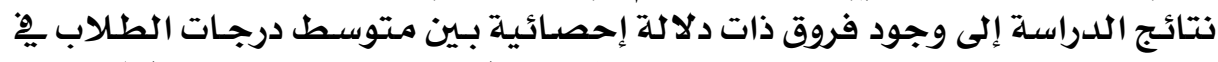

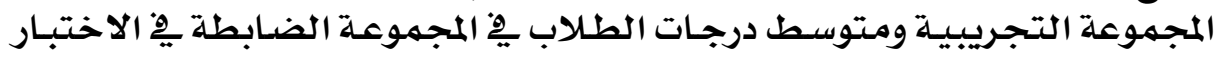

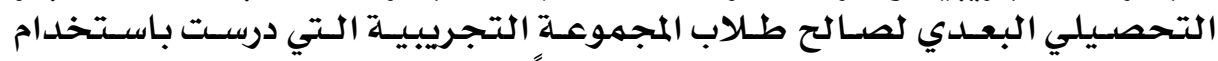

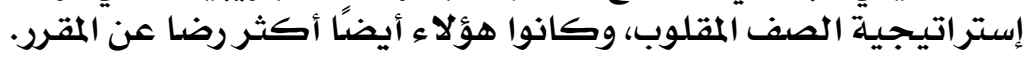

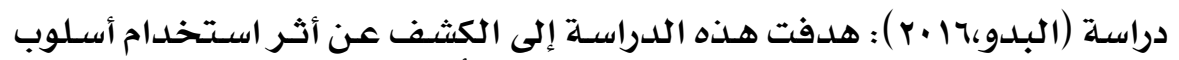

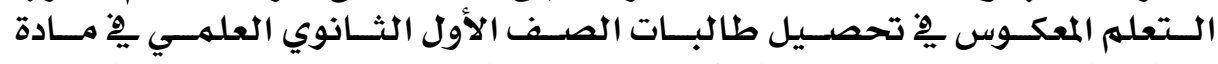

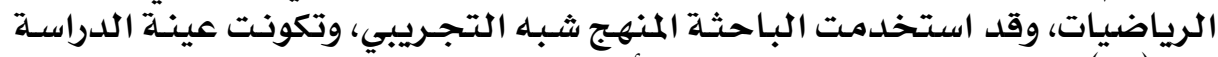

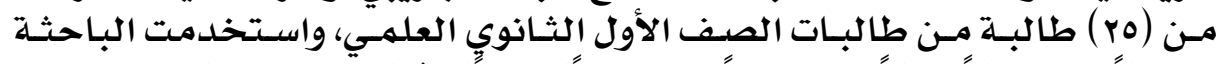

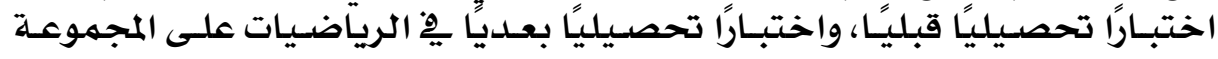

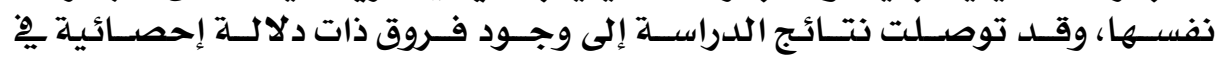

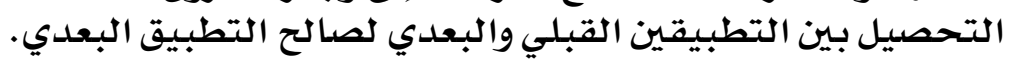

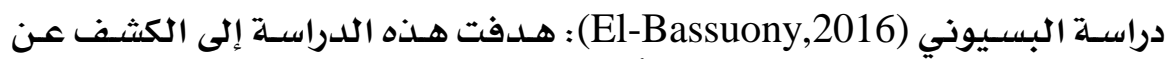

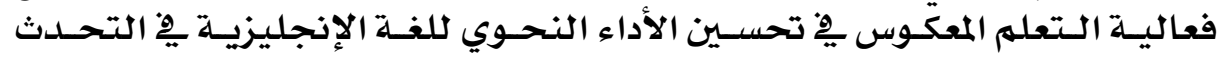

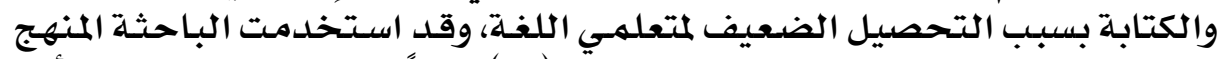

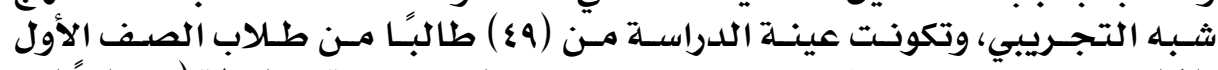

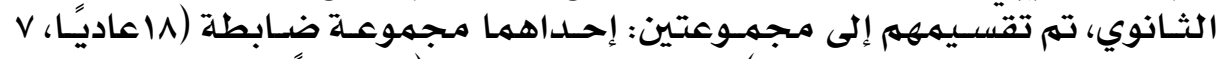

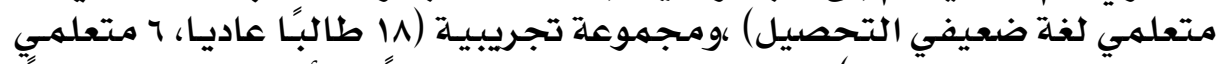

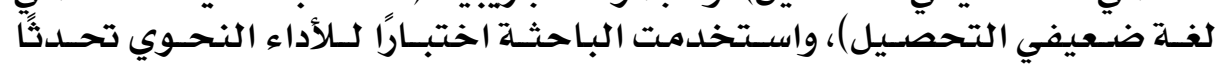

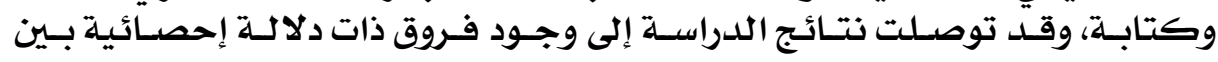

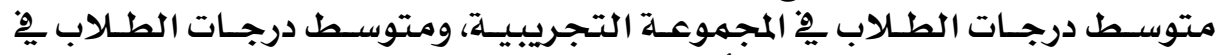

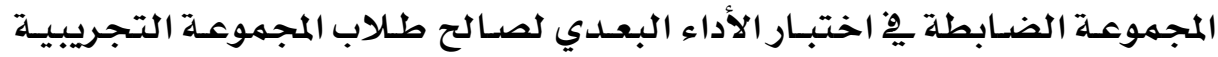

\section{YVY}




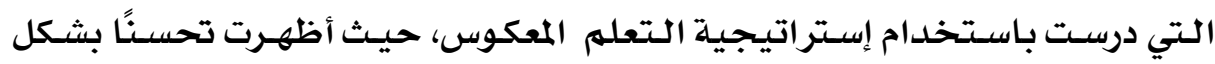

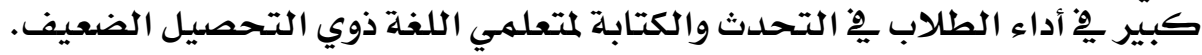

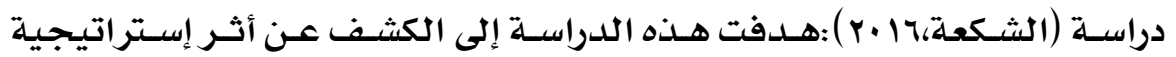

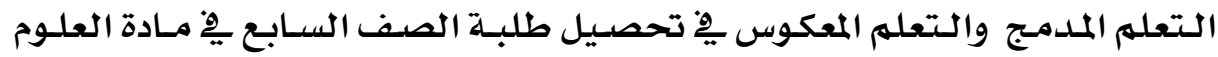

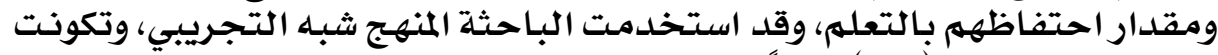

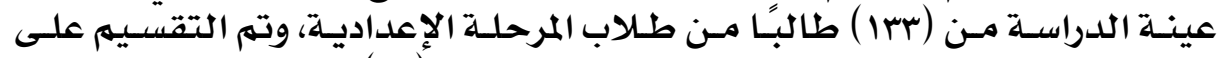

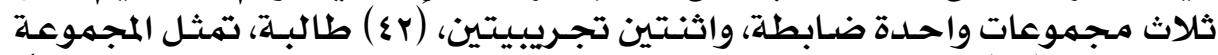

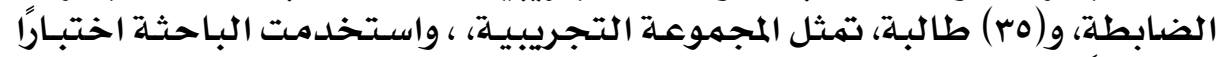

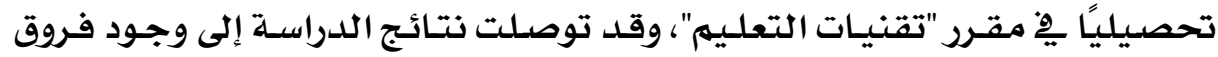

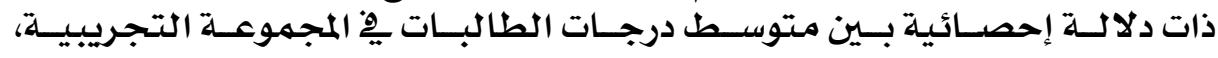

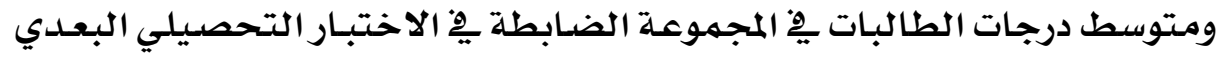

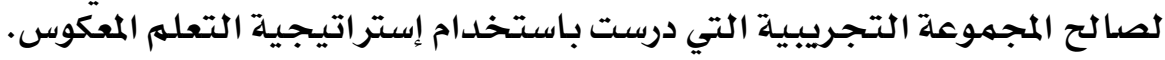

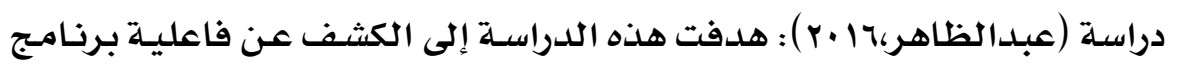

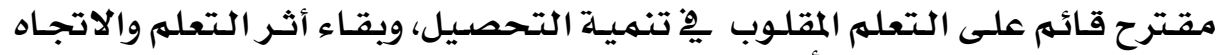

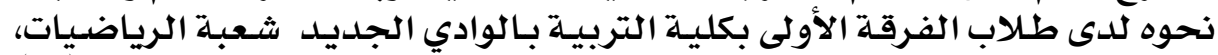

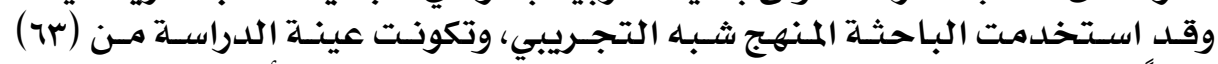

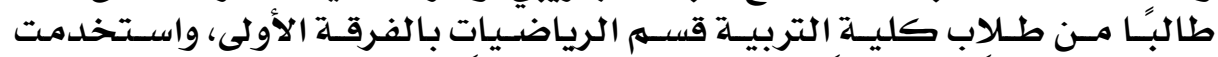

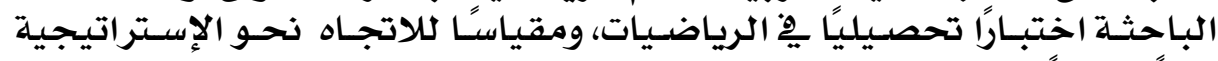

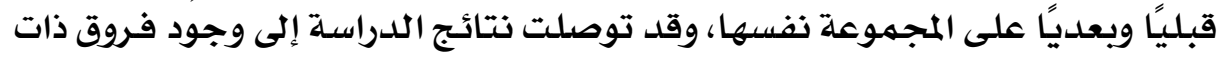

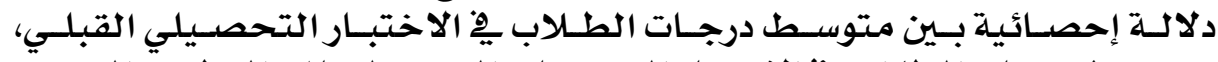

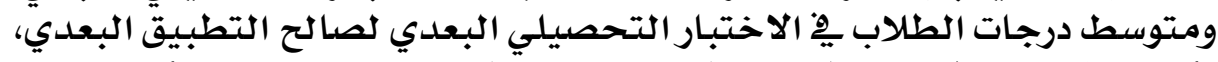

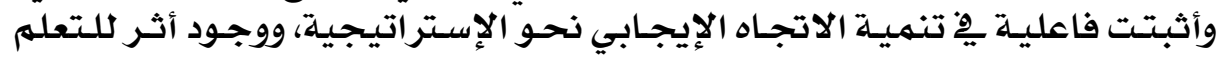
لدى الطلاب.

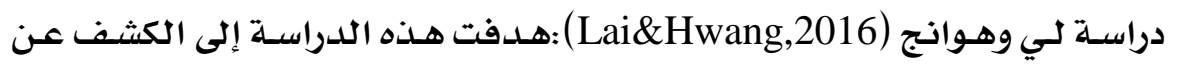

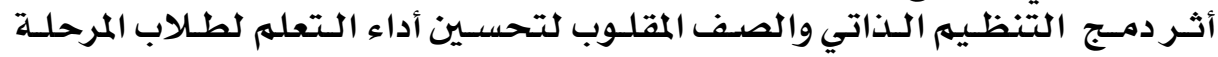

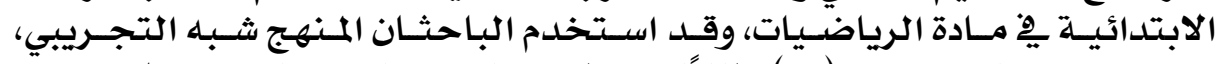

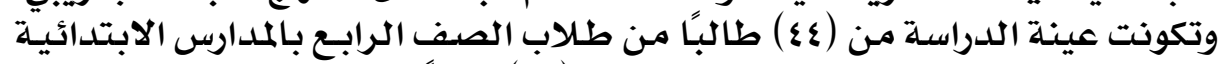

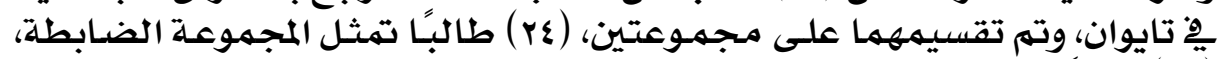

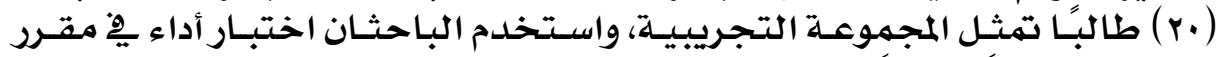

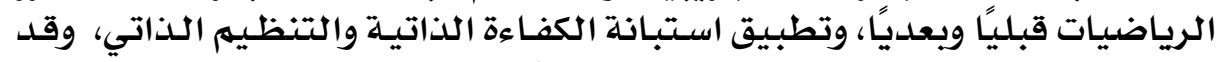

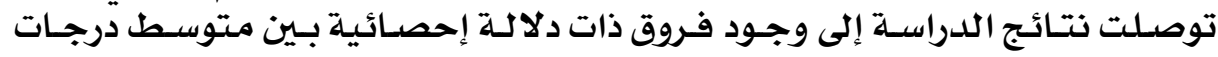

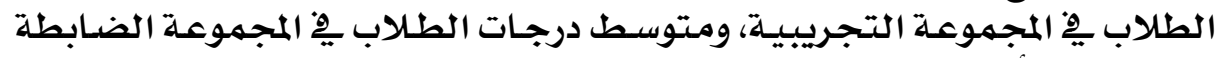

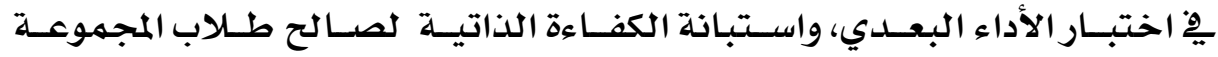

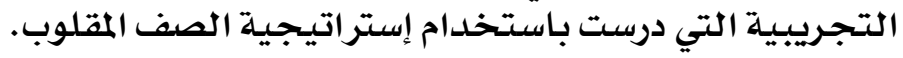




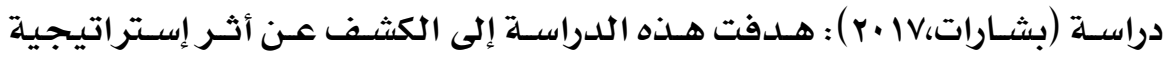

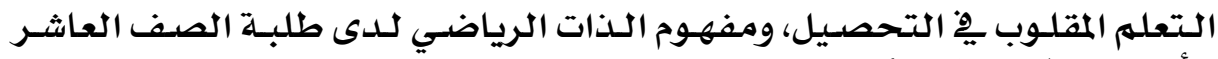

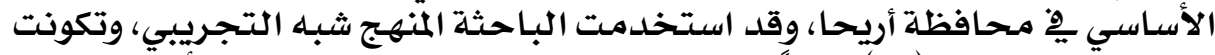

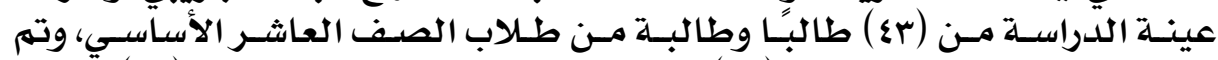

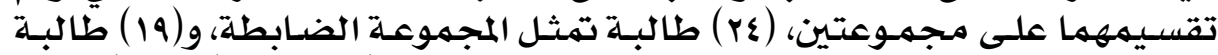

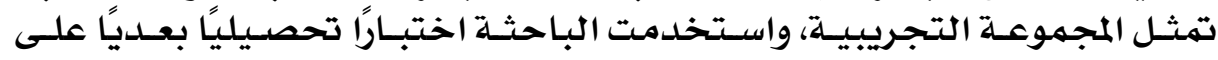

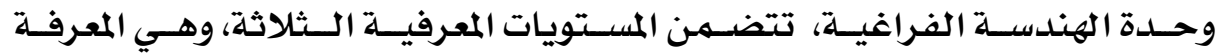

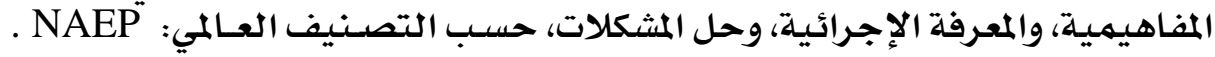
(National Assessment of Educational Progress, 2011)

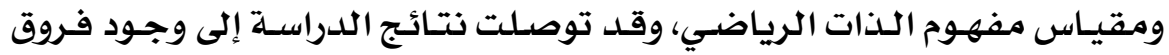

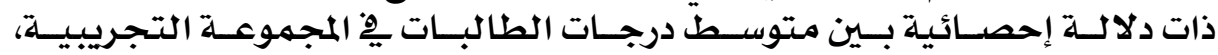

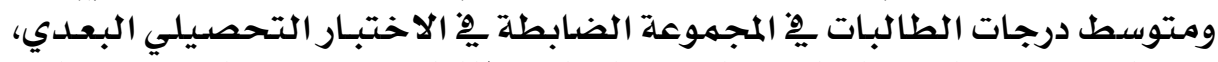

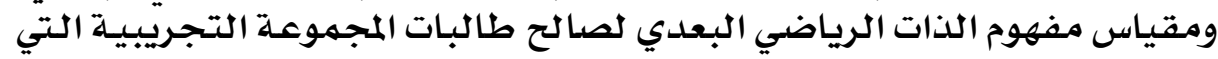

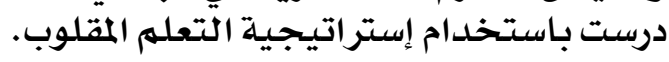

دراسـة (الدوسري، وآل مسعد، IV · ) :هدفت هذه الدراسـة إلى الكشف عن فاعليـة

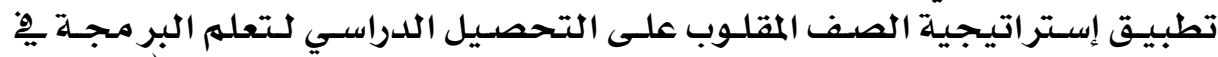

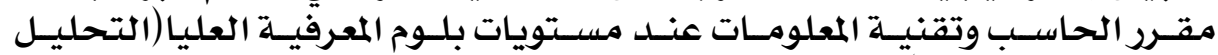

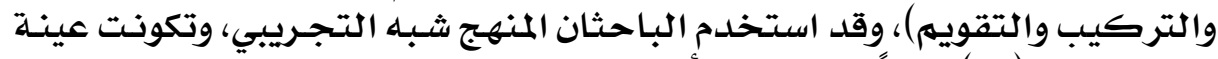

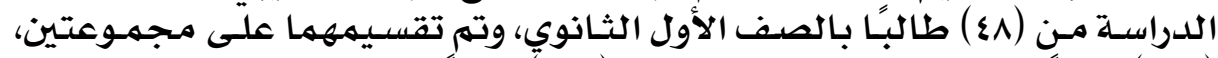

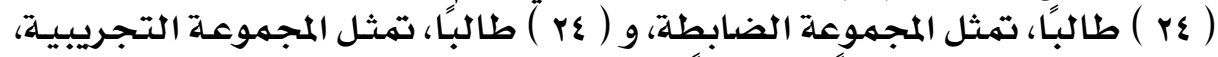

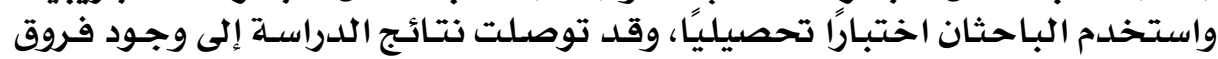

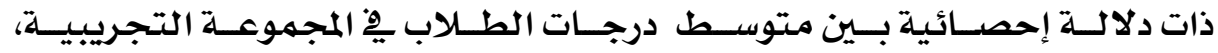

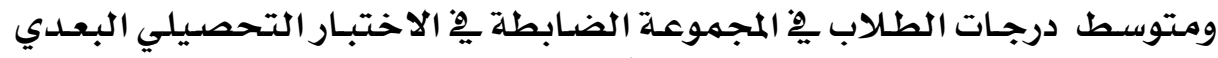

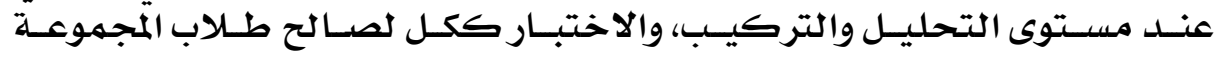

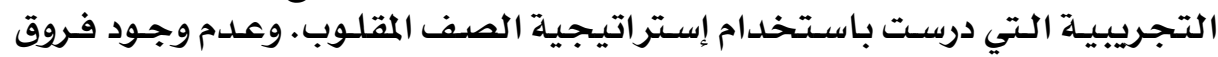

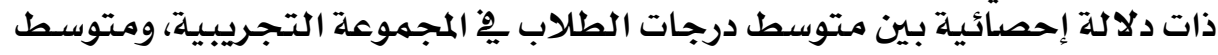

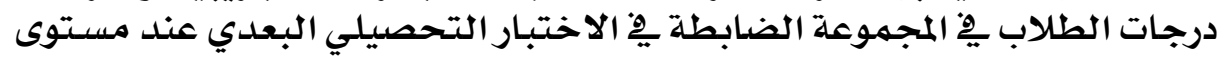
التقويهم. دوحات

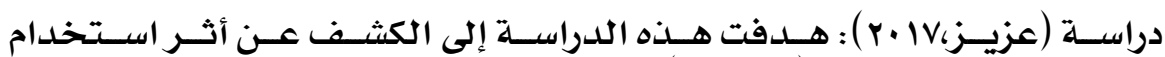

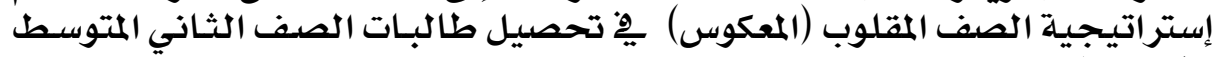

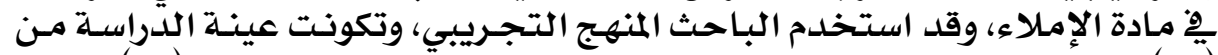

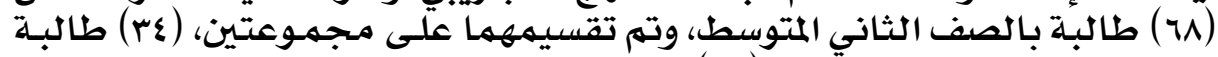

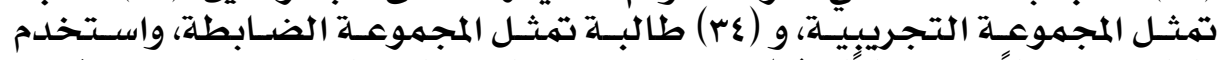

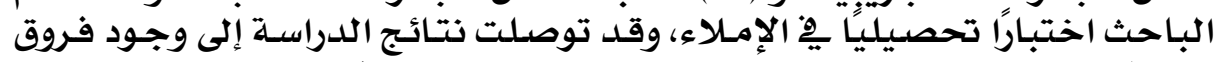

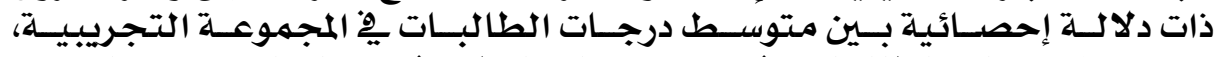

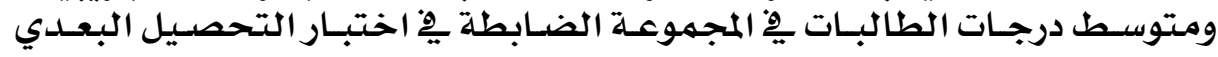




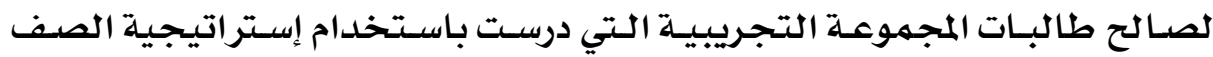
المقلوب.

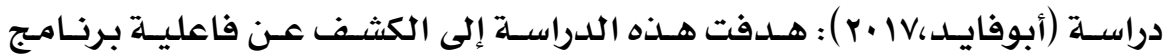

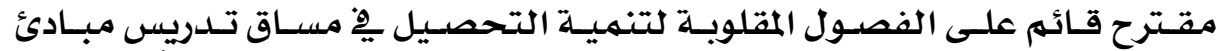

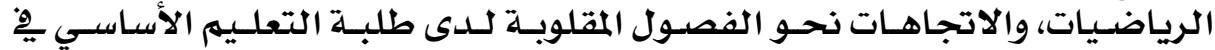

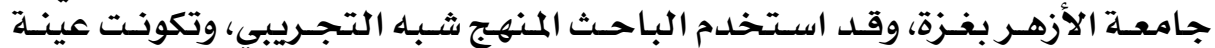

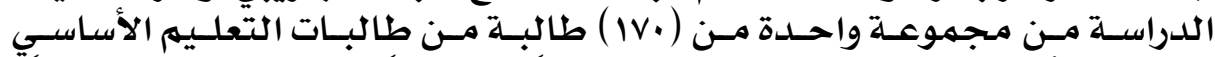

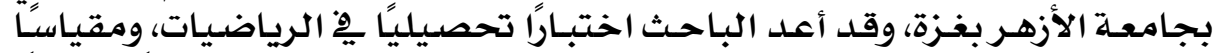

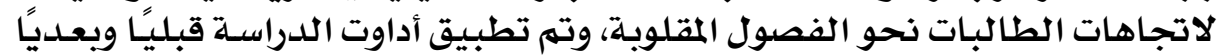

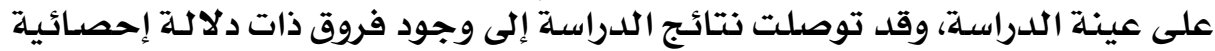

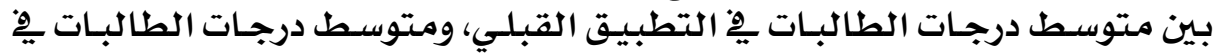

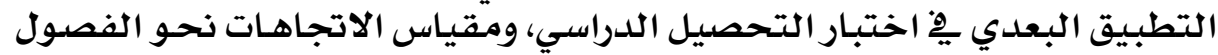
المقلوبـة لصالح التطبيق البعيق البعدي.

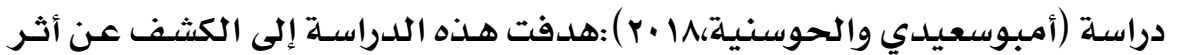

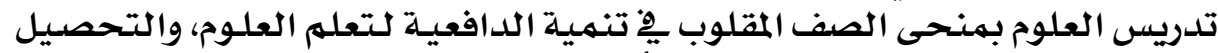

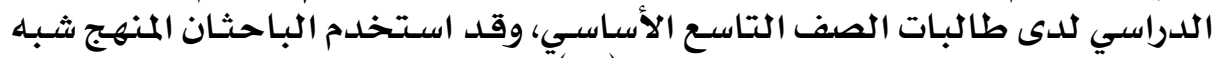

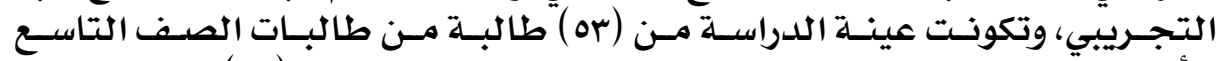

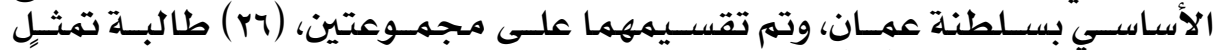

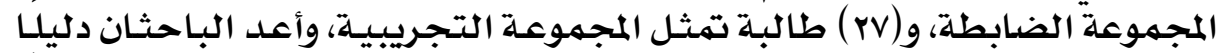

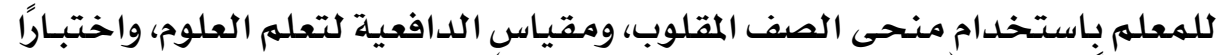

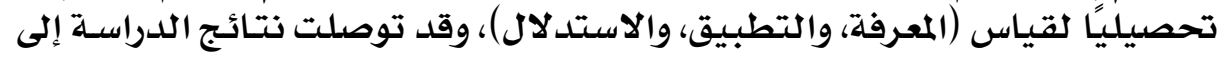

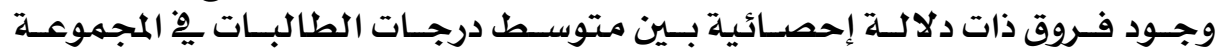

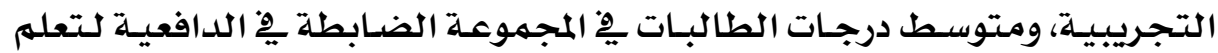

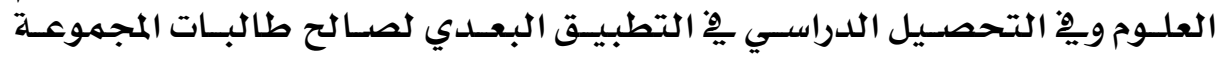

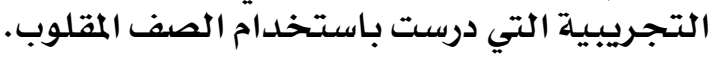

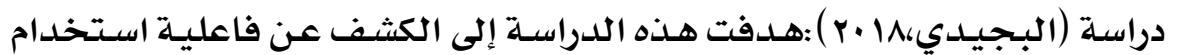

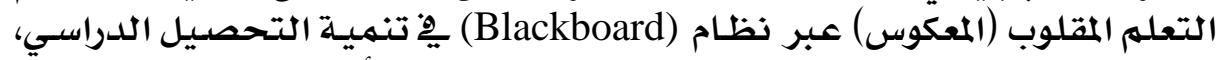

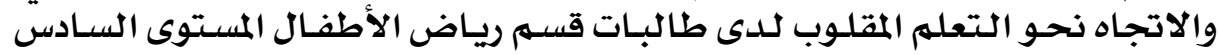

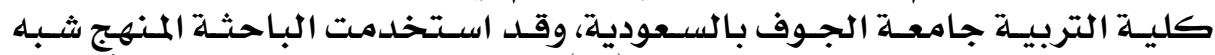

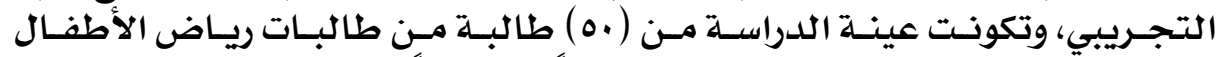

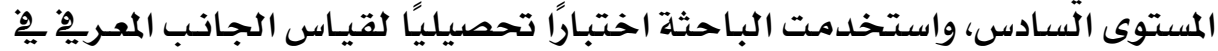

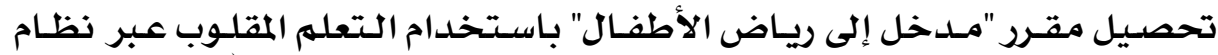

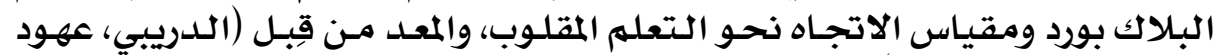

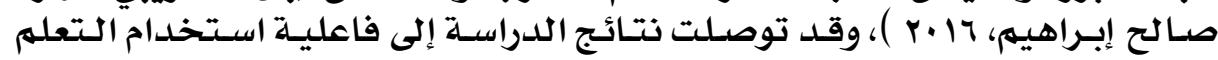

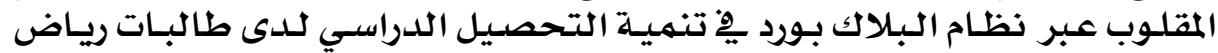




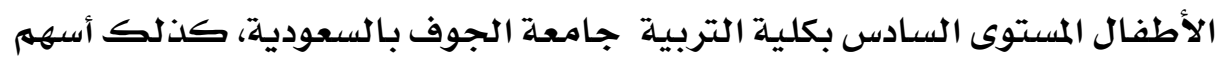

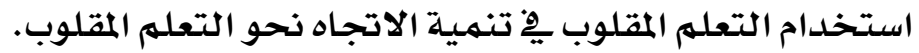

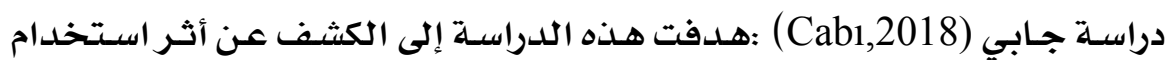

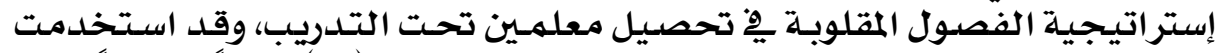

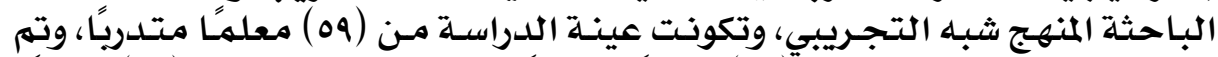

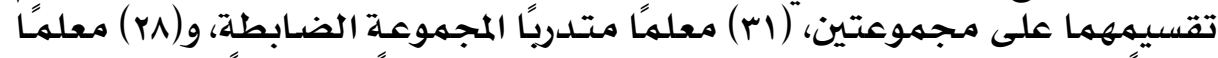

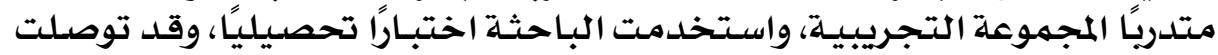

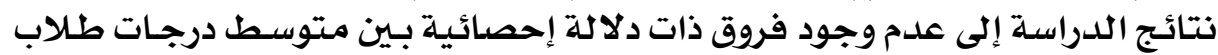

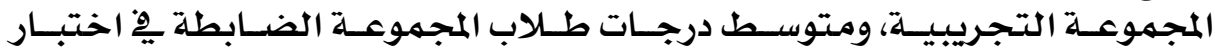

التحصيل البعدي.

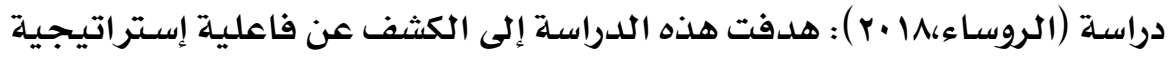

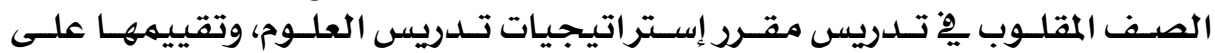

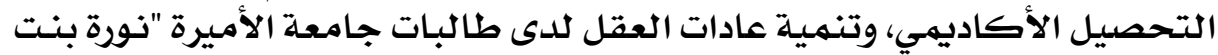

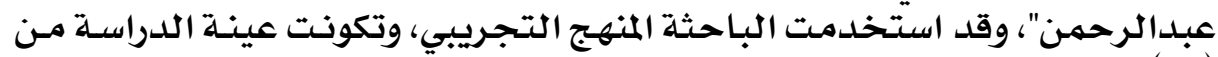

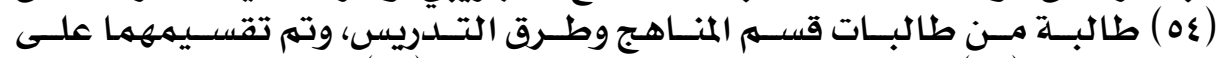

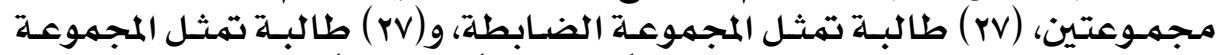

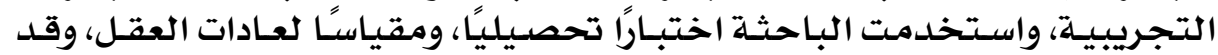

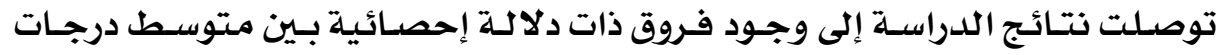

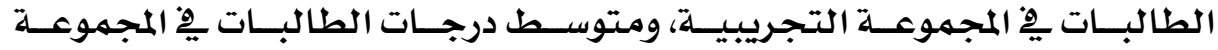

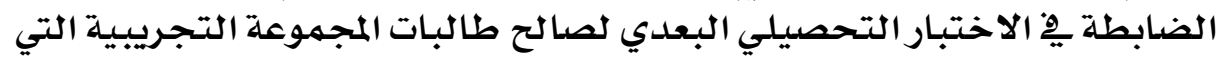

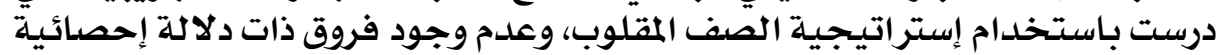

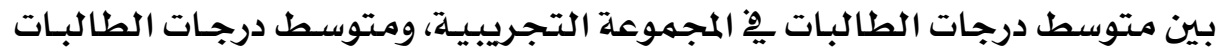

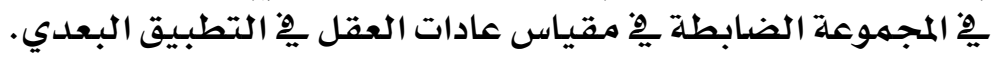

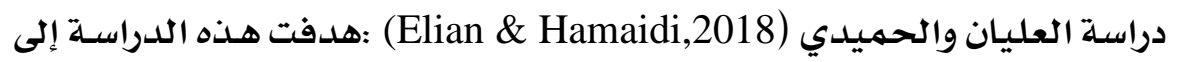

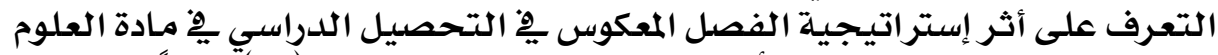

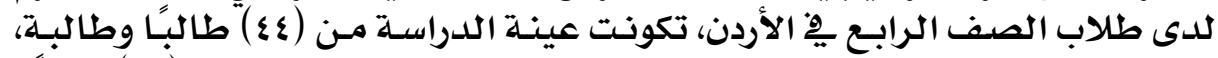

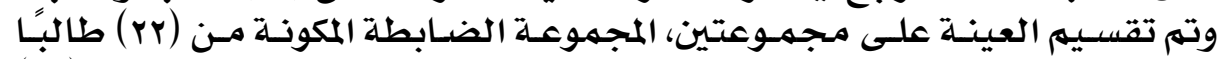

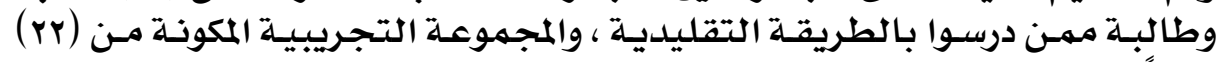

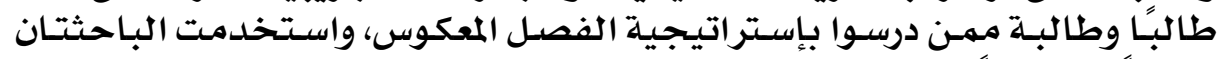

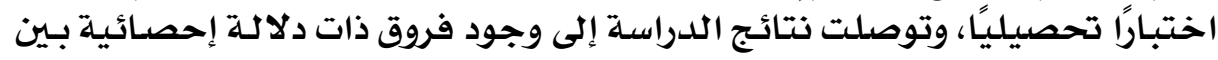

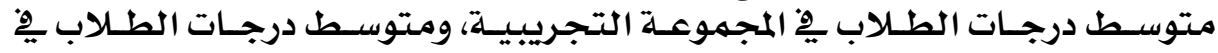

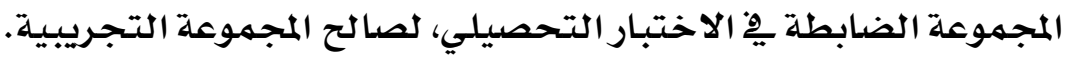

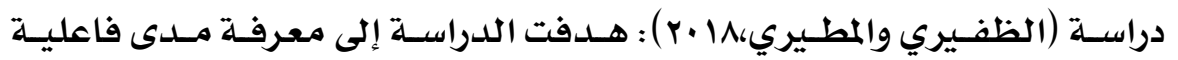

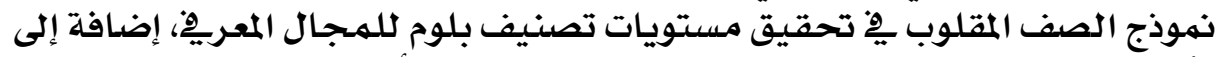

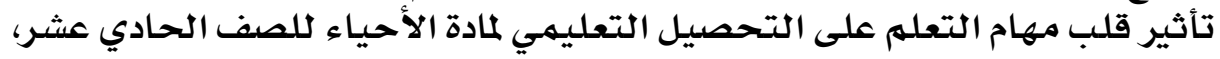




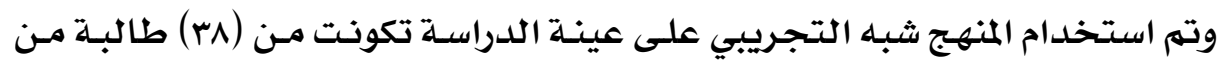

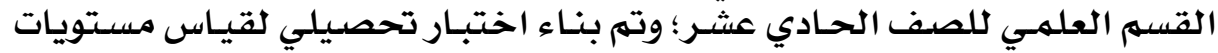

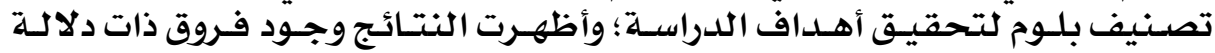

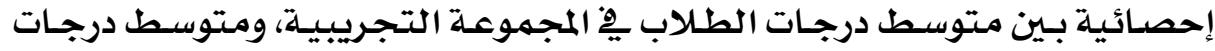

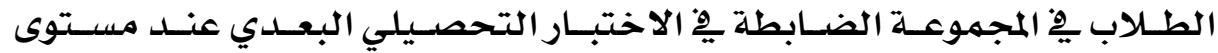

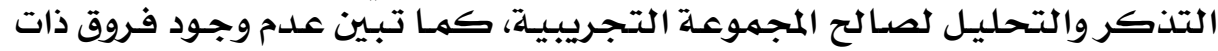

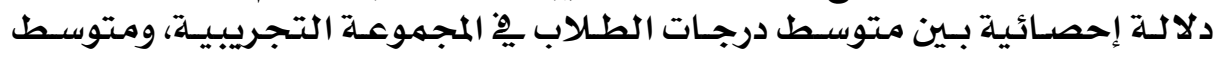

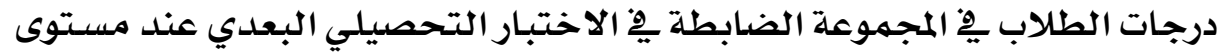

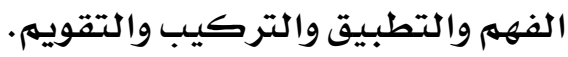

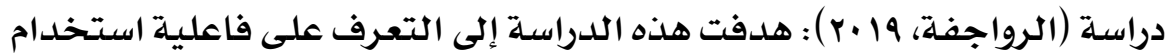

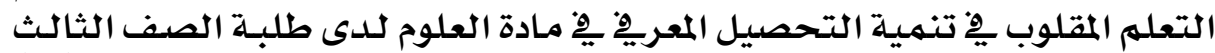

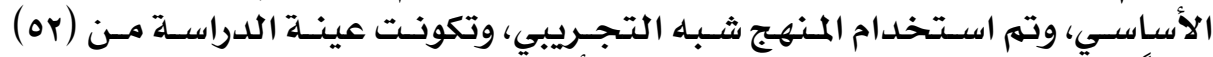

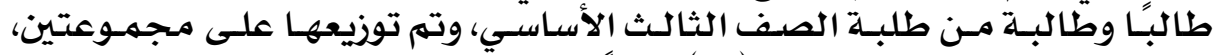

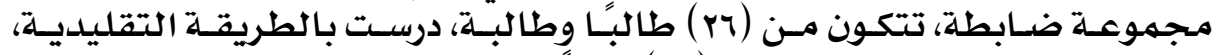

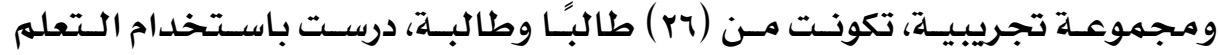

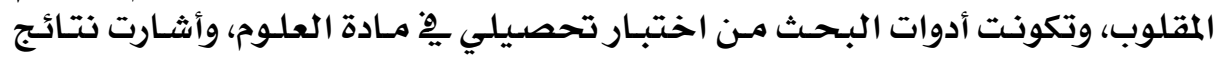

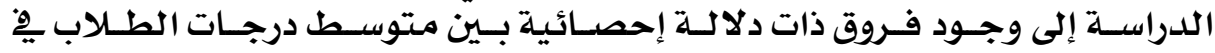

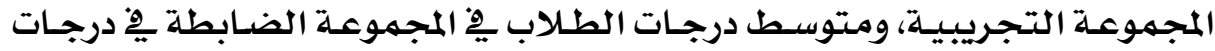

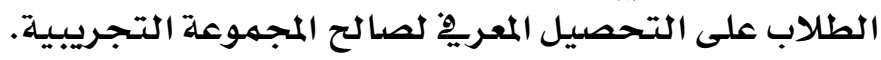

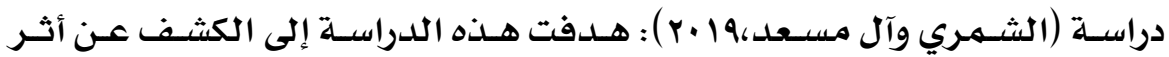

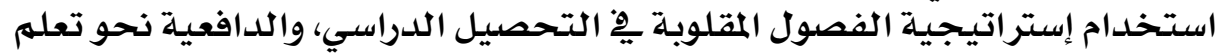

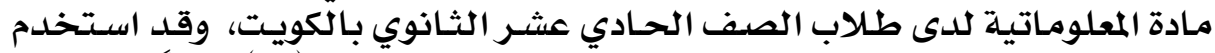

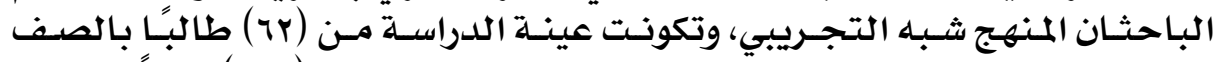

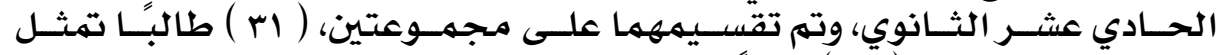

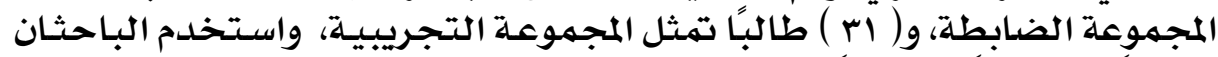

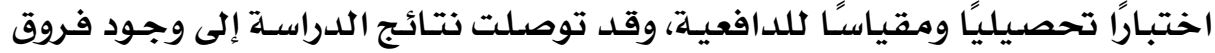

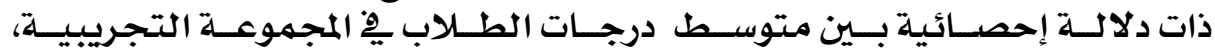

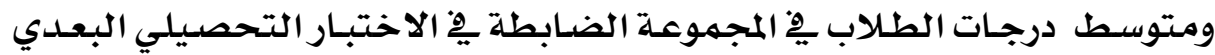

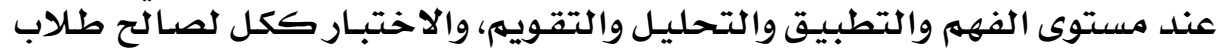

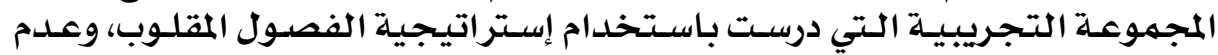

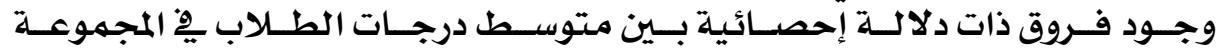

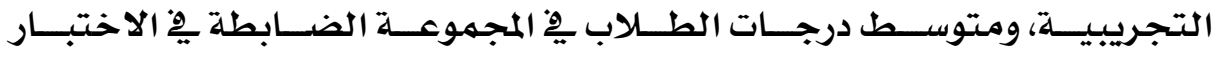

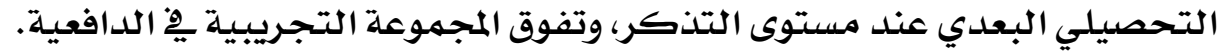

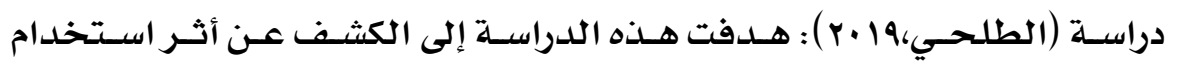

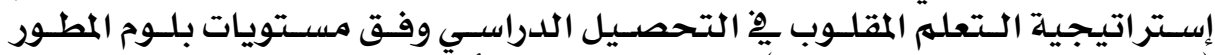

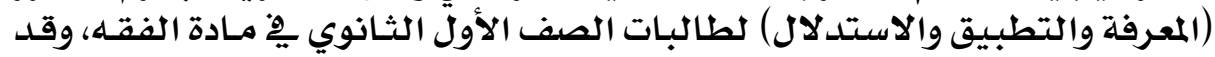

\section{YVV}




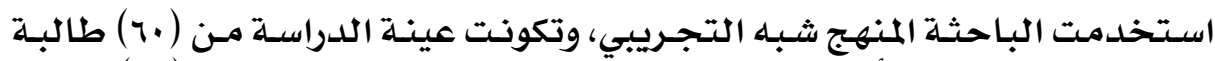

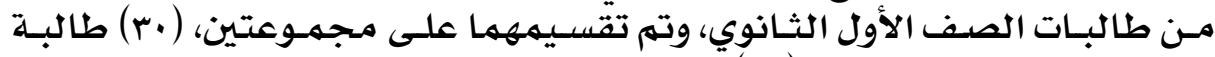

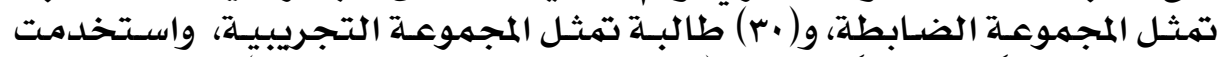

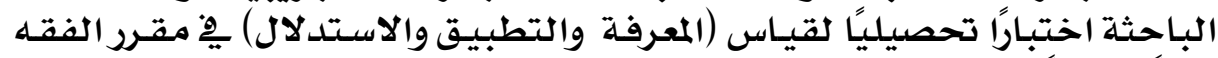

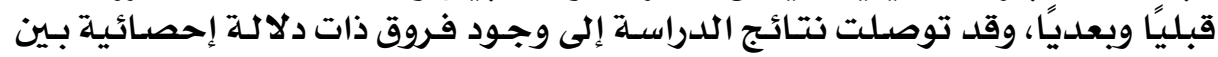

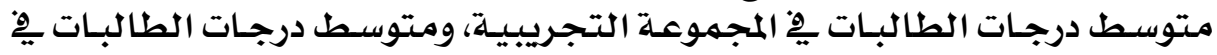

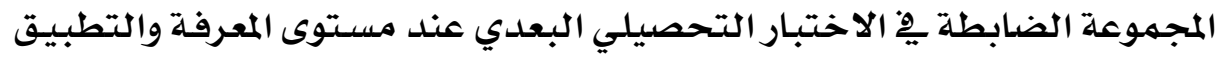

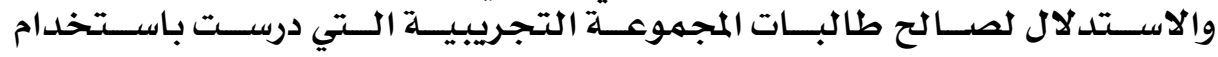

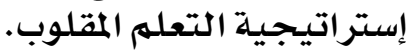

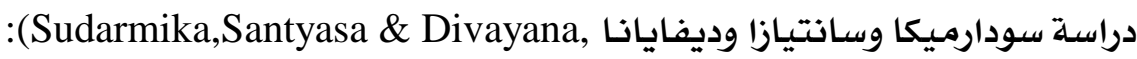

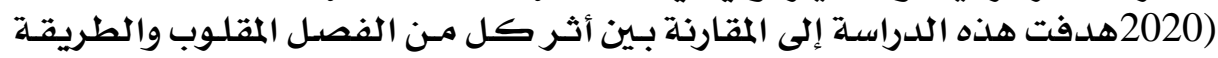

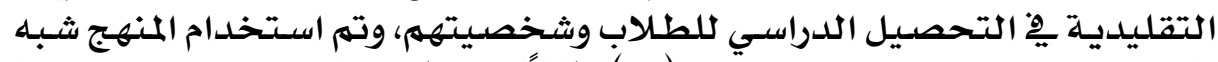

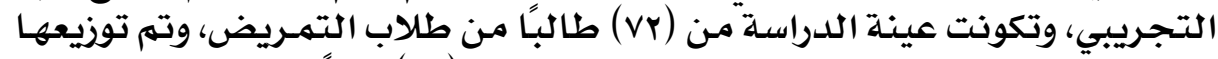

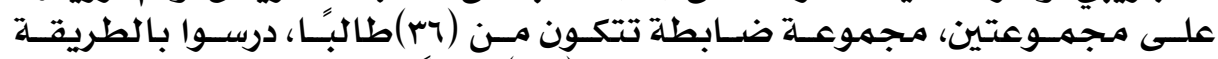

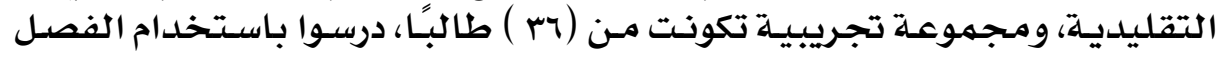

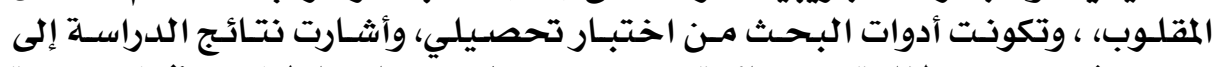

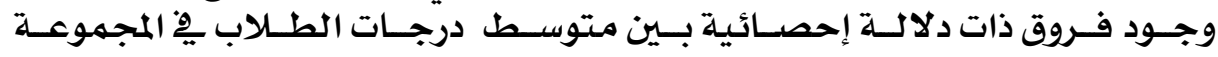

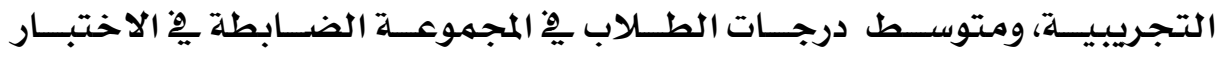

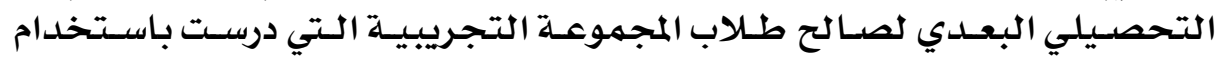

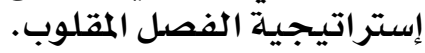

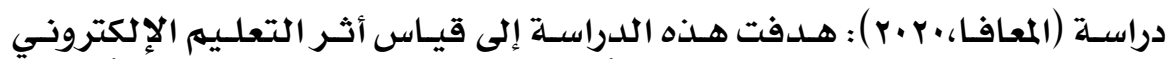

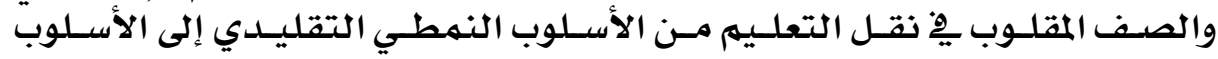

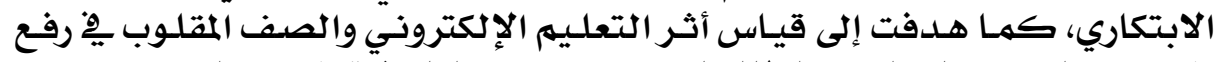

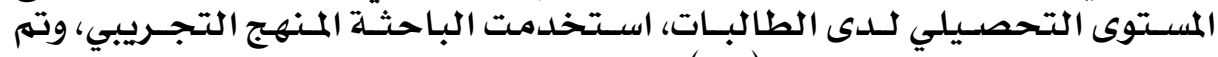

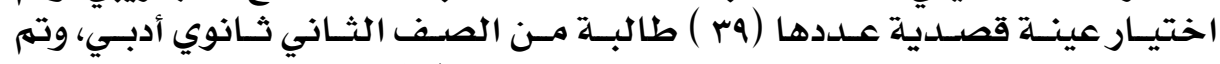

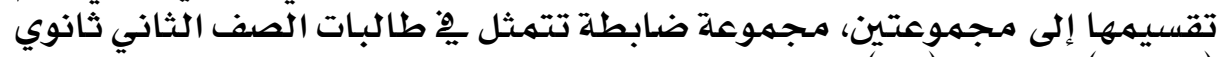

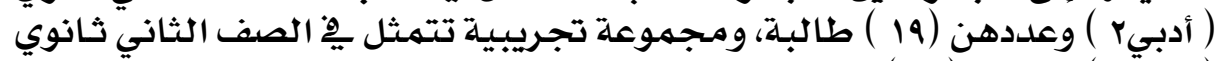

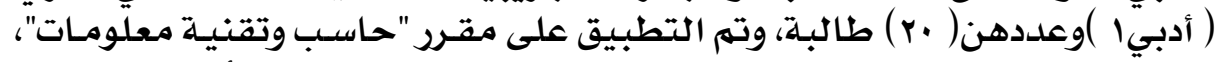

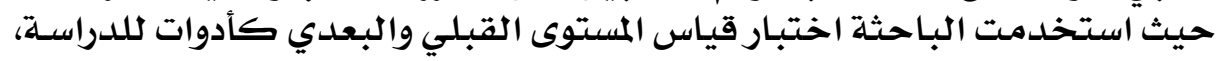

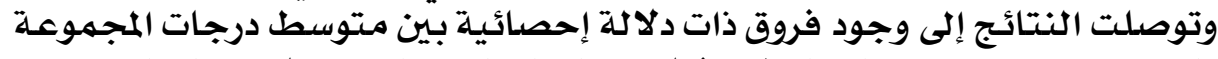

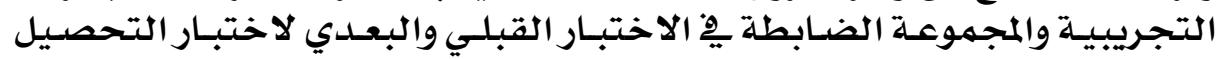
الدراسي لصالح المجمئوعة المجوعة التجريبية.

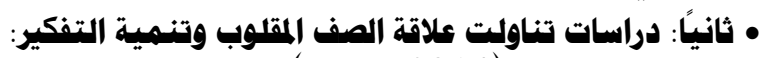

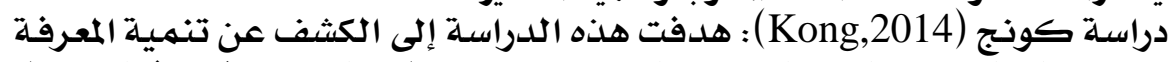

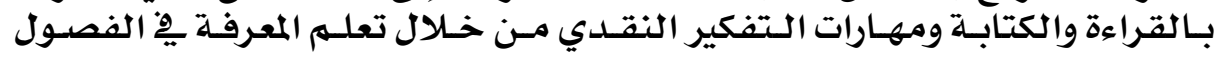

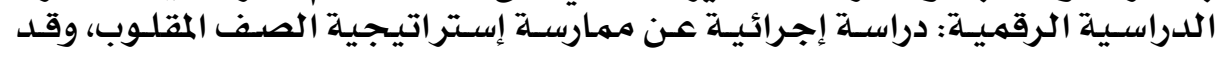

\section{YVA}




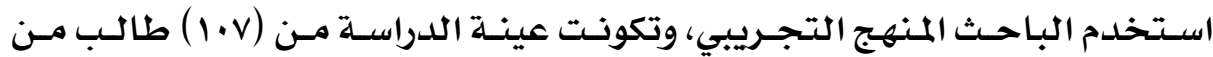

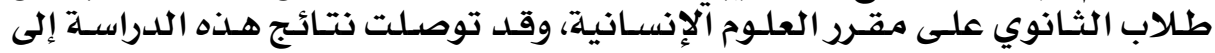

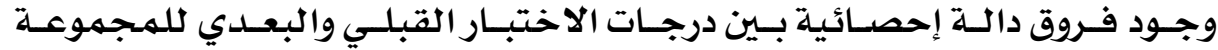

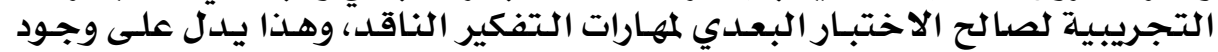

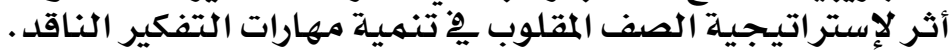

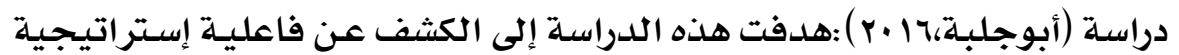

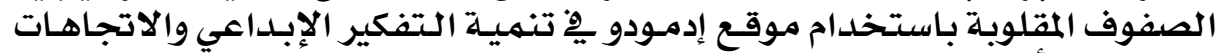

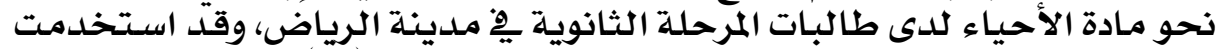

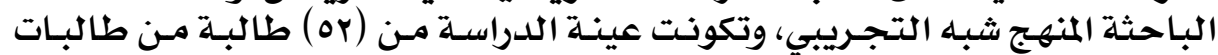

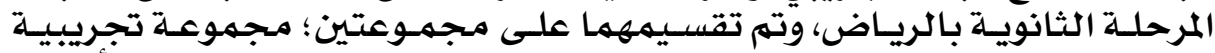

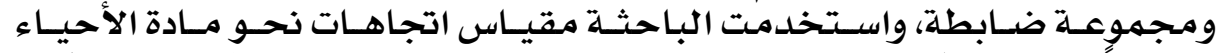

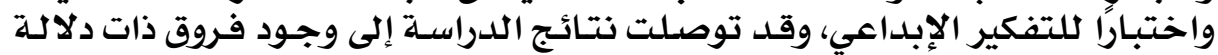

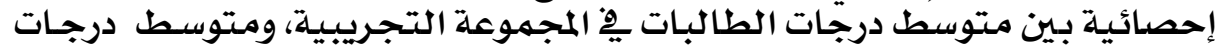

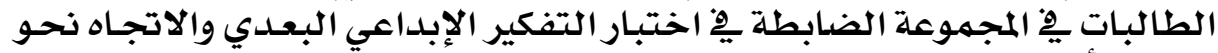

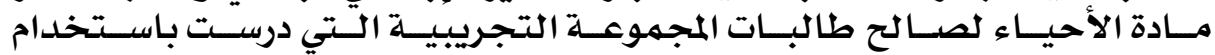
إستراتيجية الصفوف الصفوف المقلوبة.

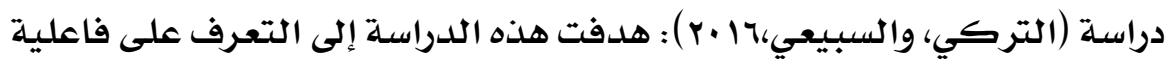

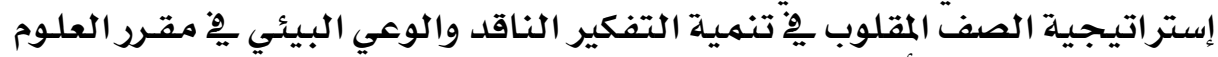

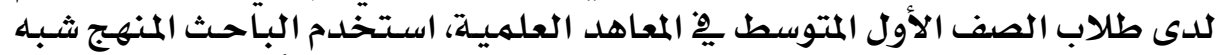

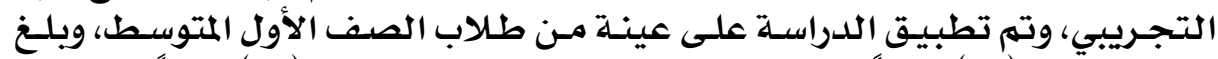

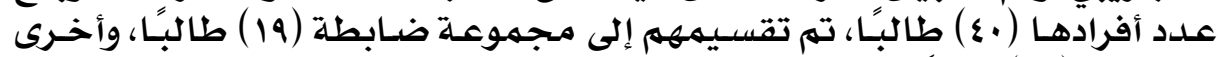

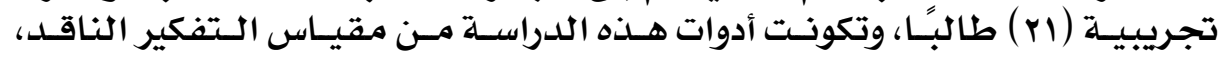

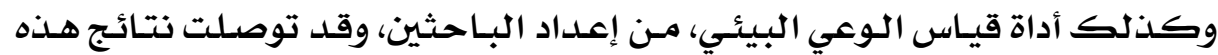

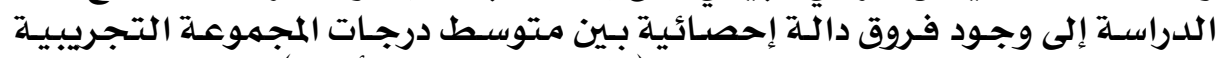

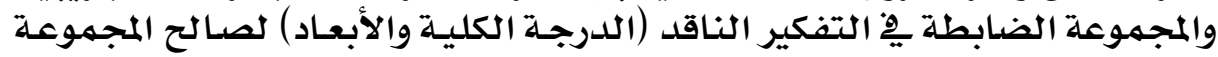

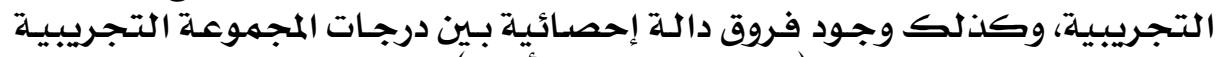

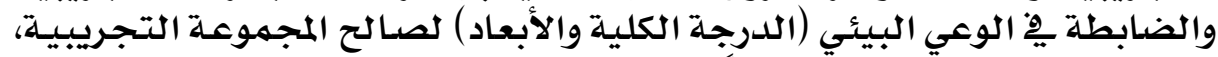

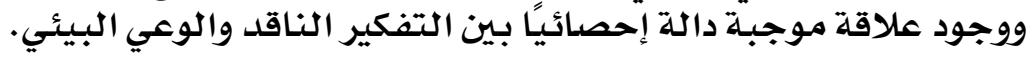

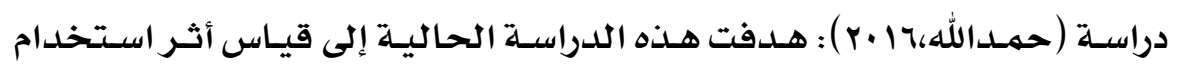

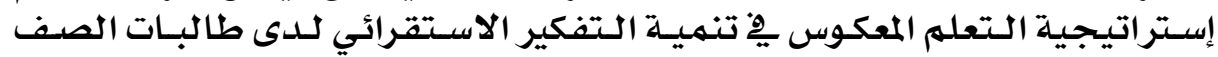

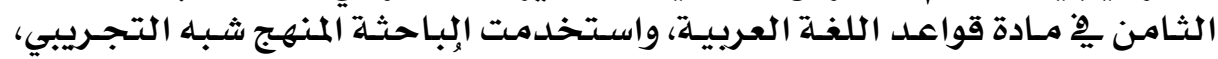

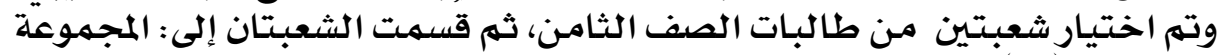

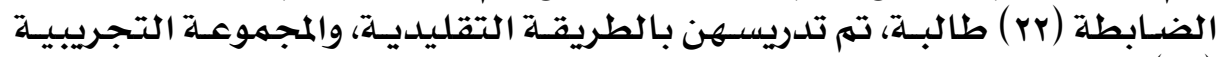

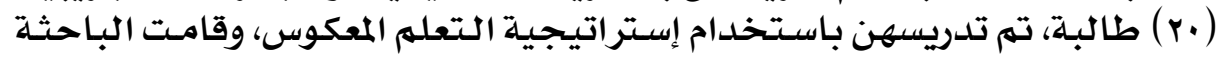

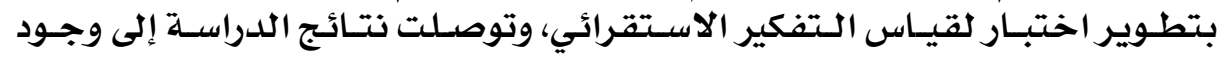

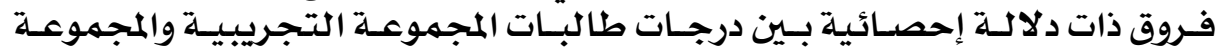
الضابطة، ولصالح المجموعة التجرية لتهريبية.

\section{YVQ}




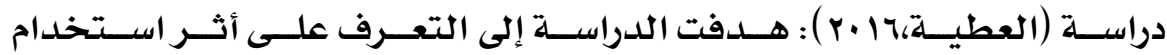

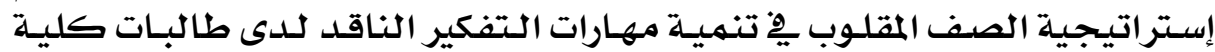

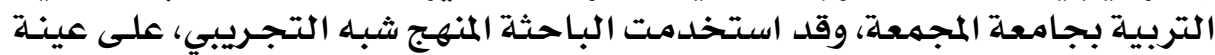

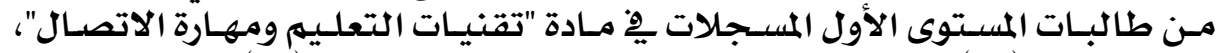

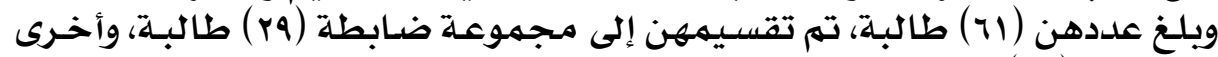

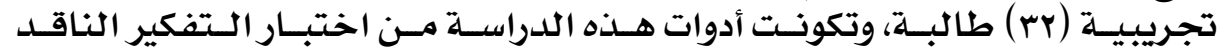

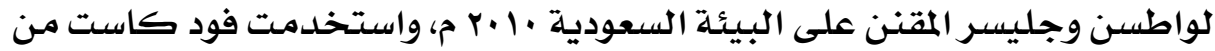

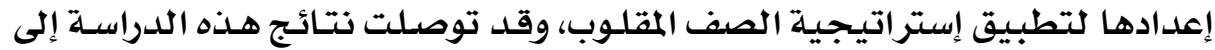

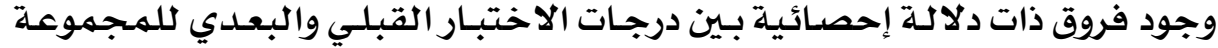

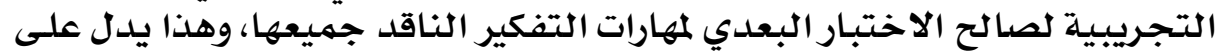

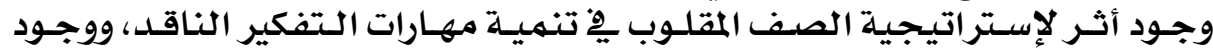

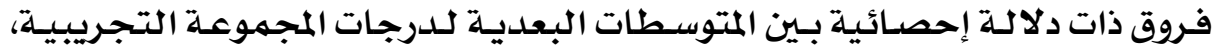

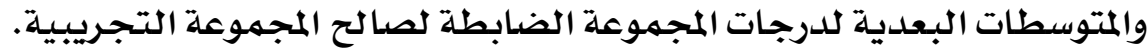

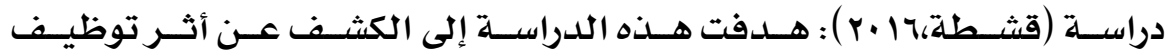

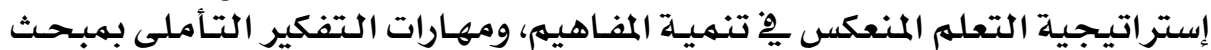

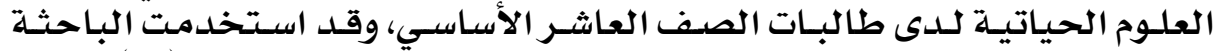

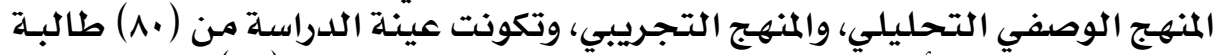

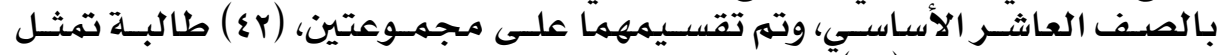

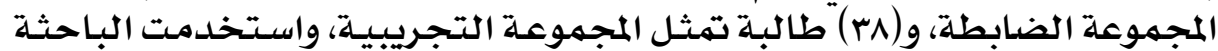

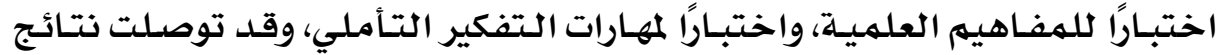

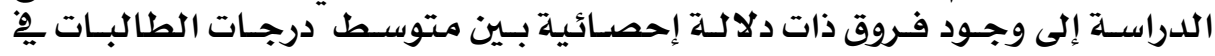

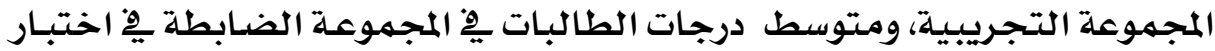

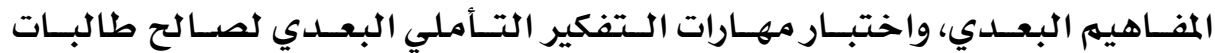

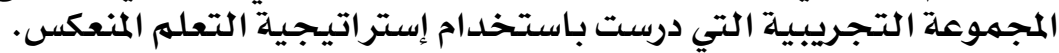

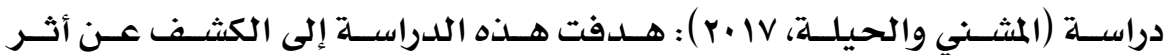

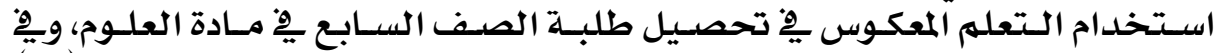

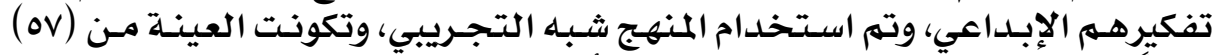

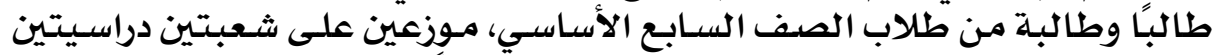

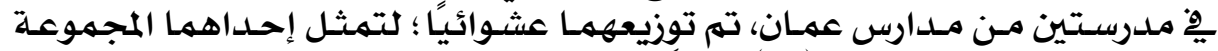

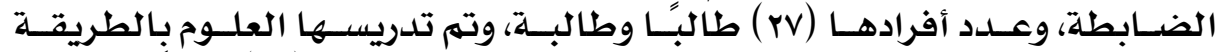

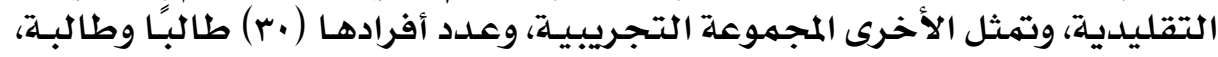

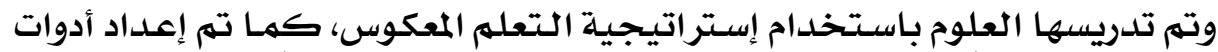

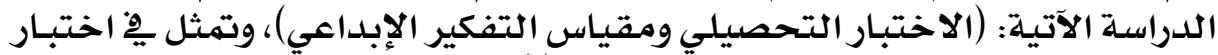

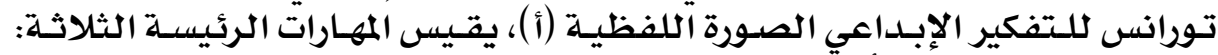

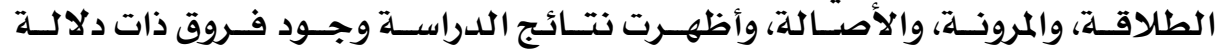

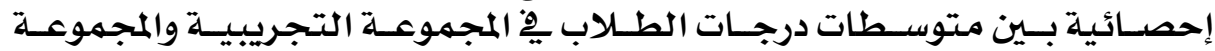




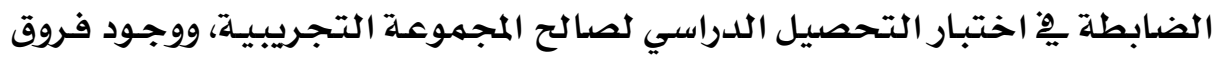

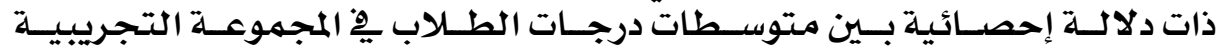

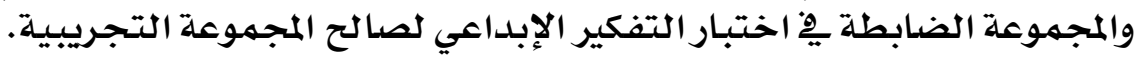

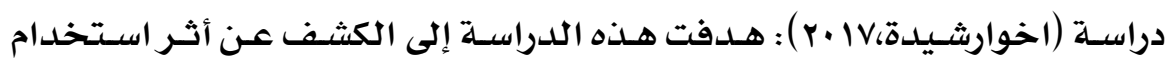

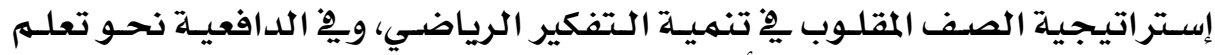

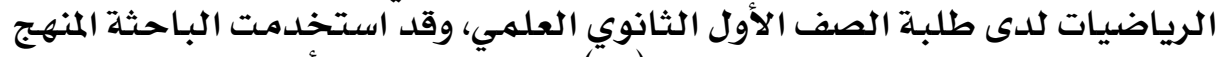

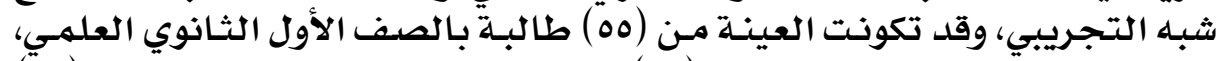

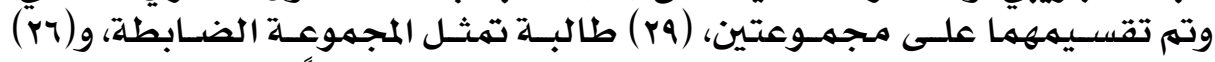

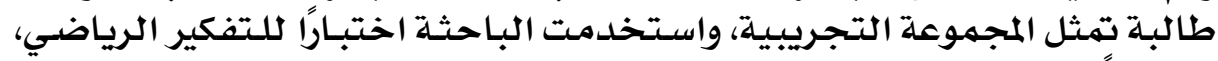

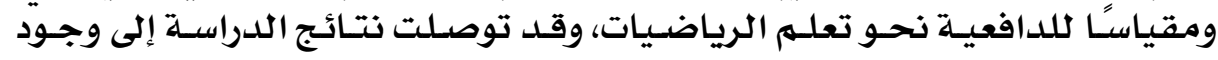

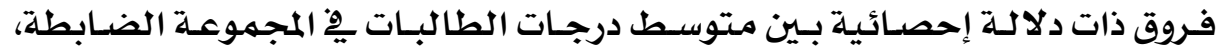

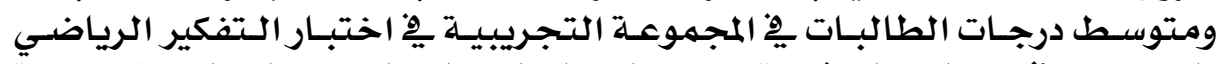

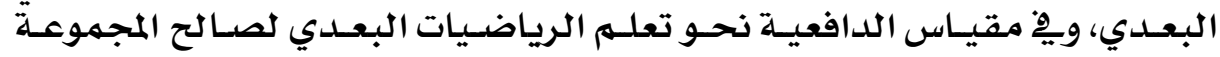

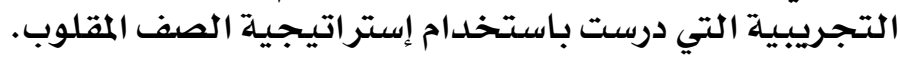

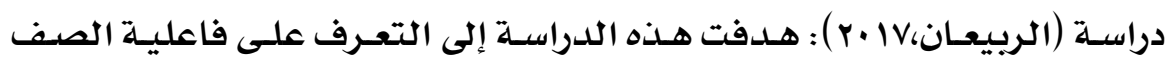

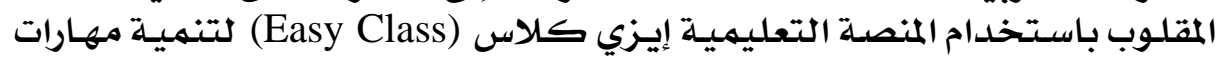

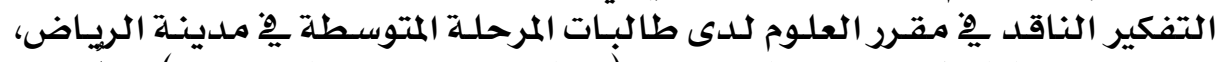

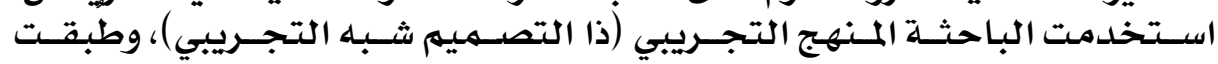

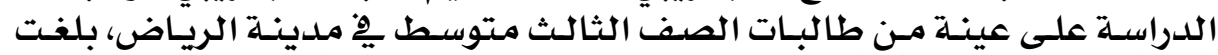

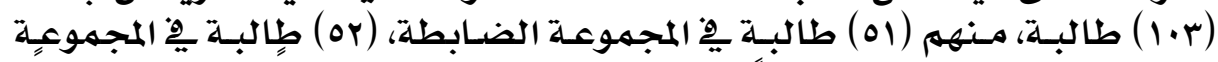

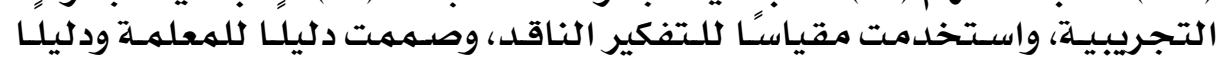

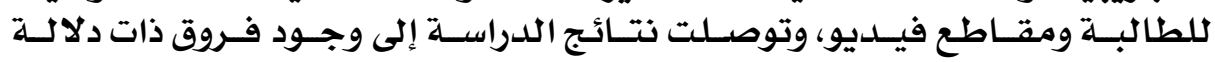

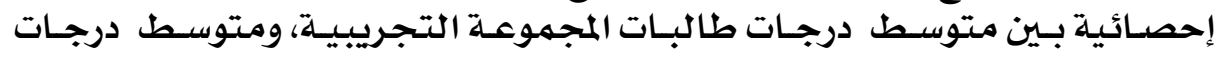

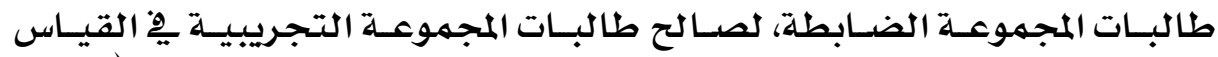

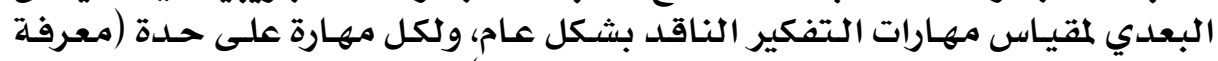

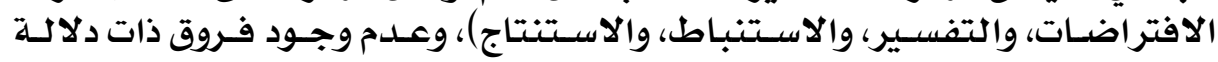

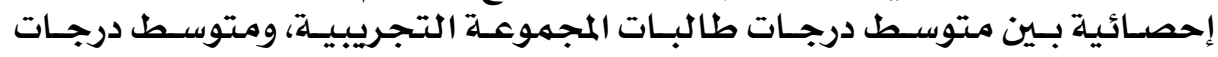

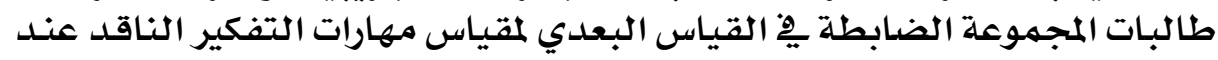

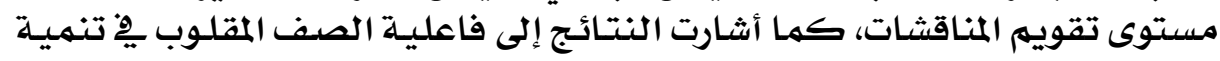

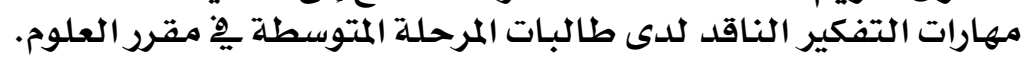

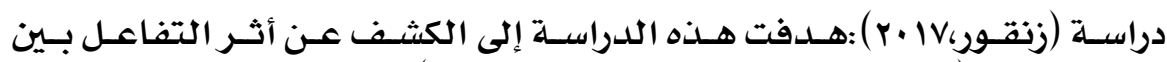

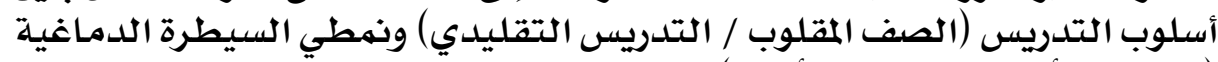

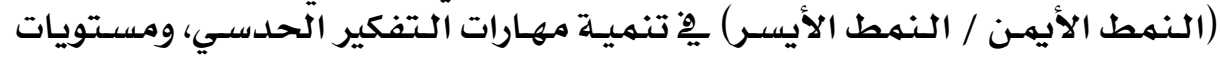

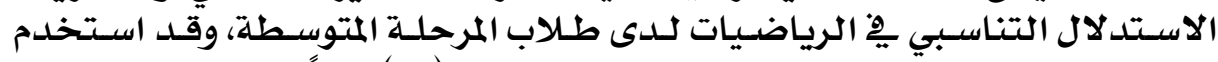

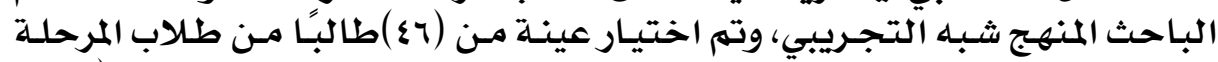

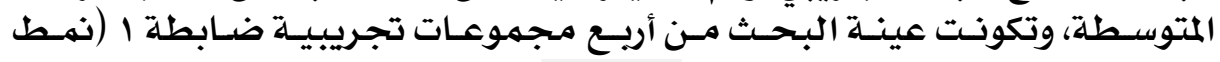

\section{$Y \wedge 1$}




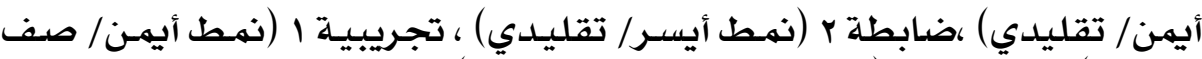

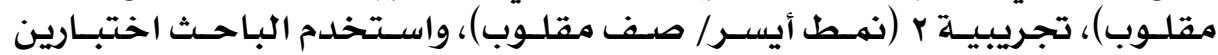

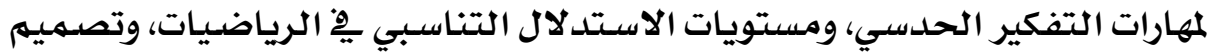

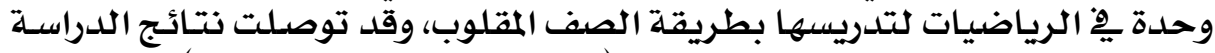

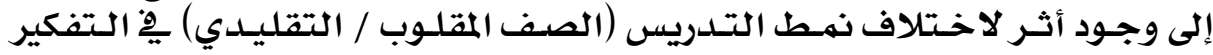

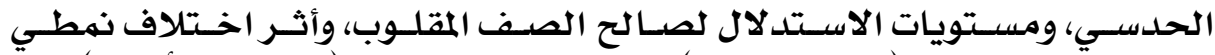

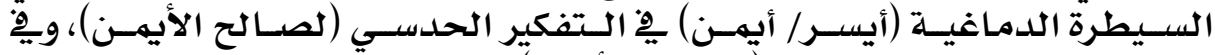

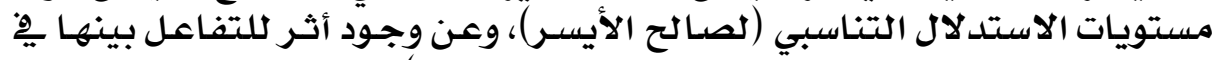

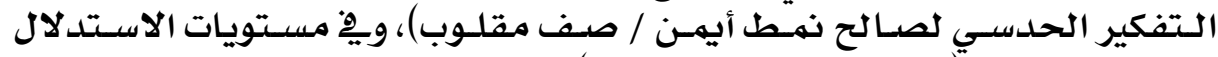

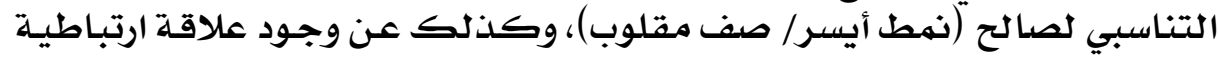
موجبة دالة بين مهارات التفكير الحدسي ومستويات الاستدلال التسل التناسبي.

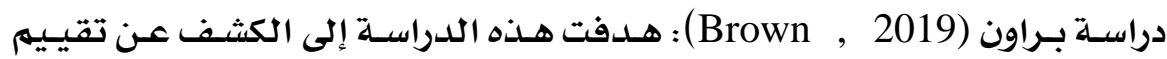

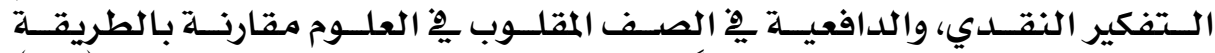

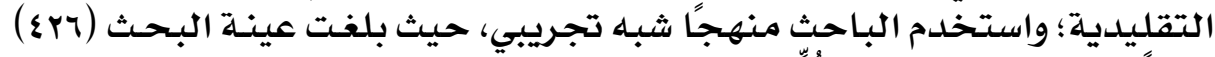

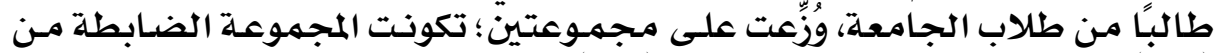

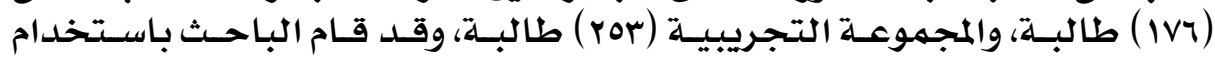

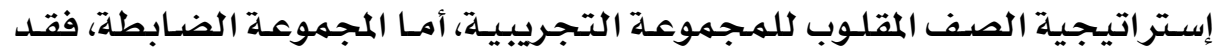

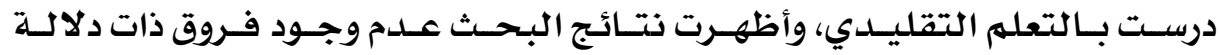

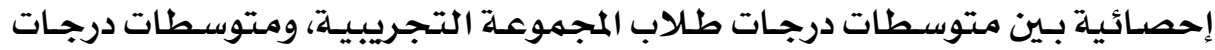

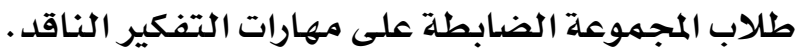

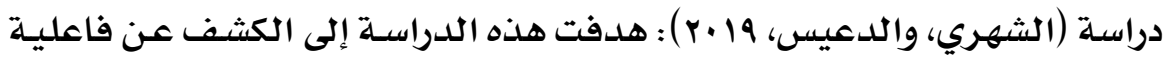

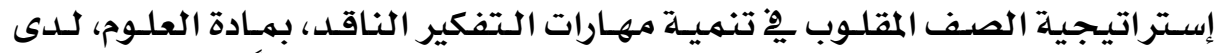

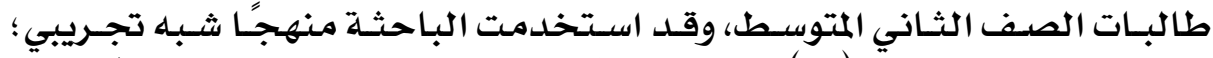

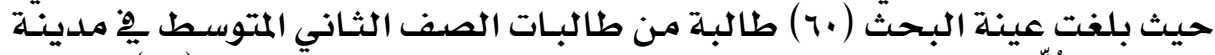

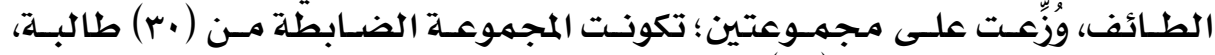

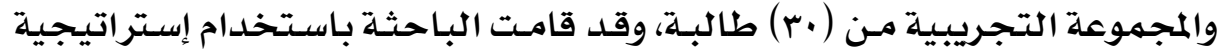

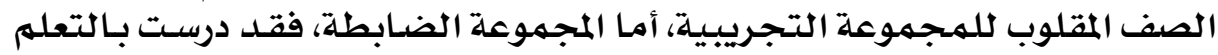

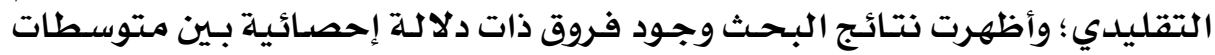

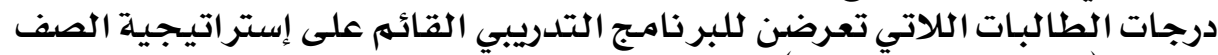

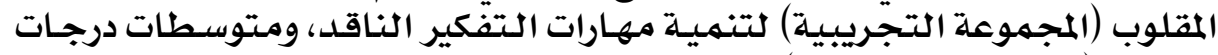

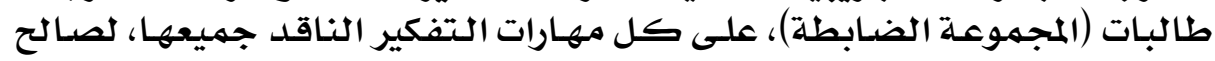

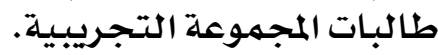

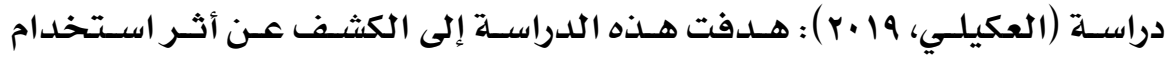

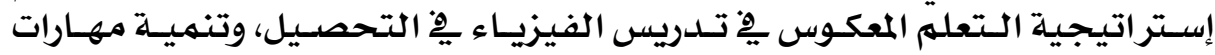

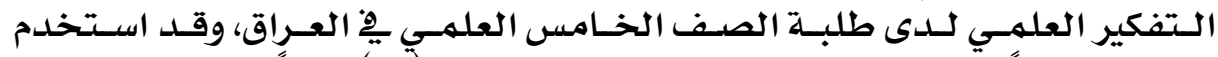

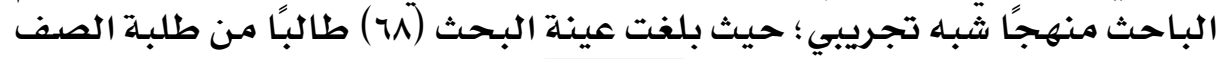

\section{YAY}




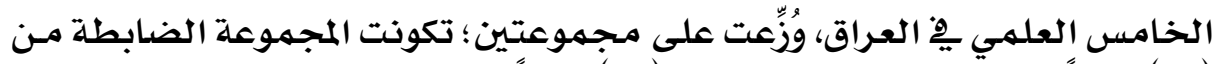

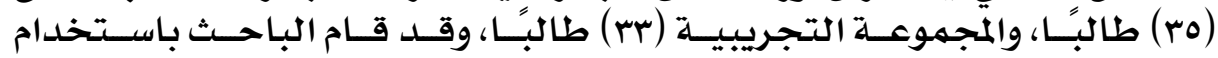

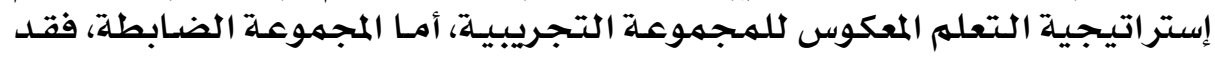

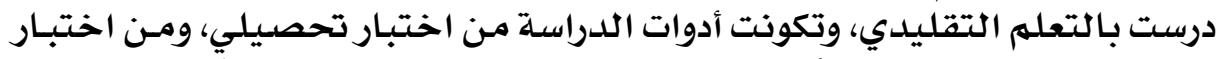

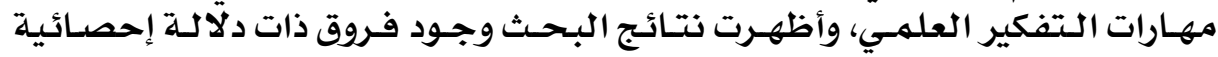

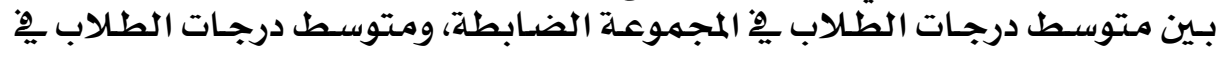

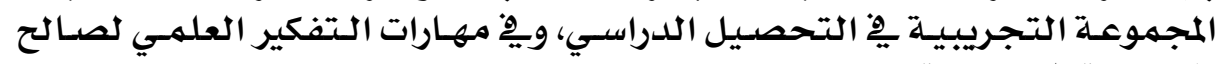
المجموعة التجريبية.

أمـا المحـور الأول: فتضــــن دراسـات تنـاولـت علاقـة إسـتراتيجية الصـف المقلـوب

\section{• التعليق} والتحصيل الدراسي:

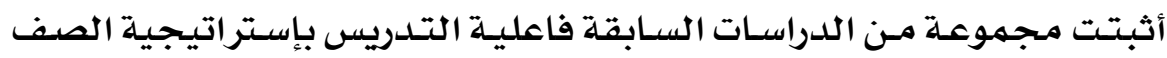

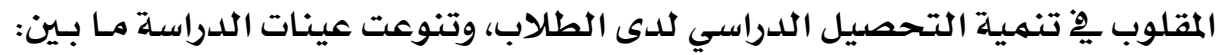

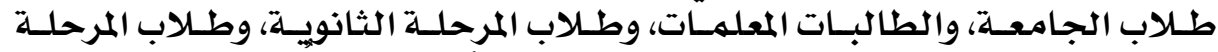

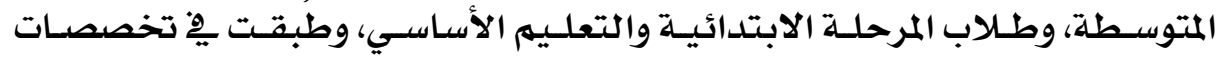

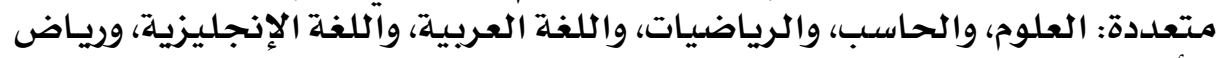

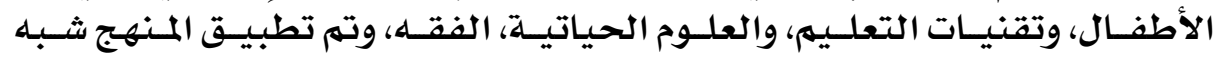

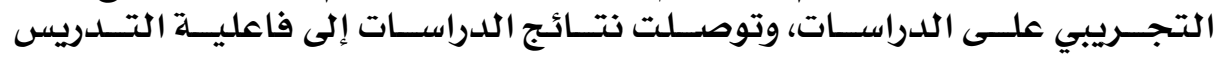

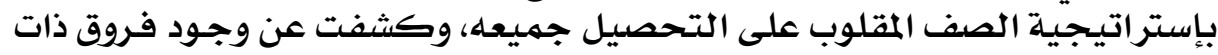

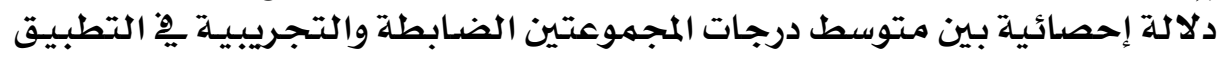

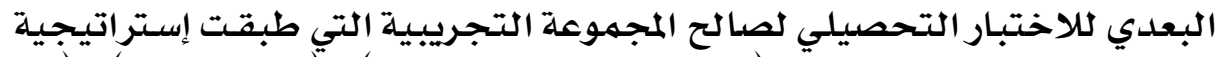

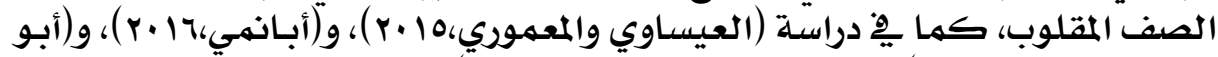

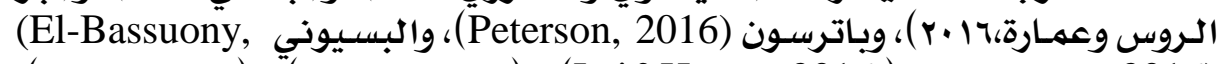

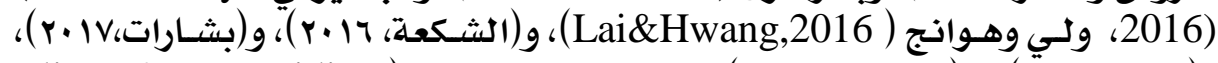

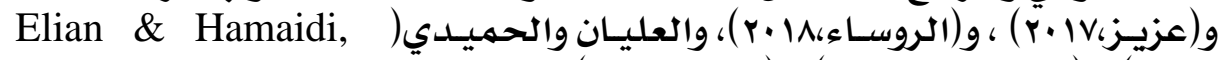

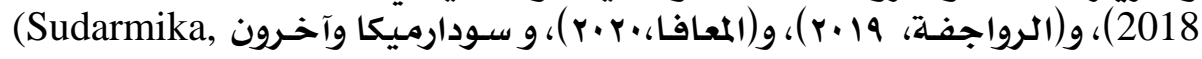

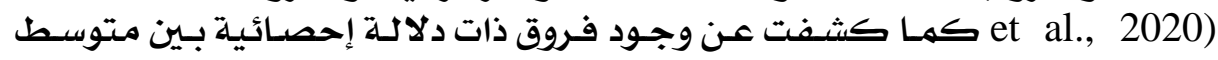

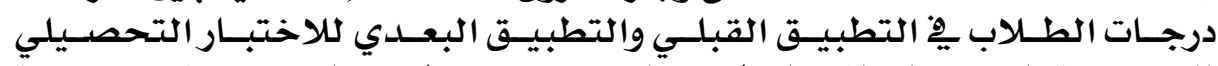

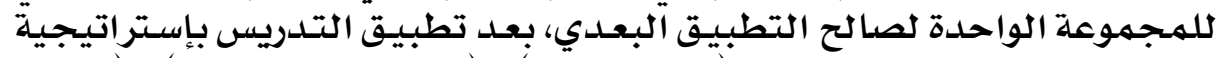

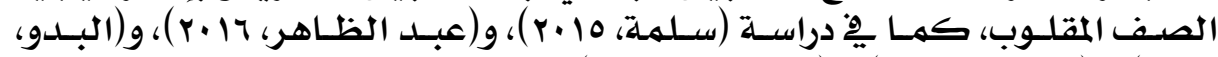

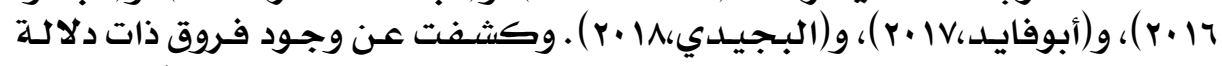

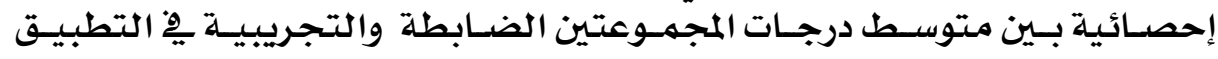

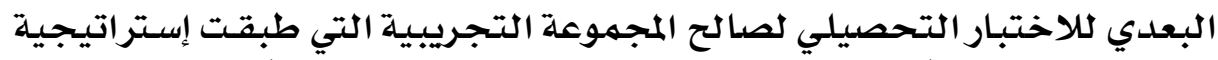

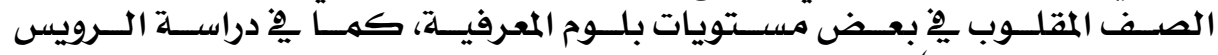

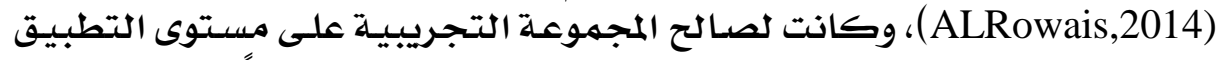

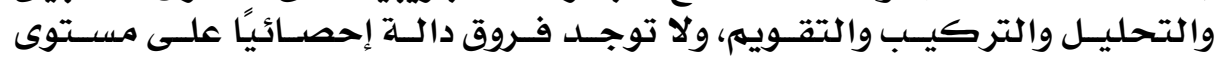




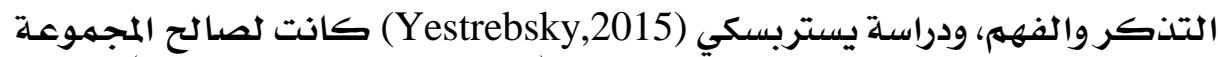

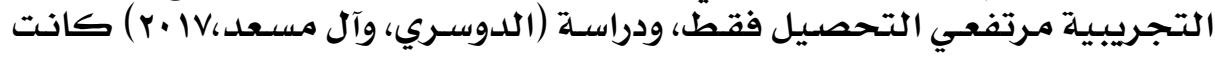

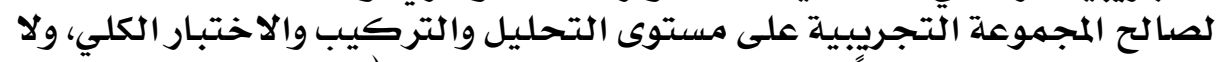

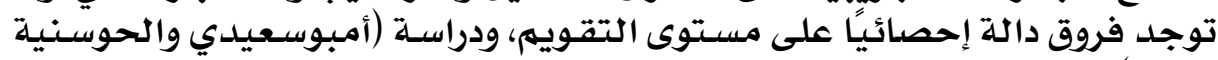

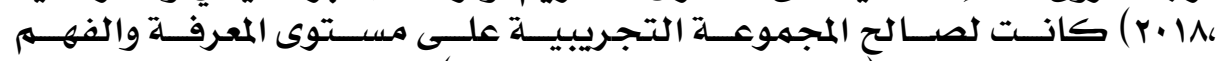

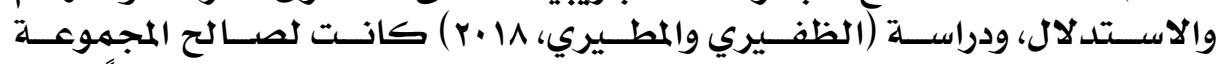

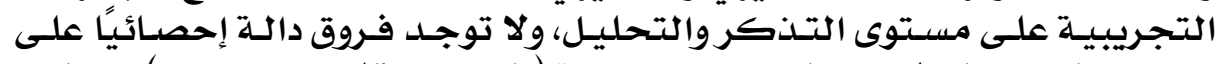

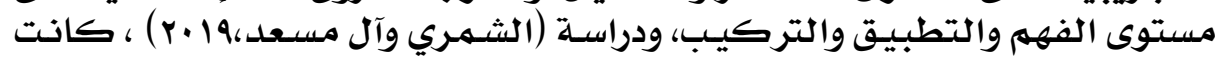

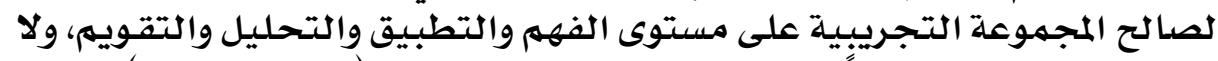

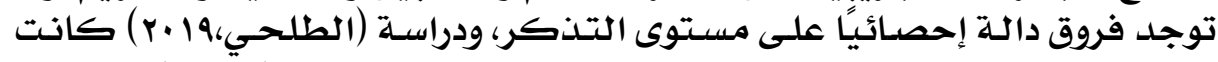

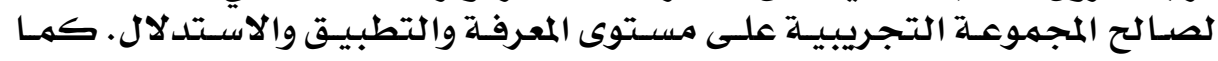

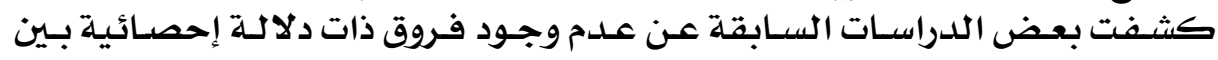

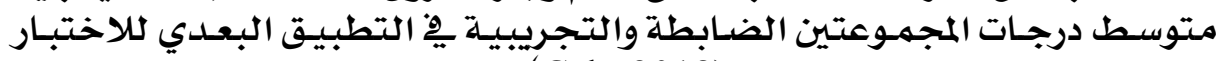
التحصيلي، كما يُخ دراسة جابي (Cab1,2018).

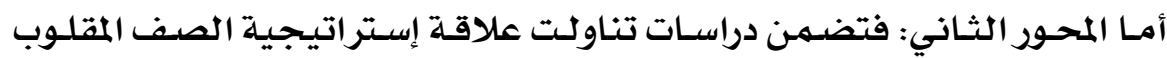

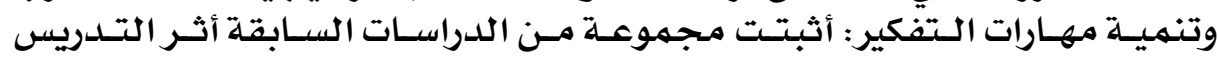

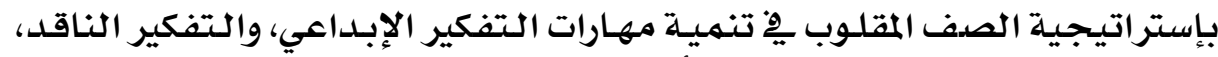

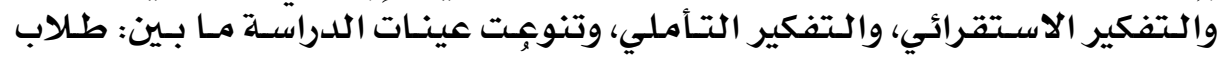

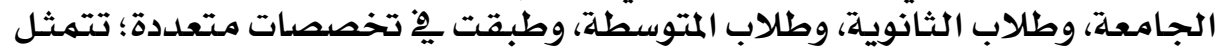

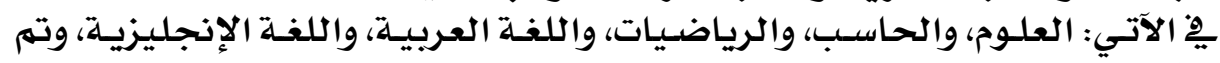

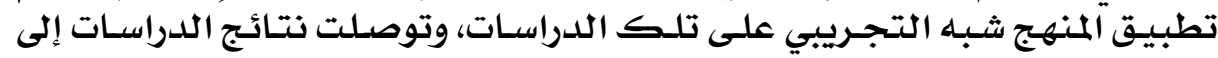

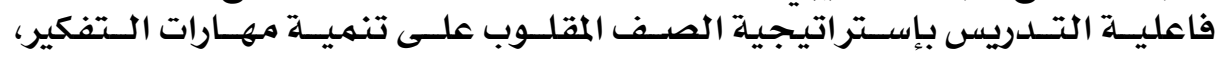

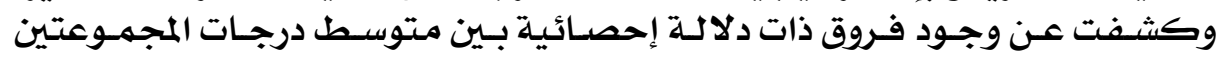

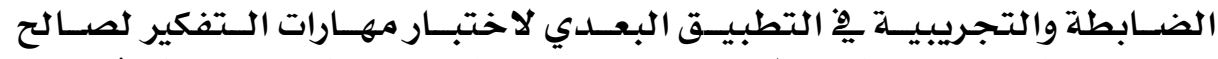

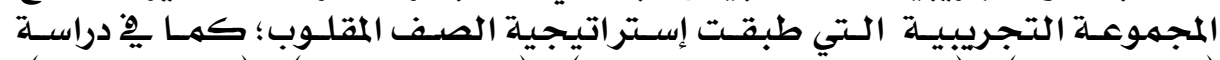

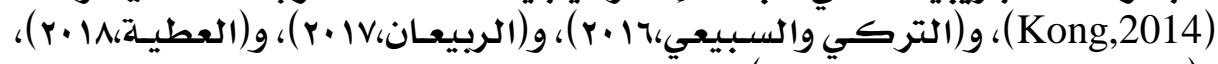

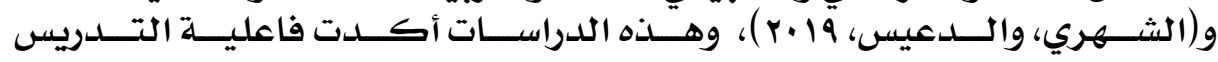

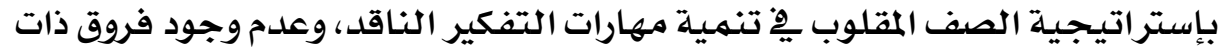

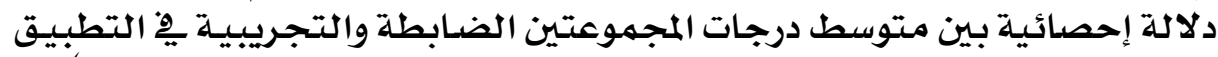

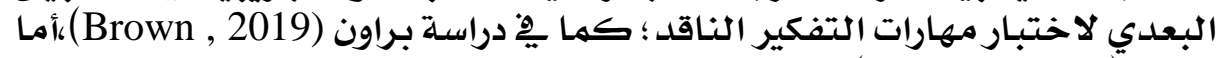

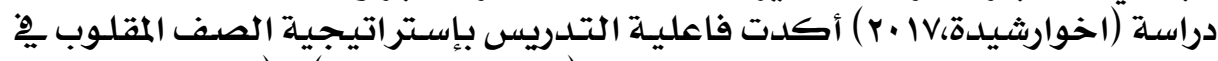

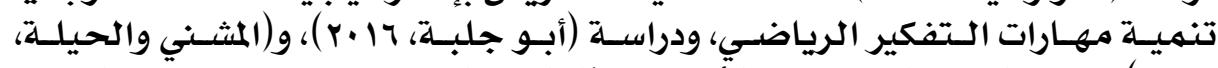

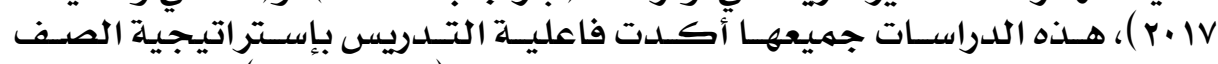

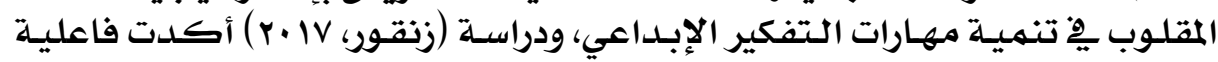

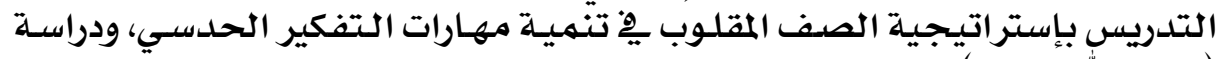

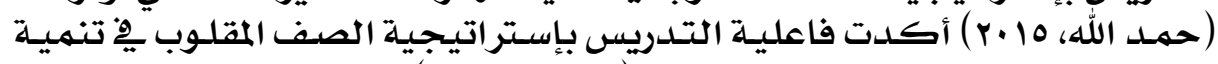

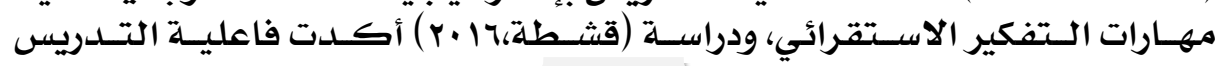

\section{$Y \wedge \varepsilon$}




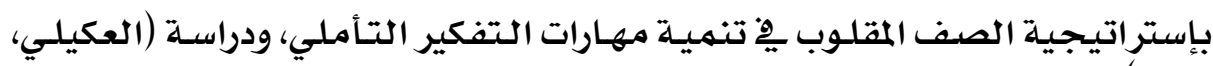

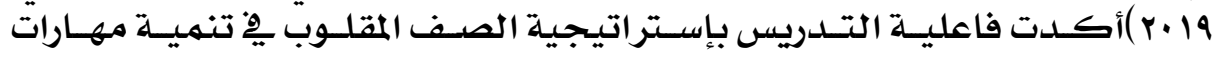

التفكير العلمي.

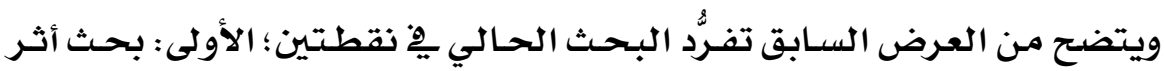

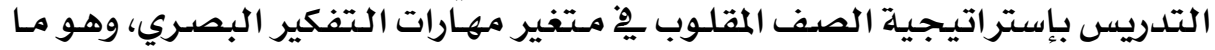

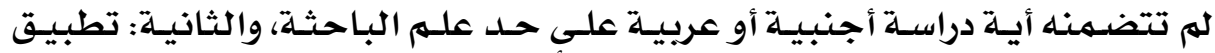

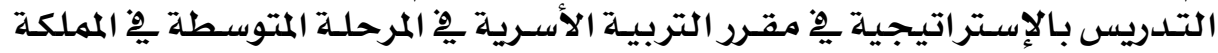

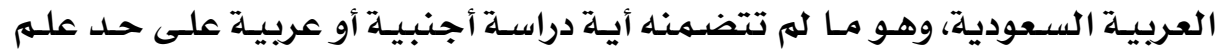

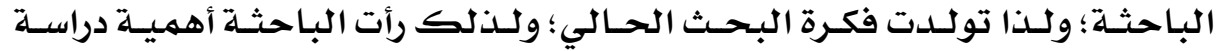

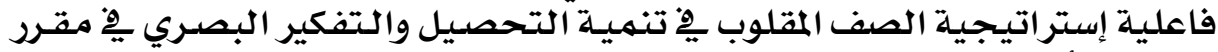

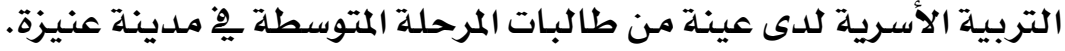

• الطريقة والإجراءات:

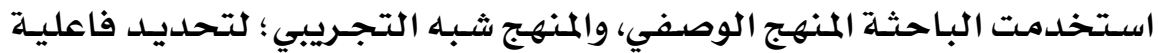

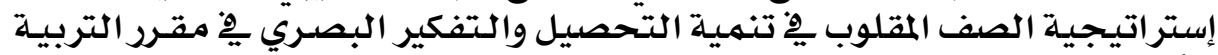

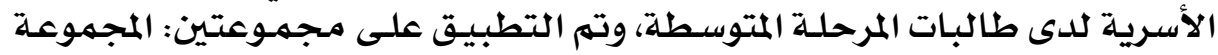

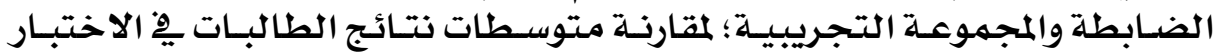

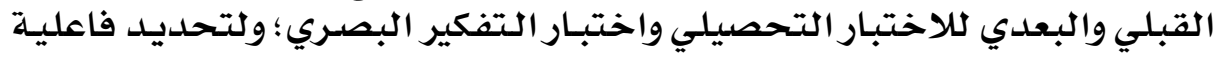

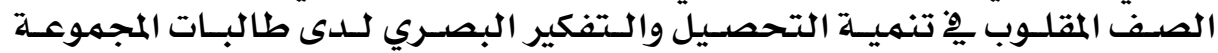

التجريبية.

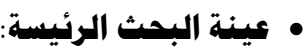

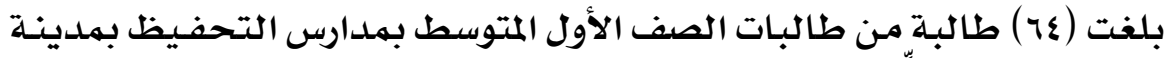

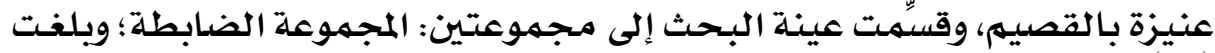

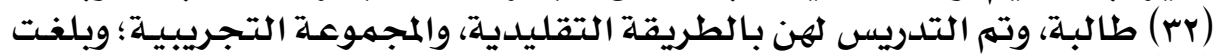

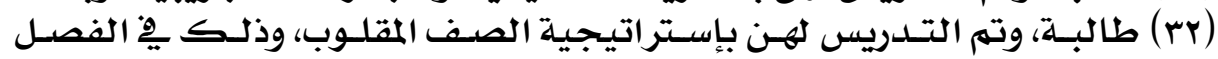

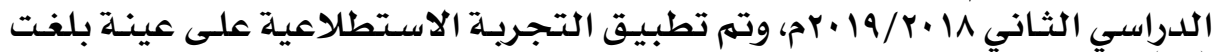

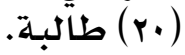

جدول (1) : توزيع عينت البحث

\begin{tabular}{|c|c|c|c|c|}
\hline المتغير التابع & المتغير المستقل & العلدد & الصف & المحموعتة \\
\hline \multirow{2}{*}{ التحصيل اللتراسي } & الصف المقلوب & rr & الأول المتوسط & التجريبيت \\
\hline & الطريقت التقليديت & rr & الأول المتوسط & الضابطت \\
\hline
\end{tabular}

• إجراءات تنفيذ البحث: الأول الوابط

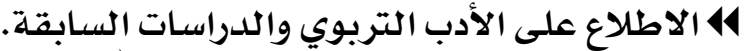

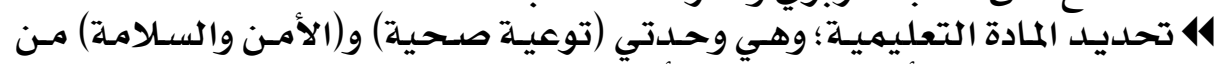

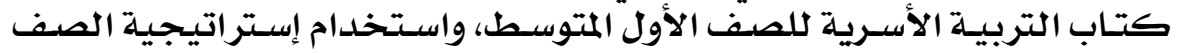




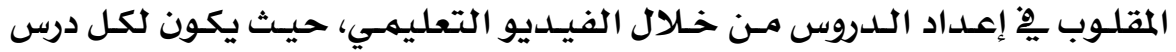

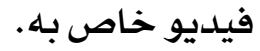

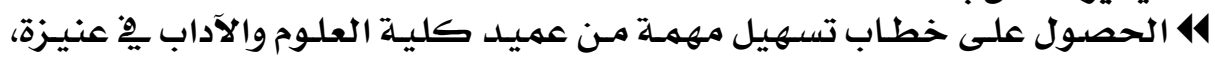

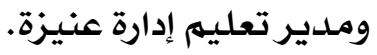

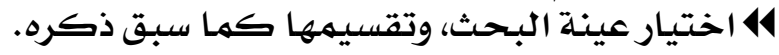

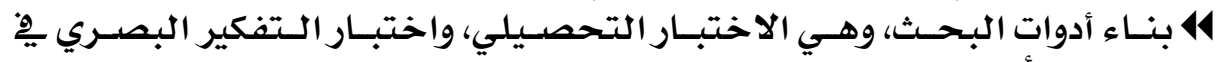

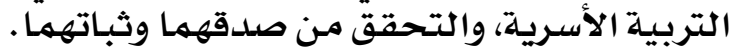

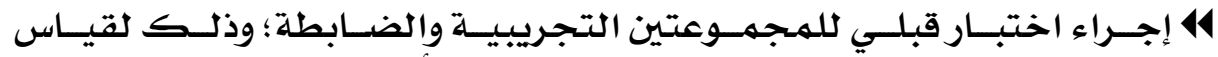

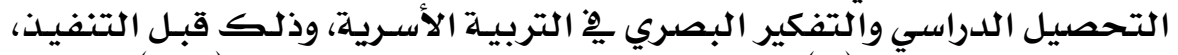

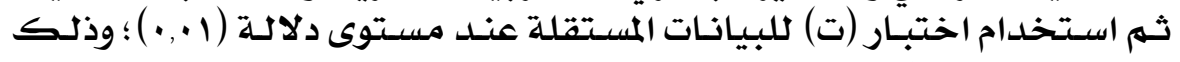

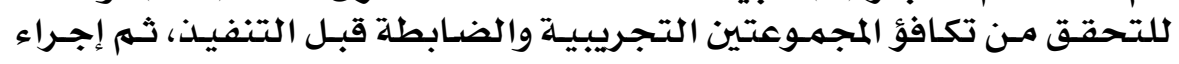

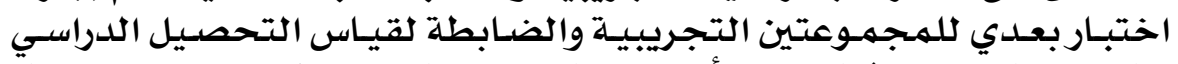

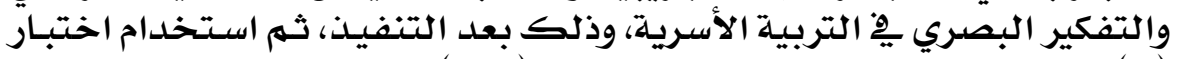

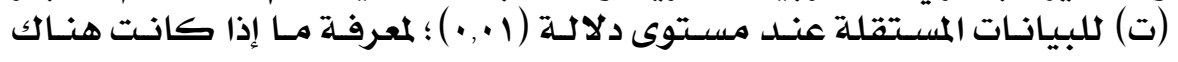

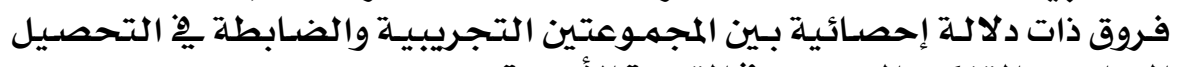

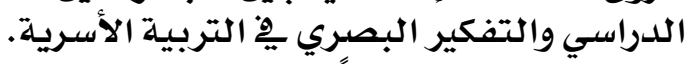

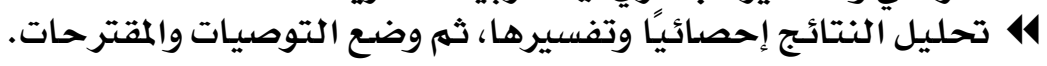

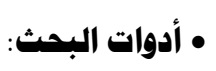

$$
\text { قامت الباحثة بإعداد أدوات للإجابة عن أسئلة البحث، وهي: البادي: }
$$

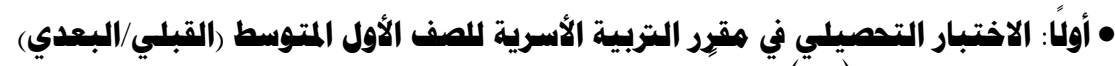

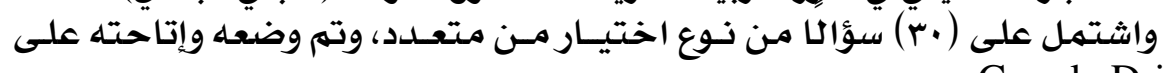

Google Drive.

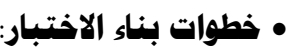

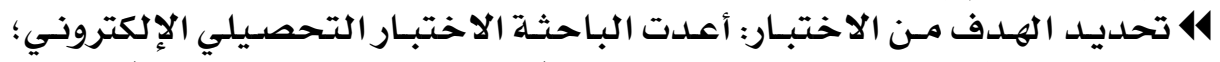

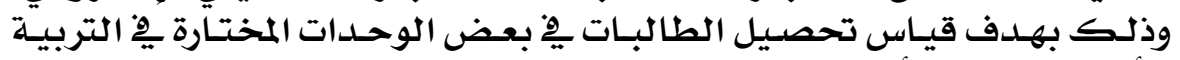

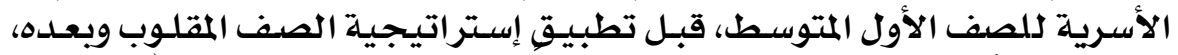

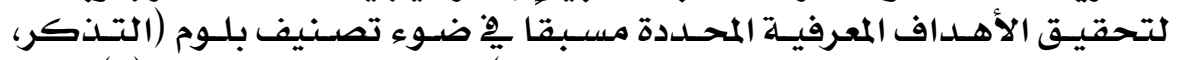

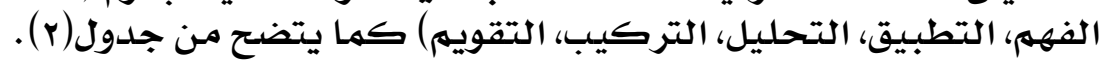

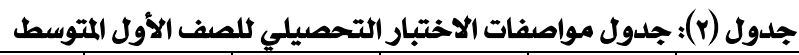

\begin{tabular}{|c|c|c|c|c|c|c|c|}
\hline المجموع & تقويم & تركيب & تحليل & تطبيق & فهم & تذكر & المستوى \\
\hline r. & $\varepsilon$ & $r$ & 7 & 7 & 0 & 7 & عدد الفقرات \\
\hline$r$. & IVGYGYGR. & ITGYYGYE & $\begin{array}{l}\text { ¿E,IYGM } \\
\text { Yo,Yq,YA }\end{array}$ & $\begin{array}{l}\text { TGAClE } \\
\text { Iq,YrGGV }\end{array}$ & 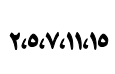 & lor/q) & المقرات \\
\hline$\%$ & rr,rון & $\%$ & $\%$.r. & $\%$ r. & $\% 17,74$ & $\%$ & المئسبتي \\
\hline
\end{tabular}

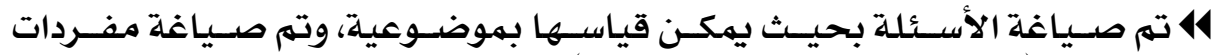

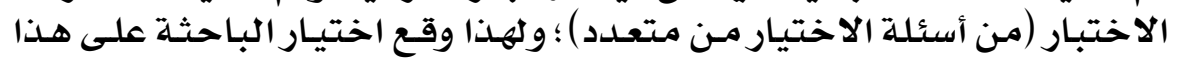




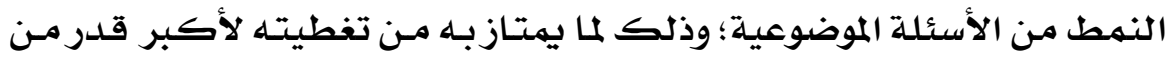

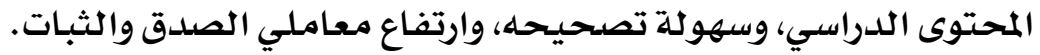

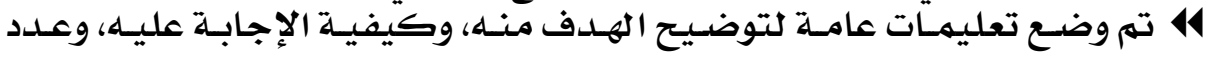
فقراته.

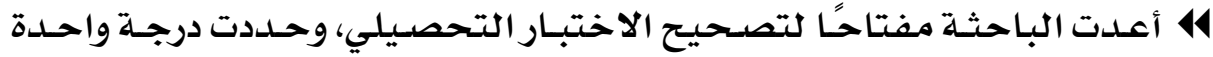

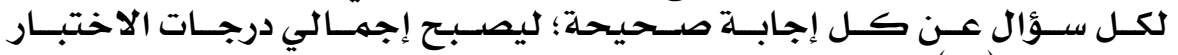

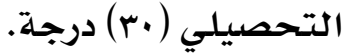

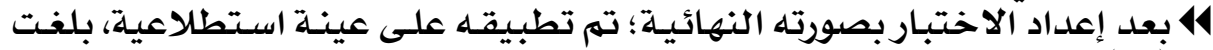

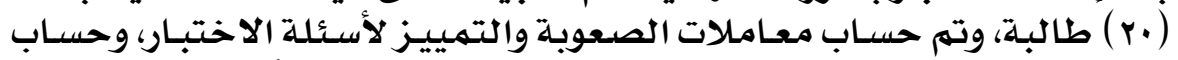

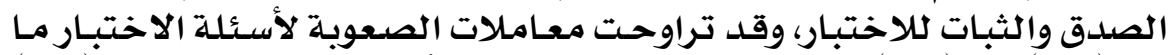

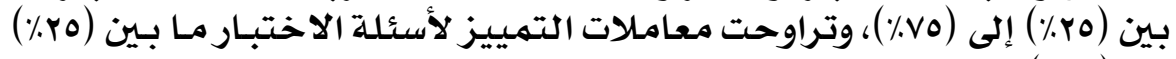

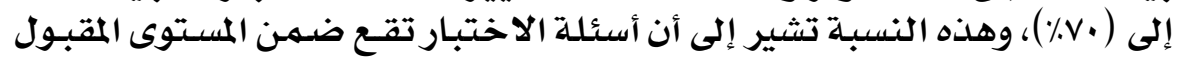

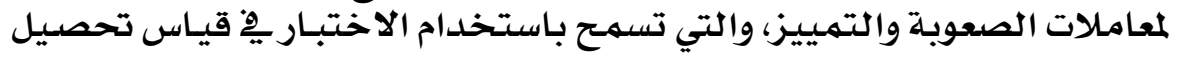
الطالبات.

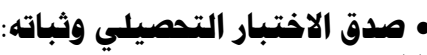

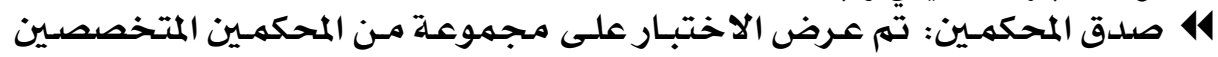

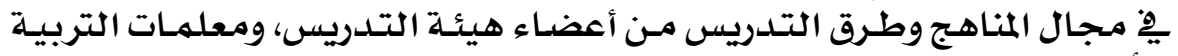

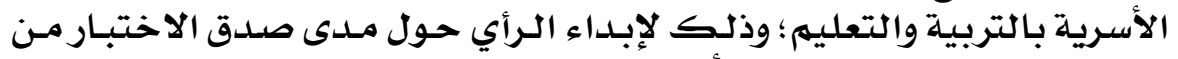

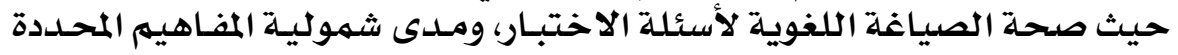

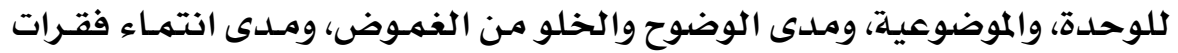

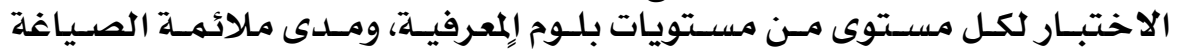

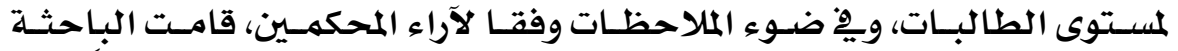

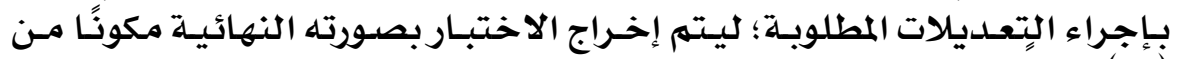

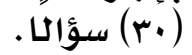

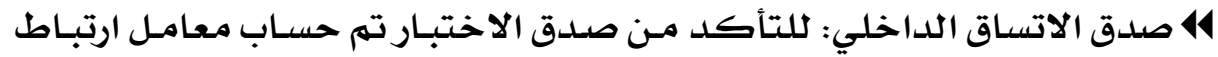

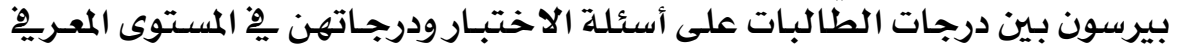

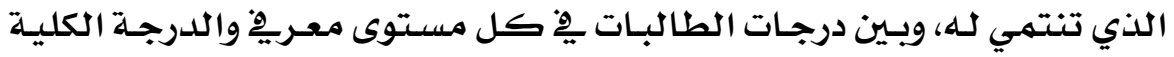

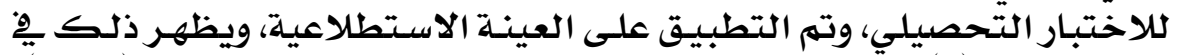

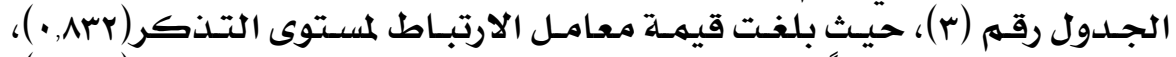

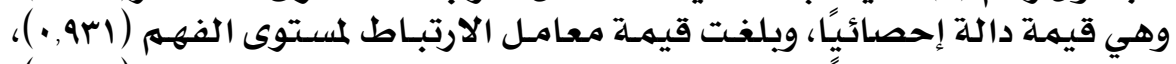

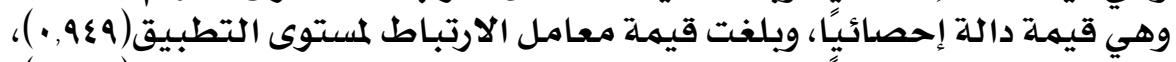

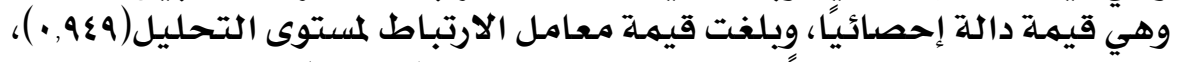

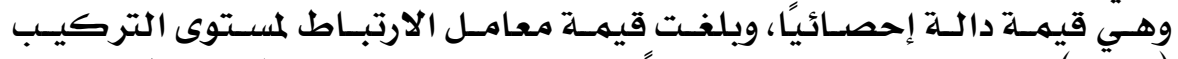

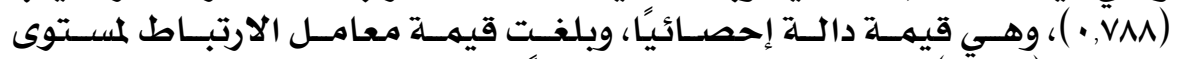

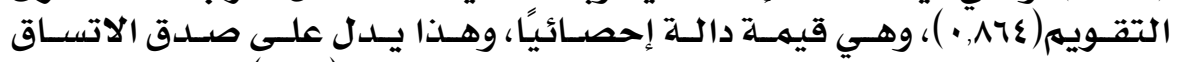

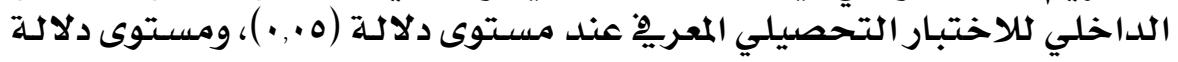




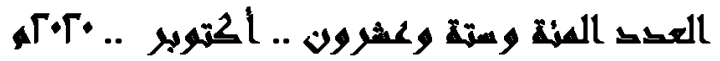

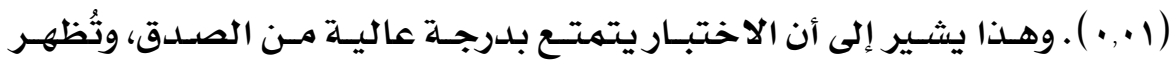

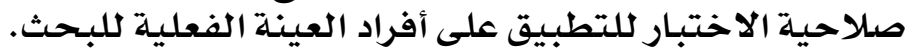

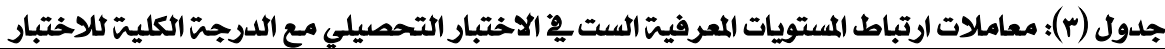

\begin{tabular}{|c|c|}
\hline معامل الارتباط مع الدرجت الكليت للاختبار & المستويات المعرفيت للاختبار \\
\hline 品, & التذكر \\
\hline , 9r1 & الفهم \\
\hline ,9ะ१ & التطبيق \\
\hline$\bullet, 9 \varepsilon 9$ & التحليل \\
\hline , VMA & التركيب \\
\hline ;,ATE & التقويم \\
\hline
\end{tabular}

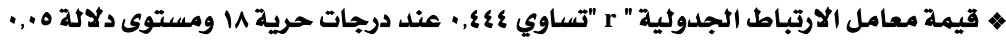

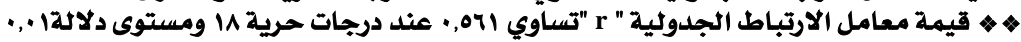

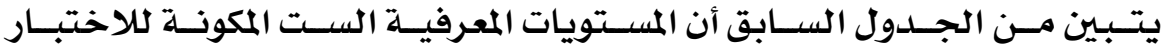

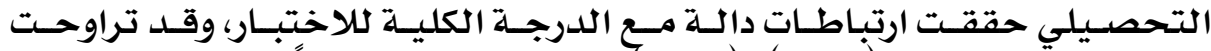

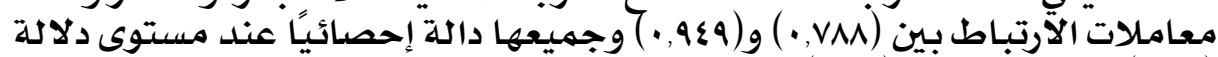

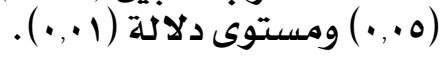

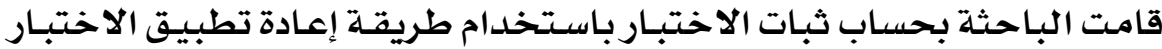

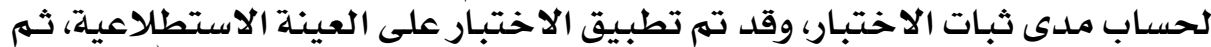

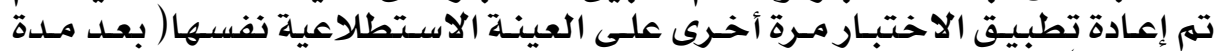

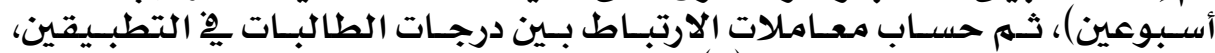

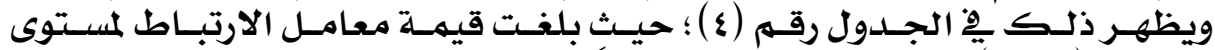

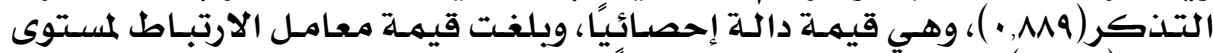

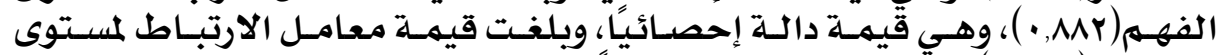

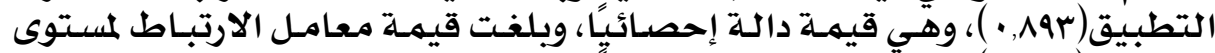

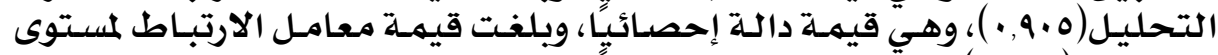

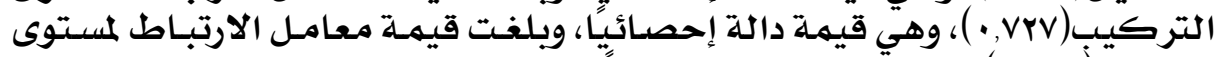

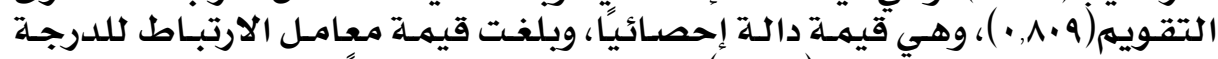

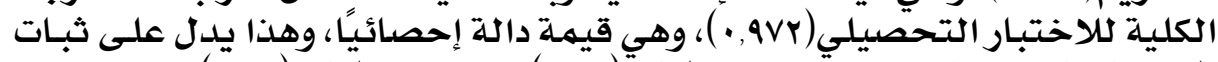

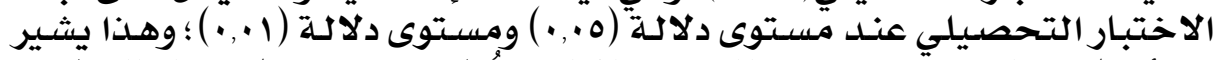

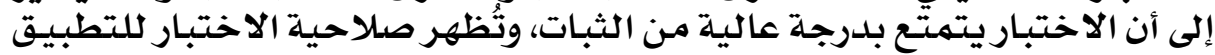

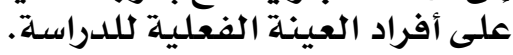

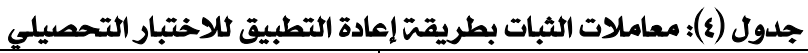

\begin{tabular}{|c|c|}
\hline معامل الثبات & المستويات المعرفيت للاختبار \\
\hline$\because, \wedge \wedge 9$ & التذكر \\
\hline •,AAY & الفهم \\
\hline • Aqr & التطبيق \\
\hline :9.0 & التحليل \\
\hline ,VYV & التركيب \\
\hline 落.9 & التقويم \\
\hline ,9vr & الدرجت الكلية \\
\hline
\end{tabular}

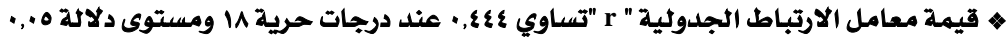




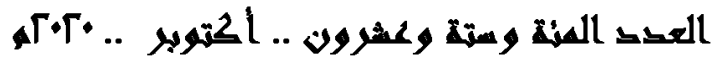

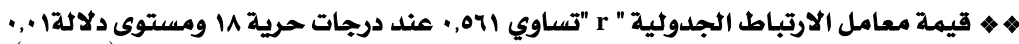

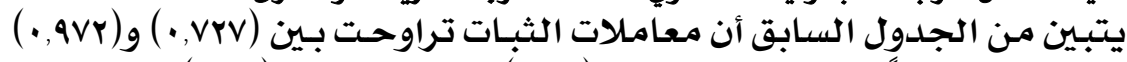

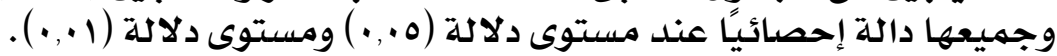

• ثانياً: اختبار التفكير البصري في التربية الأسرية للصف الأول المتوسط (القبلي/البعدي)

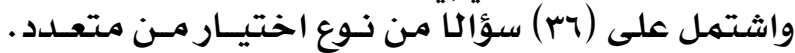

• خطوات إعداد اختبار التفكير البصري في التزبية الأسرية:

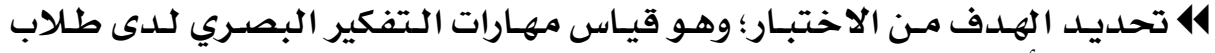

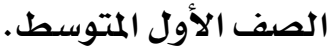

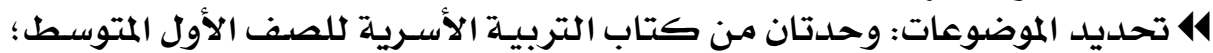

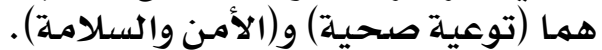

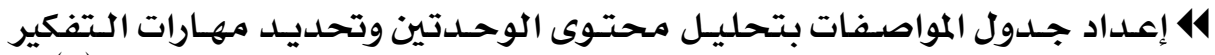

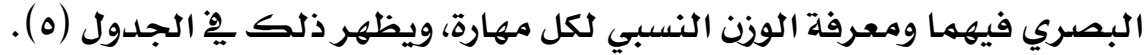

جدول (0): جدول مواصفات اختبار التفكير البصري للصف الأول المتوسط

\begin{tabular}{|c|c|c|c|c|c|c|}
\hline المجموع & استخلاص المعانى & التحليل & التفسير & التمييز & التعرف & المهارة \\
\hline ry & $v$ & 9 & 7 & $v$ & $v$ & عدد الفقرات \\
\hline r & $\begin{array}{l}\text { rolrolroll } \\
\text { rocra,rr }\end{array}$ & 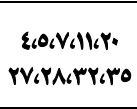 & $\begin{array}{l}\text { IEITTIV } \\
\text { TGYYGYY }\end{array}$ & 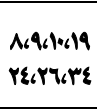 & 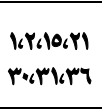 & اللفمثلت \\
\hline \% & ״19,\& & $\%$ ro & $\% 17,7$ & $\% 19,8$ & $\% 19,8$ & النسبتة \\
\hline
\end{tabular}

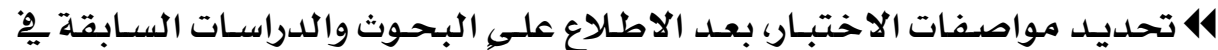

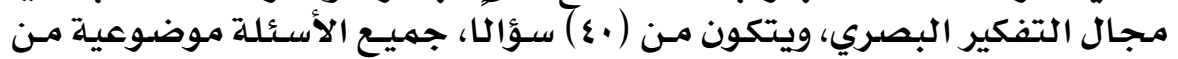

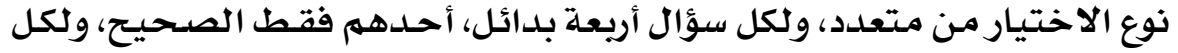

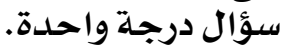

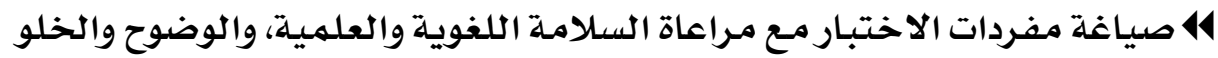

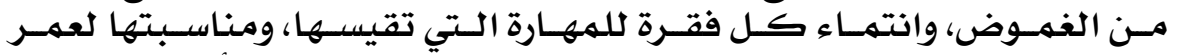

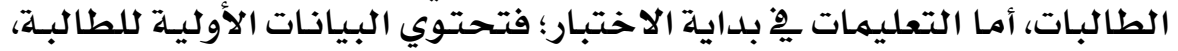

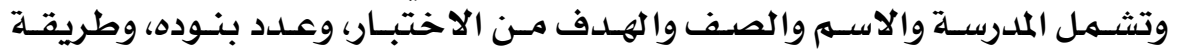
الإجابـة عنده .

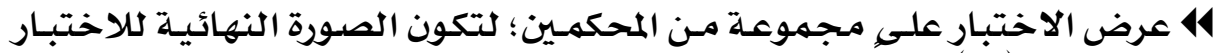

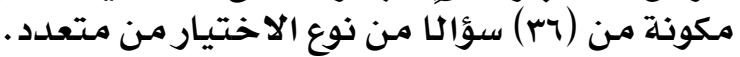

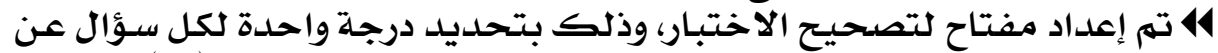

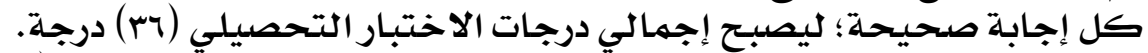

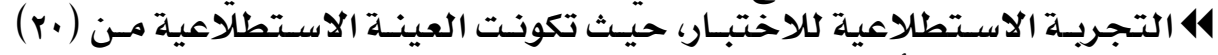

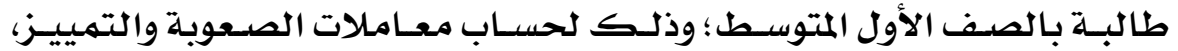
وصدق الاختبار وثباته . 


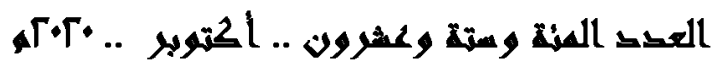

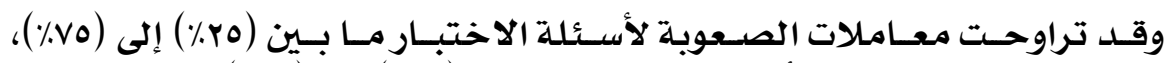

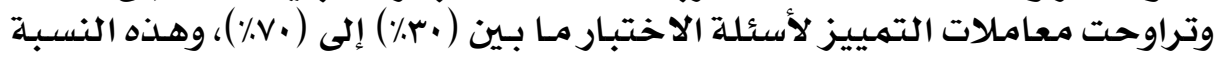

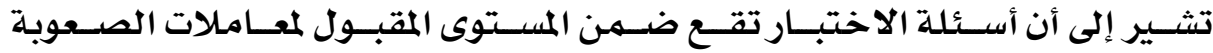

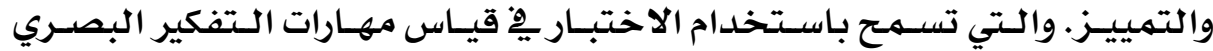

للطالبات.

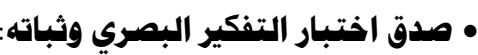

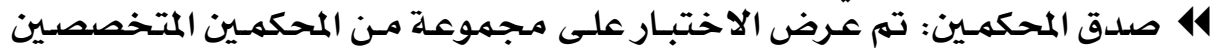

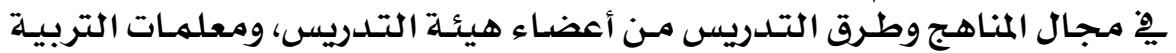

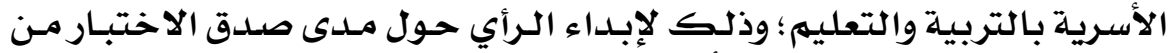

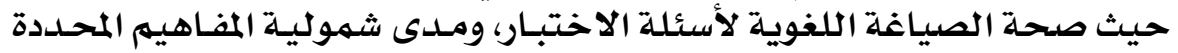

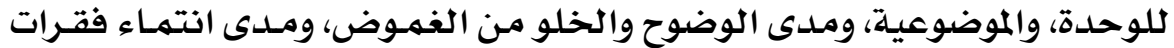

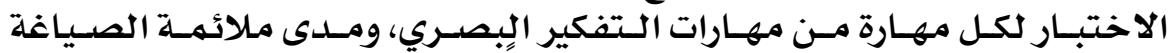

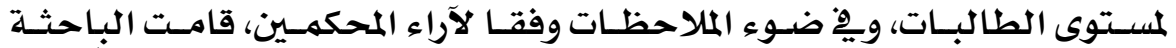

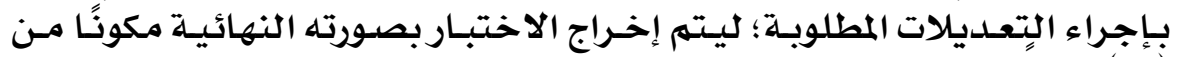

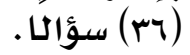

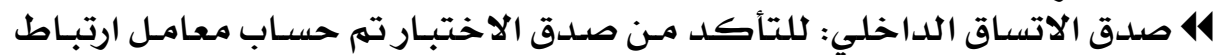

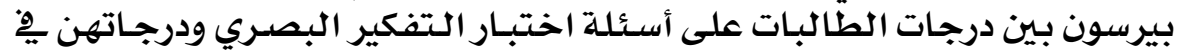

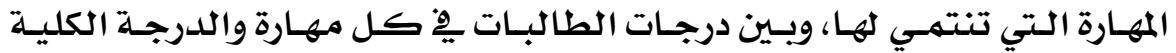

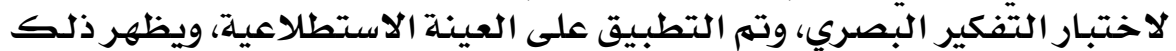

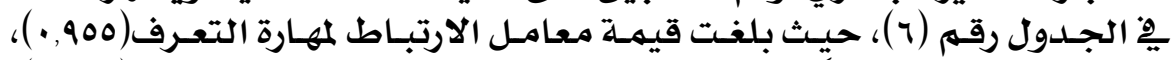

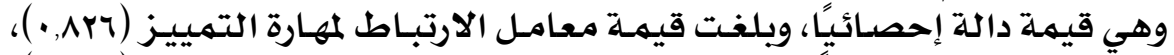

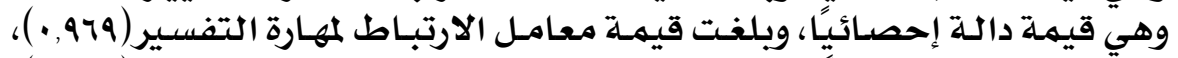

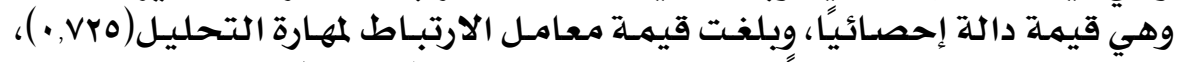

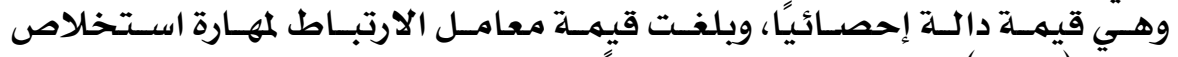

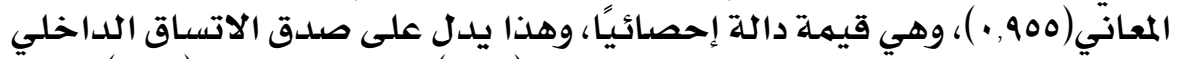

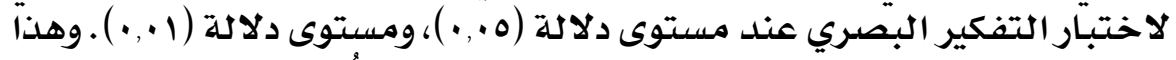

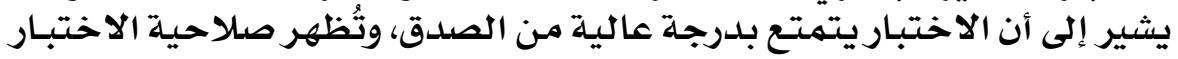

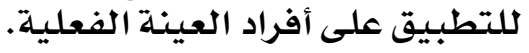

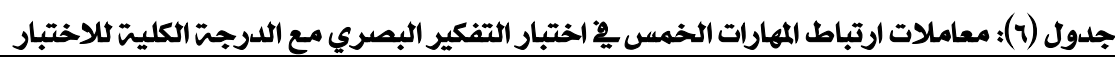

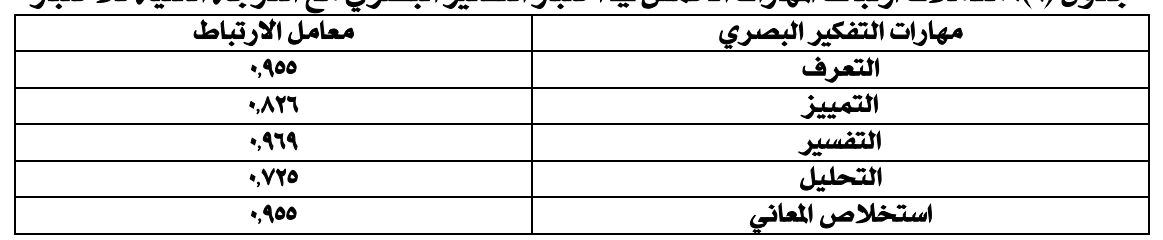

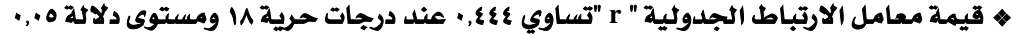

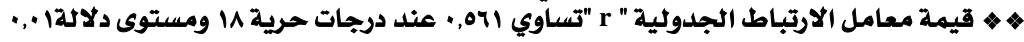




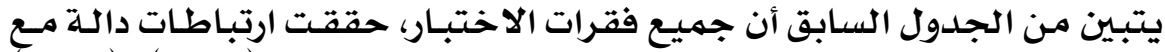

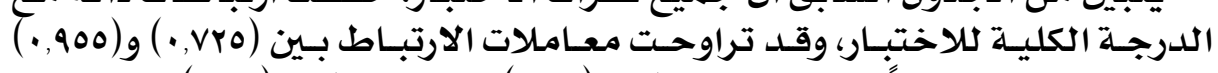

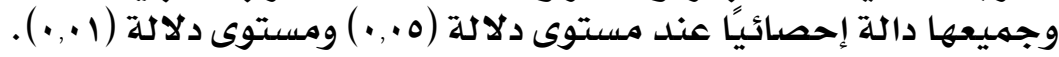

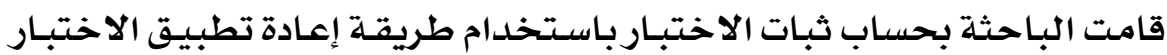

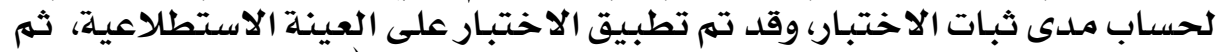

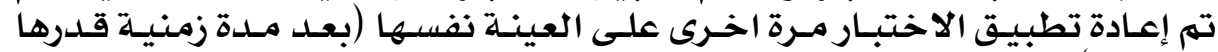

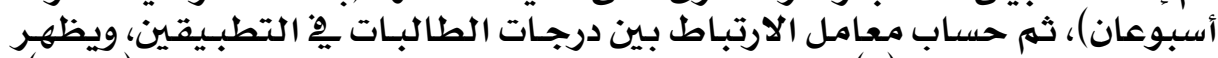

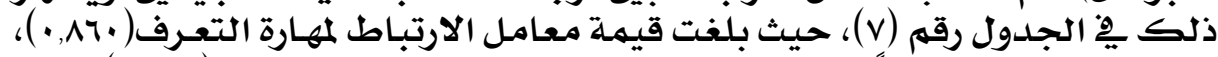

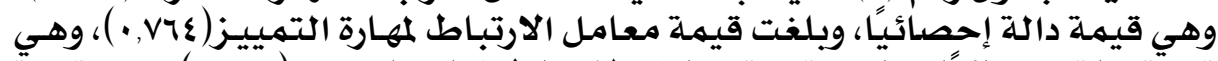

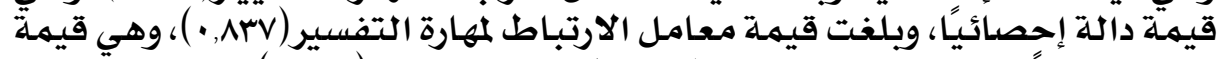

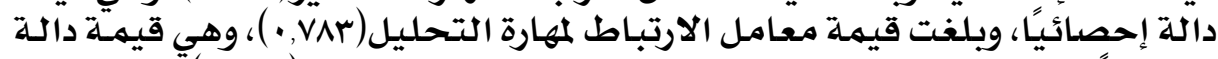

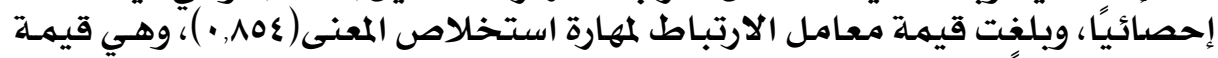

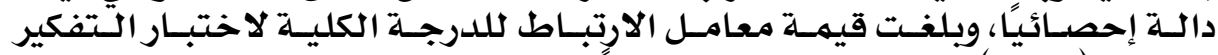

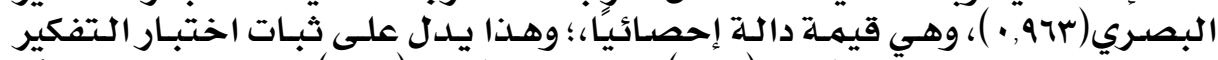

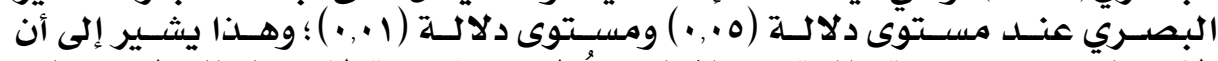

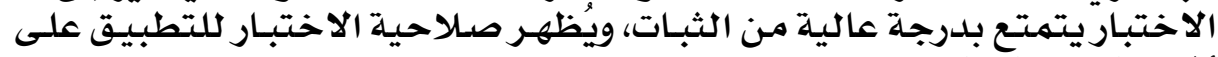

أفراد النعينتة الفعليتهة.

جدول (v): معاملات الثبات بطريقت إعادة التطبيق لاختبار التفكير البصري

\begin{tabular}{|c|c|}
\hline معامل الثبات & مهارات التفكير البصري \\
\hline ; A & التعرف \\
\hline , V7\& & التمييز \\
\hline •,ArV & التفسير \\
\hline , VAr & التحليل \\
\hline •, $10 \varepsilon$ & استخلاص المعانى \\
\hline rata & الدرجت الكليت \\
\hline
\end{tabular}

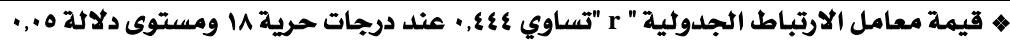

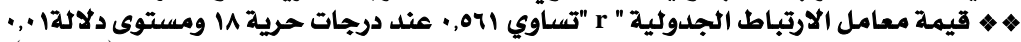

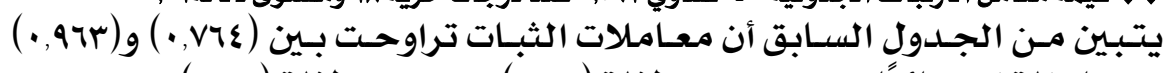

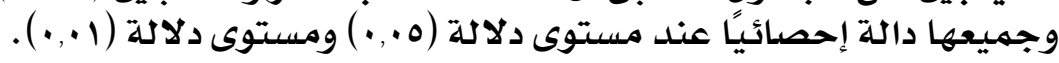

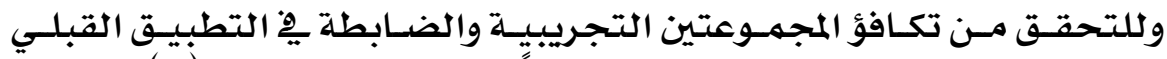

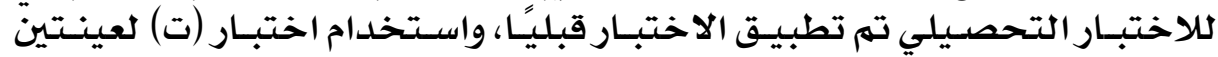

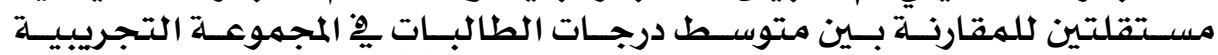

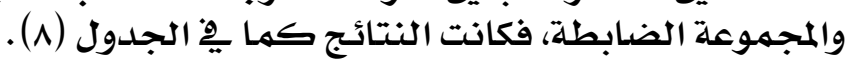

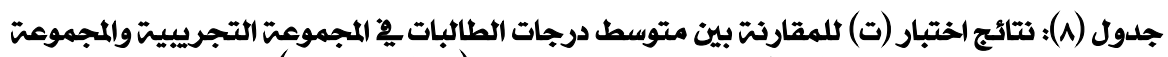

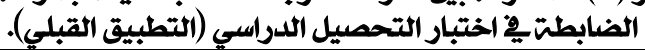

\begin{tabular}{|c|c|c|c|c|c|c|}
\hline مستوى الدلالت & قيمت (ت) & الانحراف & المتوسطابى & العدد & المجموعت & المستوى \\
\hline \multirow{2}{*}{ غير داليًا } & \multirow{2}{*}{ •, $91 \varepsilon$} & , 994 & $r, r)$ & rr & الضابطتة & \multirow[t]{2}{*}{ التذكر } \\
\hline & & 要, 910 & r,or & rr & التجريييتي & \\
\hline غير دال & .94A & , ११乏 & Y,YO & rr & الضابطت & الفهم \\
\hline
\end{tabular}




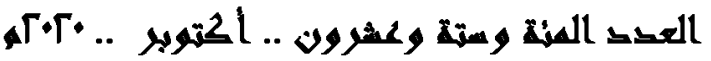

\begin{tabular}{|c|c|c|c|c|c|c|}
\hline إحصائيًا & & •,AVq & $r, \varepsilon V$ & rY & التجريبيتي & \\
\hline \multirow{2}{*}{ فير داليًا } & \multirow{2}{*}{, 99V } & I,YMT & $r,+r$ & rr & الضابطت & \multirow{2}{*}{ التطبيق } \\
\hline & & 1,YA9 & r,rA & $r r$ & التجريبيت & \\
\hline \multirow{2}{*}{ غير دالَّا } & \multirow{2}{*}{; १६० } & $1,10 \mathrm{~V}$ & $r, Y Y$ & rr & الضابطتة & \multirow{2}{*}{ التحليل } \\
\hline & & ,90. & $r, \varepsilon V$ & $r r$ & التجريبيت & \\
\hline \multirow{2}{*}{ فير داليًا } & \multirow{2}{*}{ •,190 } & , VYr & 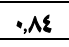 & $r r$ & الضابطت & \multirow[t]{2}{*}{ التركيب } \\
\hline & & , TVY & $1, \cdots$ & $r r$ & التتجريبيت & \\
\hline \multirow{2}{*}{ غير داليًا } & \multirow{2}{*}{$9,9.1$} & $1,0$. & ,90. & $r r$ & الضابطتة & \multirow[t]{2}{*}{ التقويم } \\
\hline & & I.VY & , 991 & $r r$ & التجريبيت & \\
\hline \multirow{2}{*}{ غير دال } & \multirow{2}{*}{, 941} & 8,110 & $|\varepsilon, M|$ & $r r$ & الضابطت & \multirow{2}{*}{ التحصتبلي } \\
\hline & & $\varepsilon, \varepsilon\}$. & $10, \mathrm{rA}$ & rr & التجريبيت & \\
\hline
\end{tabular}

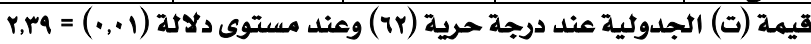

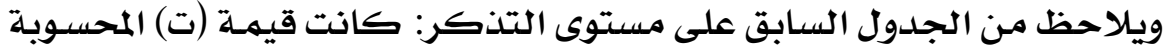

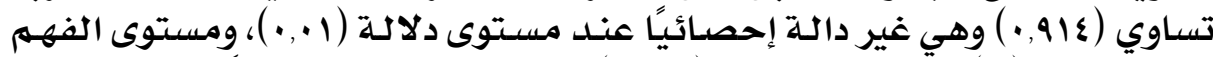

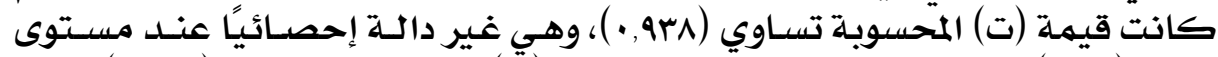

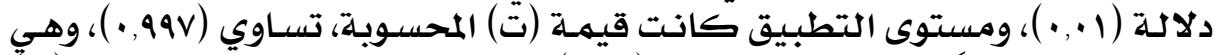

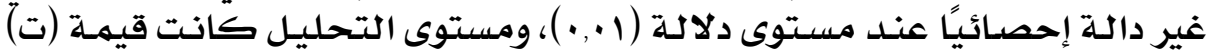

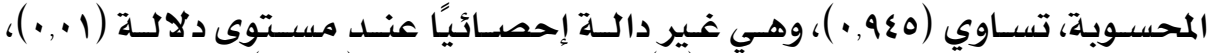

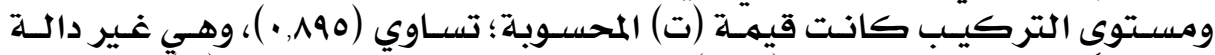

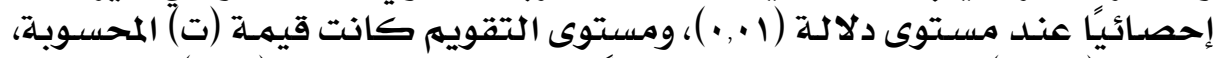

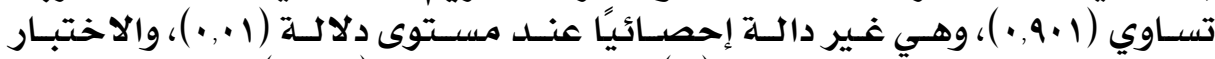

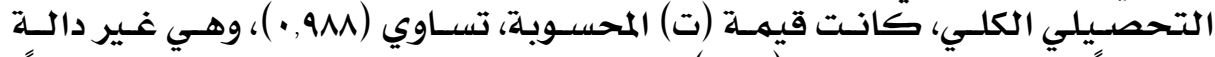

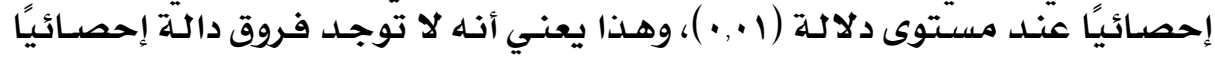

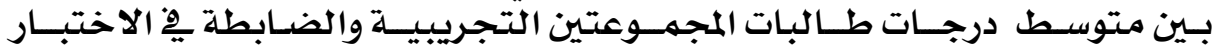

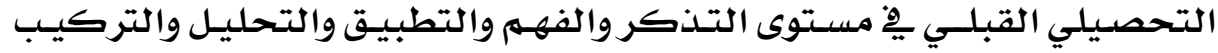

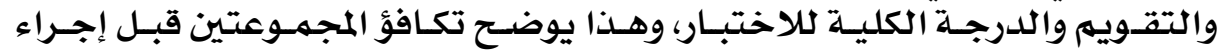

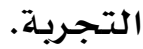

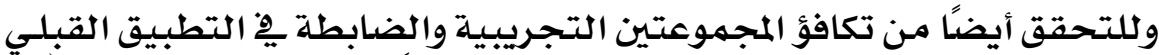

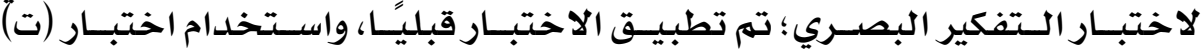

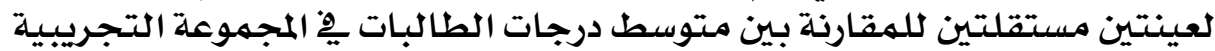

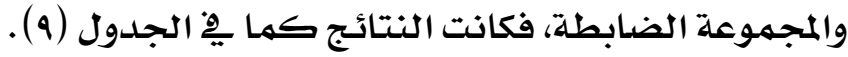

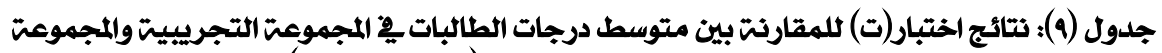

\begin{tabular}{|c|c|c|c|c|c|c|}
\hline \\
\hline مستوي & قيمة (ت) & الالمعرافي & الحسوسطى & العلدد & المجموعت & المهارة \\
\hline \multirow{2}{*}{ غير دائيًا } & \multirow{2}{*}{1,194} & ,oor & $r, \Delta \cdot$ & rY & الضابطت & \multirow[t]{2}{*}{ التعرف } \\
\hline & & rTr, & $r, \mathrm{VA}$ & rr & التجريبيت & \\
\hline \multirow{2}{*}{ غير دائيًا } & \multirow{2}{*}{$1, \varepsilon: \varepsilon$} & . & r.,q & rr & الضابطت & \multirow[t]{2}{*}{ التمييز } \\
\hline & & , $0 \vee \varepsilon$ & $r .17$ & $r Y$ & التجريبيت & \\
\hline غير دال & Tוז ו ו & , Vor & $r, q$ & $r r$ & الضابطت & التفسير \\
\hline
\end{tabular}




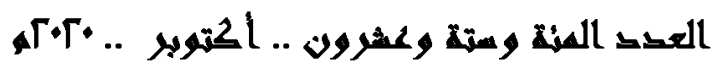

\begin{tabular}{|c|c|c|c|c|c|c|}
\hline إحصائيًا & & $1, Y V$ & $r, \varepsilon 1$ & rY & التجريبيت & \\
\hline \multirow{2}{*}{ غير داليًا } & \multirow{2}{*}{, AOV } & , १ह४ & , \&\{1 & $r Y$ & الضابطت & \multirow[t]{2}{*}{ التحليل } \\
\hline & & , val & , \&09 & $r r$ & التجريبيت & \\
\hline \multirow{2}{*}{ غير دالئا } & \multirow{2}{*}{ ו"q, } & ,9v7 & $0,1 \%$ & rr & الضابطت & \multirow{2}{*}{ استخلاصن المعنى } \\
\hline & & ;,9.Y & $0, r \varepsilon$ & $r Y$ & التجريبيت & \\
\hline \multirow{2}{*}{ فير دالئيا } & \multirow{2}{*}{$1, \cdot v \cdot$} & r,OAr & YV,YO & $r Y$ & الضابطتة & \multirow{2}{*}{ اختبار التفكير } \\
\hline & & $r, \wedge 10$ & YA,YO & $r r$ & التجريبيت & \\
\hline
\end{tabular}

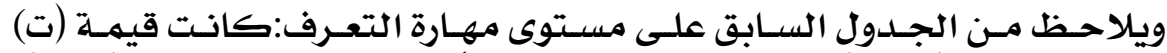

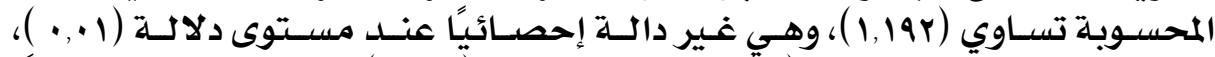

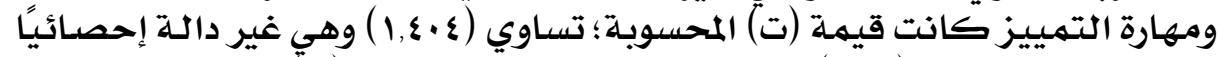

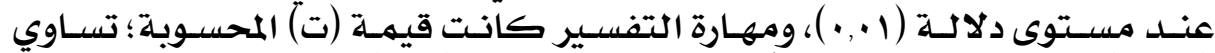

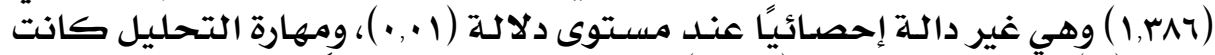

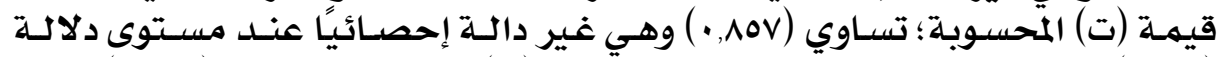

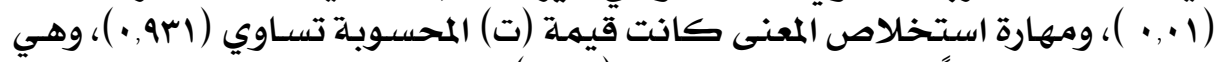

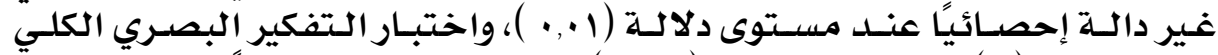

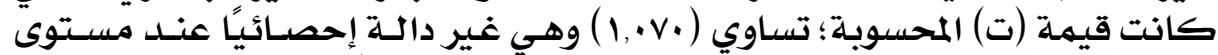

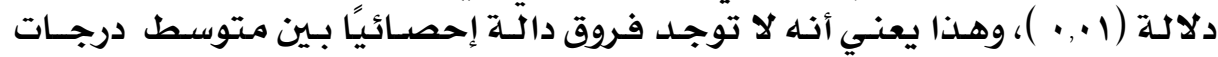

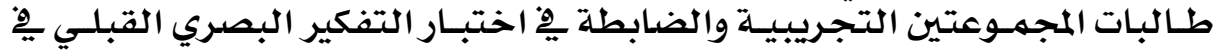

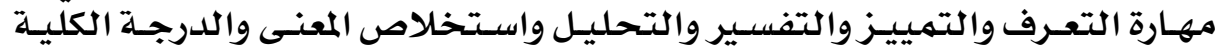

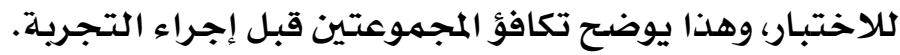

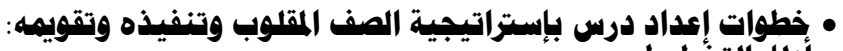
• أولا: التخطيط أعداد

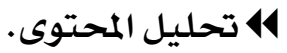
14 تحديل الأهداف. 14 14 وضع أنشطة تعليمية.

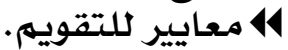

\section{• ثانيًا: التنفيذ للمجمهوعة التجريبية وينقسم إلى هرحلتين:}

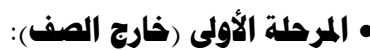

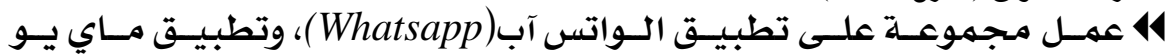

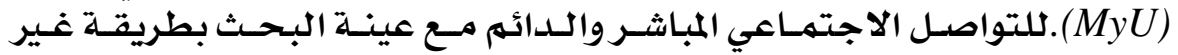

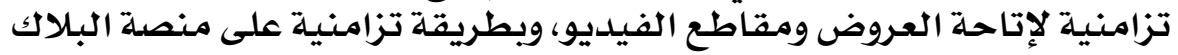

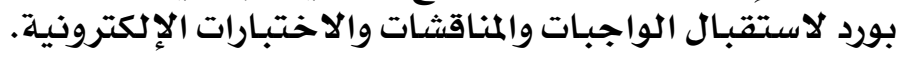

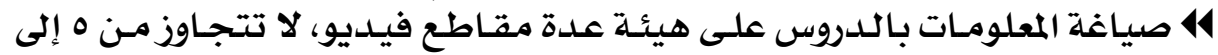

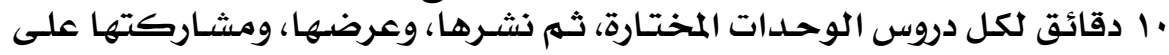

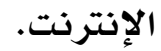
41 إعلان للطالبـات بمكان النشر وزمانه.

\section{YqY}




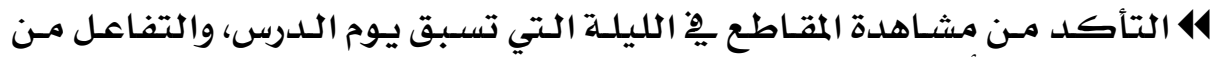

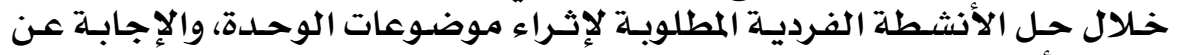

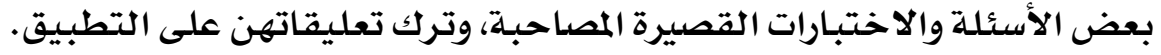
ه 4 تعلهم ذاتي.

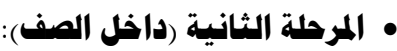
14 تهيئة البيئة الصفية الصنية.

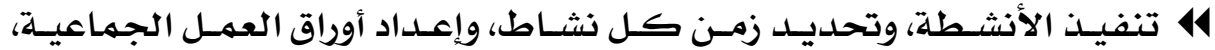

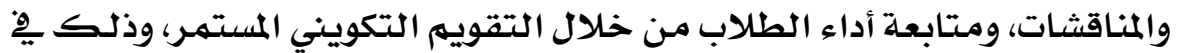

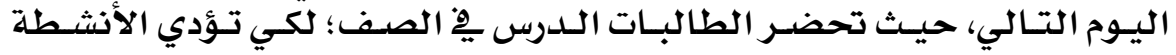

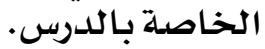

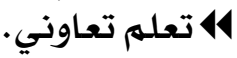

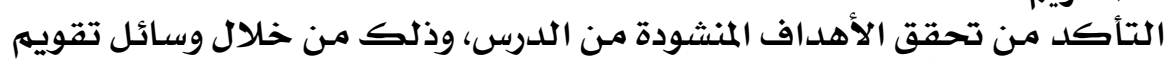

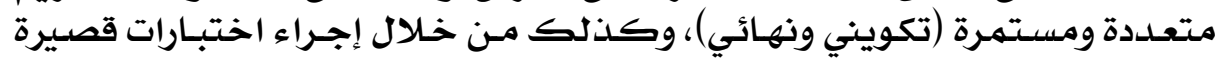
شفوية أو تحريرية فردية وجية وتكماعية.

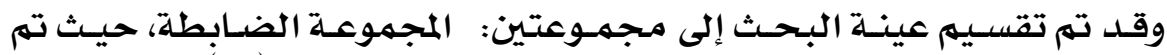

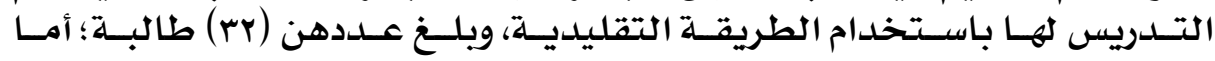

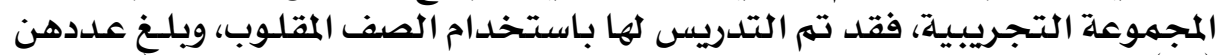

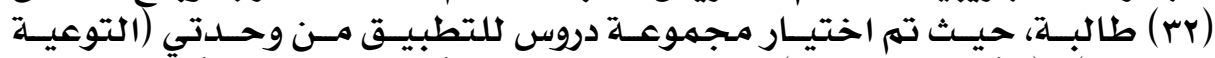

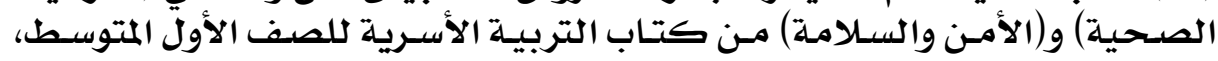

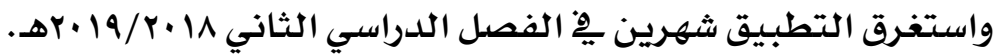
• نتائج البحث وتمليلها: • نتائج الفرض الأول وهناقشتها:

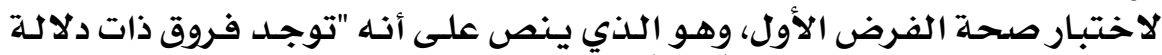

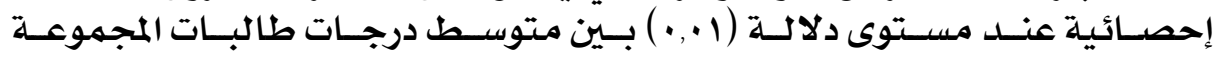

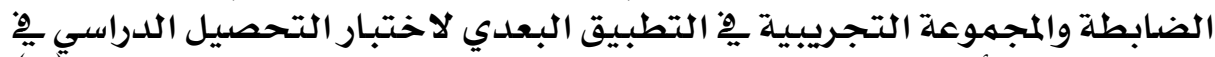

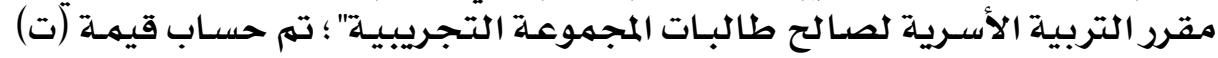

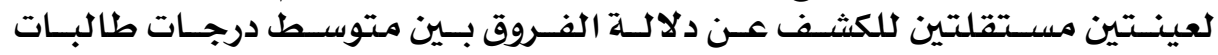

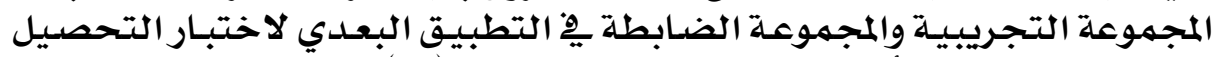

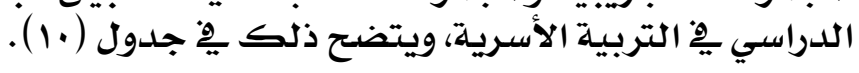

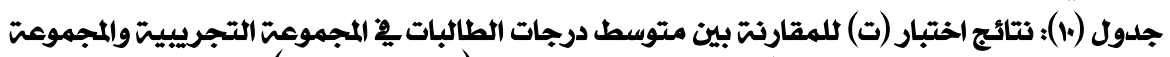

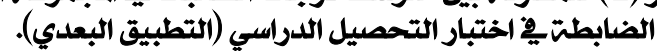

\begin{tabular}{|c|c|c|c|c|c|c|}
\hline مستوى الدلاي & قيمتة (ت) & الالمعياري & المصابط & العدد العد & المجموعت & المستوى \\
\hline \multirow{2}{*}{ دال إحصائيًا } & \multirow{2}{*}{ r.Yoq } & l, VA & $\varepsilon, \cdots$ & rr & الضابطتة & \multirow[t]{2}{*}{ لتذكر } \\
\hline & & l, v. & $\varepsilon, M$ & rr & التجريبيت & \\
\hline
\end{tabular}




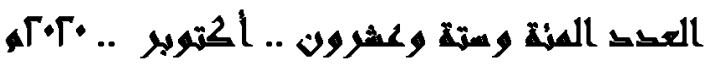

\begin{tabular}{|c|c|c|c|c|c|c|}
\hline \multirow{2}{*}{ دال إحصائًا } & \multirow{2}{*}{$0, r \varepsilon v$} & 1,rYE & Y,YA & rr & الضابطت & \multirow[t]{2}{*}{ الفهم } \\
\hline & & $1,+71$ & $r, \wedge l$ & rr & التجريبيت & \\
\hline \multirow{2}{*}{ دال إحصائًا } & \multirow{2}{*}{$r, r q$} & I,YA9 & $r, v \wedge$ & rr & الضابطتة & \multirow[t]{2}{*}{ التطبيق } \\
\hline & & l, Yv. & $\varepsilon, v_{0}$ & rr & التجريبيت & \\
\hline \multirow{2}{*}{ دال إحصائيًا } & \multirow{2}{*}{$0, \wedge १ \varepsilon$} & I,YYE & r,YA & rr & الضابطت & \multirow[t]{2}{*}{ التحليل } \\
\hline & & $1,1 \varepsilon$ & $\varepsilon, 9 \varepsilon$ & rr & التجريبيت & \\
\hline \multirow{2}{*}{ دال إحصائيًا } & \multirow{2}{*}{ r.qYI } & , 74. & 1, rr & $r r$ & الضابطت & \multirow[t]{2}{*}{ التركيب } \\
\hline & & , VTV & $r, 17$ & rr & التجريبيت & \\
\hline \multirow{2}{*}{ دال إحصائيًا } & \multirow{2}{*}{ r.01. } & ,91ध & Y,Yo & $r r$ & الضابطت & \multirow[t]{2}{*}{ التقويم } \\
\hline & & $1, \cdots \wedge$ & $\mathrm{r}, \mathrm{MA}$ & rr & التجريبيت & \\
\hline \multirow{2}{*}{ دال إحصائيًا } & \multirow{2}{*}{$\varepsilon, Y 7 \varepsilon$} & 0,971 & IV,YY & rr & الضابطتة & \multirow{2}{*}{ التحصتبلي } \\
\hline & & $0,7 \varepsilon 0$ & $r r, \varepsilon 1$ & rr & التجريبيت & \\
\hline
\end{tabular}

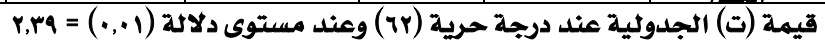

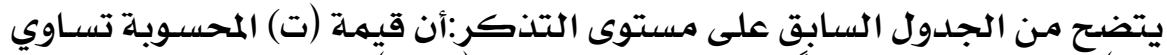

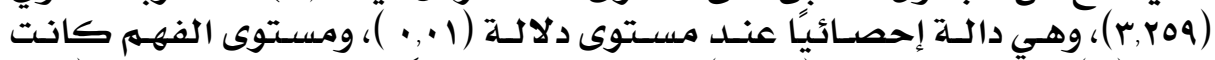

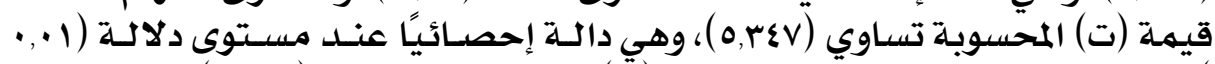

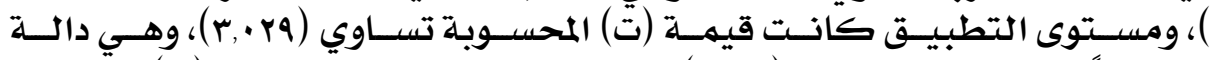

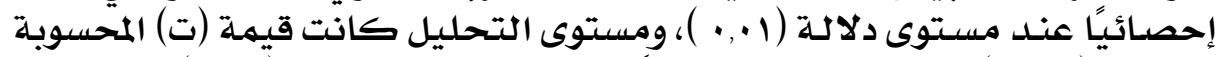

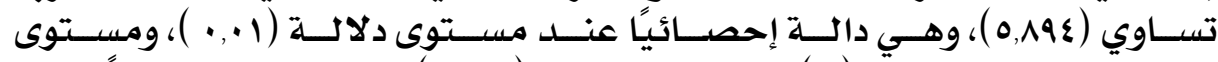

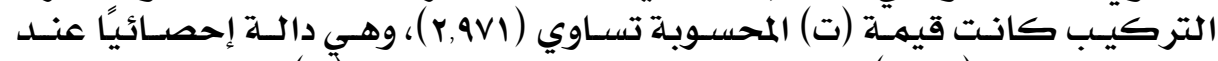

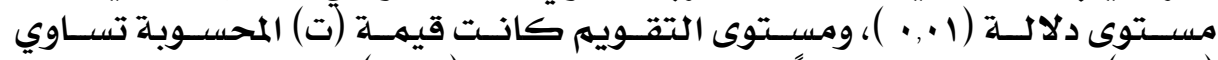

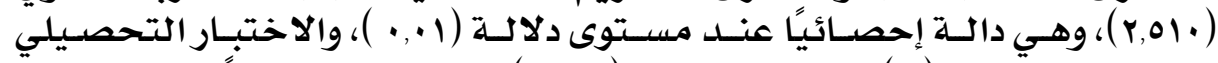

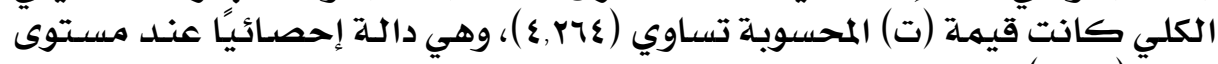
دلانة (1. (. ) ).

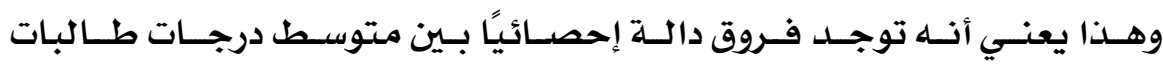

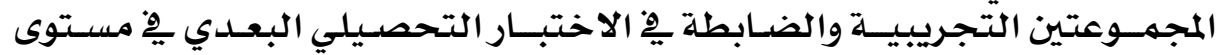

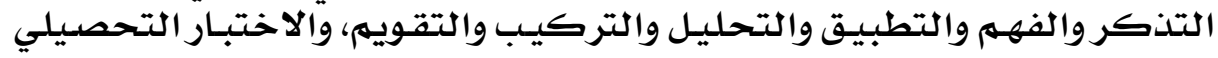

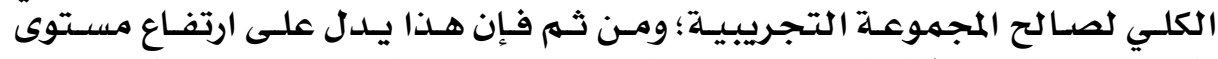

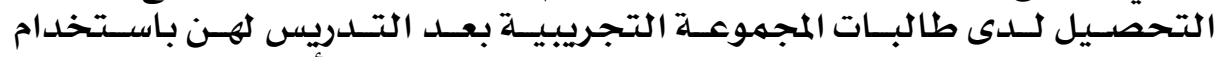

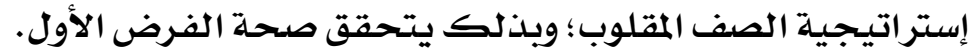




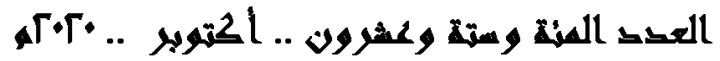

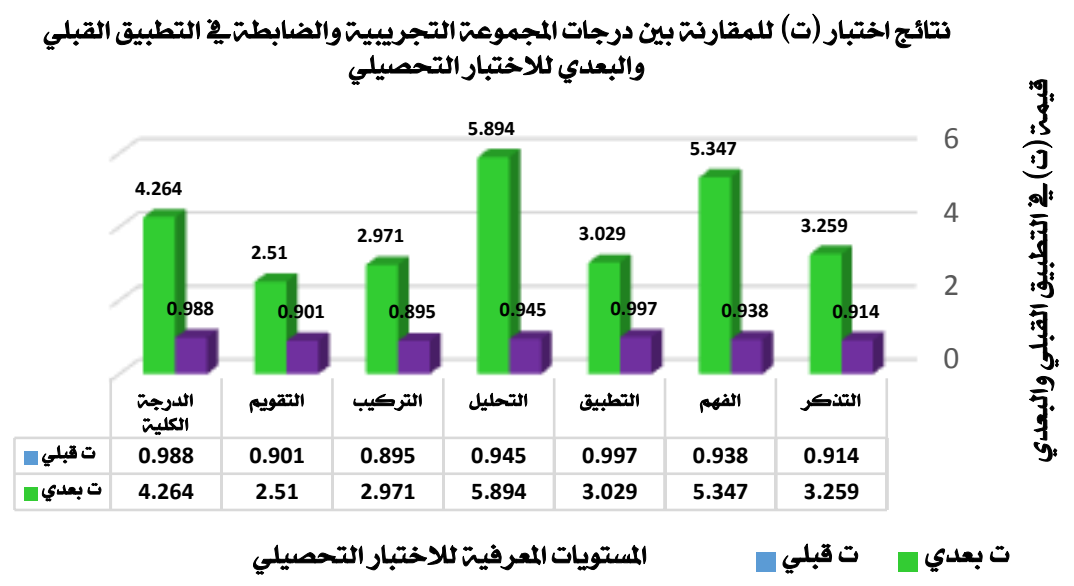

(1) (1) (1)

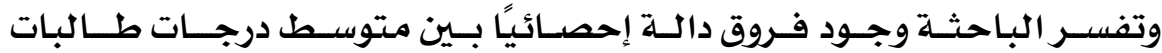

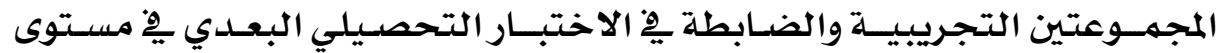

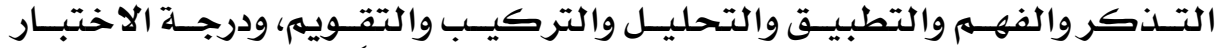

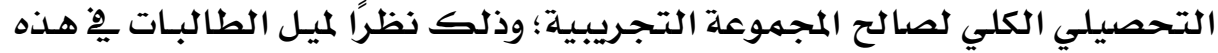

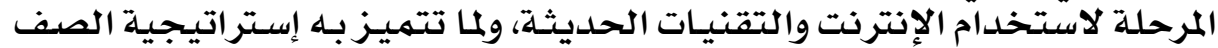

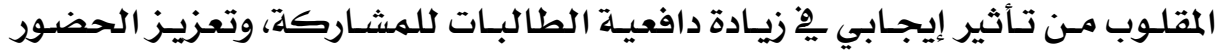

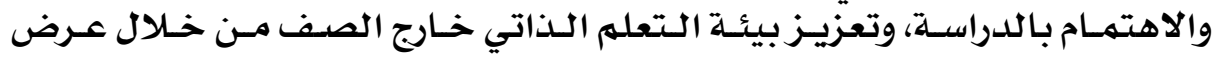

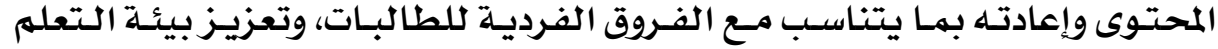

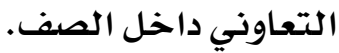

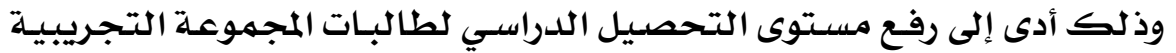

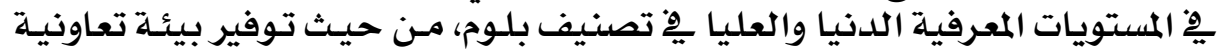

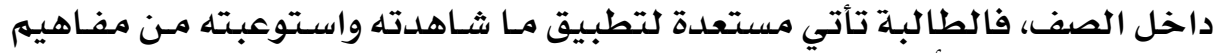

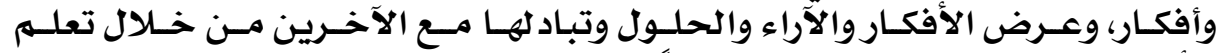

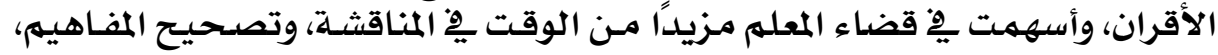

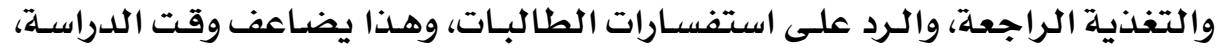

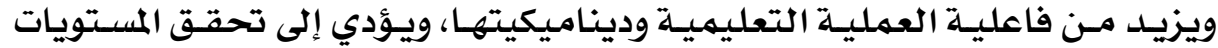

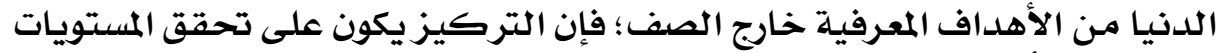

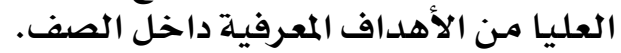

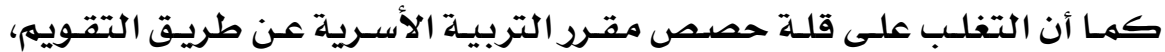

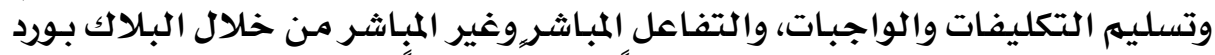

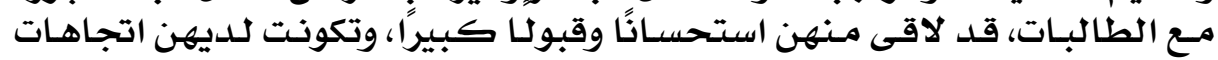

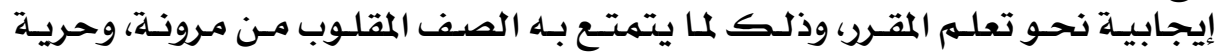

\section{Y97}




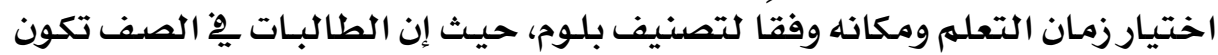

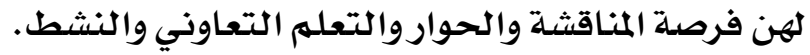

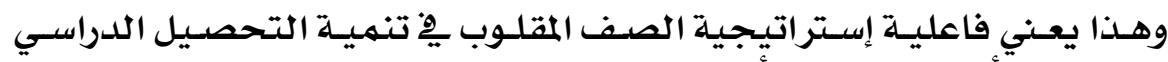

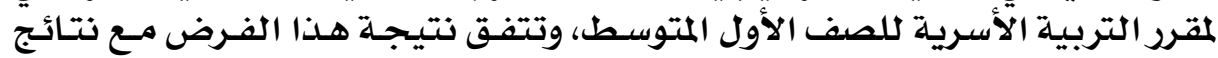

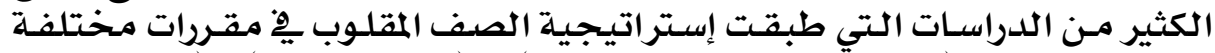

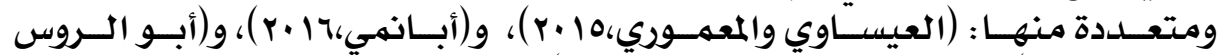

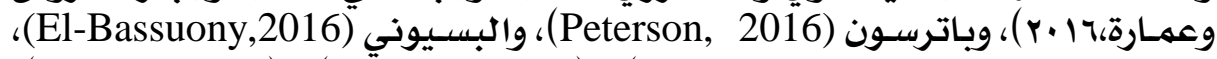

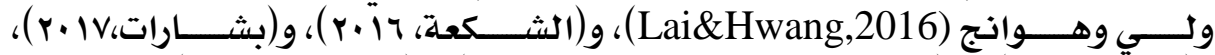

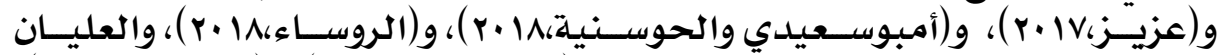

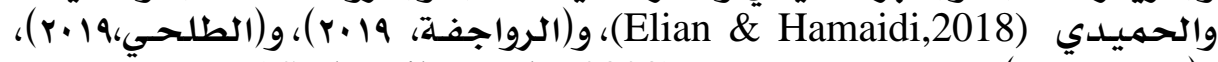

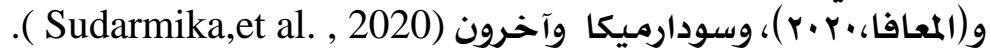

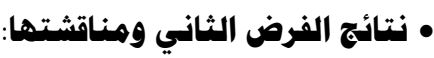

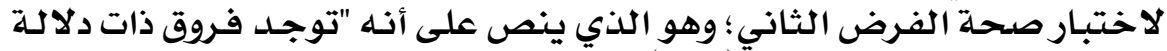

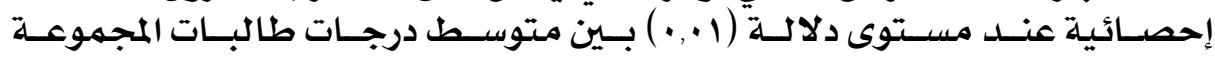

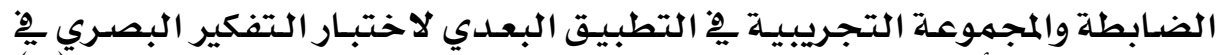

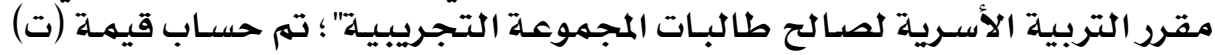

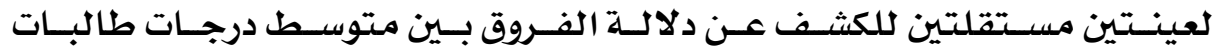

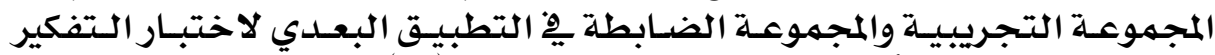

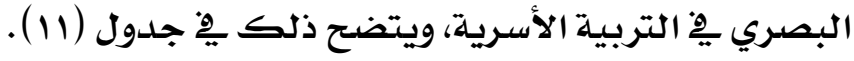

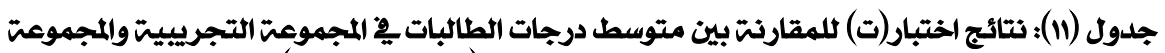

\begin{tabular}{|c|c|c|c|c|c|c|}
\hline مستوى الدلانت & قيمة & الانحراف & المتوسط & العدد & المجموعتة & المهارة \\
\hline \multirow{2}{*}{ دال إحصائيًا } & \multirow{2}{*}{ r.,qA } & 只Y & $\varepsilon, \mathrm{VA}$ & $r r$ & الضابطتة & \multirow[t]{2}{*}{ التعرف } \\
\hline & & $1,0 \varepsilon$ & $0, V Y$ & rr & التجريييت & \\
\hline \multirow{2}{*}{ دال إحصائيًا } & \multirow{2}{*}{ 1,90. } & r & $\varepsilon, V Y$ & rr & الضابطتة & \multirow[t]{2}{*}{ التمييز } \\
\hline & & r.var & T, M & $r Y$ & التجريبيتي & \\
\hline \multirow{2}{*}{ دال إحصائيًا } & \multirow{2}{*}{$0, r \varepsilon v$} & L,YYE & r,YA & rr & الضابطتة & \multirow[t]{2}{*}{ التفسير } \\
\hline & & $1, \cdot \pi 1$ & $\varepsilon, \Lambda 1$ & rr & التجريبيتي & \\
\hline \multirow{2}{*}{ دال إحصائيًا } & \multirow{2}{*}{ V,VAT } & 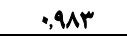 & $0, \varepsilon V$ & rr & الضابطتة & \multirow[t]{2}{*}{ التحليل } \\
\hline & & ד & V, rA & rr & التجريييت & \\
\hline \multirow{2}{*}{ دال إحصائيًا } & \multirow{2}{*}{ r.,qA } & (ATY & $\varepsilon, \mathrm{VA}$ & rr & الضابطتة & \multirow[t]{2}{*}{ استخلاص المعنى } \\
\hline & & $1,0 \varepsilon$ & $0, V Y$ & rr & التجريييت & \\
\hline \multirow{2}{*}{ دال إحصائيًا } & \multirow{2}{*}{$7,91 \cdot$} & $r, A \wedge 9$ & $r r, r$ & rr & الضابطتة & \multirow{2}{*}{ البتبار التفكير التكي } \\
\hline & & 8,1199 & $r 9,9 v$ & $r r$ & التجريبيتي & \\
\hline
\end{tabular}

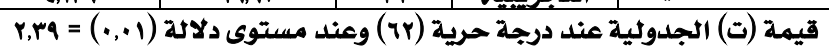

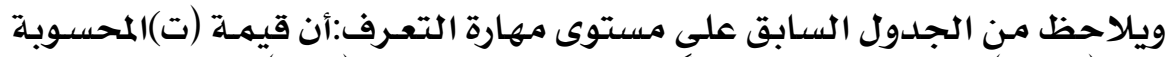

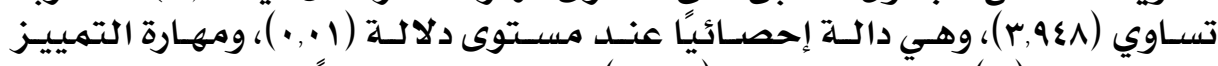

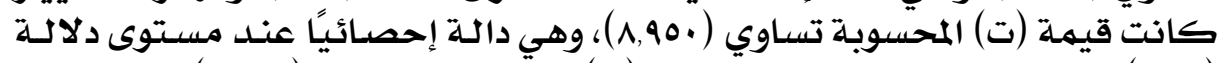

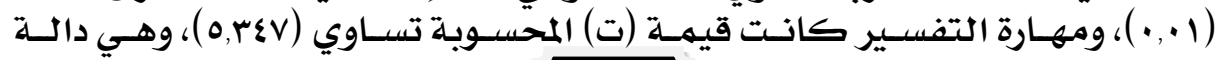

\section{rqV}




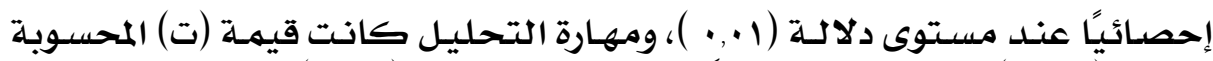

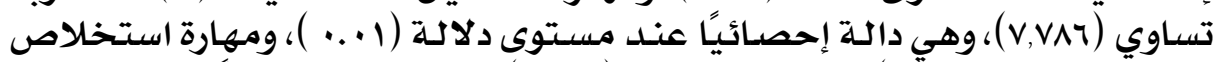

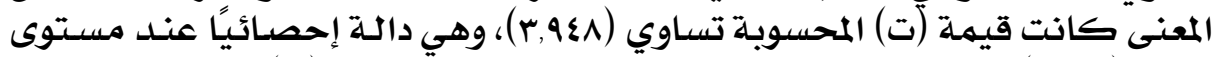

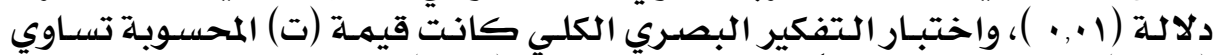

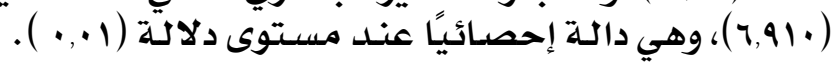

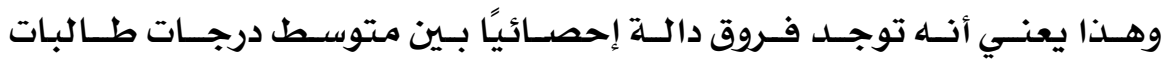

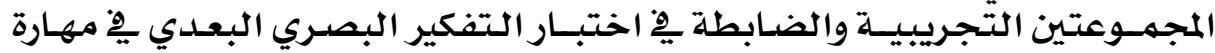

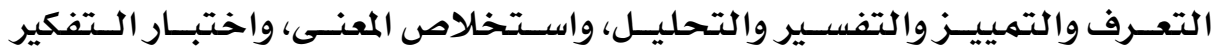

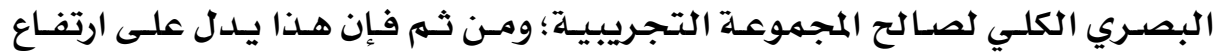

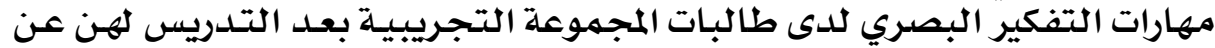

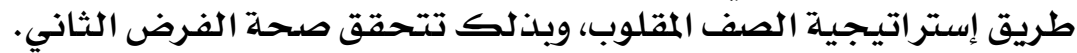

نتائج اختبار (ت) للمقارنت بين درجات المجموعت التجريبيت والضابطتّهِ التطبيق القبلي

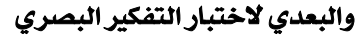

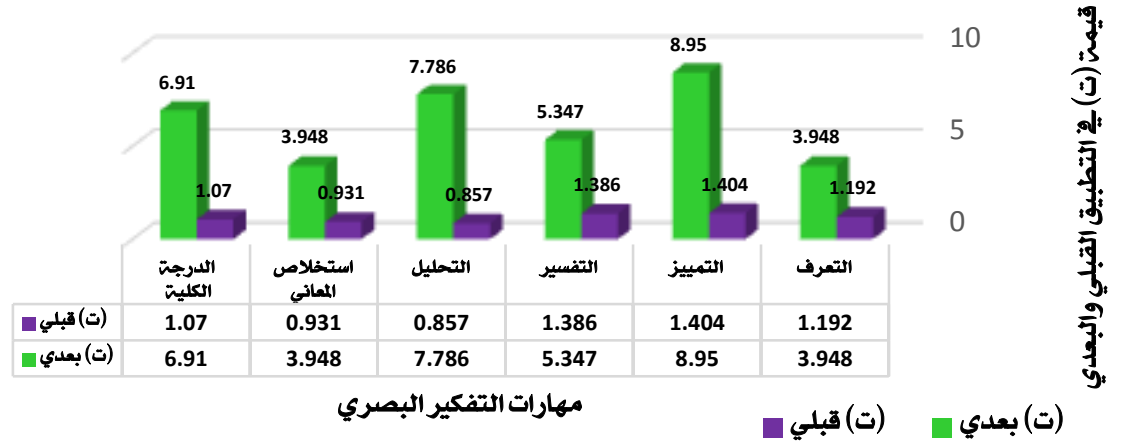

شكل (r)

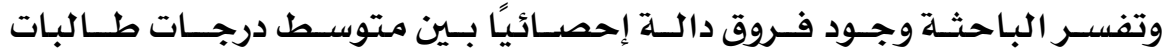

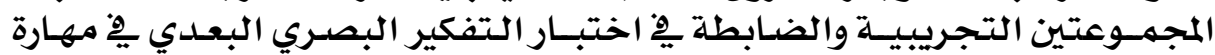

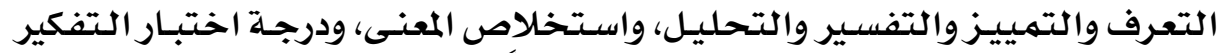

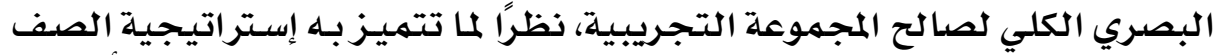

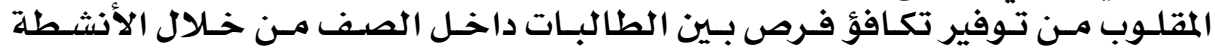

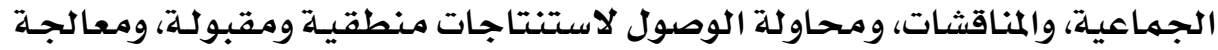

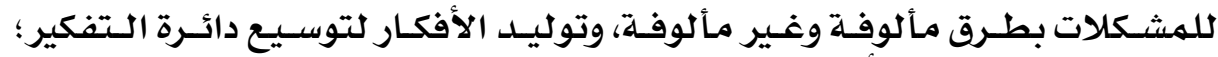

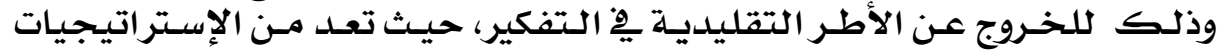

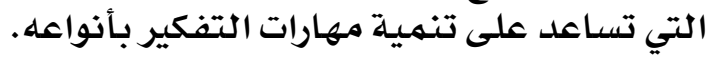

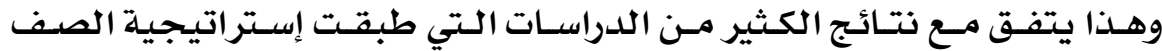

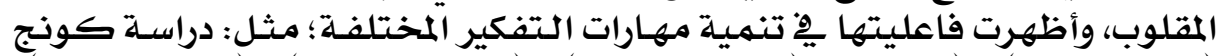

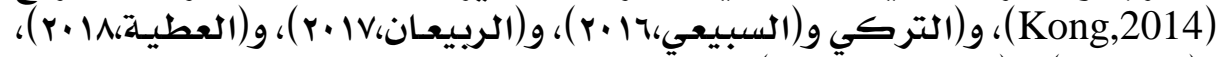

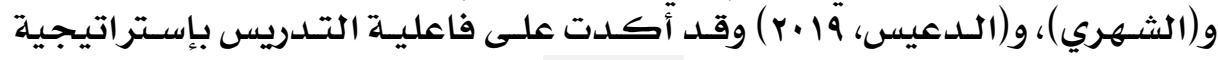




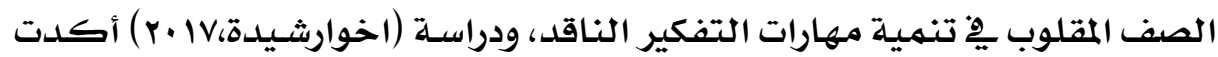

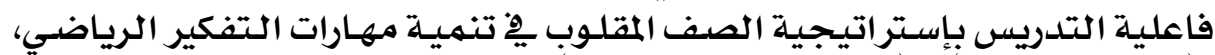

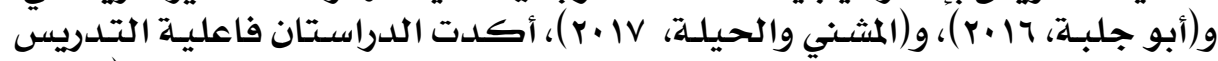

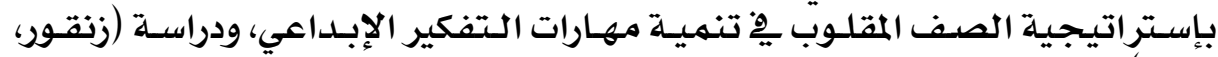

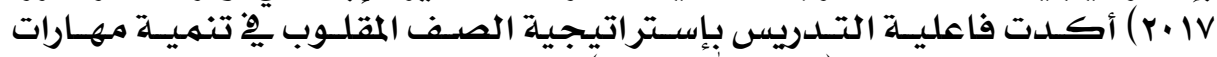

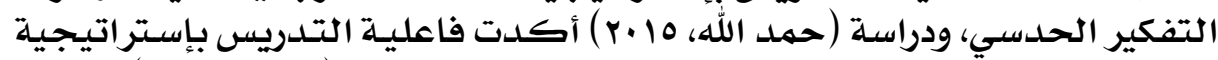

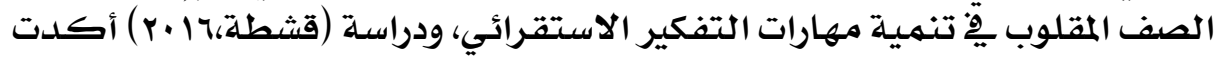

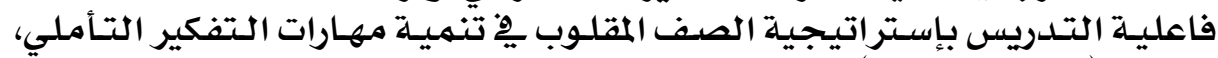

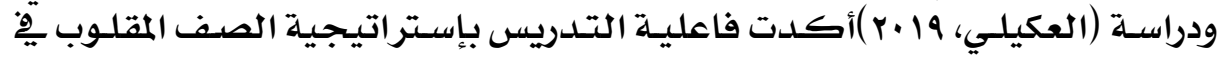

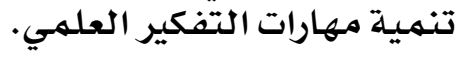

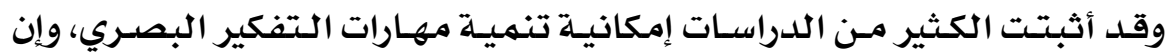

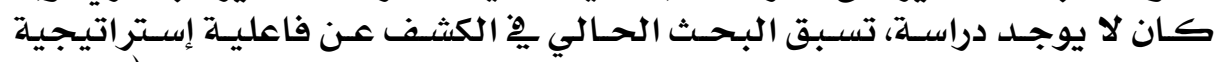

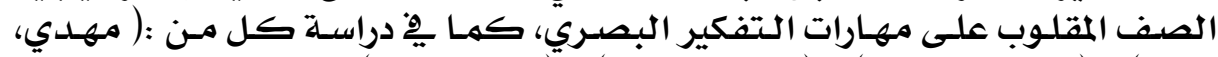

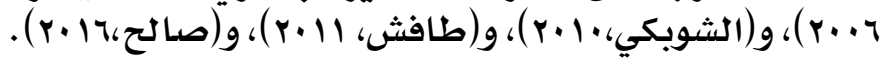

إن إستراتيـجية الصف المقلـوب فِ البـحث الحـالي على مسـتوى مهارات التفكير

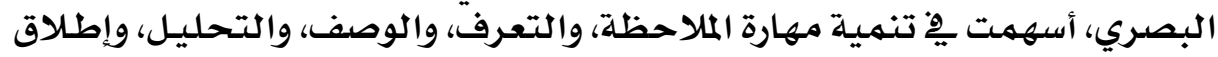

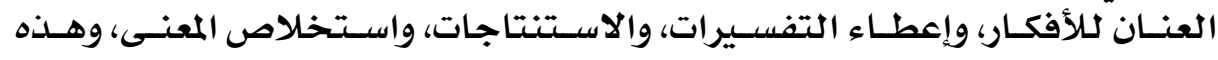

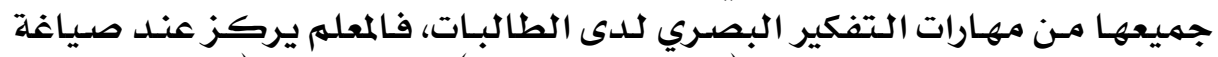

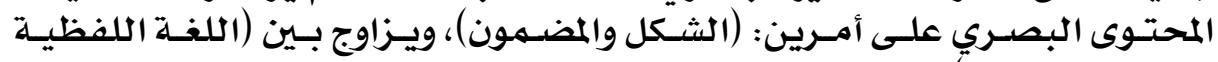

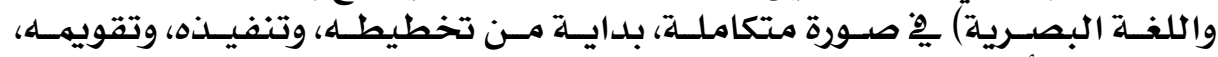

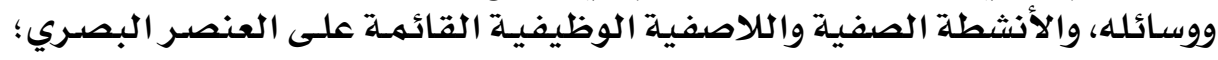

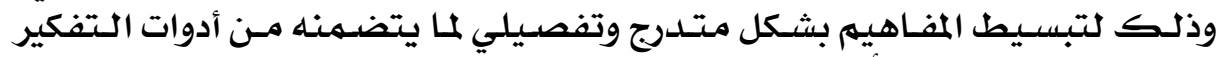

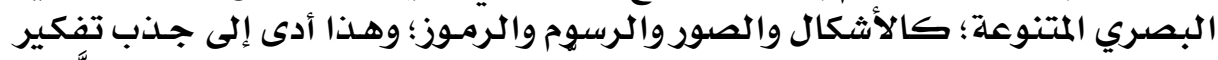

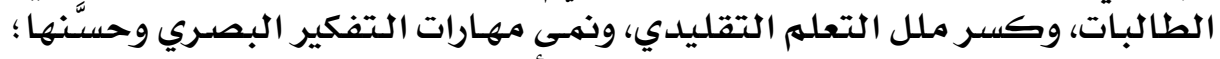

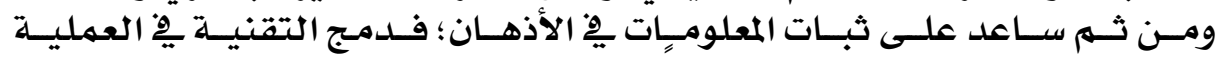

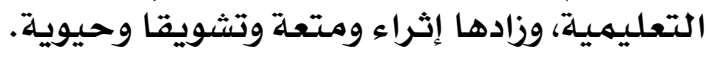

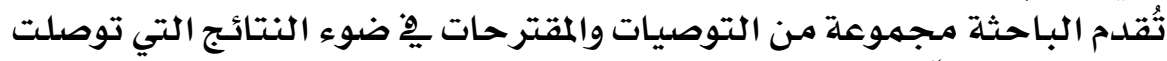

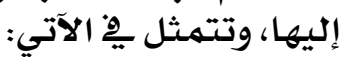

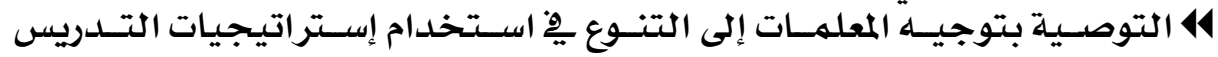

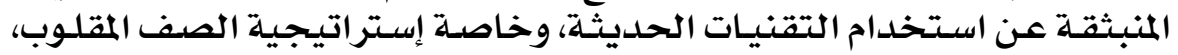

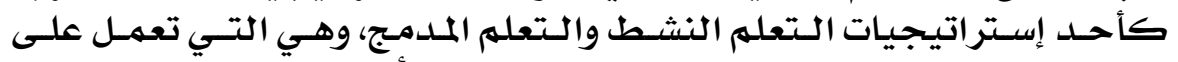

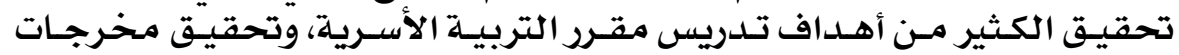

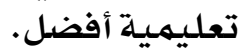

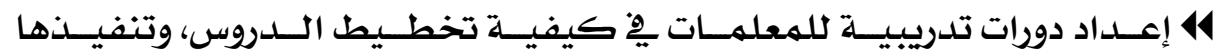

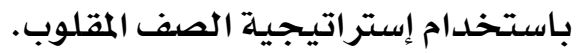




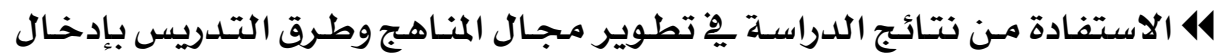

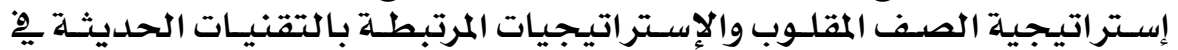

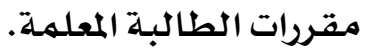

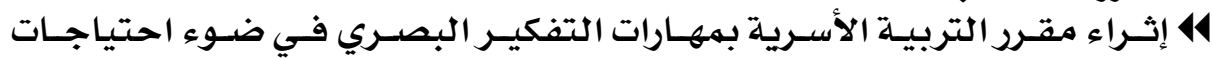

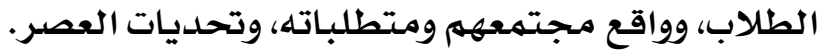

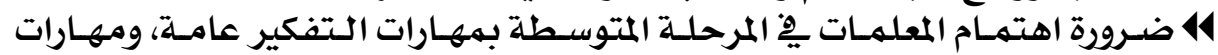
التفكير البصري اهتهـي خاصدية.

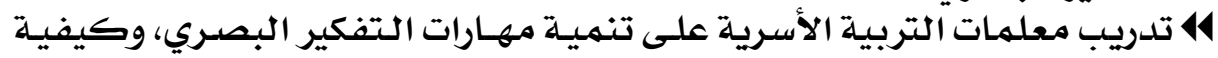

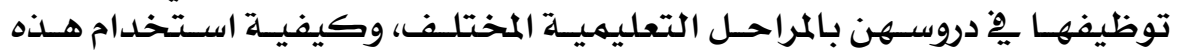
المهارات في التدريس.

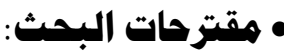

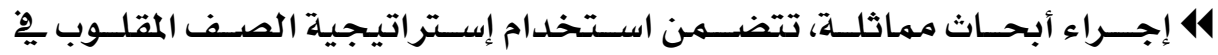

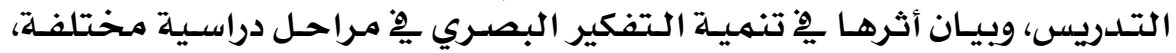

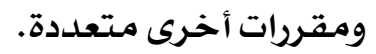

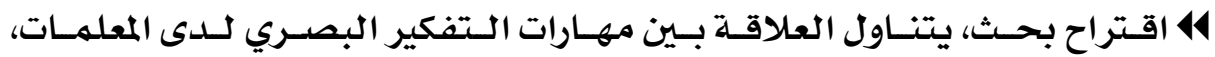

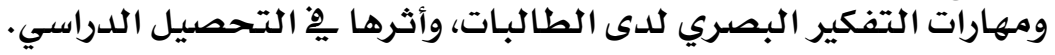

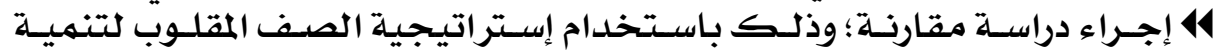

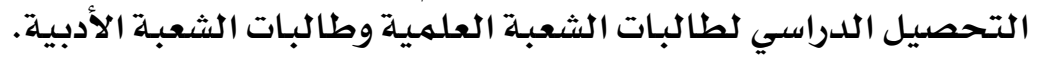

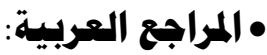

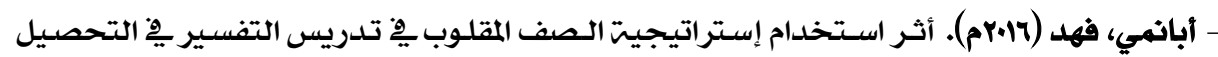

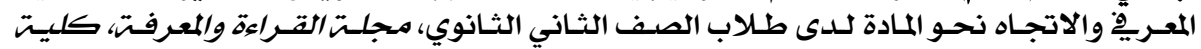

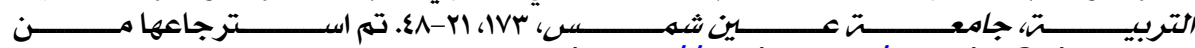
https://arabci.org/Articles?id=11167

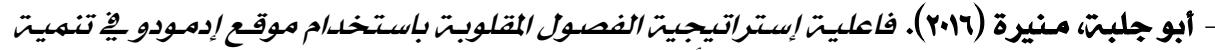

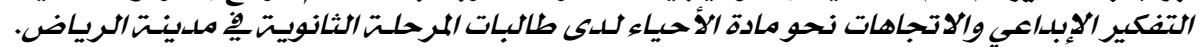

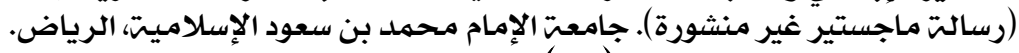

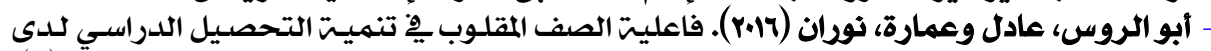

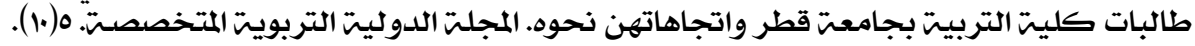

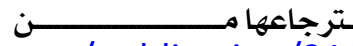

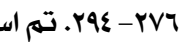
https://www.researchgate.net/publication/311453643 falyt alsf al malwb fy tnmyt althsyl aldrasy ldy talbat klyt altrbyt bjamt qtr watjahathn nhwh

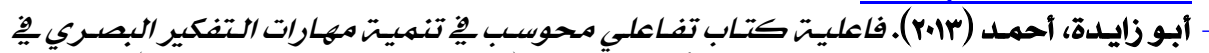

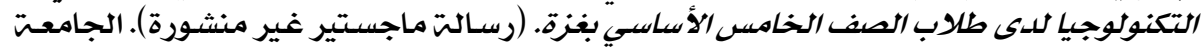

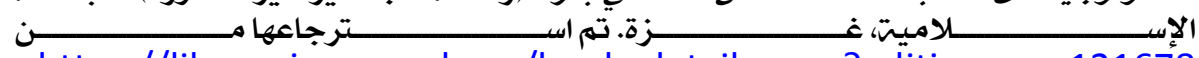
https://library.iugaza.edu.ps/book details.aspx?edition_no=121678

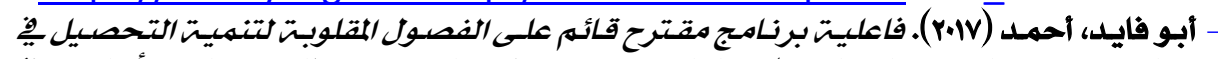

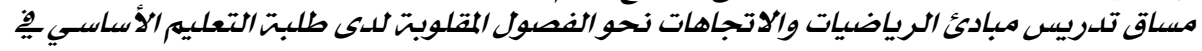




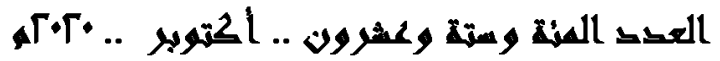

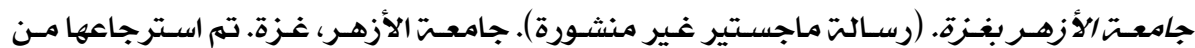
http://www.alazhar.edu.ps/arabic/He/files/20140518.pdf

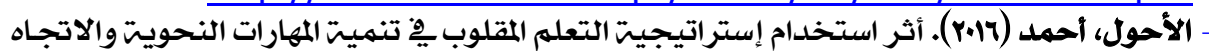

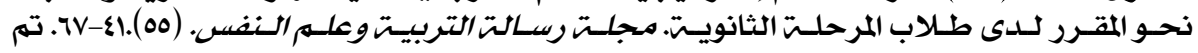

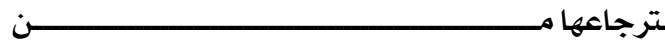

https://gesten.ksu.edu.sa/sites/gesten.ksu.edu.sa/files/imce images $\measuredangle 550 . p d f$

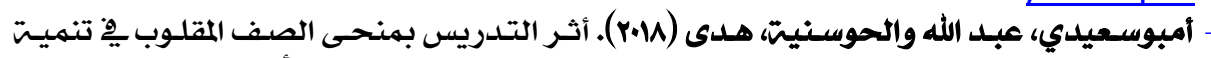

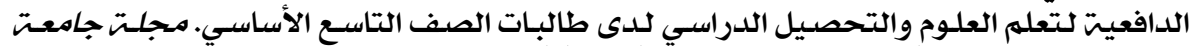

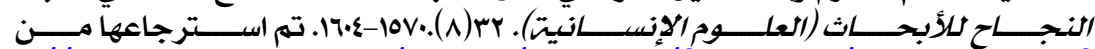
https://journals.najah.edu/media/journals/full texts/6 FqlsPvx.pdf

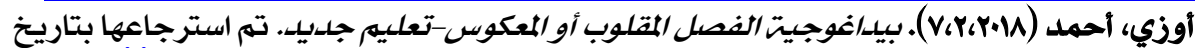
https://www.new- ن م. $\mathrm{r} .19$ و 10 educ.com/\%d8\%a8\%d9\%8a\%d8\%af\%d8\%a7\%d8\%ba\%d9\%88\%d8\%ac \%d9\%8a\%d8\%a9\%d8\%a7\%d9\%84\%d9\%81\%d8\%b5\%d9\%84\%d8\%a7 \%d9\%84\%d9\%85\%d9\%82\%d9\%84\%d9\%88\%d8\%a8\%d8\%a3\%d9\%88 \%d8\%a7\%d9\%84\%d9\%85\%d8\%b9\%d9\%83\%d9\%88\%d8\%b3

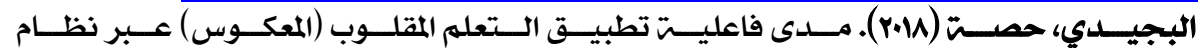
(Blackboard)

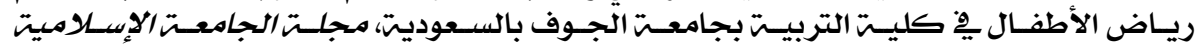

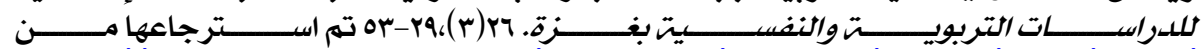
https://journals.iugaza.edu.ps/index.php/IUGJEPS/article/view/3101/ 2084

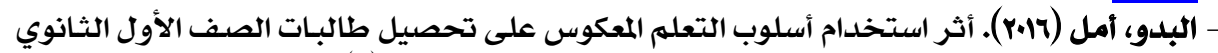

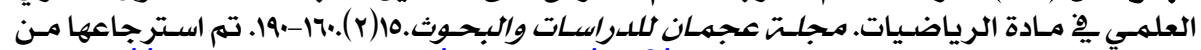
http://rshaward.org.ae/uploads/pdf/\%D8\%A7\%D9\%84\%D9\%85\%D8 \%AC\%D9\%84\%D8\%AF \%D8\%A7\%D9\%84\%D8\%AE\%D8\%A7\%D9\%85\% D8\%B3 \%D8\%B9\%D8\%B4\%D8\%B1 \%D8\%A7\%D9\%84\%D8\%B9\%D8\% AF\%D8\%AF \%D8\%A7\%D9\%84\%D8\%AB\%D8\%A7\%D9\%86\%D9\%8A.pd

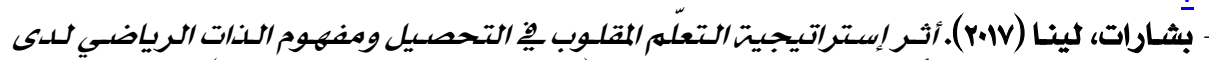

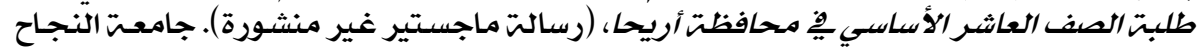

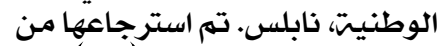

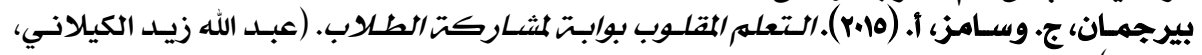

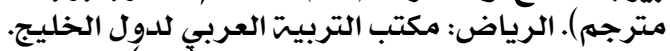

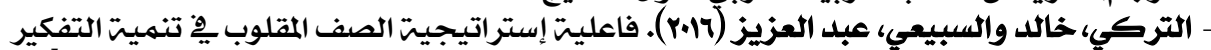

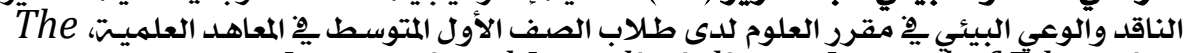
من النيn

http://askzad.com/Bibliographic?service=7\&imageName=jr3i33HcQo MBIMgrvsDi3g..\&imageCount=\&key=PAJI Bibliographic Content

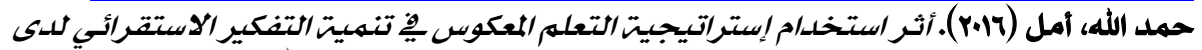

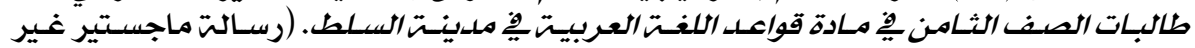




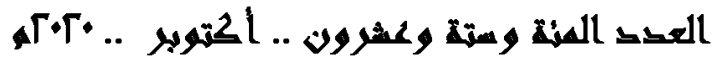

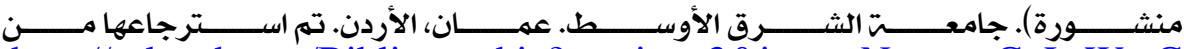
http://askzad.com/Bibliographic?service=3\&imageName=tCxLsWtzC 2gwv9hbIaI9dQ..\&imageCount=124\&key=PAD_Bibliographic_Cont $\underline{\text { ent }}$

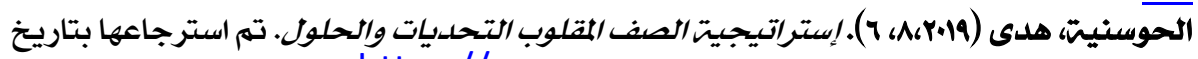
https://www.new-ن

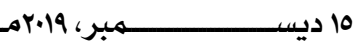
educ.com/\%d8\%a7\%d8\%b3\%d8\%aa\%d8\%b1\%d8\%a7\%d8\%aa\%d9\%8 a\%d8\%ac\%d9\%8a\%d8\%a9\%d8\%a7\%d9\%84\%d8\%b5\%d9\%81\%d8\%a7 \%d9\%84\%d9\%85\%d9\%82\%d9\%84\%d9\%88\%d8\%a8

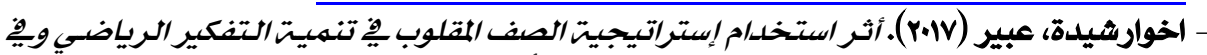

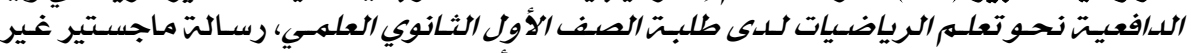

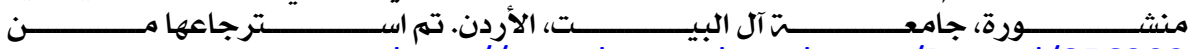
http://search.mandumah.com/Record/856303

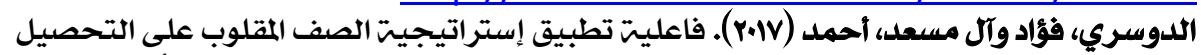

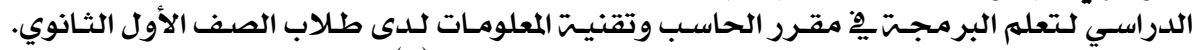

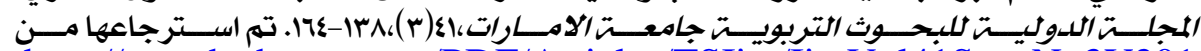
http://search.shamaa.org/PDF/Articles/TSIjre/IjreVol41SpecNo3Y201 7/ijre_2017-v41-spen3_138-164.pdf

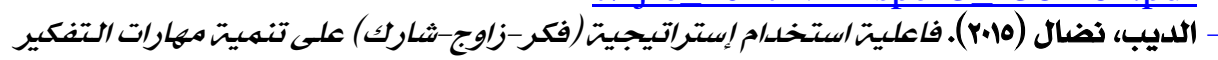

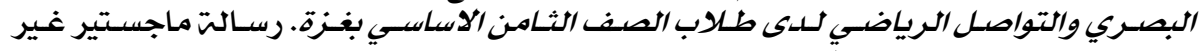

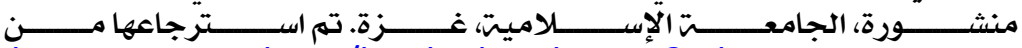
https://library.iugaza.edu.ps/book details.aspx?edition no=129384

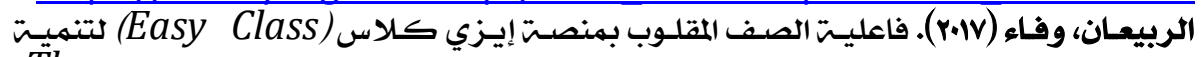

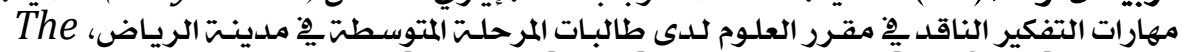
مهار ن

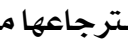

http://askzad.com/Bibliographic?service=7\&imageName=bl19mzce7 eN8hZcbwflxBg..\&imageCount=\&key=PAJI Bibliographic Content

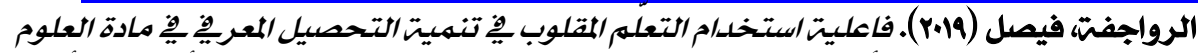

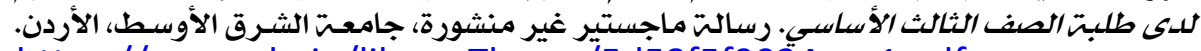

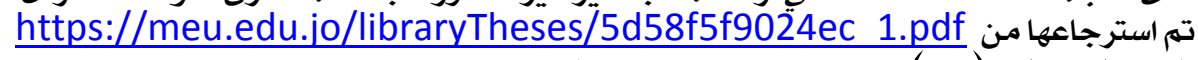

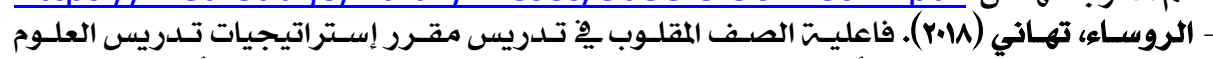

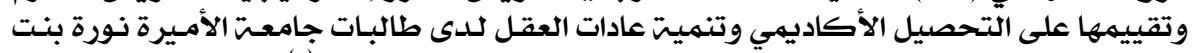

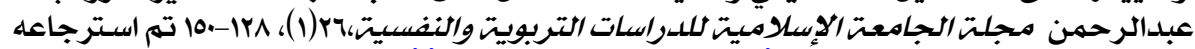

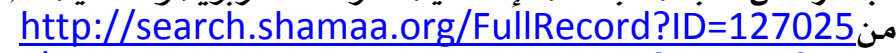
http://askzad.com/viewer?service=7\&id=zXp6KT5rSQYfQmRSDf3NJg. \&type=image

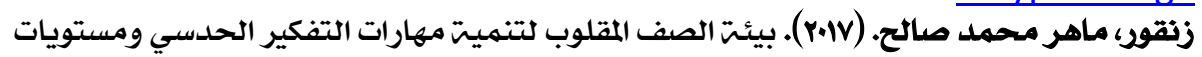

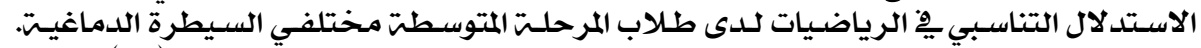

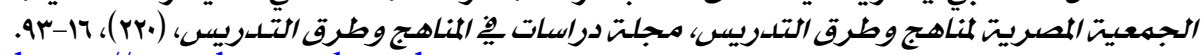
https://search-mandumah- مترجن com.sdl.idm.oclc.org/Record/802365 


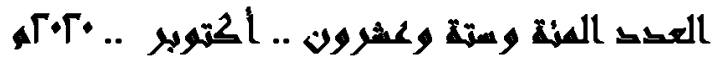

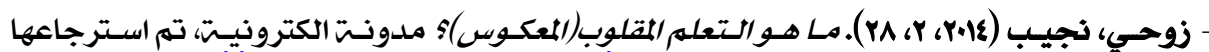

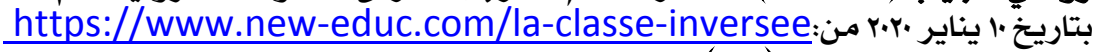

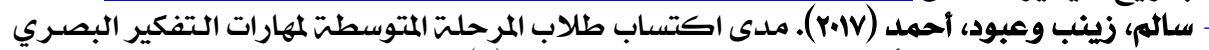

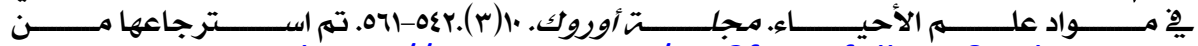
https://www.iasj.net/iasj?func=fülltext\&ald=135558 DOI: 10.18018/URUK/017-10/542-561 "

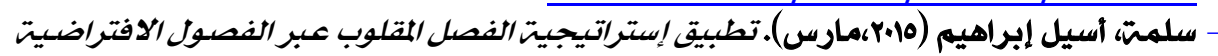

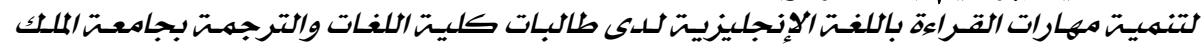

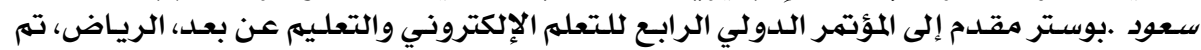

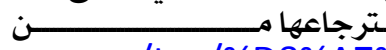

https://aseelsalamah65.wordpress.com/tag/\%D8\%A7\%D9\%84\%D9\% 81\%D8\%B5\%D9\%88\%D9\%84\%D8\%A7\%D9\%84\%D9\%85\%D9\%82\%D9\%84\%D9\%88\%D8\%A8\%D8\%A

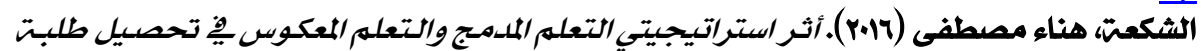

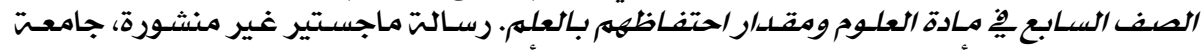

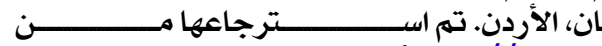

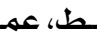

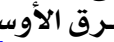
http://search.mandumah.com/Record/787782

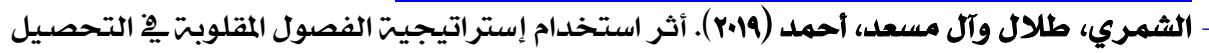

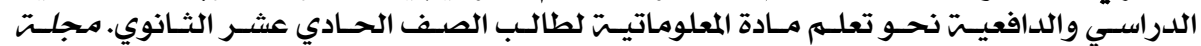

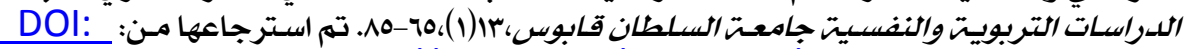
http://dx.doi.org/10.24200/jeps.vol13iss1pp65-85 https://journals.squ.edu.om/index.php/jeps/article/viewFile/2942/2

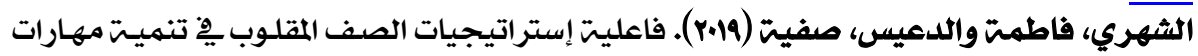

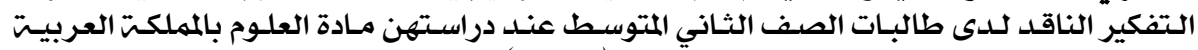

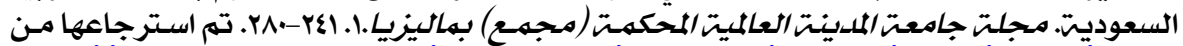
http://ojs.mediu.edu.my/index.php/majmaa/article/view/2206/828

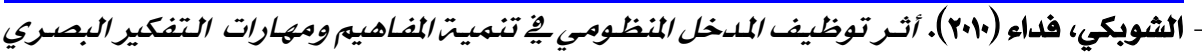

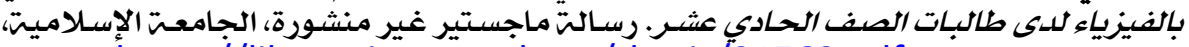

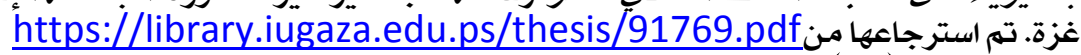

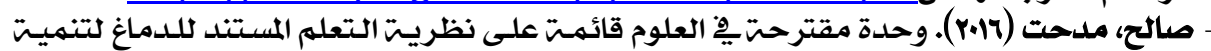

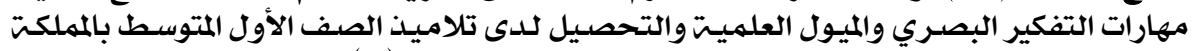

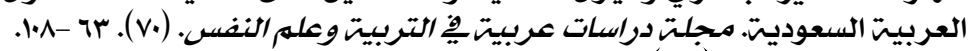

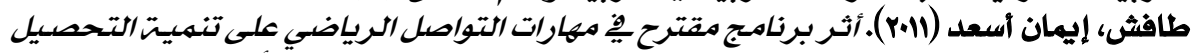

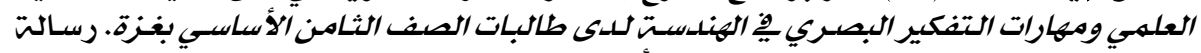

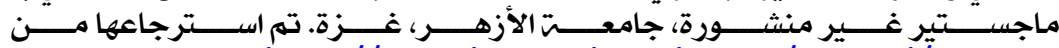
http://search.mandumah.com/Record/542089

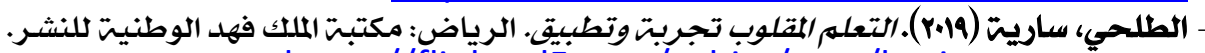

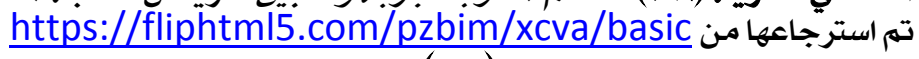

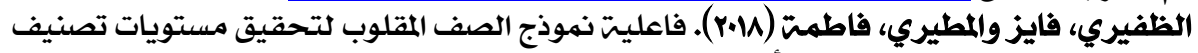

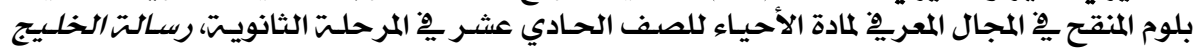
r\&-r.ra 


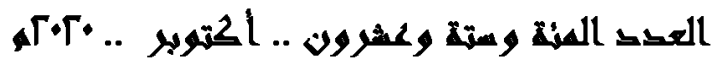

http://askzad.com/Bibliographic?service=7\&imageName=p449PHX-

K9ytBSHtqleFVg..\&imageCount=\&key=PAJI Bibliographic Content - مامر، طارق والمصري، إيهاب (1/.r). التفكير البصري (مغهووهه وهماراته وإستراتيجياته). القاهرة: المجموعت العربيت للتدريب المابعاب (بالنشر.

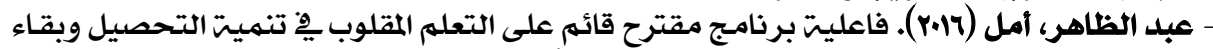

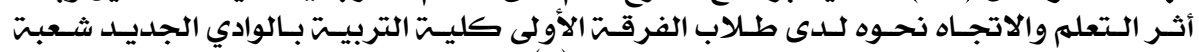

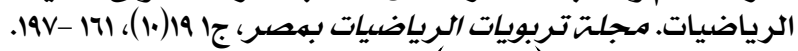

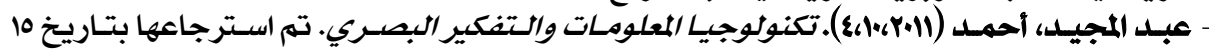

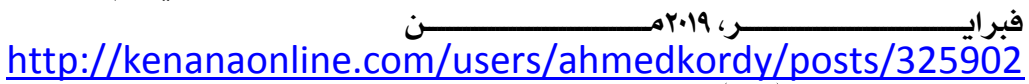

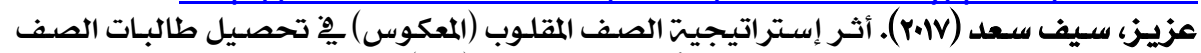

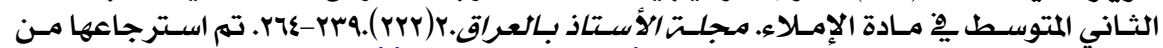
https://www.iasj.net/iasj?func=fulltext\&ald=130434

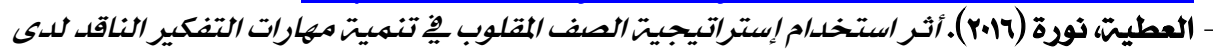

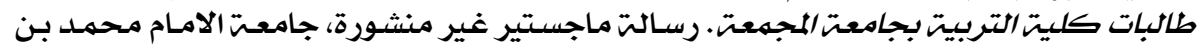

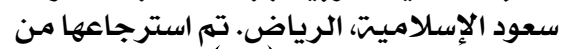

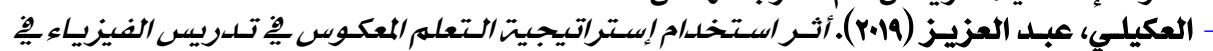

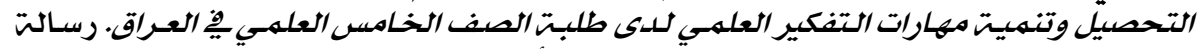

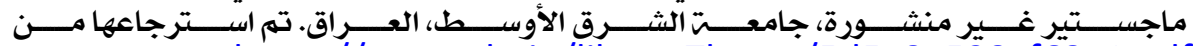
https://meu.edu.jo/libraryTheses/5d5a8e538af68 1.pdf

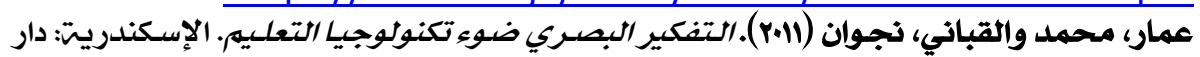

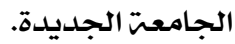

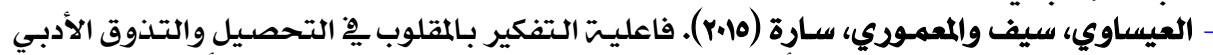

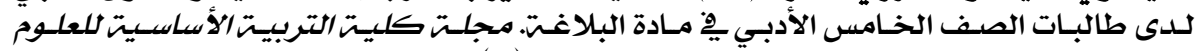

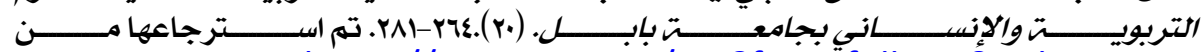
https://www.iasj.net/iasj?func=fulltext\&ald=102403

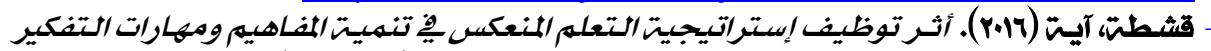

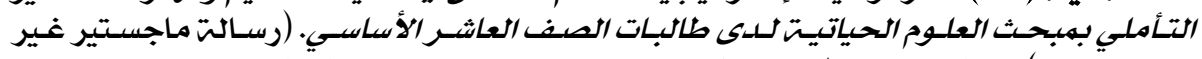

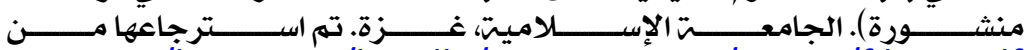
http://www.iug.ps/bitstream/handle/20.500.12358/18470/file 1.pdf ?sequence $=1$ \&isAllowed $=y$

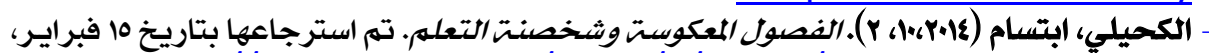

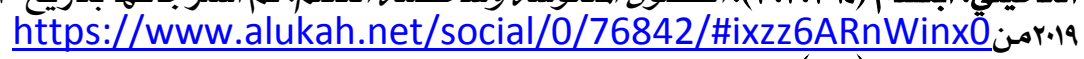

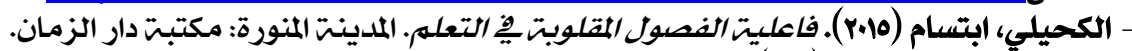

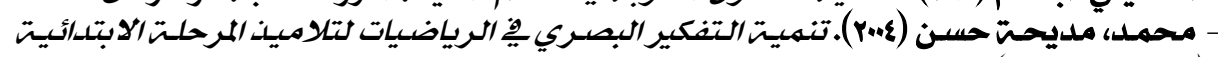

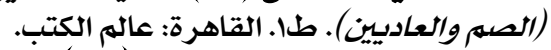

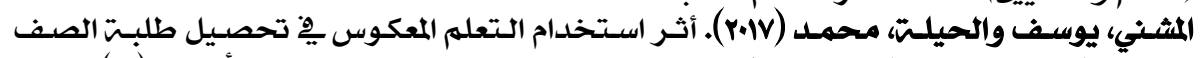

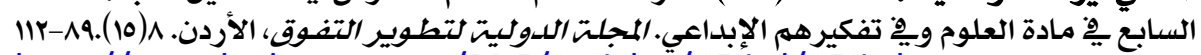

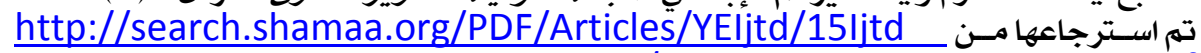
Vol8No15Y2017/ijtd 2017 v8 n15 089-112.pdf

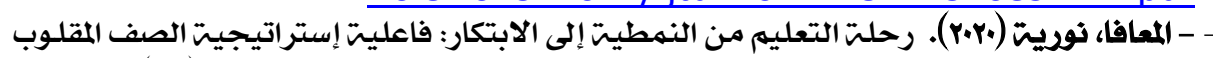

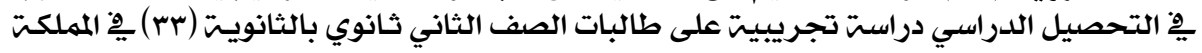




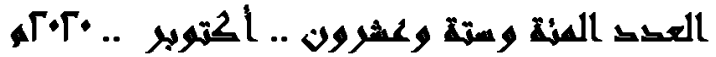

العربيتتالسعوديت:Arab Journal for Scientific Publishing (AJSP)

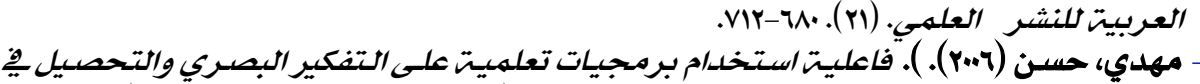

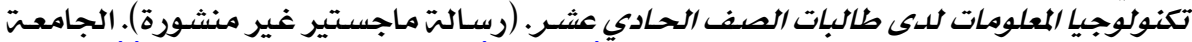

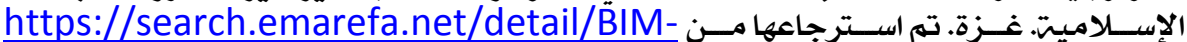

300413

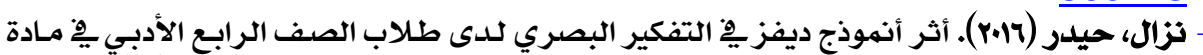

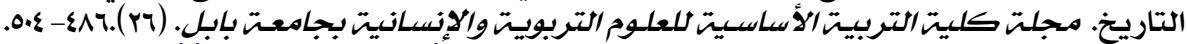
https://www.iasj.net/iasj?func=fulltext\&ald=114195 تم استرجاعها من

- Almasseri, M., \& Alhojailan, M. I. (2019). How flipped learning based on the cognitive theory of multimedia learning affects students' academic achievements,Journal of Computer Assisted Learning, 35 ,769-781. Retrieved Mars 20,2020,from https://onlinelibrary.wiley.com/doi/epdf/10.1111/jcal.12386

- Bergman, J., Overmyer, J.\& Wilie, B.(2013,July 9). The flipped class: what it is and what it is not. Retrieved 30March ,2019 from http://www.thedailyriff.com/articles/the-flipped-class-conversation689.php

- Brown ,P.(2019). A Mixed Method Study: Assessing Critical Thinking, Metacognition, and Motivation in a Flipped Classroom Instructional Model. (Published Doctoral Dissertation), The University of Southern Mississippi. Retrieved from https://aquila.usm.edu/cgi/viewcontent.cgi? article $=2709 \&$ context $=\mathrm{di}$ ssertations

- El-Bassuony, J. M. (2016). The effectiveness of Flipped Learning in developing English Grammatical performance of underachieving language learners at the secondary stage, International Journal of English Language Teaching,4(8),76-101. Retrieved March 20,2019,from http://www.eajournals.org/wp-content/uploads/THEEFFECTIVENESS-OF-FLIPPED-LEARNING-IN-DEVELOPINGENGLISH-GRAMMATICAL-PERFORMANCE-OFUNDERACHIEVING-LANGUAGE-1.pdf

- Elian, S. M.\& Hamaidi, D. A. (2018). The effect of using Flipped Classroom Strategy on the Academic Achievement of Fourth Grade Students in Jordan, International Journal of Emerging Technologies in Learning, 13(2),110-125. Retrieved March 20,2020,from https://online-journals.org/index.php/i-jet/article/view/7816

- Evseeva, A.\&Solozhenko, A. (2015). Use of Flipped Classroom Technology in Language Learning, Procedia - Social and Behavioral Sciences, 206, 205 - 209. Retrieved June 20,2019,from https://www.sciencedirect.com/science/article/pii/S18770428150513 93 


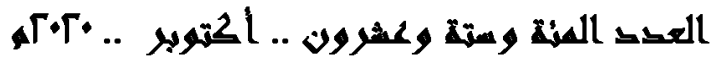

- Flipped Learning Network (2014). The Four Pillars of F-L-I-P, Retrieved Desomber 20,2019,from https://flippedlearning.org/ definition-of-flipped-learning/

- -Cab1, E. (2018). The Impact of the Flipped Classroom Model on Students' Academic Achievement. The International Review of Research in Open and Distributed Learning, 19(3),202-221. Retrieved from https://doi.org/10.19173/irrodl.v19i3.3482

- Kim, M.K., Kim, S.M., Khera, O.\& Getman, J. (2014). The experience of three flipped classrooms in an urban university: an exploration of design principles, Journal of Internet and Higher Education, 22, 37-50. Retrieved July 20,2019,from https://www.sciencedirect.com/science/article/abs/pii/S10967516140 00219?via\%3Dihub

- Komives, C. (2018). Flipped classroom increases achievement of student learning outcomes. Journal of Engineering Education Transformations, (31), 120-123.

- Kong, S.C. (2014). Developing information literacy and critical thinking skills through domain knowledge learning in digital classrooms: An experience of practicing flipped classroom strategy. Computers \& Education,78,160-173. Retrieved July 20,2019,from https://www.sciencedirect.com/science/article/abs/pii/S03601315140 01316?via\%3Dihub

- Lai, C.L., \& Hwang, G.J. (2016). A self-regulated flipped classroom approach to improving students' learning performance in a mathematics course, Computers \& Education ,100, 126-140.

- O'Flaherty. \& Philips. (2015). The use of flipped classrooms in higher education: A scoping review, The Internet and Higher Education, 25, 85-95. Retrieved March 20,2019, from

- https://reader.elsevier.com/reader/sd/pii/S109675161500038X?token =13528F8307FF9B755C695FEAF732E8DC26B7C871E3E083215C 27E5E2A9F40A458F5E37ADAD0FDAF877EF293AF379C179

- -Peterson, D. J. (2016). The Flipped Classroom Improves Student Achievement and Course Satisfaction in a Statistics Course: A Quasi-Experimental Study, Teaching of Psychology. (43). 10.1177/0098628315620063, Retrieved from https://www. researchgate.net/publication/285627099 The_Flipped_Classroom_I mproves_Student_Achievement_and_Course_Satisfaction_in_a_Stat istics_Course_A_Quasi-Experimental_Study

- ALRowais, A.S. (2014). The Impact of Flipped Learning on Achievement and Attitudes In Higher Education. International Journal for Cross-Disciplinary Subjects in Education (IJCDSE), Special Issue ,4 Issue 1,1914-1921. Retrieved June 20,2019, from 
- https://infonomics-society.org/ijcdse/published-papers/special-issuevolume-4-2014/

- -Saunders. (2014) .The flipped classroom; its effect on student academic Achievement and critical thinking skills in high school Mathematics. (Unpublished Doctoral Dissertation), Liberty University, USA.

- Sudarmika, P., Santyasa, I.W. \& Divayana, D. G. (2020). Comparison between Group Discussion Flipped Classroom and Lecture on Student Achievement and Student Characters. International Journal of Instruction. 13(3). 171-186. 10.29333/iji.2020.13312a. Retrieved from http://www.e-iji.net/ dosyalar/iji_2020_3_12.pdf

- Walsh, K. (2013, June 16). Flipped Classroom Panel Discussion Provides Rich Insights into a Powerful Teaching Technique. Retrieved September 20,2019,from https://www.Emerging edtech.com/2013/06/flipped-classroom-panel-discussion-providesrich-insights-into-a-powerful-teaching-technique/

- Yestrebskya, C.L. (2015). Flipping the Classroom in a Large Chemistry Class-Research University Environment, Procedia Social and Behavioral Sciences ,191,1113-1118. Retrieved June 20,2019,from https://www.sciencedirect.com/science/article/pii/ $\underline{\mathrm{S} 1877042815026300}$ 